\title{
Um framework baseado em componentes para desenvolvimento de aplicações web e um processo de instanciação associado
}

\author{
Elaine Quintino da Silva
}

Orientador: Prof. Dr. Dilvan de Abreu Moreira

Tese apresentada ao Instituto de Ciências Matemáticas e de Computação - ICMC-USP, como parte dos requisitos para obtenção do título de Doutor em Ciências - Ciências de Computação e Matemática Computacional.

\section{“VERSÃO REVISADA APÓS A DEFESA"}

Data da Defesa:

$06 / 04 / 2006$

Visto do Orientador:

USP - São Carlos

Julho/ 2006 
Um framework baseado em componentes para desenvolvimento de aplicações web e um processo de instanciação associado 
"Nenhum trabalho, nenhuma tarefa é tão insignificante, tão simples, tão humilde, que não brilhe aos olhos de Deus".

Portanto, seja qual a tarefa que você tem a desempenhar, receba-a e cumpra como se fosse a mais bela e mais importante.

Não dimensione a sua obrigação pelo que ela possa parecer diante da vaidade humana, mas pelo que possa valer diante da sua consciência."

Autor desconhecido

Este trabalho é dedicado àqueles que me deram a chance de realizá-lo: meus pais, Nelma e Cornélio. 
A Deus, por me fazer capaz de realizar este trabalho e a minha história.

Aos meus pais, Nelma e Cornélio, pelo esforço dedicado à minha formação e pelo apoio, amor e carinho oferecidos gratuitamente.

Ao Beto, por toda a paciência, estímulo e força que me impulsionaram na realização deste trabalho.

Aos meus irmãos, Giovana e Alexandre, pelo carinho compartilhado em todos os momentos.

Ao professor Dilvan, pela oportunidade e confiança.

Às professoras Graça Pimentel e Renata Fortes pelas valiosas contribuições, especialmente, nas etapas finais deste trabalho.

À CAPES (Coordenação de Aperfeiçoamento de Pessoal de Nível Superior), pelo apoio financeiro para a realização deste trabalho.

Aos amigos que conquistei durante todos esses anos. A estes, cujos nomes não preciso citar, deixo uma mensagem:

\section{"O importante da amizade não é conhecer o amigo} e sim saber o que há dentro dele!

Cada amigo novo que ganhamos na vida, nos aperfeiçoa e enriquece, não pelo que nos dá, mas pelo quanto descobrimos de nós mesmos.

Ser amigo não é coisa de um dia. São gestos, palavras, sentimentos que se solidificam no tempo e não se apagam jamais.

O amigo revela, desvenda, conforta.

É uma porta sempre aberta em qualquer situação." 
Índice de Figuras e Tabelas............................................................................

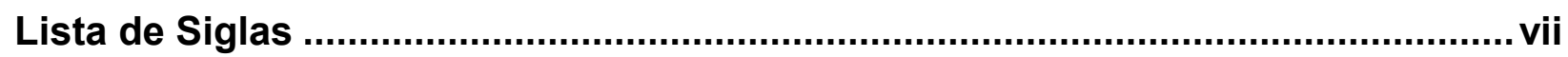

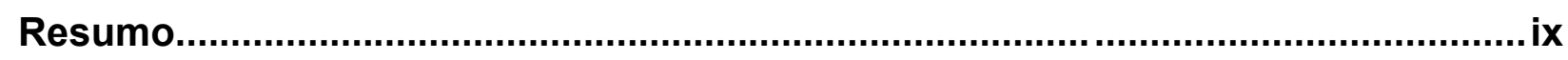

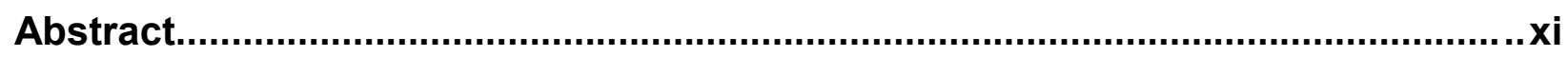

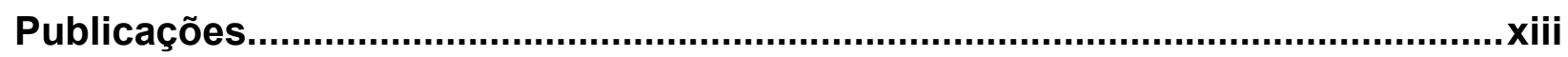

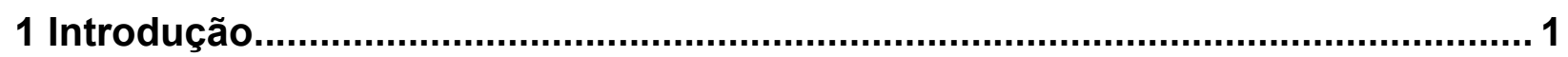

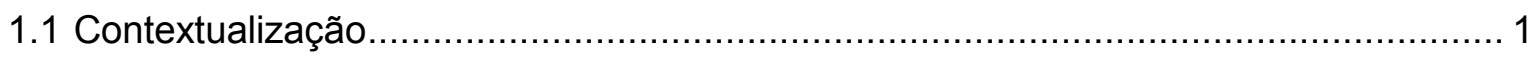

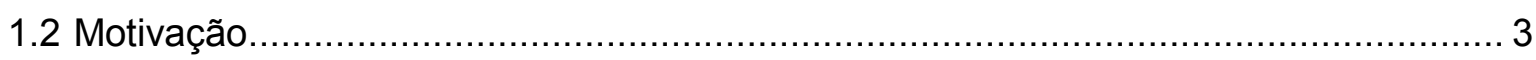

1.3 Objetivos

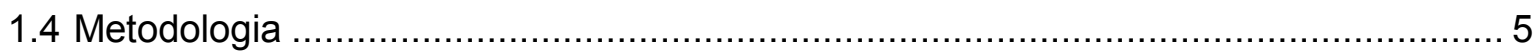

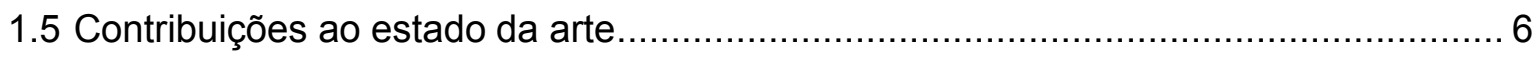

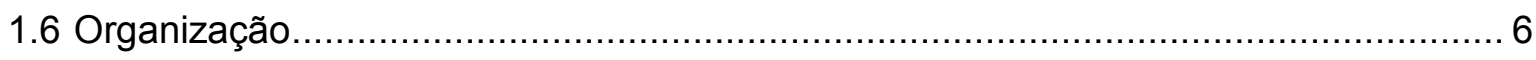

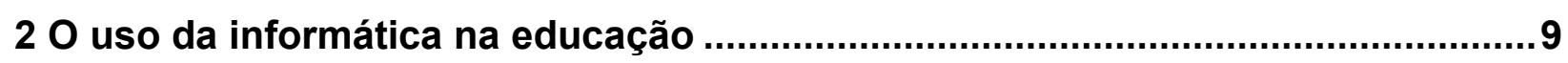

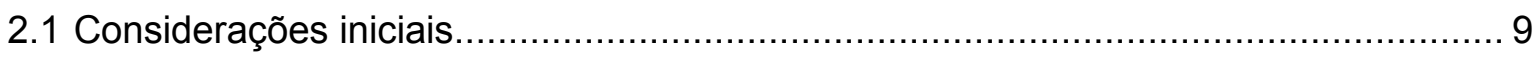

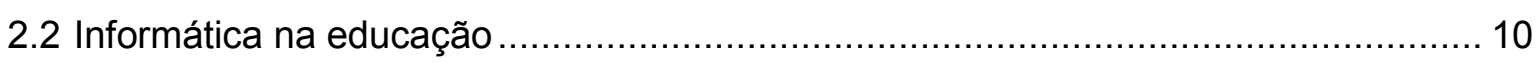

2.3 Ambientes virtuais de apoio à educação na Web …………………….................... 11

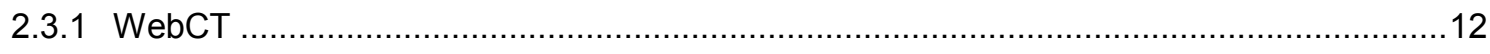

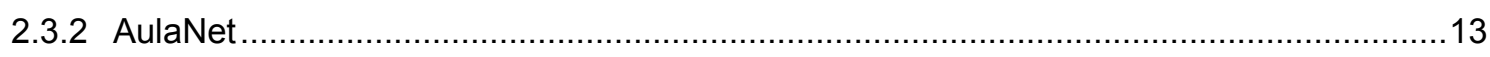

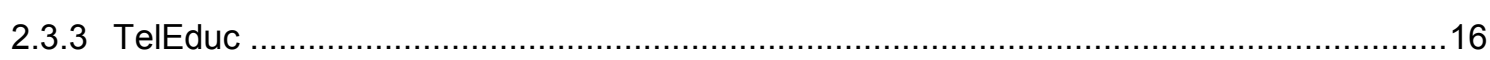

2.4 Sistemas educacionais voltados para apoio à sala de aula .................................... 18

2.4.1 Captura de experiências em sala de aula - iClass .......................................................19

2.4.2 Edição colaborativa de documentos - CoTeia ...............................................................21

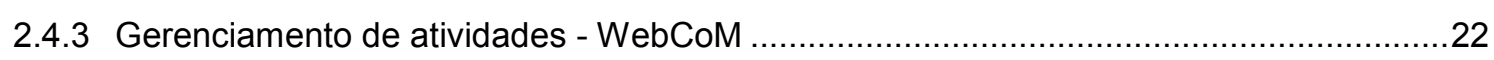

2.4.3.1 O método educacional de Peer Review...................................................................24

2.5 Análise das aplicações educacionais sob o aspecto da adaptabilidade ....................26

2.6 Características para um sistema educacional flexível ........................................... 29

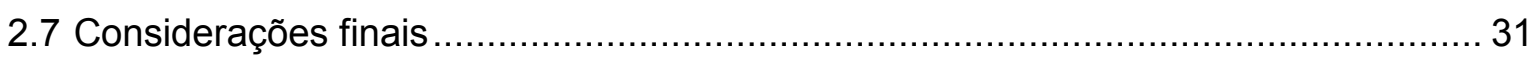

3 Projeto de software adaptável e extensível......................................................33

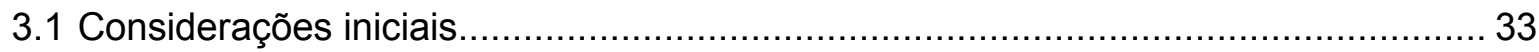




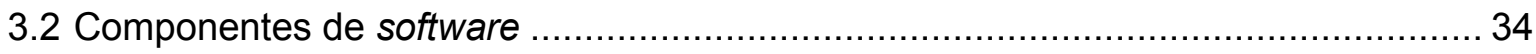

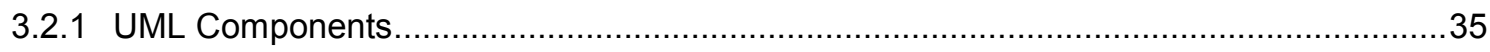

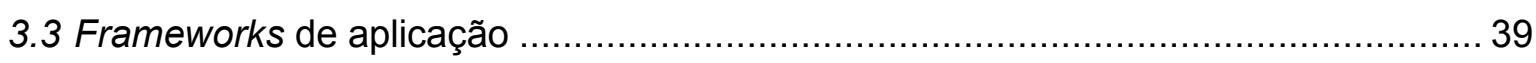

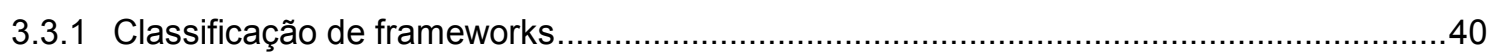

3.3.2 Desenvolvimento de sistemas baseados em frameworks ...........................................41

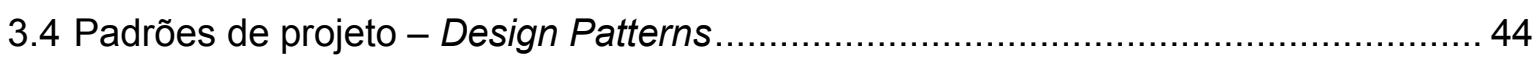

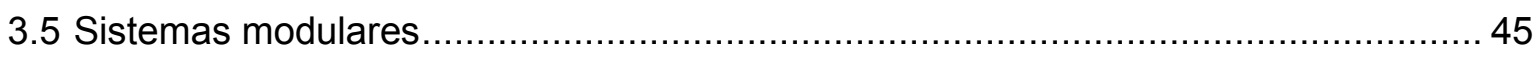

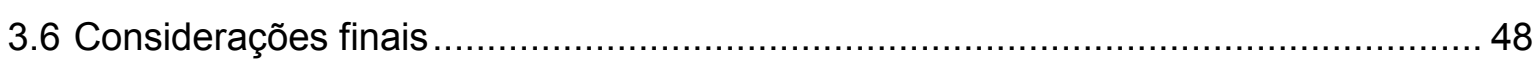

4 WebMODE: desenvolvimento modular de aplicação Web.................................51

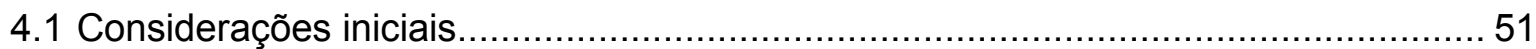

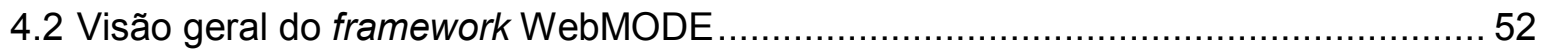

4.3 Processo de especificação e desenvolvimento do framework ................................ 54

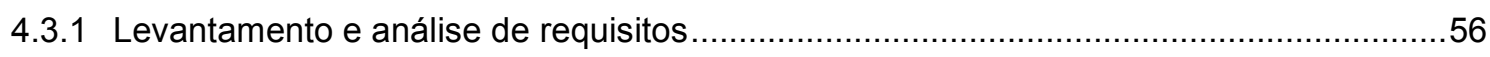

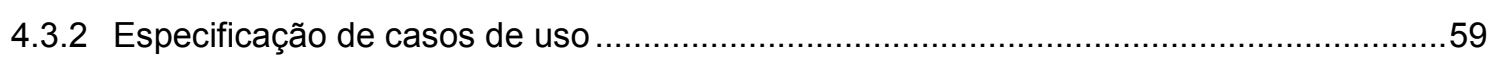

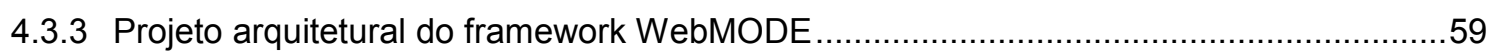

4.4 Exemplo de abordagem tecnológica para uma implementação do WebMODE .........66

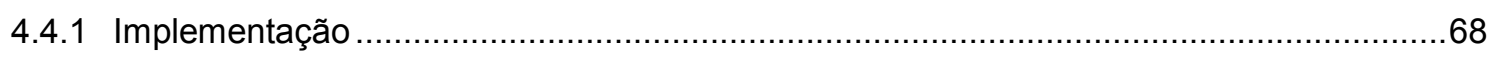

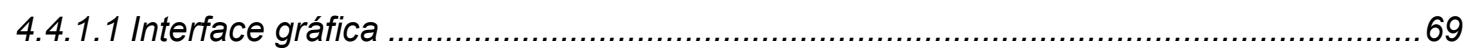

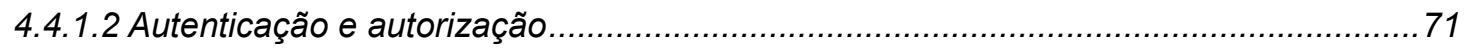

4.4.1.3 Extensão do framework WebMODE-J2EE ........................................................... 73

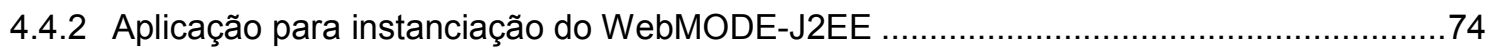

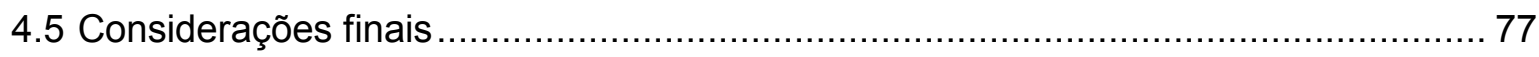

5 Um processo para instanciação de aplicações WebMODE ...............................79

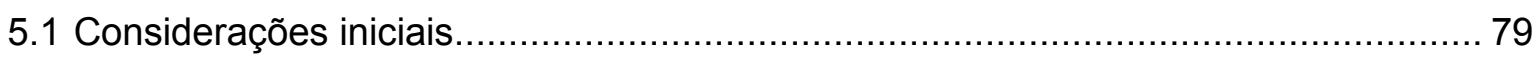

5.2 Domínio: Gerenciamento de atividades didáticas via Web ................................... 79

5.3 O processo de instanciação: visão geral ....................................................... 80

5.4 Análise e especificação da aplicação ............................................................. 81

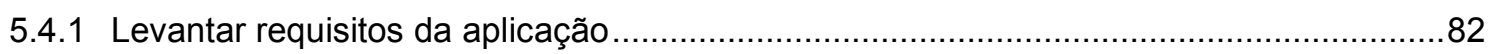

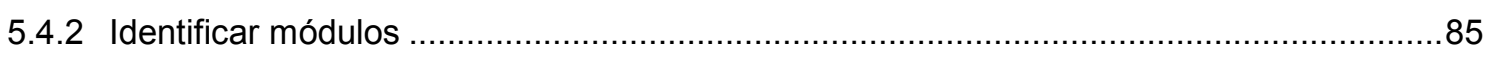

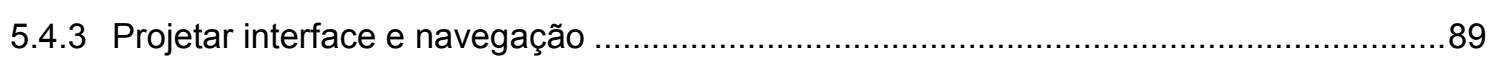

5.4.4 Especificar controladores de módulo e componentes de negócio...................................90

Fase 1: Especificar interfaces e operações de sistema ........................................................ 91

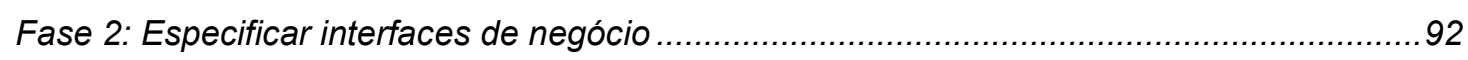

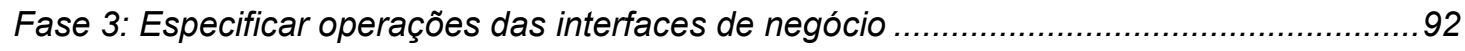

Fase 4: Atualizar documento de descrição de módulos ....................................................93

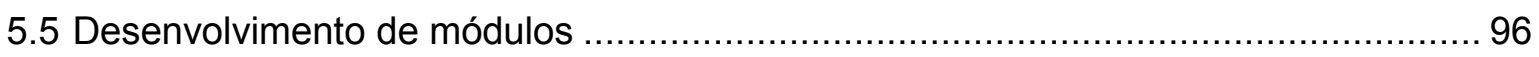

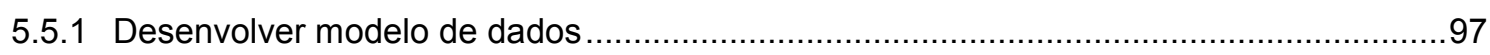




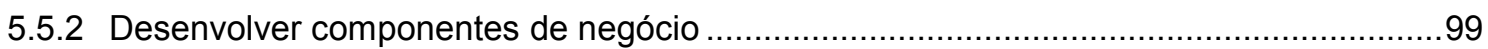

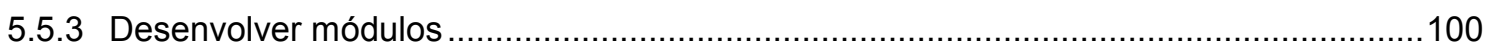

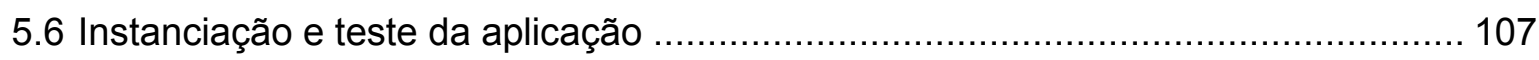

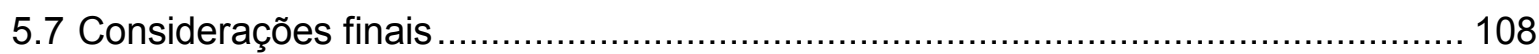

6 Um exemplo de aplicação WebMODE-J2EE................................................109

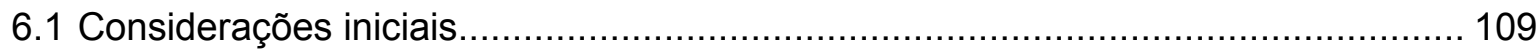

6.2 A aplicação de gerenciamento de atividades ........................................................ 109

6.3 Adaptando a aplicação de gerenciamento de atividades .................................... 117

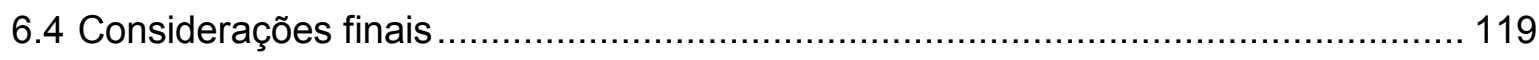

7 Outras abordagens de desenvolvimento Web.............................................. 121

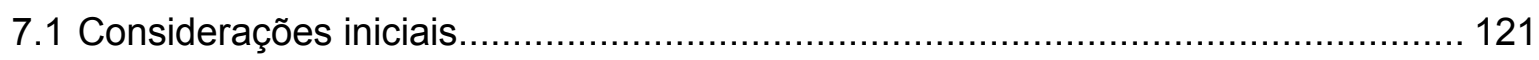

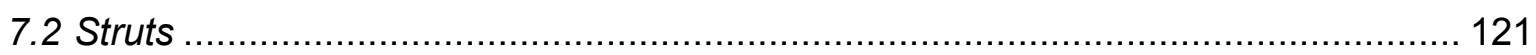

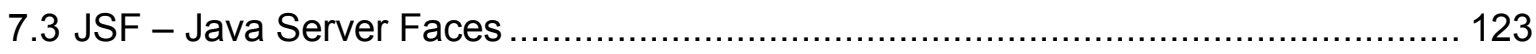

7.4 Sistemas de Gerenciamento de Conteúdo (CMSs) ............................................ 125

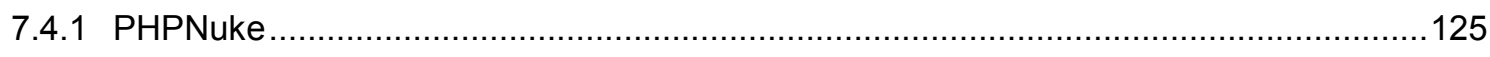

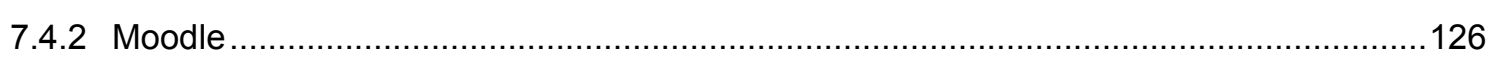

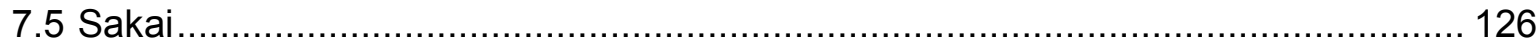

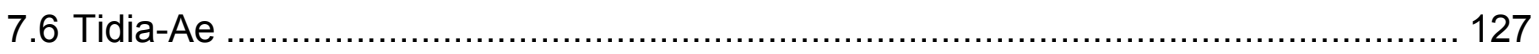

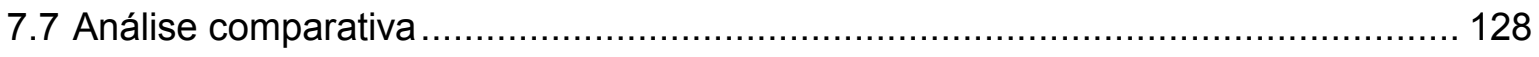

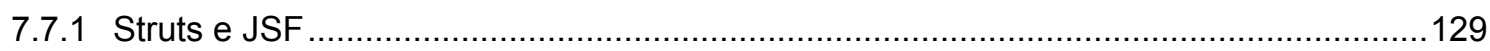

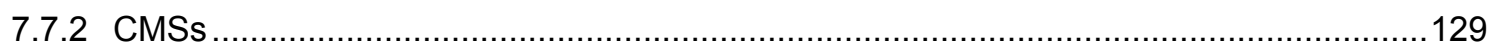

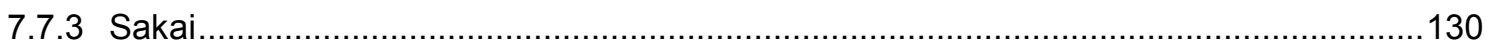

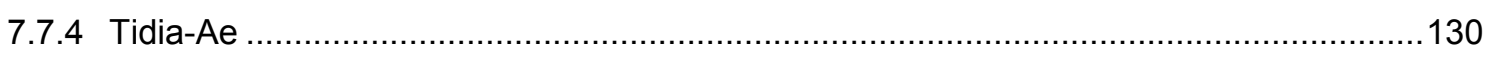

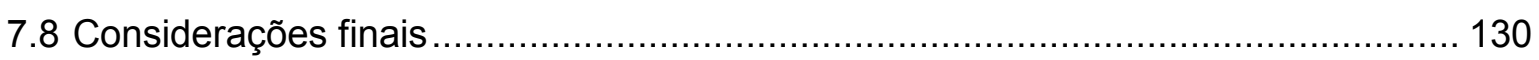

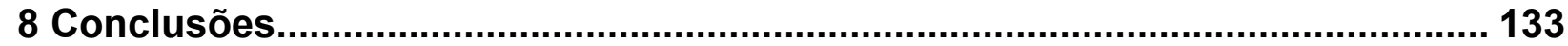

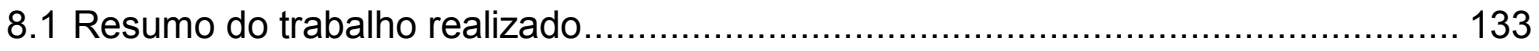

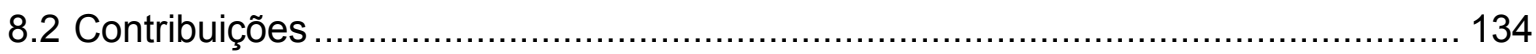

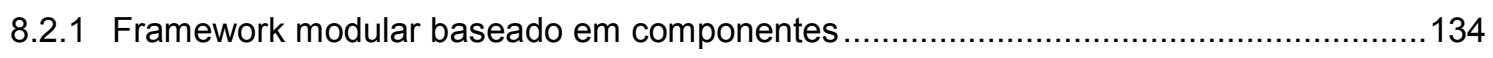

8.2.2 Processo de instanciação de aplicações sobre o WebMODE .......................................... 134

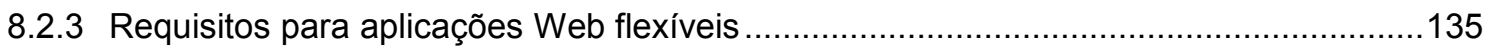

8.2.4 Características para flexibilização de sistemas educacionais ......................................135

8.3 Oportunidades para desenvolvimento ...................................................... 135

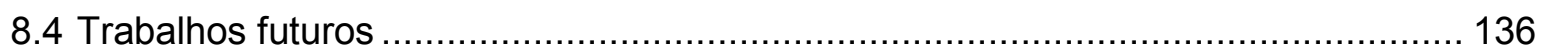

Referências bibliográficas ....................................................................... 139 
Figura 2.1 - Interface do ambiente WebCT acessada pelo estudante (WebCT, 2006) ............... 14

Figura 2.2 - Interface principal de um curso no ambiente Aulanet (Aulanet, 2005)................. 15

Figura 2.3 - Interface de um curso no ambiente TelEduc (TelEduc, 2005) .............................. 18

Figura 2.4 - Sala de aula para captura e hiperdocumentos gerados (Jardim et al., 2005) ............ 20

Figura 2.5 - Edição (a) e visualização (b) de página da CoTeia................................................22

Figura 2.6 - Applet do WebCoM sendo apresentado em um hiperdocumento.............................24

Figura 3.1 - Uso de interfaces para definição de componentes (Cheesman \& Daniels, 2001) ....35

Figura 3.2 - Processo UML Components (Cheesman \& Daniels, 2001) ......................................36

Figura 3.3 - Fluxo de especificação detalhado (Cheesman \& Daniels, 2001).............................. 38

Figura 4.1 - Estrutura de uma aplicação WebMODE ..............................................................53

Figura 4.2 - Casos de uso de uma aplicação para instanciação do WebMODE ............................59

Figura 4.3 - Colaboração entre os elementos principais do WebMODE ....................................63

Figura 4.4 - Modelo de dados utilizado base do framework WebMODE ................................... 64

Figura 4.5 - Colaboração de mais baixo nível entre os elementos do WebMODE ......................66

Figura 4.6 - Documento template.jsp que representa a visão principal do WebMODE-J2EE..... 70

Figura 4.7 - Página principal de uma aplicação instanciada sobre o WebMODE-J2EE...............71

Figura 4.8 - Interfaces de aplicação WebMODE acessadas por usuário admin (a) e user (b).... 73

Figura 4.9 - Interface para a criação de uma aplicação WebMODE-J2EE .................................. 75

Figura 4.10 - Interface para edição de aplicação (a) e para configuração de módulo (b) ............76

Figura 4.11 - Interface para seleção de módulos ........................................................................ 76

Figura 4.12 - Interface do WebMODE-J2EE com a lista de aplicações disponíveis ................... 77

Figura 5.1 - Processo de instanciação de aplicações utilizando o WebMODE ........................... 81

Figura 5.2 - Fluxo de análise e especificação da aplicação detalhado ......................................... 82

Figura 5.3 - Diagrama de casos de uso da aplicação de gerenciamento de atividades................. 83

Figura 5.4 - Modelo conceitual da aplicação de gerenciamento de atividades ............................. 84

Figura 5.5 - Diagrama de casos de uso agrupados para modularização (passo 1)....................... 86

Figura 5.6 - Diagrama de casos de uso agrupados para modularização (passo 2)....................... 87

Figura 5.7 - Documento de descrição de módulos ....................................................................... 88

Figura 5.8 - Modelo de navegação da opção "Gerenciar usuários" ............................................ 90

Figura 5.9 - BTM da aplicação de gerenciamento de atividades ............................................... 93

Figura 5.10 - Documento de descrição de módulos completo ..................................................99

Figura 5.11 - Relacionamentos entre controladores de módulos e componentes........................95

Figura 5.12 - Fluxo de desenvolvimento de módulos detalhado ................................................ 96

Figura 5.13 - Modelo de dados da aplicação de gerenciamento de atividades............................97

Figura 5.14 - Formato de distribuição dos objetos Hibernate para o WebMODE-J2EE ............. 98 
Figura 5.15 - Exemplo de um objeto DAO no WebMODE-J2EE ........................................... 99

Figura 5.16 - Exemplo do código de um componente de negócio no WebMODE-J2EE .......... 100

Figura 5.17 - Exemplo de arquivo de configuração de módulo (module . xml) ...................... 102

Figura 5.18 - Arquivo de propriedades UserModule_en_US . properties ..................... 103

Figura 5.19 - Classe de constantes do módulo (ConstantValues . Java) .......................... 103

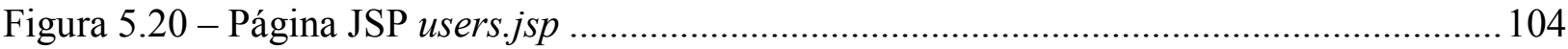

Figura 5.21 - Interface da aplicação mostrando o conteúdo visualizado na página users.jsp .... 105

Figura 5.22 - Controlador de módulo do módulo de usuário (UserModule)............................ 106

Figura 5.23 - Estrutura dos pacotes para distribuição dos módulos do WebMODE-J2EE ........ 107

Figura 5.24 - Fluxo de instanciação e teste da aplicação........................................................... 108

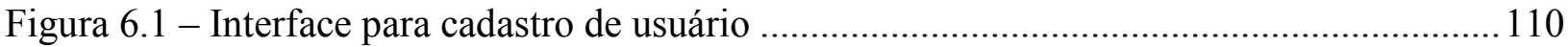

Figura 6.2 - Interfaces para gerenciamento (a) e inclusão (b) dos membros da turma .............. 111

Figura 6.3 - (a) Interface para criação de um tipo de atividade e (b) para edição de atividade.. 112

Figura 6.4 - Interface para a edição de um projeto que faz parte de uma atividade ................... 113

Figura 6.5 - Interface para formação de grupo e escolha de projeto ........................................ 114

Figura 6.6 - Interface para acesso (a) e realização (b) de atividades em grupo.......................... 114

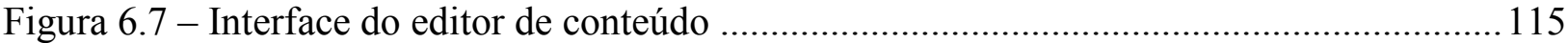

Figura 6.8 - Interface para alocação de revisores de uma atividade individual......................... 115

Figura 6.9 - Interface para visualização dos resultados das atividades individuais .................. 116

Figura 6.10 - Interface para configuração do módulo de atividade........................................... 118

Figura 6.11 - Interface para edição de atividades pelo usuário monitor..................................... 119

Tabela 4.1. Relação entre os requisitos do framework e a tecnologia adotada. 67 
BTM Business Type Model

CBD Component-based Development

CMS Content Management System

DAO Data Access Object

EJB Enterprise Javabeans

FTP File Transfer Protocol

GPL GNU Public Licence

HTML Hypertext Markup Language

HTTP Hypertext Transfer Protocol

J2EE Java 2 Enterprise Edition

JAAS Java Authentication and Authorization Service

JNDI Java Naming and Directory Interface

JSF JavaServer Faces

JSP JavaServer Pages

JSTL Java Standard Tag Library

MVC Model View Controller

ORM Object Relational Mapping

SGBD Sistema Gerenciador de Base de Dados

WWW World Wide Web

XHTML Extensible HyperText Markyp Language

XML Extensible Markup Language 


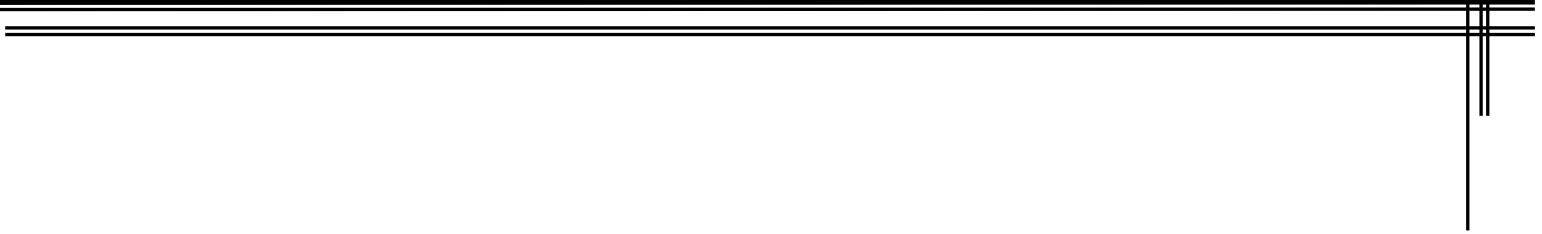

Nos últimos anos, a área de educação vem passando por mudanças importantes em relação à introdução das tecnologias da informação no processo de ensino/aprendizagem. Como resultado dessas mudanças e dos esforços para aproveitar os benefícios dessas tecnologias, diversos sistemas (ou ambientes virtuais) de apoio à educação foram desenvolvidos. Apesar do vasto conjunto de ferramentas oferecidas por esses ambientes, muitos usuários ainda optam pelo desenvolvimento de suas próprias aplicações de apoio à educação. Isso acontece em função da diversidade das técnicas de ensino e avaliação existentes entre diferentes professores. Devido ao fato dos ambientes educacionais tradicionais não serem projetados para oferecer muitas possibilidades de adaptação e extensão, principalmente em termos de funcionalidades, os usuários são desmotivados a utilizar esses sistemas e acabam criando suas próprias aplicações. Como uma alternativa para essa falta de flexibilidade, nesta tese, um framework modular baseado em componentes (WebMODE - Web MOdular DEvelopment) foi proposto para o desenvolvimento de aplicações Web mais adaptáveis e extensíveis (em especial as aplicações de apoio à educação). Além disso, também foi proposto um processo de software para a instanciação de aplicações sobre esse framework. Tal processo enfatiza as atividades de especificação dos módulos, que fazem parte dessas aplicações, de forma independente da tecnologia que será utilizada na sua implementação. Os pontos principais deste framework são o uso de padrões de projeto, como o MVC (Model View Controller) e o uso de sistemas modulares e baseados em componentes no desenvolvimento de aplicações Web que são compostas de módulos com funcionalidades configuráveis. O WebMODE foi projetado como um framework conceitual e, posteriormente, implementado e avaliado utilizando a tecnologia J2EE (Java 2 Enterprise Edition). 


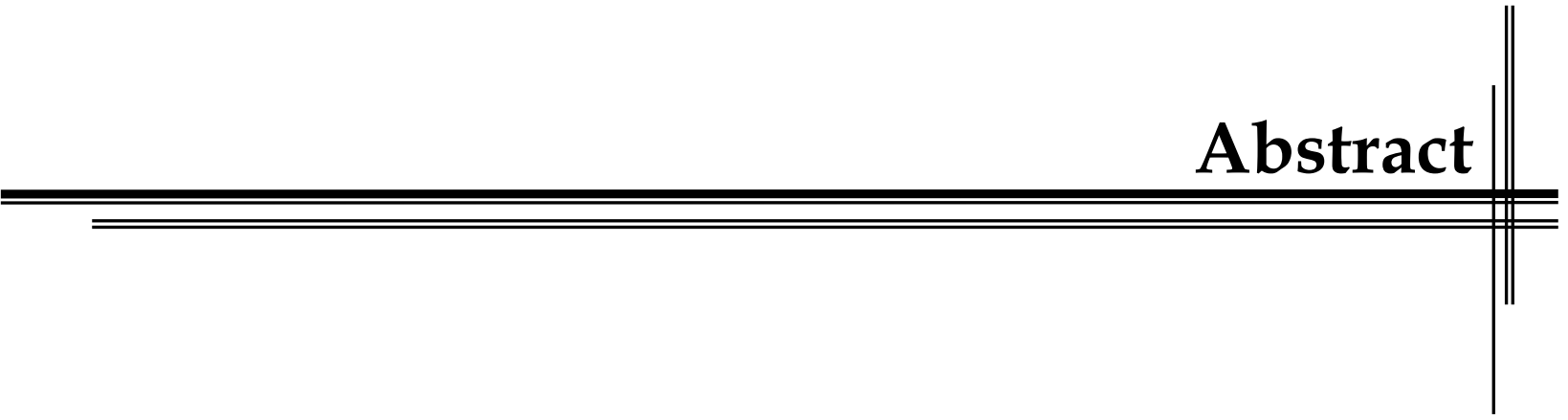

In the last few years, education has been going through important changes related to the introduction of information technology in the learning process. As a result of these changes and of efforts to take advantage of the benefits provided by this technology, many systems (or virtual environments) for supporting the learning process have been developed. However, despite the great number of tools offered by those systems, many users still prefer to develop their own tools. This happens because there is a lot of diversity in teaching and evaluation techniques among different teachers and traditional learning systems are not designed to adapt to this diversity. They do not offer many possibilities for functionality adaptation and extension. This makes users unmotivated to use them and forces them to write their own applications. As an alternative to this flexibility problem, a modular, component-based framework (WebMODE Web MOdular DEvelopment) was proposed for the development of more adaptable and extensible Web applications, especially for web-based learning systems. In addition, a software process for instantiating software applications using this framework was also proposed. This software process emphasizes the specification of the modules that form these software applications in a format independent of the technology used for their implementation. The main features of this framework are the use of design patterns, such as MVC (Model View Controller), and the use of concepts from modular and component-based systems for the development of web applications composed by modules with configurable functionalities. The WebMODE was designed as a conceptual framework and later implemented and evaluated using the J2EE (Java 2 Enterprise Edition) technology. 
Silva, E. Q. and MoreirA, D.A.: WebMODE - Desenvolvimento modular de aplicações Web para gerenciamento de atividades. World Congress on Computer Sciense, Engineerin and Technology Education-WCCSETE, Santos, SP, Brazil, COPEC - Conselho de Pesquisas em Educacão e Ciências, 19-22 March, 2006. pp. 1562 - 1566.

Silva, E. Q. and MoreirA, D. A.: A Component-based Framework for Customizable Webbased Education Application Development. International Conference on Engineering and Computer Education - ICECE, Madri, Spain, 2005. pp. 48 (CDROM pp.1-6).

Silva, E. Q. and MoreirA, D. A.: Developing customizable web-based educational applications through a component based framework. International Conference on Next Generation Web Servicess Practices-NWeSP, Seoul, Korea, August, 2005. pp. 394-399.

Silva, E. Q. and MoreirA, D. A.: A Framework for Development of Web-based Tools for Management of Educational Activities. 5th IEEE International Conference on Advanced Learning Technologies - ICALT, Kaohsiung, Taiwan, IEEE Computer Society Press, July, 2005. pp. 922-924.

Moreira, D. A. and Silva, E. Q. D.: Improving Student Interaction with Internet \& Peer Review. In: PaGANI, M., Encyclopedia of multimedia technology and networking. Hershey USA, Idea Group Reference, 2005. 375-381.

Silva, E. Q. and Moreira, D. A.: Um Framework de Componentes para o Desenvolvimento de Aplicações Robustas de Apoio à Educação. XIII Simpósio Brasileiro de Informática na Educação-SBIE, Manaus-AM, Brasil, Novembro, 2004. pp. 158-167.

Silva, E. Q., Brancalhone, P. and Moreira, D. A.: Peer Review e Aprendizagem Colaborativa: Experiências em Cursos de Computação. XXIV Congresso Nacional da Sociedade Brasileira de Computação - Workshop de Ensino de Informática, Salvador-BA, Brasil, Julho, 2004. pp. 141 (Anais em mídia digital pp. 1114-1125).

Silva, E. Q. and Moreira, D. A.: WebCoM: A tool to use peer review to improve student interaction. Journal on Education Resources in Computing - JERIC, ACM Press, v.3, n.1, pp. $1-14,2003$.

SILVA, E. Q. and MoreIRA, D. A.: Increasing Student Interaction using Student Groups and Peer Review over the Internet. IFIP Journal of Education and Information Technologies, v.8, n.1, pp. 47-54, 2003. 
Moreira, D. A. and Silva, E. Q.: A Method to Increase Student Interaction using Student Groups and Peer Review over the Internet. IFIP WG3.2 Working Conference on Informatics Curricula, Teaching Methods and Best Practice, Florianópolis, SC, Brazil, July, 2002. pp. 183191. http://java.icmc.usp.br/dilvan/publications.html.

Silva, E. Q., Rosa, V. F. and Moreira, D. A.: Peer Review e Educação Continuada a Distância utilizando o WebCoM como Ferramenta de Suporte. XIII Simpósio Brasileiro de Informática na Educação - SBIE'2002, São Leopoldo, RS, Brasil, Novembro, 2002. pp. 254262. 


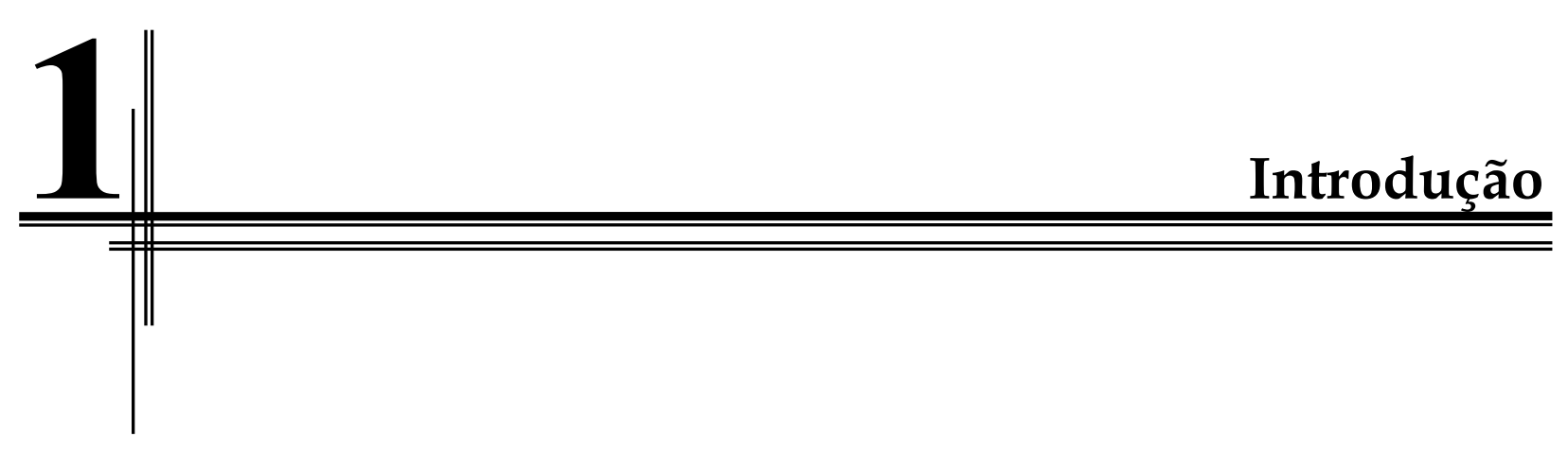

\subsection{Contextualização}

Com a evolução e a disseminação da Internet, o desenvolvimento de sistemas baseados na Web tem se tornado uma prática cada vez mais comum. Além da popularidade, esses sistemas têm evoluído consideravelmente em relação ao seu escopo e complexidade (Ginige \& Murugesan, 2001). Atualmente é possível observar uma variedade de formas de uso dessa tecnologia nos diferentes domínios, tais como educação, jornalismo, publicidade, governo, entre outros.

No contexto da educação, de modo especial, a $W e b$ tem se destacado como um importante recurso tecnológico utilizado para promover e/ou apoiar os métodos educacionais atuais por meio de diversas aplicações e ambientes virtuais, tais como: WebCT (WebCT, 2006), BlackBoard (Blackboard, 2006), TeleEduc (Rocha, 2002b; TelEduc, 2005), AulaNet (Aulanet, 2005), WebCoM (Silva \& Moreira, 2003b) e Col (COL, 2006).

Em geral, essas aplicações e ambientes oferecem uma variedade de ferramentas para a criação e acompanhamento de cursos baseados na Web (World Wide Web), como o gerenciamento de material didático, de usuários, de atividades, de notas e a comunicação entre usuários. No entanto, apesar do vasto conjunto de ferramentas oferecidas por esse tipo de sistema, ainda hoje, muitos usuários optam pelo desenvolvimento de suas próprias aplicações de apoio à educação, como pode ser visto na literatura (Brusilovsky, 2004; Eberspächer \& Joab, 2005; Wong et al., 2005). Isso acontece em função da diversidade do currículo e das técnicas de ensino e avaliação existentes entre diferentes instituições e, até mesmo, entre professores dentro de uma mesma instituição, o que muitas vezes dificulta a adoção de um sistema existente e sua completa adaptação a necessidades específicas (Roschelle et al., 1999; Anido-Rifón et al., 2001; Siemens, 2004). 
Um exemplo de dificuldade de adaptação pode ser encontrado no suporte ao método educacional baseado na revisão por pares (peer review). O peer review, bastante conhecido no mundo acadêmico para a revisão de artigos, tem sido aplicado por vários pesquisadores (Gehringer, 2000; Helfers et al., 2000; Nelson, 2000; Liu et al., 2001; Kern et al., 2003; Crespo et al., 2004; Silva et al., 2004) como um método educacional que atende objetivos diferentes sob diferentes estratégias de aplicação, tais como revisão cega ou aberta, com uma ou várias revisões, com nota dividida entre o trabalho original e o trabalho de revisão, entre outras. Apesar de receber a atenção de muitos educadores, esse método educacional ainda não é suportado pela maioria dos sistemas educacionais existentes. Por outro lado, quando suportado por um sistema, como é o caso do WebCoM (Silva \& Moreira, 2003b), o gerenciamento da atividade que utiliza o método aborda uma estratégia específica, não podendo atender técnicas e objetivos distintos.

Em geral, para suportar as diferentes necessidades de seus usuários, os sistemas Web precisam ser mais flexíveis, principalmente, em relação às suas funcionalidades. Como no âmbito educacional a necessidade de adaptação do conjunto de funcionalidades é um fator importante, muitas vezes é necessário que os sistemas permitam a sua customização em termos de código como forma de ampliar sua flexibilidade de adaptação e extensão para além de alterações de configuração. Porém, esse tipo de customização nem sempre é viável pois alguns sistemas não disponibilizam seus códigos-fonte e os sistemas de código aberto geralmente são construídos sobre arquiteturas integradas, cuja customização é complexa pela necessidade de se entender o código do sistema como um todo para qualquer tipo de adaptação (Roschelle et al., 1999; AnidoRifón et al., 2001; Pimentel et al., 2005).

Uma explicação para essa complexidade pode estar na forma como muitos desses sistemas são construídos (por exemplo, de maneira ad hoc). De acordo com a disciplina de Engenharia de $W e b$, que busca estabelecer metodologias, processos, ferramentas e diretrizes para desenvolvimento de aplicações e sistemas Web com qualidade, a falta de processos de software bem definidos no desenvolvimento de aplicações e sistemas Web pode acarretar uma série de problemas que incluem a dificuldade de manutenção, adaptação e extensão do sistema (Ginige \& Murugesan, 2001).

Além da complexidade na arquitetura, há outras características encontradas nos sistemas educacionais que também dificultam sua adaptação, por exemplo, papéis e permissões fixos no 
sistema; dependência de plataforma e de bases de dados específicas e conjunto de funcionalidades projetado de acordo com experiências locais (em geral, experiências dos seus desenvolvedores).

Na tentativa de criar sistemas de apoio à educação na Web mais adaptáveis, novas abordagens de desenvolvimento têm sido exploradas. Com isso está surgindo uma nova geração de sistemas educacionais baseados nos sistemas de gerenciamento de conteúdo (CMS - Content Management Systems) (Browning \& Lowndes, 2001) utilizados na construção de websites e portais comerciais personalizados. Os CMSs comerciais tentam resolver o problema de adaptação permitindo que o projetista do website escolha (e desenvolva, se for necessário) as funcionalidades, ou módulos, que deseja disponibilizar. O Moodle (Dougiamas \& Taylor, 2003) é um exemplo de CMS open-source para gerenciamento de cursos via Web.

Apesar dessa abordagem ser importante no aspecto de adaptação dos sistemas às necessidades dos usuários (Graf \& List, 2005), atualmente, a utilização de CMSs, como o Moodle, não é tão trivial no aspecto de alteração ou adição de novas funcionalidades no sistema. Isso se deve ao fato de que os CMSs existentes, incluindo o Moodle, se preocupam basicamente com a forma tecnológica de se construir os módulos, deixando de lado questões importantes sobre o que significam os módulos, como eles podem ser projetados, como eles são organizados para formar a aplicação, etc.

\subsection{Motivação}

Diante das dificuldades de adaptação dos sistemas educacionais, que acontece em função dos aspectos mencionados na seção anterior, torna-se relevante investigar modelos de desenvolvimento de software que ofereçam um nível maior de flexibilidade para esses sistemas.

Uma abordagem que merece ser investigada para esse problema é uso de frameworks e componentes de software. Frameworks são definidos como aplicações semi-completas e reutilizáveis que, quando especializadas, produzem aplicações personalizadas dentro de um domínio específico (Johnson \& Foote, 1988). Componentes de software são partes substituíveis de um sistema que enfatizam a separação entre interface e implementação. Essa separação facilita a comunicação entre os componentes do sistema e a substituição das suas implementações, pois toda a comunicação com o componente é feita por meio de sua interface (Larsson \& Sandberg, 2000). Apesar de serem tipicamente voltados para o reuso, frameworks e 
componentes possuem características, como dependência de interfaces bem definidas, reuso de projeto e arquitetura, uso de padrões, que podem auxiliar no desenvolvimento de sistemas com arquiteturas mais organizadas para permitir maior facilidade de adaptação e extensão.

$\mathrm{Na}$ literatura existem várias abordagens de desenvolvimento de aplicações e sistemas baseados na $W e b$, sendo que algumas delas são propostas com base nessas técnicas de projeto, tais como Struts (Spielman, 2003), JSF (Mahmoud, 2004), Sakai (Counterman et al., 2005). Porém, abordagens como Struts e JSF, que são de uso geral, estão mais preocupadas com o oferecimento de bibliotecas de código que auxiliam na tarefa de codificação, não oferecendo nenhuma vantagem específica relacionada com a flexibilidade. O Sakai, de uso mais específico do domínio educacional, apesar de usar conceitos de frameworks e componentes, está mais preocupado com a construção de um sistema educacional em particular, deixando de lado questões como documentação e processos de desenvolvimento que auxiliem na adaptação ou extensão do sistema. A abordagem do Sakai pode tornar-se mais interessante se houver uma maior preocupação com o desenvolvimento de outros sistemas educacionais e não apenas com um sistema em particular.

\subsection{Objetivos}

Esta tese teve como objetivo principal investigar o uso de frameworks e componentes de software no desenvolvimento de aplicações baseadas na Web, em especial as aplicações de apoio à educação, e propor um framework que viabilizasse o desenvolvimento dessas aplicações contemplando os aspectos de adaptabilidade e extensibilidade não encontrados nos sistemas existentes. Entende-se por adaptabilidade, a capacidade de uma aplicação ter suas funcionalidades adaptadas às necessidades dos usuários e por extensibilidade, a possibilidade de uma aplicação poder ser estendida para acomodar um requisito não previamente identificado.

Apesar dos requisitos iniciais desse framework, chamado WebMODE (Web Modular Development), terem sido estabelecidos a partir de estudos sobre sistemas educacionais baseados na $W e b$, a análise desses requisitos revelou que ele podia ser generalizado para o desenvolvimento de aplicações Web em geral. O termo "aplicação Web" ou "aplicação baseada na Web" deve ser entendido, nesta tese, como um sistema Web que permite, ao usuário, executar lógica de negócio por meio de um navegador Web (Conallen, 2002). 
O WebMODE foi projetado sob uma visão conceitual independente da tecnologia de desenvolvimento, o que não é considerado pelas abordagens de desenvolvimento Web disponíveis na literatura.

Além da proposta do framework, também fez parte dos objetivos desta tese, avaliar o projeto conceitual desse framework com base numa implementação funcional; instanciar uma aplicação no domínio educacional sobre essa implementação e analisá-la sob o aspecto da adaptação, e propor um processo de software para auxiliar no desenvolvimento das aplicações utilizando esse framework.

\subsection{Metodologia}

A metodologia de pesquisa adotada nesta tese foi baseada nas seguintes atividades:

1) Inicialmente, procurou-se explorar a área de informática na educação com o objetivo de analisar os sistemas educacionais existentes e identificar aspectos que dificultam sua adaptação. O resultado dessa exploração, realizada principalmente com base na revisão da literatura e nos testes desses sistemas, foi um conjunto de características, que incluem estruturação do código, independência de plataforma, possibilidade de integração com sistemas legados, facilidade de configuração e extensão de funcionalidades, flexibilidade nos tipos de usuários, que podem auxiliar na criação de um sistema educacional mais flexível.

2) Após essa investigação, passou-se à revisão da literatura de Engenharia de software na busca por técnicas de projeto que viabilizassem o desenvolvimento de aplicações com as características identificadas na atividade anterior. Esse estudo teve como ponto de partida a busca por soluções baseadas em frameworks e componentes de software.

3) Identificadas as técnicas de projeto de software viáveis para resolver o problema, iniciou-se a atividade de especificação do framework. Juntamente com a especificação foram realizadas as atividades de implementação que permitiram avaliar os conceitos envolvidos na proposta.

4) A partir dessa implementação, foi instanciada uma aplicação, no domínio educacional, para avaliar o correto funcionamento da implementação do framework.

5) Com base na instanciação dessa aplicação, foi definido o processo de software para guiar o desenvolvimento de módulos de uma aplicação instanciada sobre o framework proposto. 


\subsection{Contribuições ao estado da arte}

Esta tese teve como principais contribuições:

1.Um conjunto de características para incluir flexibilidade (adaptação e extensão) em sistemas de apoio à educação na Web de maneira especial.

2. O projeto de um framework de aplicação modular baseado em componentes (WebMODE) para o desenvolvimento de aplicações $W e b$ mais adaptáveis e extensíveis e um exemplo de implementação funcional desse projeto.

3. O processo de instanciação de aplicações Web sobre o framework proposto. A característica principal desse processo é que ele contempla a especificação de módulos das aplicações instanciadas sobre o WebMODE de forma independente da tecnologia de implementação. Como será discutido no Capítulo 7, não foi encontrado na literatura nenhum framework para desenvolvimento $\mathrm{Web}$ que esteja associado a um processo de especificação das suas aplicações.

4. Um conjunto de requisitos para suportar o desenvolvimento de aplicações $\mathrm{Web}$ mais flexíveis.

\subsection{Organização}

Esta tese está organizada de forma a apresentar o contexto teórico no qual está inserida, bem como os resultados obtidos e suas contribuições para a comunidade acadêmica.

No Capítulo 2 é feita uma revisão da literatura sobre informática na educação. Inicialmente, apresenta-se uma visão geral sobre as práticas mais comuns de uso da tecnologia na educação citando exemplos de sistemas que apóiam essas práticas. Posteriormente, apresenta-se uma análise desses sistemas em relação aos aspectos de adaptabilidade e o conjunto de características que favorecem a criação de sistemas educacionais mais flexíveis.

No Capítulo 3 discute-se sobre algumas técnicas de projeto, da literatura de Engenharia de Software, que podem ser utilizadas no desenvolvimento de sistemas mais adaptáveis e extensíveis. São apresentados os conceitos de componentes, frameworks de aplicação, padrões de projeto e sistemas modulares, que foram utilizados como base da proposta desta tese. 
No Capítulo 4 é apresentada a proposta de framework para o desenvolvimento de aplicações Web modulares. Inicialmente apresenta-se a proposta de framework (WebMODE), em termos do seu projeto conceitual e, posteriormente, a implementação realizada como exemplo utilizando a tecnologia J2EE (Java 2 Enterprise Edition) . Essa implementação recebeu o nome de WebMODE-J2EE.

No Capítulo 5 o processo detalhado para a instanciação de aplicações sobre a proposta de framework é descrito. As atividades de especificação são independentes da tecnologia de implementação, enquanto as atividades de desenvolvimento estão ligadas à implementação WebMODE-J2EE.

No Capítulo 6 é apresentada a aplicação de gerenciamento de atividades que foi instanciada sobre o WebMODE-J2EE. O aspecto de adaptabilidade dessa aplicação é discutido com base na implementação de uma funcionalidade não originalmente contemplada pela aplicação.

No Capítulo 7 apresenta-se uma visão geral sobre outras abordagens de desenvolvimento Web que buscam contemplar os aspectos de adaptabilidade das aplicações. O objetivo nesse capítulo é comparar o trabalho proposto nesta tese com as demais abordagens.

Finalmente, no Capítulo 8, são apresentadas as conclusões desta tese, incluindo propostas de continuidade desta pesquisa. 


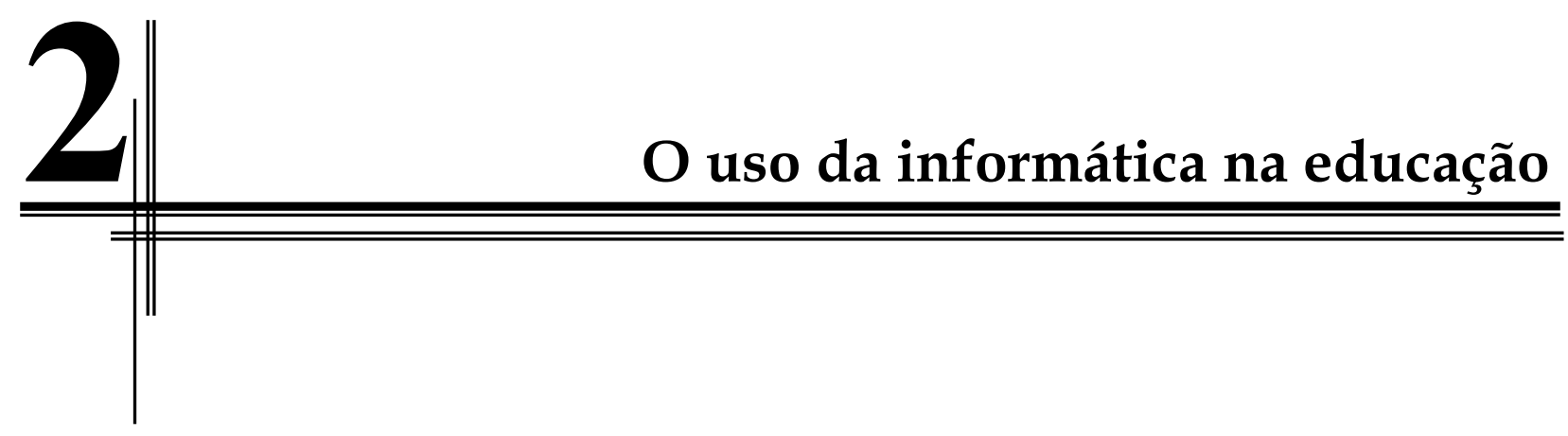

\subsection{Considerações iniciais}

A área de informática na educação tem sido alvo de grande interesse nos últimos anos devido, principalmente, à importância da utilização de ferramentas computacionais no apoio ao processo de ensino-aprendizagem. O uso dos computadores e da Internet na educação tem sido estabelecido como fator importante para a evolução dos métodos educacionais atuais e futuros (Filho \& Machado, 2004).

Assim, tanto no âmbito acadêmico, quanto no comercial, muitos esforços vêm sendo realizados no sentido de explorar o uso de recursos computacionais na construção de sistemas educacionais. Como exemplo desses esforços, pode-se observar o número de ferramentas e ambientes virtuais voltados para a educação existentes atualmente, tais como WebCT (WebCT, 2006), TelEduc (TelEduc, 2005), AulaNet (Aulanet, 2005), Blackboard (Blackboard, 2006), TopClass (TopClass, 2006), WebCoM (Silva \& Moreira, 2003b), Col (COL, 2006), iClass (iClass, 2006), Angel (Jafari, 2002), entre outros.

Como a motivação desta tese foi originada no contexto da informática na educação, apresenta-se, neste capítulo, uma visão geral sobre essa área de atuação. São descritas as formas mais comuns de uso da tecnologia no contexto educacional e apresentados alguns exemplos de sistemas de software e ambientes virtuais que apóiam ou viabilizam essas práticas.

Numa primeira parte, os exemplos de sistemas são descritos em termos de suas características gerais. Mais ao final do capítulo, é apresentada uma análise desses sistemas em relação aos seus aspectos de flexibilidade para se adaptar às necessidades dos usuários e suportar futuras evoluções. O resultado dessa análise forneceu subsídios para o estabelecimento de um conjunto de características consideradas essenciais para adicionar adaptabilidade, extensibilidade e 
flexibilidade às aplicações educacionais baseadas na Web. Tais características formaram a base da proposta apresentada nesta tese, que é descrita a partir do Capítulo 4.

\subsection{Informática na educação}

De acordo com Valente (1995), existem diferentes maneiras de usar o computador na educação, variando desde a simples informatização dos métodos tradicionais de instrução (paradigma instrucionista) até o desenvolvimento de novas formas de aprendizagem (paradigma construcionista).

As primeiras experiências de uso dos computadores na educação enfatizavam a estruturação de um conjunto de informações sobre assuntos específicos, de modo que os estudantes eram condicionados a estudar essas informações numa seqüência pré-determinada pelo projetista do software. Posteriormente, com o aumento no nível de interação e com o uso de novas tecnologias, especialmente as de comunicação, o enfoque das pesquisas em informática na educação passou a ser o projeto de ambientes e ferramentas que serviam não apenas como instrutores ou apresentadores de conteúdo, mas também como auxiliares do processo de ensinoaprendizagem.

A Internet, considerada um poderoso meio de distribuição de informação, passou a ser intensamente explorada em programas de treinamento e educação em função das facilidades oferecidas para seus usuários. De modo especial, a Web se destaca entre os serviços disponíveis na Internet por atrair um grande número de usuários dispersos por todo o mundo, além de ser um meio de baixo custo tanto para a produção quanto para o acesso às suas informações. A possibilidade de inserção de recursos multimídia nos documentos Web aumenta a sua relevância para o contexto da educação por permitir incrementar o processo de aprendizagem do estudante através da utilização de imagens, sons, simulações e outros recursos (Keegan, 1996). Os demais serviços disponíveis na Internet, como FTP (File Transfer Protocol), teleconferência, correio eletrônico, entre outros, complementam os requisitos necessários para que a Internet seja tomada como base da grande maioria dos projetos envolvidos com a informática na educação.

Programas de educação/treinamento presencial, caracterizados pela sala de aula, lousa e giz, podem utilizar os sistemas educacionais baseados na Internet para apoio ao processo de ensino (Abowd et al., 2000; Silva et al., 2000). Nesse caso, os sistemas educacionais são utilizados para auxiliar no gerenciamento das atividades propostas e realizadas pelas entidades envolvidas no 
processo educacional (professores, estudantes, monitores, etc) e para armazenar e organizar materiais didáticos. Atualmente, grande parte dos professores, especialmente em universidades, faz uso das facilidades da Internet para apoio às suas aulas presenciais, seja para disponibilizar conteúdos ou para estabelecer mecanismos de comunicação com os estudantes (e entre eles).

Além do apoio à sala de aula, a Internet também passou a ser utilizada na educação a distância ${ }^{1}$ que, inicialmente, era feita por correspondência, televisão, vídeo ou rádio (Roberts, 1996). Em programas de educação a distância via Internet, o uso de sistemas educacionais vai além do simples apoio à tarefa realizada na sala de aula. Nesse caso, os recursos oferecidos nos sistemas são os principais meios pelos quais o conhecimento é transmitido aos estudantes e pelos quais estes têm acesso aos professores e aos outros estudantes, já que nessa forma de educação não existe a noção de sala de aula física, mas sim o conceito de sala de aula virtual.

Dentre as vantagens potenciais em se fazer educação via Internet, destacam-se: a distribuição do conhecimento em larga escala e com baixos custos, em função do alcance mundial dessa rede; a existência de diferentes meios de comunicação que facilitam o feedback do estudante ao professor e um melhor acompanhamento do processo como um todo; e a facilidade de acesso e compatibilidade, sendo que o material na Internet pode ser acessado de qualquer lugar .

\subsection{Ambientes virtuais de apoio à educação na Web}

Nos últimos dez anos, diversos projetos de aplicação das tecnologias computacionais na educação foram propostos e implementados. A maioria desses projetos, geralmente caracterizados por ambientes virtuais de educação, teve como foco principal fornecer ferramentas síncronas e assíncronas, baseadas na $W e b$, para suportar a educação a distância no que tange à criação e gerenciamento de cursos online. Dentre as funcionalidades mais comuns desses ambientes pode-se citar a autoria de materiais didáticos, exercícios e avaliações, o gerenciamento de atividades (por exemplo, entrega de trabalhos ou realização de avaliações), a comunicação entre professores e estudantes e entre os próprios estudantes, o acompanhamento de estudantes, entre outras.

\footnotetext{
${ }^{1}$ A educação (e o treinamento) a distância é caracterizada basicamente pela separação física (ou temporal) entre professores e estudantes e pela utilização de meios de comunicação para unir o professor ao estudante e transmitir os conteúdos educativos (Keegan, 1996).
} 
Apesar da variedade de ambientes virtuais de apoio à educação existente na literatura, a maioria deles apresenta um conjunto de funcionalidades bastante semelhante, já que foram desenvolvidos para serem utilizados por diversos tipos de usuários.

Para exemplificar esses ambientes virtuais, nas subseções seguintes são apresentados os ambientes WebCT (desenvolvido sob os moldes das universidades norte-americanas), AulaNet e TelEduc (produtos de pesquisa desenvolvidos no Brasil).

\subsubsection{WebCT}

O WebCT (Web Course Tools), proposto por Murray W. Goldberg da University of British Columbia (Canadá) em 1996 (Goldberg, 1996, 1997), é um dos mais conhecidos entre os ambientes computacionais destinados à educação baseada na Web. Ao lado de outros ambientes citados na literatura, o ambiente WebCT é tido como um dos mais completos para a manutenção de cursos na $\mathrm{Web}$ por fornecer, aos estudantes e professores, a maioria dos recursos necessários para a realização do curso, incluindo tanto ferramentas de autoria de conteúdos quanto de gerenciamento de material e de tarefas didáticas.

Apesar de ter sido inicialmente desenvolvido como um projeto de pesquisa, o WebCT se tornou um produto comercial em 1997. Atualmente ele é vendido em duas versões diferentes: WebCT Campus Edition e WebCT Vista (WebCT, 2006). A principal diferença entre elas é que o WebCT Vista, além de suportar as funcionalidades básicas para gerência de cursos (foco da versão WebCT Campus Edition), também oferece recursos para gerência acadêmica, por exemplo, para o controle de várias unidades de uma instituição de forma centralizada.

Nas últimas versões do WebCT Campus Edition há seis grupos principais de usuários (papéis) que possuem direitos de acesso diferentes sobre as ferramentas do ambiente (WebCT, 2006):

- Administrador: é o usuário que administra o servidor do ambiente WebCT. Ele tem acesso a um conjunto de páginas para criação, inicialização e remoção de cursos e para controle de senha dos usuários. O administrador cria os cursos e estabelece seus membros, inclusive o projetista (designer).

- Projetista (designer): é o usuário que define o projeto gráfico das seções de cursos (cada ocorrência de um mesmo curso é chamado de uma seção daquele curso) e determina as ferramentas a serem utilizadas. Porém, ele não tem acesso às ferramentas de gerenciamento do curso, tais como manipulação de notas ou conteúdo didático. 
- Instrutor: é o usuário responsável pelo gerenciamento de uma seção de um curso. É esse usuário que manipula o conteúdo didático, cria avaliações e exercícios, estabelece notas e acompanha o progresso dos estudantes, cria grupos de trabalho e manipula as contas dos estudantes da seção do curso, entre outras atividades.

- Monitores: são os usuários que auxiliam os professores a gerenciar algumas atividades de uma seção de curso. Eles possuem os mesmos privilégios dos estudantes, mas podem realizar correção de testes e atribuir notas aos estudantes.

- Estudantes: são os usuários que realizam o curso. Eles podem visualizar conteúdos, fazer testes, submeter trabalhos, modificar sua página pessoal, etc.

- Auditores: são os usuários que participam do curso mas não são avaliados.

O uso do WebCT não requer instalação de nenhum software no computador do usuário, pois ele é totalmente baseado na $W e b$ e executado a partir de um navegador. De acordo com a documentação disponível (WebCT, 2006), o ambiente WebCT é desenvolvido utilizando tecnologias da plataforma J2EE (Java 2 Enterprise Edition), sendo portanto independente de plataforma. Por ser um produto comercial, não é disponibilizada nenhuma documentação mais detalhada sobre a estrutura interna do ambiente.

Entre as ferramentas educacionais oferecidas pelo ambiente WebCT (baseado na versão Campus Edition) pode-se citar a gerência de calendário, material didático, mecanismos de comunicação (sistema de conferência, chat, correio eletrônico), acompanhamento do aluno, suporte para projetos colaborativos (área compartilhada de dados entre os alunos), auto-avaliação (quiz), distribuição e visualização de notas, glossário, etc. A título de ilustração, a Figura 2.1 apresenta um esboço da interface principal de um curso no WebCT.

O conjunto de funcionalidades oferecidas pelo WebCT permite que esse ambiente virtual seja utilizado tanto como ferramenta de ensino em programas de educação a distância quanto como ferramenta de apoio à sala de aula em cursos presenciais.

\subsubsection{AulaNet}

O AulaNet é um ambiente virtual para criação, participação e administração de cursos baseados na $W e b$, cujo desenvolvimento foi iniciado em 1997 no Laboratório de Engenharia de Software (LES) do Departamento de Informática da Pontifícia Universidade Católica do Rio de Janeiro 
(PUC-RIO) (Aulanet, 2005). De acordo com seus desenvolvedores, o AulaNet foi concebido tendo-se como principal objetivo a colaboração entre os seus participantes, daí a característica de groupware do ambiente (Lucena et al., 1998).

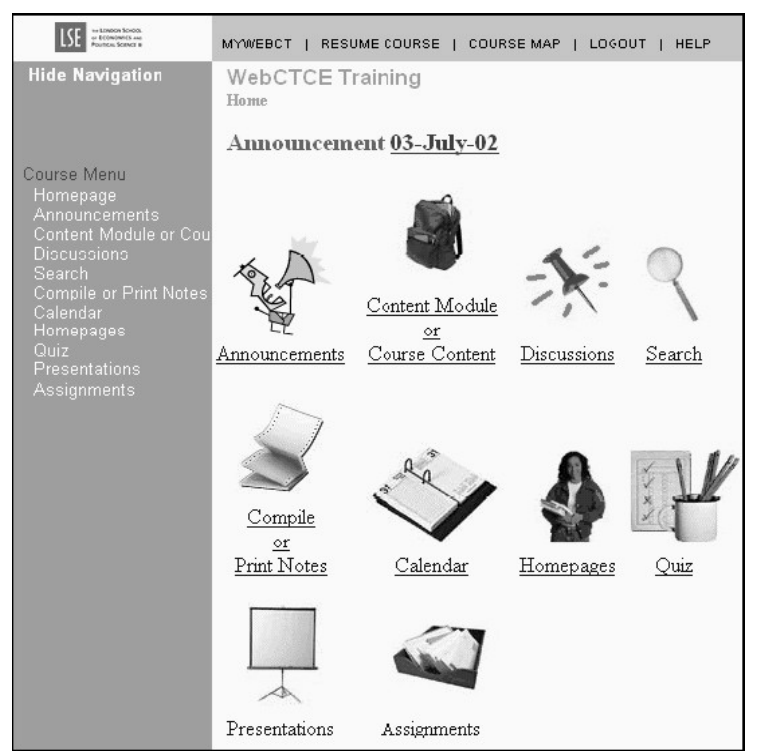

Figura 2.1 - Interface do ambiente WebCT acessada pelo estudante (WebCT, 2006)

No ambiente Aulanet, existem três atores (Lucena et al., 1998; Lucena et al., 1999):

- Administrador: é quem atua na operação do ambiente, facilitando a integração professor/ambiente/estudante. Ele é responsável por cadastrar novos departamentos e/ou instituições, fazer matrícula de estudantes, registrar professores, entre outras tarefas. $\mathrm{O}$ administrador também pode definir o layout do ambiente que afeta todos os cursos.

- Professor: é o criador do curso, participando desde a sua descrição inicial até a entrada do conteúdo didático. Um professor pode ou não ser o responsável pela aplicação do curso, podendo contar com o auxílio de um professor co-autor.

- Estudante: é o usuário final do curso que acessa o material didático, faz as atividades, participa das discussões, entre outras tarefas.

A criação de um curso no ambiente Aulanet é feita passo a passo como um wizard e inclui a descrição das informações gerais do curso (nome, descrição sumário e ementa), a seleção dos recursos que serão utilizados (há um conjunto pré-selecionado que pode ser modificado), a preparação de um plano de aulas e, posteriormente, a entrada do conteúdo didático. 
Os recursos oferecidos pelo ambiente AulaNet (para serem utilizados nos cursos) estão divididos em três categorias (Lucena et al., 1998): mecanismos de comunicação, de coordenação e de cooperação. Os mecanismos de comunicação compreendem os recursos para comunicação entre professores e estudantes e entre os estudantes, tais como: correio eletrônico, grupos de interesse (newsgroup), grupos de discussão (forum) e debates (bate-papo e videoconferência). Os mecanismos de coordenação envolvem os recursos para agendamento de tarefas e avaliações, tais como agenda, notícias do curso (news), prova, trabalho e exercício. Os mecanismos de cooperação $^{2}$, que incluem bibliografias, webliografias, documentações e downloads, correspondem ao instrumental pedagógico utilizado durante o curso (devem ser previamente selecionados pelo professor).

Para o acesso ao curso é necessário que o estudante esteja cadastrado no ambiente e que sua matrícula seja solicitada para cada curso desejado. Os recursos selecionados pelo professor ficam disponíveis para acesso dos estudantes conforme mostra a Figura 2.2, que apresenta a interface principal de um curso oferecido no ambiente AulaNet.

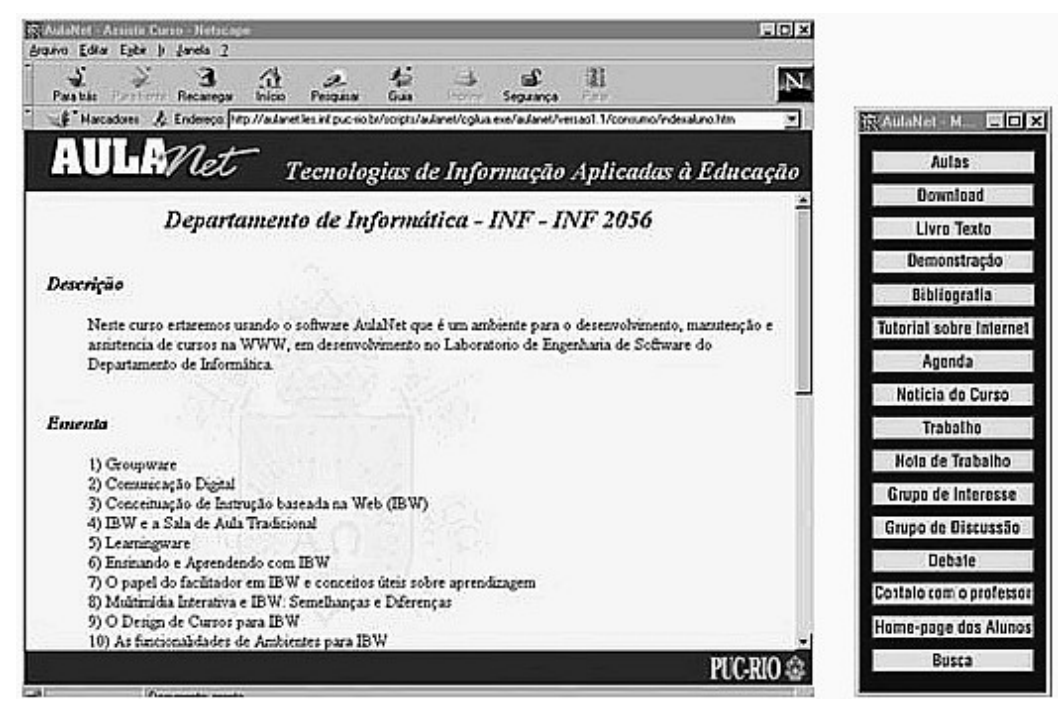

Figura 2.2 - Interface principal de um curso no ambiente Aulanet (Aulanet, 2005)

Apesar de toda a interação com o AulaNet ser por meio de um navegador $W e b$, alguns recursos mais sofisticados de interação, como a videoconferência, requerem a instalação de programas específicos (plug-ins) no computador do cliente.

\footnotetext{
${ }^{2}$ No AulaNet, o conceito de cooperação deve ser entendido como a preparação do material pelo professor ou, de um ponto de vista mais construtivista, a criação de um espaço para a contribuição de outros participantes (outros professores e os próprios estudantes) (Lucena et al., 1999).
} 
O ambiente Aulanet, como o WebCT, também pode ser utilizado tanto para o educação a distância como para a complementação das atividades de educação presencial ou treinamento de profissionais.

Atualmente o AulaNet está na versão 2.x e por uma limitação da tecnologia de desenvolvimento, a sua versão atual só pode ser utilizada em um servidor Windows. Porém, uma nova versão (3.0) está sendo desenvolvida e promete mudar significativamente a estrutura interna desse ambiente (Fuks et al., 2003; Pimentel et al., 2005).

\subsubsection{TelEduc}

O TelEduc (TelEduc, 2005) é um ambiente de suporte ao ensino-aprendizagem a distância, cujo desenvolvimento teve início em 1998 no Núcleo de Informática Aplicada à Educação (NIED) da Universidade de Campinas (UNICAMP). Sua proposta inicial teve como alvo o processo de formação de professores para Informática Educativa baseado numa metodologia construída com base na análise de experiências de profissionais formadores do NIED (Rocha, 2002a).

De acordo com seus desenvolvedores, o ambiente TelEduc (Rocha, 2002b) (cujo nome vem da junção das palavras Telemática e Educação) foi desenvolvido tendo como elemento central a ferramenta "Atividades". Essa abordagem considera que o aprendizado de conceitos de qualquer domínio do conhecimento acontece a partir da resolução de problemas com subsídio de diferentes materiais colocados à disposição do aluno, tais como textos, software e instruções de uso.

As ferramentas oferecidas pelo TelEduc são dividas em três grupos: coordenação, comunicação e administração (Rocha, 2002b).

O grupo de coordenação engloba as ferramentas que organizam e oferecem suporte para as ações do curso, tais como agenda, histórico e dinâmica do curso (tempo de duração do curso, objetivos, o que é esperado dos estudantes, etc). As ferramentas que disponibilizam material didático de apoio às atividades do estudante, como as ferramentas leituras, material de apoio, atividades e perguntas freqüentes, também fazem parte do grupo de coordenação.

O grupo de comunicação inclui ferramentas como correio eletrônico, bate-papo, grupos de discussão, mural de recados e portifólio (área que o estudante tem para compartilhar informações 
pessoais) que veiculam a comunicação entre os estudantes com seus formadores e com outros estudantes do curso.

No grupo de administração estão as ferramentas que fornecem apoio ao formador para o gerenciamento da parte administrativa do curso:

- gerenciamento de alunos e formadores (professores) e grupos de estudantes, inscrições, datas de início e término de curso;

- apoio à autoria, ou seja, inserção de conteúdo para as ferramentas: leituras, material de apoio, atividades;

- atualização de informações das ferramentas: agenda e dinâmica de curso;

- $\quad$ seleção de ferramentas disponíveis no curso;

- acompanhamento dos acessos diários dos estudantes às ferramentas disponíveis no curso.

O ambiente TelEduc conta basicamente com dois tipos de usuários que são os formadores e os estudantes. As ferramentas dos grupos de coordenação e comunicação podem ser acessadas por formadores e estudantes, mas as ferramentas de administração só estão disponíveis ao usuário formador.

Além dos formadores e estudantes, há também a figura do administrador do ambiente TelEduc, que é o responsável pelas funções administrativas do servidor. O administrador é responsável por instalar o servidor do ambiente TelEduc, fazer atualização de versões, criar áreas de cursos para os formadores e, também, emitir relatórios de utilização do ambiente.

Uma característica marcante no ambiente TelEduc é a sua preocupação com a avaliação formativa $^{3}$ dos estudantes. Algumas pesquisas nesse ambiente, visando esse tipo de avaliação, tentam favorecer a análise de dados quantitativos (Romani, 2003) e qualitativos (Ferreira et al., 2003) das participações dos estudantes num curso, principalmente nas ferramentas de comunicação (interação).

\footnotetext{
${ }^{3}$ Entende-se por avaliação formativa o tipo de avaliação que tem como objetivo principal melhorar o processo de ensino-aprendizagem em andamento e não apenas verificar as aprendizagens adquiridas, como acontece na maioria dos ambientes virtuais de educação (Ferreira et al., 2003).
} 
O ambiente TelEduc é um software distribuído livremente sob os termos da licença GPL ${ }^{4}(G N U$ General Public License). Ele foi desenvolvido utilizando-se a linguagem PHP $^{5}$ e o gerenciador de banco de dados MySQL ${ }^{6}$, sendo que sua versão atual, a v3.3.5, é suportada por servidores Linux (TelEduc, 2005).

Apesar de ter sido inicialmente projetado para a educação a distância, o TelEduc também tem sido utilizado para apoiar aulas presenciais. A Figura 2.3 apresenta uma interface do ambiente TelEduc sendo acessada por um formador. O acesso ao ambiente é feito por meio de um navegador sem necessidade de instalação de software específico no computador do usuário.

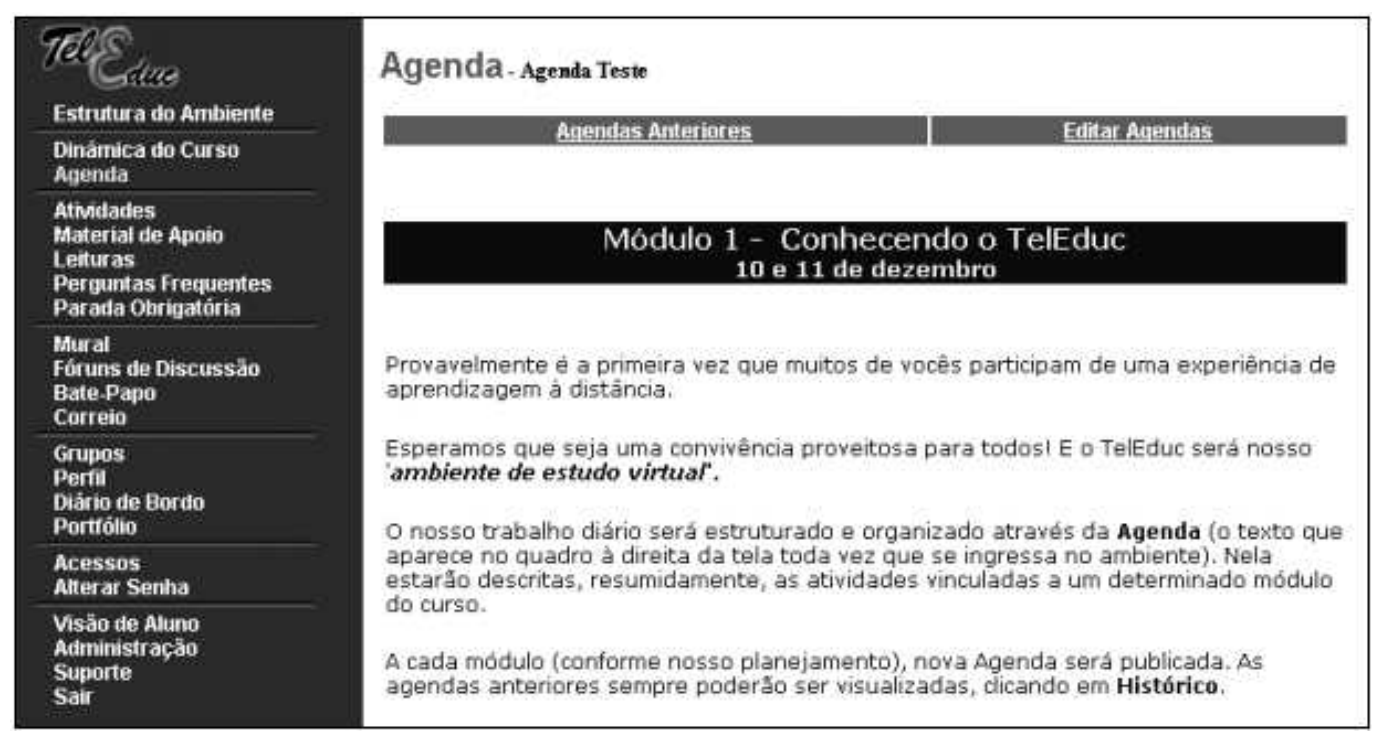

Figura 2.3 - Interface de um curso no ambiente TelEduc (TelEduc, 2005)

\subsection{Sistemas educacionais voltados para apoio à sala de aula}

Conforme pôde ser observado nas subseções anteriores, os ambientes virtuais de apoio à educação na $W e b$ podem, também, ser utilizados como ferramenta de apoio às atividades da sala de aula tradicional. Utilizando ambientes como WebCT, AulaNet e TelEduc (entre outros), os professores podem disponibilizar conteúdo de aula ou de apoio para os estudantes, gerenciar notas, promover discussões enquanto os estudantes se beneficiam da existência de um local centralizado para assuntos dos cursos que freqüentam. Apesar dessa prática ser comum, muitos educadores ainda preferem utilizar sistemas mais específicos ao invés de utilizar um ambiente virtual completo, especialmente quando se trata do apoio às atividades da sala de aula.

\footnotetext{
${ }^{4}$ http://www.gnu.org/copyleft/gpl.html

${ }^{5}$ Hipertext Processor - http://www.php.net/

${ }^{6} \mathrm{http}: / / \mathrm{www} . \mathrm{mysq}$ l.com
} 
No Instituto de Ciências Matemáticas e de Computação (ICMC) da Universidade de São Paulo (USP), a informática é utilizada no apoio ao ensino tradicional de diferentes formas: para captura e disponibilização de experiências da sala de aula (Cattelan, 2003), edição colaborativa de conteúdo (Arruda-Jr. et al., 2002), gerenciamento de atividades didáticas específicas (Silva et al., 2004), entre outras. Essas práticas são suportadas por ferramentas de software específicas, desenvolvidas por pesquisadores da própria instituição.

\subsubsection{Captura de experiências em sala de aula - iClass}

O projeto iClass (Cattelan, 2003, 2004), em desenvolvimento no ICMC-USP com base nas funcionalidades do projeto eClass, desenvolvido pelo Instituto de Tecnologia da Georgia (GATECH) em Atlanta (Abowd et al., 1999; Abowd, 1999; Abowd et al., 2000), tem como objetivo a criação de um modo automatizado para transformar o conteúdo de uma sala de aula tradicional em mídias digitais extensíveis para que possam ser reutilizadas a curto e longo prazo.

O sistema iClass é um ambiente de computação ubíqua (Weiser, 1991) que permite a captura de diferentes fluxos de informação produzidos durante uma aula convencional realizada em uma sala de aula instrumentada. A informação capturada pode incluir os slides utilizados pelo professor em uma lousa eletrônica (whiteboard) e as anotações (strokes) sobre esses slides, o áudio gravado a partir de um microfone, o vídeo proveniente de uma webcam e as URLs dos websites visitados. Ao final da aula, um documento hipermídia, que integra as diferentes mídias capturadas, é gerado e processado para criar documentos derivados em vários formatos de apresentação que ficam disponíveis na Web para acesso dos interessados (Cattelan, 2004).

O software iClass foi desenvolvido com base nos resultados provenientes do projeto InCASERVE (Infrastructure for Capture and Access - Store, Extend, Retrieve and Visualize Evolutionary information $)^{7}$ cujo objetivo era produzir infra-estruturas de captura e acesso genéricas e fornecer facilidades para o armazenamento, extensão, recuperação e visualização de informações provenientes de captura.

O processo de captura e acesso utilizando o iClass ocorre em quatro fases (Cattelan, 2003):

- pré-produção: configuração da aula a ser capturada (é possível carregar slides prépreparados que serão projetados na lousa eletrônica para serem anotados);

\footnotetext{
${ }^{7}$ Projeto INCA-SERVE, parceria entre ICMC-USP e GATECH, disponível em http://coweb.icmc.usp.br/incaserve
} 
- gravação "ao vivo": captura e sincronização dos fluxos de informação (conteúdo da lousa eletrônica e, opcionalmente, o áudio e o vídeo da aula);

- pós-produção: encerramento da sessão de captura com a geração de um documento hipermídia com todas as informações capturadas; e

- acesso: visualização da informação capturada em diferentes formatos.

Na Figura 2.4 são ilustrados uma sala de aula equipada com o hardware para a captura das aulas, um exemplo de um hiperdocumento gerado a partir da captura, nos quais é possível observar as anotações feitas sobre os slides, e a interface de captura do iClass.
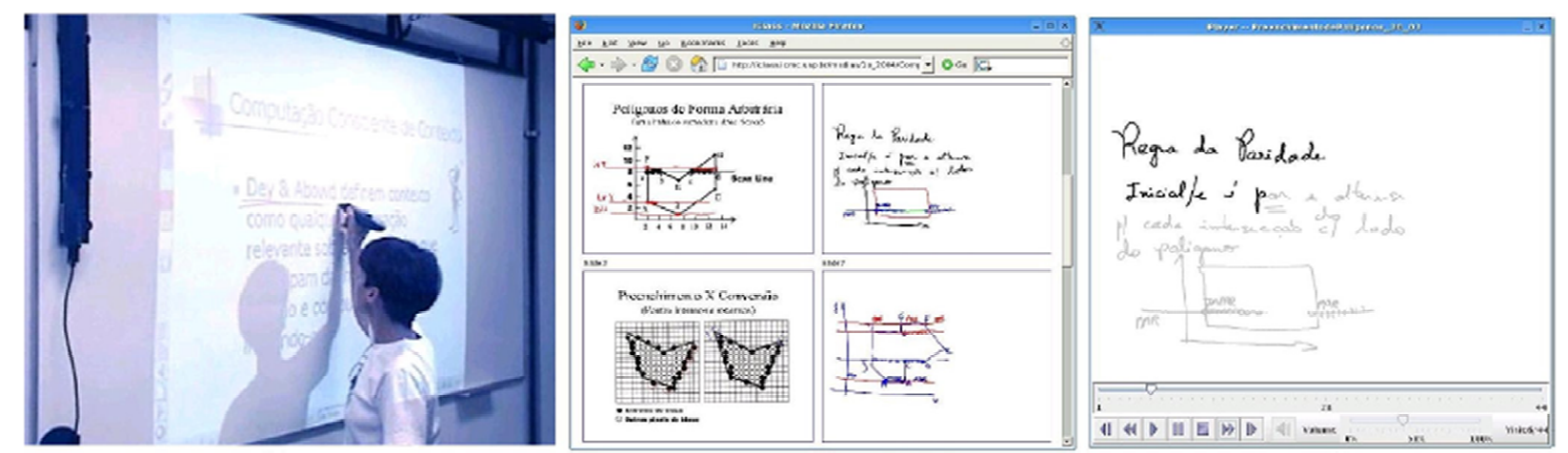

Figura 2.4 - Sala de aula para captura e hiperdocumentos gerados (Jardim et al., 2005)

Diferente de outros exemplos apresentados neste capítulo, o sistema iClass (iClass, 2006) não é um ambiente de gerenciamento de cursos porque não possui ferramentas de coordenação tais como gerência de estudantes, de atividades, de notas, de grupos, entre outras.

No iClass também não há a preocupação com a educação a distância, ou seja, o sistema é oferecido apenas como meio de suporte à aulas presenciais no sentido de manter informações (capturadas na sala de aula) que podem ser reutilizadas tanto por professores quanto por estudantes. Uma iniciativa de uso desse tipo de captura voltada para a educação a distância está sendo realizada no projeto Tidia-Ae (Tecnologia da Informação no Desenvolvimento da Internet Avançada - Aprendizado Eletrônico) (Tidia-Ae, 2006), apresentado no Capítulo 7. Nesse projeto está sendo desenvolvida uma ferramenta Whiteboard distribuída na qual vários participantes de uma sessão de captura podem compartilhar informações de forma colaborativa e síncrona. Essas informações ficam disponíveis a todos os autorizados a acessá-la. 


\subsubsection{Edição colaborativa de documentos - CoTeia}

A CoTeia ${ }^{8}$ (Arruda-Jr. et al., 2002) é uma ferramenta de trabalho cooperativo para edição compartilhada e assíncrona de hiperdocumentos na $W e b$. Ela foi desenvolvida no ICMC-USP com base nas funcionalidades do sistema CoWeb (Collaborative Web Site) (Guzdial, 1999), proposto inicialmente por pesquisadores do Laboratório de Software Colaborativo do Instituto de Tecnologia da Geórgia (GATECH).

No ICMC-USP, a CoTeia é utilizada como uma ferramenta para apoio a aulas presenciais. Cada professor solicita a abertura de um repositório (Swiki) na CoTeia (uma área em que ele pode compartilhar hiperdocumentos) e a utiliza para disponibilizar variados tipos de informação: material didático, exercícios, notas de trabalhos e avaliações, trabalhos dos estudantes, etc. Os repositórios criados pelo administrador da CoTeia são preenchidos com páginas Web (hiperdocumentos) que podem ser editadas colaborativamente por todos os usuários que tiverem a autorização para edição, ou seja, a senha para desbloqueio da página.

A linguagem para a edição de páginas da CoTeia é baseada em XML (Extended Markup Language) (W3C, 2004a). A CoTeia disponibiliza algumas tags específicas como $<$ upload $></$ upload $>$ (para referenciar arquivos que foram colocados no repositório da CoTeia) e $<\operatorname{lnk}></ \operatorname{lnk}>$ (para criar links entre as páginas da CoTeia). Entretanto, a formatação das páginas pode ser feita por meio das tags de formatação da linguagem HTML (Hypertext Markup Language) (W3C, 1999a). Na Figura 2.5 é apresentada uma página da CoTeia sendo editada (a) e a sua visualização pelo usuário final (b).

Dentre as funcionalidades oferecidas pela CoTeia estão: gerenciamento de repositórios Swiki pelo administrador, criação e edição de páginas, visualização de histórico e versão das páginas, busca, upload e ligação de documentos, anotações, etc.

Assim como no iClass, na CoTeia também não há a preocupação com educação a distância e nem com aspectos para gerenciamento de cursos na Web. Entretanto, suas características permitem que ela seja utilizada para realizar algum tipo de gerenciamento de recursos e atividades didáticas, por exemplo: criação de calendários, upload de trabalhos, divulgação de notas e bate-papo (há uma ferramenta de bate-papo integrada à CoTeia).

\footnotetext{
${ }^{8}$ http://coteia.icmc.usp.br
} 


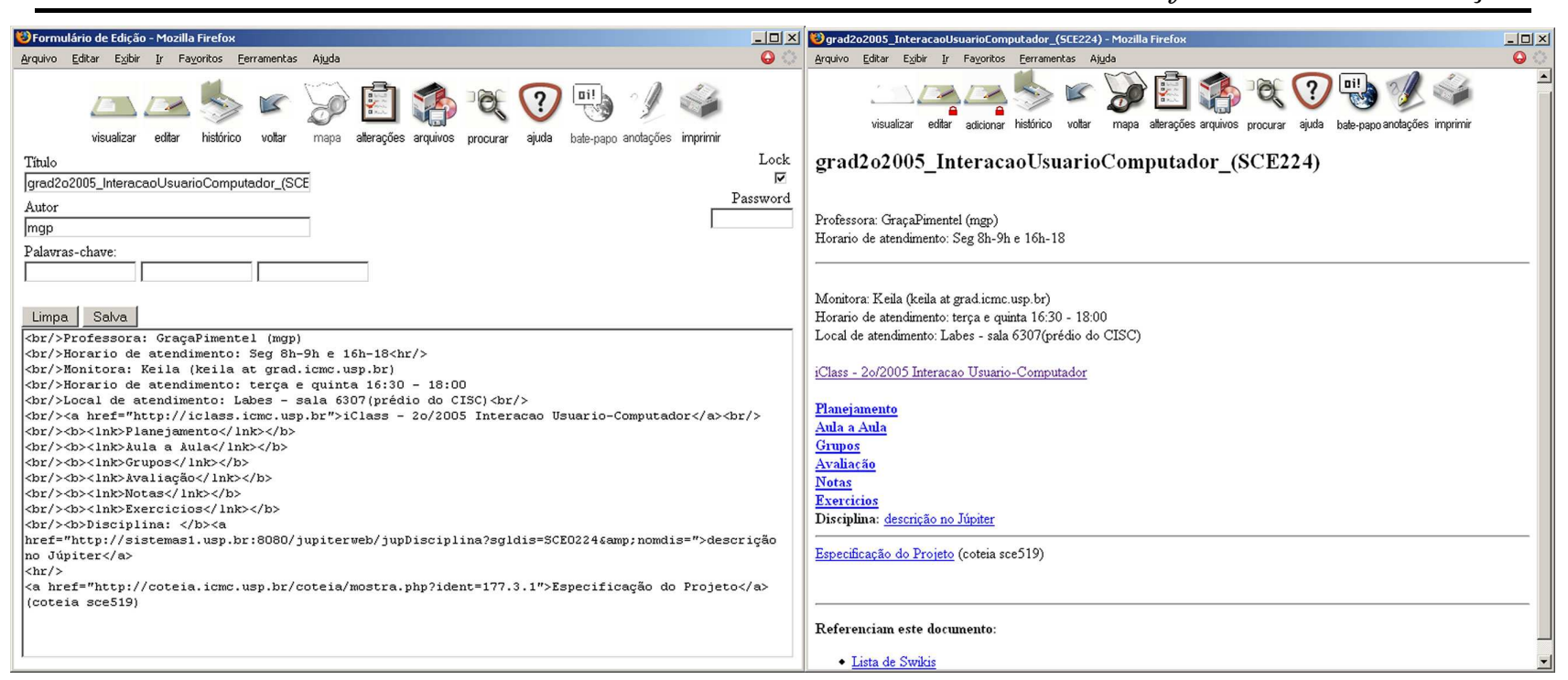

(a)

(b)

Figura 2.5 - Edição (a) e visualização (b) de página da CoTeia

\subsubsection{Gerenciamento de atividades - WebCoM}

A proposta do WebCoM (Web Course Manager), desenvolvido em um projeto de mestrado (Silva \& Moreira, 2000a) no ICMC-USP, é facilitar o gerenciamento da informação produzida durante a realização de um curso, fornecendo mecanismos para a definição e coordenação de atividades pelo professor e para a interação dos estudantes com essas atividades.

O WebCoM foi desenvolvido com base no conceito de agentes de software sob a definição adotada por Moreira e Walczowski (1997), na qual agentes são vistos como entidades capazes de interoperar para resolver problemas complexos. Os agentes do WebCoM são considerados assistentes porque facilitam a realização das tarefas de baixo nível (como acesso a bases de dados e manipulação de espaços físicos em disco) enquanto estudantes e professores utilizam interfaces gráficas para realizar as tarefas de mais alto nível (como entrada de informações) (Silva \& Moreira, 2000c, 2000b).

O foco principal do WebCoM está no gerenciamento das atividades definidas pelo professor. Após criar seu curso, o professor define as atividades a serem cumpridas pelos estudantes. Essas atividades são então realizadas e seus resultados são postados, na forma de relatórios, no ambiente virtual do curso utilizando as funcionalidades de upload oferecidas. Todo o material resultante dessas atividades é automaticamente organizado e disponibilizado aos estudantes do 
curso por meio de documentos Web. Dessa forma, cria-se uma área de compartilhamento de informações importante para todos os estudantes.

Os tipos de atividades suportadas pelo WebCoM são (Silva \& Moreira, 2000b):

- Projetos (assignments): atividades realizadas em grupos que permitem ou não a realização de revisões (peer-review) de trabalhos por outros grupos e devem ter um relatório de resultados postado no ambiente do curso. O método baseado na técnica de peer review suportado pelo WebCoM é apresentado em detalhes na subseção 2.4.3.1.

- Relatórios (reports): atividades realizadas individualmente que devem ter um relatório de resultados postado no ambiente do curso.

- Testes (tests): atividades individuais, por exemplo, avaliações ou exercícios, que não têm relatórios de resultados postados no ambiente do curso.

Os tipos de usuários suportados pelo $\mathrm{WebCoM}$ e as funcionalidades que eles têm direito são (Silva \& Moreira, 2000a):

- Administrador: criar ambiente e gerenciar turmas, notas, usuários e revisões.

- Estudante: cadastrar candidato, gerenciar grupos, participar de grupos de discussão, postar trabalhos e visualizar os trabalhos postados e notas.

- Monitor: gerenciar turmas, notas, usuários e revisões, fazer upload de arquivos para as áreas dos estudantes e dos grupos e participar de grupos de discussão.

A função criar ambiente, realizada pelo administrador (que pode ser o próprio professor do curso), corresponde à criação do curso no servidor.

O WebCoM é apresentado ao usuário na forma de um applet Java que pode ser inserido em qualquer página HTML (W3C, 1999a). Na Figura 2.6 é apresentada a página de um curso do ICMC-USP com o applet do WebCoM destacado por uma elipse. Por ser desenvolvido utilizando-se a linguagem Java no modelo cliente-servidor, o WebCoM é independente de plataforma, mas requer a instalação do plugin Java no computador do cliente para que o applet possa ser executado.

Um aspecto diferencial do WebCoM é que ele foi projetado para dar suporte a um método educacional baseado na revisão pelos pares - Peer-Review - especificamente adotado no ICMC- 
USP por (Moreira \& Silva, 2002; Moreira \& Silva, 2005). Esse método, descrito em mais detalhes na próxima subseção, era utilizado no ICMC-USP desde 1997 sem suporte computacional apropriado.

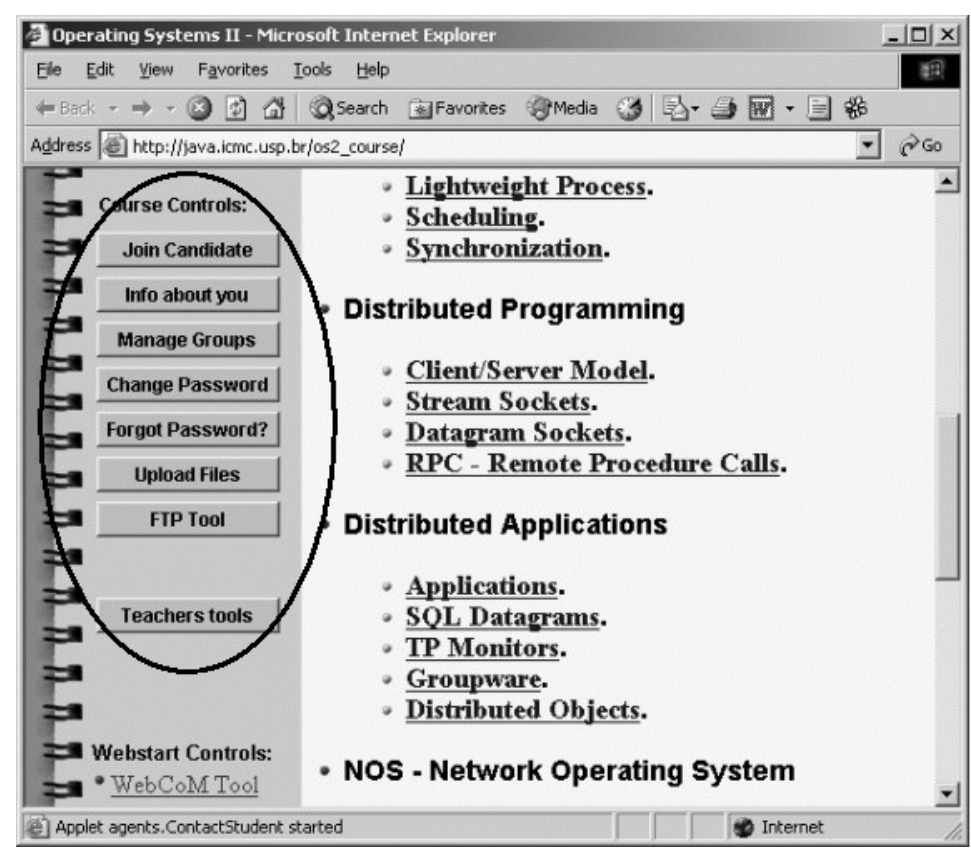

Figura 2.6 - Applet do WebCoM sendo apresentado em um hiperdocumento

Apesar de já ter sido utilizado numa experiência de educação a distância (Rosa, 2001; Silva et $a l ., 2002)$ e ter sido inicialmente projetado com esse objetivo, o WebCoM é mais utilizado atualmente com ferramenta de apoio às atividades de cursos presenciais.

\subsubsection{O método educacional de Peer Review}

O peer review, ou revisão pelos pares, é um método de avaliação bastante conhecido na comunidade acadêmica cuja forma de uso mais comum é a avaliação de artigos, na qual um artigo tem seus méritos avaliados por pares de revisores seguindo critérios pré-estabelecidos.

No contexto educacional, esse tipo de avaliação vem sendo aplicado, há alguns anos, na forma de métodos educacionais com diferentes objetivos, por exemplo, para promover a comunicação e aumentar a qualidade do trabalho escrito e das apresentações orais (Helfers et al., 2000; Nelson, 2000; Kern et al., 2003). No ICMC-USP, o método de peer review é adotado em parceria com o trabalho em grupo para promover interação entre estudantes (Moreira \& Silva, 2002).

Nesse método, os estudantes de um curso são divididos em pequenos grupos e cada grupo desenvolve uma atividade proposta pelo professor. O resultado dessa atividade é disponibilizado 
na $W e b$ e, posteriormente, avaliado por um outro grupo de estudantes da mesma turma. Cada grupo revisor analisa um trabalho seguindo os critérios definidos pelo professor. O resultado dessa avaliação também é disponibilizado na $W e b$ sob a forma de um relatório de revisão, de modo que todos os trabalhos e suas respectivas avaliações fiquem disponíveis para acesso a todos os interessados. Após essa etapa de avaliação, o professor agenda uma data para um debate presencial (ou via chat, no caso de um curso a distância) entre o grupo que fez o trabalho e o grupo revisor, com a participação dos outros estudantes do curso. Nesse debate, cada grupo apresenta seu trabalho e se defende das críticas feitas pelo grupo revisor, enquanto estes apresentam e fundamentam suas críticas. Cada grupo recebe uma nota pelo trabalho desenvolvido e outra nota pelo trabalho de avaliação.

Entre os tipos de atividades que podem ser realizadas com esse método estão pesquisas bibliográficas, experimentos em laboratórios, projeto e implementação de software, seminários, entre outras, que variam de acordo com o tipo de curso em que o método é aplicado. Os critérios de avaliação também variam de acordo com o objetivo da aplicação do método.

O suporte do WebCoM (descrito anteriormente) a esse método de peer review se dá por meio das atividades caracterizadas como assignments. Cada assignment pode conter um ou mais projetos que os grupos de estudantes podem escolher para realizar. Entre as funcionalidades disponíveis no WebCoM para o controle desse método estão:

- a definição dos assignments e dos prazos para entrega (trabalho e relatório de revisão);

- a definição de grupos revisores;

- a atribuição de notas para os grupos (e para cada membro do grupo individualmente);

- a formação de grupos de estudantes (pelos próprios estudantes);

- o acesso aos trabalhos desenvolvidos e aos relatórios de revisão;

- o upload de arquivos para entrega de trabalhos;

- a visualização e download de trabalhos e relatórios de revisões; e

- a visualização de notas.

Apesar de poder ser realizado manualmente através da impressão e distribuição dos trabalhos e revisões entre os estudantes ou pela disponibilização manual dos trabalhos na $W e b$, essa prática pode gerar uma carga considerável de trabalho para o professor e, assim, comprometer a 
eficiência do método em si. Portanto, para o sucesso desse método, a utilização de um software adequado é altamente recomendável. Além do WebCoM, que foi especificamente desenvolvido para suportar o método descrito nesta seção, existem outras ferramentas, disponíveis na literatura, que também oferecem alguma forma de controle para atividades de peer review (Nicol, 1996; Gehringer, 2000; Liu et al., 2001; CyberChair, 2005).

O método de peer review aliado à estratégia de trabalho em grupo oferece benefícios para os professores e estudantes (Moreira \& Silva, 2005). No caso dos estudantes, eles têm a oportunidade de aprender a apresentar seus trabalhos, convencer outras pessoas sobre sua importância, avaliar o trabalho de outros fazendo críticas construtivas e aceitar a crítica de seus colegas. Os estudantes também têm a oportunidade de aprender outros assuntos, que não sejam unicamente aqueles relacionados aos seus trabalhos, a partir da revisão que eles fazem do trabalho de outros e do debate em classe. No caso do professor, os benefícios acontecem, principalmente, em relação ao controle da atividade. Com essa forma de avaliação, realizada em parte pelos próprios estudantes, o professor ganha tempo para gerenciar mais grupos com número menor de membros. Com isso, o professor pode ter maior controle sobre o trabalho realizado por cada membro do grupo.

Esse método de peer review, apoiado pela Internet por meio do WebCoM, vem sendo aplicado em cursos do ICMC-USP desde o ano 2001. Avaliações (questionários) aplicadas aos estudantes que utilizaram o método mostram que ele é bem aceito e tem grande potencial para auxiliar no processo de ensino-aprendizagem (Silva et al., 2002; Silva \& Moreira, 2003b, 2003a; Silva et al., 2004).

\subsection{Análise das aplicações educacionais sob o aspecto da adaptabilidade}

Analisando as aplicações educacionais citadas nas seções anteriores (em especial as que suportam o gerenciamento de cursos via $W e b$ ) sob o ponto de vista da facilidade de adaptação às diferentes necessidades dos usuários, nota-se que, em geral, elas apresentam algumas características comuns que podem dificultar a sua total adequação a situações específicas. Tais características são discutidas nos tópicos seguintes. 


\section{a)Papéis e permissões de acesso}

Os papéis ${ }^{9}$ disponíveis nas aplicações (e seu conjunto de permissões) são fixos. Por serem voltados para a educação, os sistemas analisados oferecem papéis de professor e estudante por padrão, porém, papéis mais específicos, como monitores, administradores e visitantes nem sempre são oferecidos. Por exemplo, o WebCT traz um conjunto de seis (6) papéis que o usuário do sistema pode assumir; enquanto o TelEduc, AulaNet e WebCoM consideram apenas os papéis de professor, estudante e administrador.

O problema com essa característica é que, se a instituição que adota o software possui um tipo de usuário diferenciado (por exemplo, um usuário que ajuda o professor na coordenação de suas atividades, mas que não seja um monitor), ele terá que adaptar seu usuário a um (ou mais) dos tipos de usuários que o sistema oferece, ao contrário de adaptar o sistema para suas necessidades. A possibilidade de delegar mais de um papel a um usuário resolve esse problema em parte, mas nesse caso, um usuário pode ter mais permissões do que o desejado.

\section{b)Funcionalidades}

Por terem sido propostos no âmbito acadêmico (e, alguns, posteriormente transformados em produtos comercializados), os sistemas educacionais baseados na $\mathrm{Web}$ oferecem funcionalidades que suportam técnicas ou metodologias educacionais utilizadas na instituição em que foram desenvolvidos. Por exemplo, no caso do trabalho em grupo, no ambiente WebCT o professor cria os grupos de estudantes e define os trabalhos de cada grupo, enquanto no WebCoM, os próprios estudantes criam seus grupos e escolhem o trabalho que desejam fazer (o professor só define os temas mas não os delega aos grupos). Tanto WebCT quanto WebCoM são limitados quando a necessidade do usuário não é contemplada pelo sistema: se o professor que usa o WebCoM quer criar os seus grupos de estudantes, ele não tem o suporte do sistema; por outro lado, se o professor que usa o WebCT quer delegar aos grupos a escolha de seus trabalhos, ele também não tem como fazê-lo via software.

Outro exemplo que mostra a limitação das aplicações em termos da funcionalidade, é o suporte ao método de peer review oferecido pela ferramenta WebCoM. Nessa ferramenta, por suportar um método em especial, a visualização dos trabalhos, revisores, notas, etc, é totalmente livre a

\footnotetext{
9 Papéis (Roles) são rótulos que identificam classes de usuários de um sistema, por exemplo: administrador, professor, estudante, etc. Os papéis são caracterizados por um conjunto de permissões sobre as funcionalidades do sistema. Essas permissões definem o que o usuário, portador do papel, pode fazer no sistema.
} 
todos usuários da internet, pois não há controle de acesso às páginas que mostram essas informações. Numa situação em que a revisão precisasse ser feita de forma anônima (blind review), a funcionalidade oferecida pelo WebCoM não seria suficiente. Mesmo assim, ele é o único sistema (dos analisados) que suporta esse tipo de prática educacional que vem sendo bastante utilizada nos últimos anos.

O problema com essa característica dos sistemas educacionais é que quando o usuário não consegue se adaptar ao que o sistema utilizado oferece, ele geralmente opta por uma das seguintes alternativas: troca o sistema por um outro, tenta encaixar seu problema nas funcionalidades que o sistema oferece ou busca desenvolver seu próprio sistema. Essas três alternativas podem ser problemáticas para os usuários. Uma solução mais interessante seria a customização do sistema ou por interfaces gráficas ou por meio de ajustes no código-fonte. Em geral, a customização de forma gráfica é limitada a incluir ou não determinada funcionalidade (na forma de ferramentas) no curso que se está realizando, como permitem os ambientes WebCT, TelEduc e AulaNet. Já a customização por meio de código pode não ser tão simples, como comentado no tópico seguinte.

\section{c) Arquitetura e organização do código-fonte}

Uma das formas de se adaptar um sistema é por meio da customização do seu código-fonte. Entretanto, essa alternativa torna-se inviável quando o código-fonte do sistema não está disponível (no caso dos sistemas comercializados como o WebCT), quando a alteração do código é dificultada em função da forma como o sistema foi desenvolvido ou quando não há documentação suficiente sobre o código e arquitetura do sistema.

Nos sistemas educacionais apresentados neste capítulo, não há uma grande preocupação com as futuras modificações para agregar novas funcionalidades e comportamentos. Em geral, muitos dos sistemas educacionais open-source, como WebCoM e TelEduc, apresentam um conjunto de funcionalidades implementadas sobre arquiteturas integradas que dificultam sua alteração. Em geral, isso acontece porque esses sistemas foram projetados para atender a um conjunto de objetivos bem definidos inicialmente, e não para serem moldados ao gosto do usuário. Pequenas alterações em pontos específicos desses sistemas podem afetar o comportamento do sistema se o desenvolvedor não conhecer detalhes sobre todo o código. No caso do ambiente AulaNet, os próprios desenvolvedores estão, atualmente, refazendo sua estrutura interna para permitir o 
acoplamento de novas funcionalidades e, até mesmo, facilitar sua manutenção, devido à complexidade do seu código (Pimentel et al., 2005).

d) Plataforma de execução e sistemas gerenciadores de banco de dados

A dependência de plataforma de um sistema educacional pode ter influência sobre a escolha dos usuários por um sistema ou outro. De acordo com suas documentações, o ambiente WebCT e o WebCoM podem ser utilizados tanto em servidores Linux quanto em Windows, com algumas restrições de versões; o ambiente AulaNet em servidores Windows; e o ambiente TelEduc em servidores Linux.

Dos sistemas analisados, todos são dependentes de algum SGBD (Sistema Gerenciador de Banco de Dados) específico. O WebCT requer o servidor Oracle ou SQLServer com versões específicas. Já o TelEduc requer o SGBD MySQL, enquanto o AulaNet utiliza o Microsoft Access, mas disponibiliza versões para os servidores SQL Server e Oracle (também em versões específicas).

Embora a dependência de plataforma e de SGBD não esteja diretamente relacionada com o aspecto de adaptabilidade, ela pode afetar a decisão de uma instituição em escolher determinado sistema educacional. Por exemplo, se uma instituição já tem a cultura de utilizar servidores Windows, dificilmente ela irá escolher um sistema que requeira a plataforma Linux, e vice versa. O mesmo acontece com o SGBD, cuja maioria é pago. Uma instituição que já usa SQL Server para outros sistemas, tendo investido dinheiro e tempo nesse banco de dados, pode não ter a intenção de utilizar um sistema baseado em MySQL, por exemplo.

Todas essas características influenciam na escolha de qual sistema cada instituição deve adotar ou se um sistema mais específico deve ser desenvolvido.

\subsection{Características para um sistema educacional flexível}

A partir da análise descrita na seção anterior e da identificação dos aspectos que podem comprometer a adaptação efetiva de um sistema educacional às diferentes necessidades de seus usuários, procurou-se identificar um conjunto mínimo de características que possa oferecer aos sistemas educacionais maior flexibilidade e extensibilidade. Essas características são: 
1. Possibilidade de criar papéis e definir permissões de acordo com as necessidades dos usuários. Isso inclui o direito de adicionar qualquer permissão específica a qualquer papel, por exemplo, dar ao monitor o direito de acesso sobre as notas dos estudantes (caso ele não tenha) ou dar a um usuário externo (anônimo) o direito de visualizar os trabalhos desenvolvidos no curso.

2. Permitir o acúmulo de papéis pelos usuários e a escolha do papel com o qual o usuário deseja acessar o sistema (tal que ele veja somente as funcionalidades que tem direito de acesso).

3.Possibilidade de autenticação/autorização de usuários tanto em bases de dados específicas para o sistema quanto a partir da integração com sistemas legados. Essa característica é interessante porque muitas instituições já possuem cadastros atualizados de usuários, não tendo que recadastrá-los no sistema de apoio à educação na $W e b$.

Essas características estão mais ligadas à adaptação do sistema sem a necessidade de alterar seu código. As próximas estão relacionadas com a organização interna do sistema, que influência a facilidade para alterar ou acrescentar funcionalidades para adaptá-lo aos seus objetivos:

4. Uso de uma estrutura interna bem particionada, modularizada que permita a implementação/agregação de novas funcionalidades ao sistema, ou, até mesmo, a alteração de alguma funcionalidade já disponível, para atender uma necessidade específica. Esse requisito, cujo foco está na separação de interesses (separation of concerns), é o principal para adicionar extensibilidade ao sistema.

5. Uso de uma linguagem de desenvolvimento que torne o sistema independente de plataforma e de software específico.

6. Uso de padrões em geral para facilitar o entendimento, a extensão e alteração de funcionalidades do sistema.

7. Uso de mecanismos de persistência que tenham a capacidade de isolar o banco de dados do sistema do SGBD, tal que este possa ser trocado por outro sem grandes alterações. 
Conforme se observa, esse conjunto de características, apesar de extraído de sistemas educacionais, pode ser utilizado em aplicações de outros domínios, já que nenhuma delas está especificamente ligada ao domínio educacional.

Apesar de algumas dessas características serem suportadas pelos sistemas educacionais existentes, nenhum deles se preocupa com todas. Esse conjunto de sete características utilizadas em conjunto foi definido com o intuito de dar maior flexibilidade aos sistemas para que estes possam ser estendidos e modificados a fim de atender objetivos específicos de cada usuário.

\subsection{Considerações finais}

Há um tempo atrás os interesses da informática na educação estavam voltados para o desenvolvimento de sistemas de autoria/disponibilização de material didático e de gerenciamento de cursos online de propósito geral. Passada a fase de adaptação e familiarização com o uso desses sistemas, os professores passaram a explorar técnicas e métodos educacionais que antes eram difíceis de realizar sem o uso da tecnologia (em especial da Internet). Exemplos disso são as formas de uso da Internet na educação desenvolvidas no ICMC-USP por meio dos sistemas iClass, CoTeia e WebCoM (com o método de peer review) que diferem da forma tradicional de educação suportada pela maioria dos ambientes virtuais.

A exploração dessas novas técnicas e métodos exige, dos sistemas educacionais, um nível mais alto de flexibilidade para que possam ser mais facilmente estendidos e adaptados às necessidades de seus usuários. Tal flexibilidade pode ser alcançada por meio da observação das características identificadas neste capítulo quando do desenvolvimento desses sistemas educacionais.

De modo especial, as características relacionadas com o código dos sistemas podem ser atendidas, em parte, utilizando-se técnicas adequadas de projeto de software. Algumas dessas técnicas são discutidas no capítulo seguinte.

O conjunto de características identificado neste capítulo serviu fundamentou a especificação dos requisitos do framework proposto nesta tese. 


\section{Projeto de software adaptável e extensível}

\subsection{Considerações iniciais}

Em função das rápidas transformações das tecnologias, organizações e necessidades dos usuários, a capacidade de adaptação e extensão de um sistema de software torna-se uma característica essencial para seu sucesso. No entanto, essa não é uma necessidade recente, sendo que na literatura de 1996 pesquisadores já enfatizavam que o software produzido para hoje deve ter capacidade de ser modificado para atender às necessidades de amanhã (Fayad \& Cline, 1996).

Para tornar um sistema de software mais flexível, ou seja, para que novas funcionalidades possam ser mais facilmente adicionadas ou as existentes modificadas para atender algum objetivo específico, é necessário manter uma boa organização da estrutura interna do sistema (arquitetura de software). Essa organização pode ser obtida com o uso das diversas técnicas de projeto e desenvolvimento, tais como arquiteturas, padrões e boas práticas, existentes na literatura de engenharia de software.

Neste capítulo, apresenta-se uma visão geral sobre algumas dessas técnicas de projeto de software que são úteis para o desenvolvimento de sistemas mais adaptáveis e extensíveis. São apresentados conceitos e modelos de processos relacionados com o desenvolvimento baseado em componentes e em frameworks de aplicação orientados a objeto, bem como aspectos sobre padrões de projeto e sistemas modulares. Embora o foco principal dessas técnicas seja na reusabilidade, não só de código, mas também de esforços de todas as fases do processo de desenvolvimento, sua aplicação também oferece a vantagem de direcionar o desenvolvimento do software para a construção de arquiteturas bem organizadas. 


\subsection{Componentes de software}

O desenvolvimento baseado em componentes (CBD - Component Based Development) (Brown \& Short, 1997) propõe que sistemas de software sejam implementados e mantidos mais facilmente usando uma estratégia de "dividir para conquistar". Essa forma de desenvolvimento estende as idéias dos sistemas modulares (Myers, 1975; Maynard, 1976), estruturados (PageJones, 1988) e orientados a objetos (Coad \& Yourdon, 1990) enfatizando a composição do sistema pelo agrupamento (reuso) de peças de código (componentes) reusáveis (Johnson, 1997).

$\mathrm{Na}$ literatura, o conceito de componente não é muito bem definido, porém a maioria das definições encontradas trata os componentes como sendo essencialmente partes independentes, substituíveis e reusáveis de um software (Meijler \& Nierstrasz, 1997; Pree, 1997).

Uma característica chave na definição de componentes é:

Um componente oferece uma interface que descreve seu comportamento e a implementação dessa interface que corresponde ao estado interno do componente (Sommerville, 2001).

A implementação do componente é o conjunto de instruções que realiza o serviço prestado por ele, enquanto a interface é uma descrição abstrata desses serviços. A interface define a lista de operações (assinatura dos métodos) que o componente disponibiliza.

A utilização de interfaces é importante porque permite que um código cliente solicite a execução de um serviço a um componente sem conhecer a forma como o serviço é implementado internamente (Brown \& Short, 1997). Assim, se a implementação do serviço for alterada no componente, essa alteração é "transparente" para o objeto cliente, que continua utilizando a mesma interface. Na Figura 3.1 é apresentado um exemplo de como a mudança na implementação de um componente, ou até mesmo na sua interface, é feita sem que o cliente seja alterado. O Componente $A$ que implementa a interface $I A$ é modificado para implementar também a interface $I A$ ' que possui um comportamento necessário para a execução do Cliente 2. Por conhecer o componente por meio de sua interface, o Cliente 1 não precisa ser alterado após a mudança na implementação do componente, pois a interface utilizada por ele permanece a mesma. 


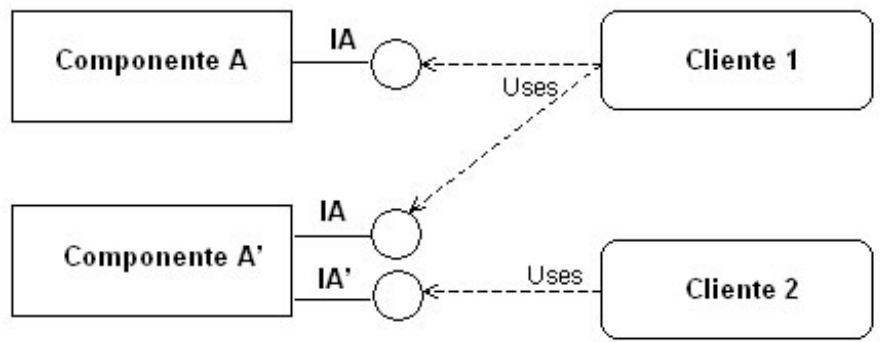

Figura 3.1 - Uso de interfaces para definição de componentes (Cheesman \& Daniels, 2001)

Inicialmente, componentes eram vistos quase que exclusivamente como trechos reusáveis de código-fonte que eram compilados juntamente com o código dos sistemas que os utilizavam. Nos últimos anos, os componentes de software têm evoluído para a forma de componentes binários (off-the-shelf) (Parrish et al., 2001). Esses componentes constituem artefatos de software que existem na forma compilada e estão tipicamente prontos para serem utilizados independente de um software em particular. Essa forma de desenvolvimento de componentes está diretamente ligada com as questões de padronização, que tem por objetivo especificar como o componente deve ser desenvolvido e como ele pode ser utilizado. Atualmente, os padrões de desenvolvimento de componentes mais utilizados no mercado são CORBA (OMG, 2006), J2EE (Sun, 2006), .NET (Microsoft, 2006b) e COM (Microsoft, 2006a).

Como na engenharia de software tradicional, a engenharia baseada em componentes também conta com diversos modelos de processos que ajudam a coordenar e controlar o desenvolvimento do software baseado em componentes. Em termos gerais, um processo de desenvolvimento engloba um conjunto de atividades que devem ser seguidas durante o desenvolvimento para que o software seja produzido no período estimado e com a qualidade desejada (Pressman, 2005). O processo UML Components, apresentado a seguir, é um dos processos mais utilizados atualmente para o desenvolvimento de sistemas baseados em componentes.

\subsubsection{UML Components}

Como o próprio nome sugere, o processo UML Components está baseado no uso da linguagem UML (Unified Modeling Language) (UML, 2006) para a modelagem de componentes. Esse processo usa os conceitos de fluxos de trabalho (workflows) e artefatos definidos no processo RUP (Rational Unified Proccess) (Kroll \& Kruchten, 2003) voltado para desenvolvimento de sistemas em geral. De acordo com o processo RUP, um fluxo de trabalho compreende uma 
seqüência de atividades que produz resultados de valores observáveis - os artefatos - que podem servir de entrada para a execução de outros fluxos (Kroll \& Kruchten, 2003).

O processo geral de desenvolvimento do UML Components é ilustrado na Figura 3.2. Os fluxos de trabalho do processo são indicados pelas caixas; as setas rotuladas indicam os artefatos trocados entre os fluxos. As caixas em branco equivalem aos fluxos especificados no processo RUP, enquanto as caixas em cinza são fluxos específicos do processo UML Components que substituem os fluxos de análise, projeto e implementação do RUP.

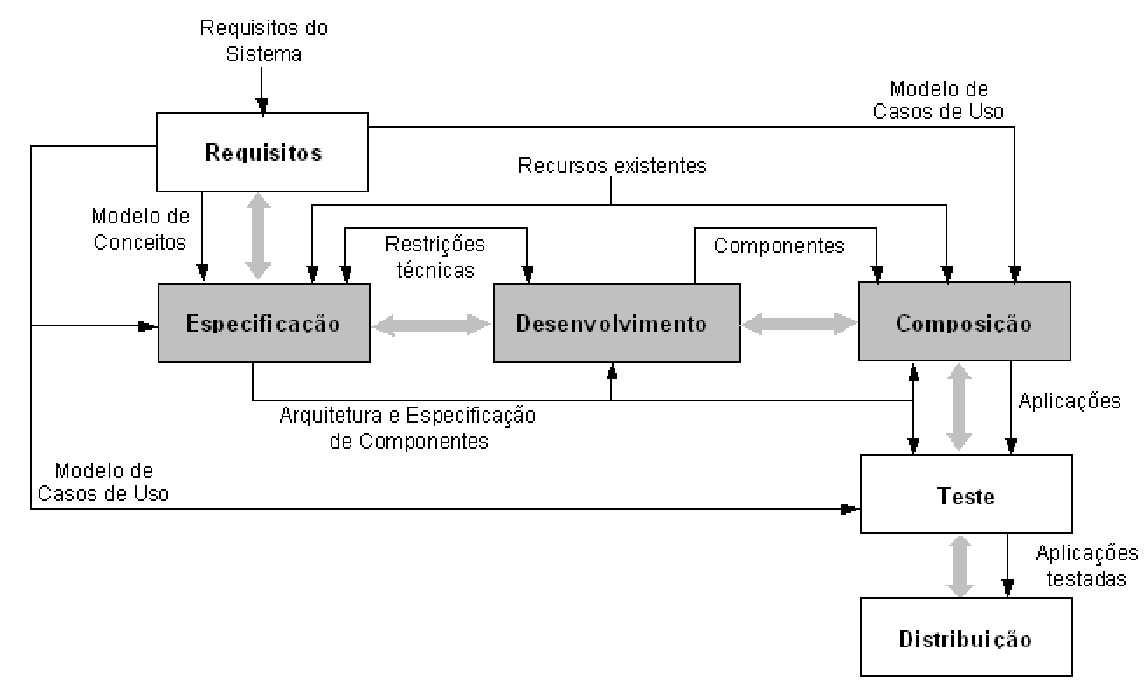

Figura 3.2 - Processo UML Components (Cheesman \& Daniels, 2001)

O fluxo de requisitos, cujo objetivo é o levantamento e análise dos requisitos do sistema a ser desenvolvido, produz como artefatos o modelo de casos de uso do sistema e um modelo conceitual do domínio. Esses dois artefatos servem de entrada para o fluxo de especificação que tem por objetivo especificar os componentes e a arquitetura de componentes do sistema. Essas especificações são usadas no fluxo de desenvolvimento, juntamente com as restrições técnicas, para a implementação dos componentes. O modelo de casos de uso, os componentes e outros recursos (ou componentes) já existentes são usados no fluxo de composição para criar as aplicações (ou sistemas). As aplicações passam pelo fluxo de teste para serem avaliadas e, posteriormente, pelo fluxo de distribuição, que é quando as aplicações testadas são entregues aos usuários. 
O processo UML Components pode ser considerado um processo iterativo: o desenvolvimento do software ocorre por meio de várias iterações sobre os fluxos de trabalho tal que essas iterações incrementam o software até que ele esteja de acordo com seus requisitos.

Esse processo considera o desenvolvimento de sistemas em camadas de componentes (Cheesman \& Daniels, 2001):

- camada de negócios: componentes responsáveis pelas regras e informações do núcleo do sistema; correspondem aos componentes com maior potencial de reuso em outros sistemas; e

- camada de sistema: componentes responsáveis por oferecer os serviços do sistema; funcionam como fachada para os componentes de negócio, agrupando esses componentes para fornecer um serviço específico.

O fluxo de especificação (Figura 3.2), considerado um dos mais importantes no processo $U M L$ Components, é subdividido nas atividades: identificação, interação e especificação de componentes, como apresentado na Figura 3.3.

A atividade de identificação de componentes tem como entrada o modelo de casos de uso e o modelo conceitual produzidos no fluxo de requisitos. Seu objetivo é produzir a especificação inicial de uma arquitetura de componentes e de um conjunto de interfaces de negócio e de sistema para os componentes de negócio e sistema respectivamente. As interfaces de negócio são especificadas com base no modelo de tipos de negócio (BTM - Business Type Model) (criado a partir do modelo conceitual) enquanto as interfaces de sistema são especificadas a partir do modelo de casos de uso.

A atividade de interação de componentes tem por objetivo estabelecer como os componentes devem trabalhar em conjunto para oferecer as funcionalidades desejadas no sistema. A partir das operações do sistema e de interações entre os componentes (modelados com diagramas UML de colaboração) é possível refinar as definições de interface da atividade anterior e identificar novas interfaces e operações para os componentes. Há também um refinamento na arquitetura de componentes. 


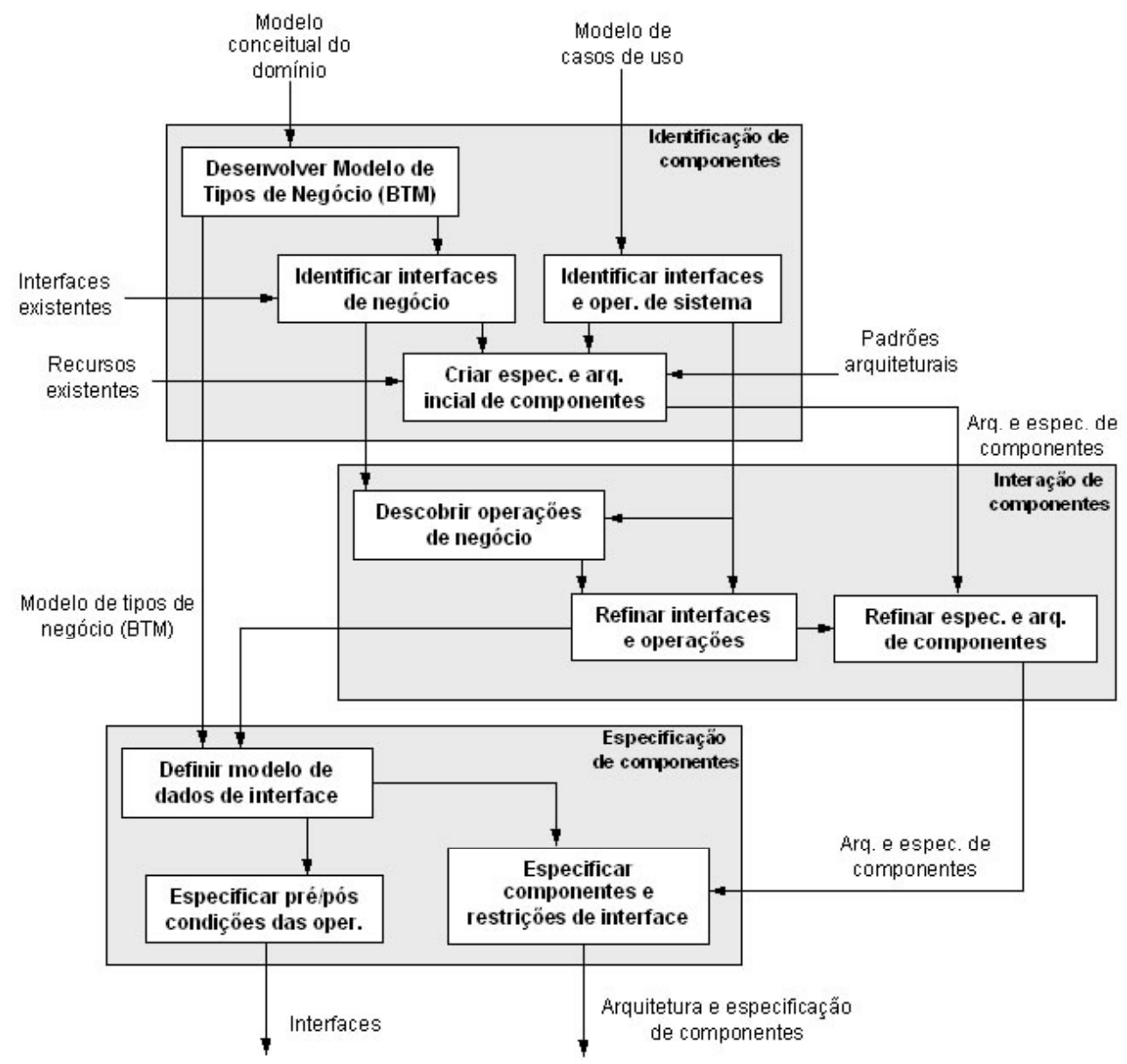

Figura 3.3 - Fluxo de especificação detalhado (Cheesman \& Daniels, 2001)

A atividade de especificação de componentes é responsável por detalhar a especificação das interfaces definidas na atividade anterior incluindo o modelo de informação ao qual a interface está relacionada e também as restrições de pré e pós-condições para suas operações.

O resultado final do fluxo de especificação é a especificação completa das interfaces dos componentes a serem desenvolvidos e a arquitetura de componentes que especifica como os componentes devem interagir para atender às necessidades do sistema.

Como pode se observar, esse modelo está mais envolvido com a especificação dos componentes do que com a forma de desenvolvimento do software como um todo. O processo $U M L$ Components delega a gerência do processo para outros processos, por exemplo, o RUP. 


\subsection{Frameworks de aplicação}

Um framework de aplicação, também referenciado como framework de software orientado a objetos, consiste de uma ampla estrutura que pode ser reusada como um todo na construção de sistemas (Bosch et al., 1999).

Desde a sua concepção, no final dos anos 80 , os frameworks ${ }^{10}$ ganharam a atenção de muitos pesquisadores e engenheiros de software, sendo que vários deles foram propostos para os mais variados domínios de aplicação, tais como para interfaces de usuário, sistemas operacionais e controle de processos.

O conceito de framework, assim como o de componente, não possui uma definição exata na literatura. Entretanto, a maioria dos autores concorda que um framework é uma arquitetura de software reusável que compreende código e projeto (design). Por essa razão, seu maior benefício não é o reuso de implementação, como no caso dos componentes, mas sim o reuso da arquitetura (estrutura) abstrata oferecida por ele (Jacobson \& Nowack, 1999).

Sob o ponto de vista do propósito, um framework pode ser definido como o esqueleto de uma aplicação que é instanciado por um desenvolvedor de aplicações (Johnson, 1997). Em outras palavras, um framework é uma aplicação semi-completa e reutilizável que, quando especializada, produz aplicações personalizadas (Johnson \& Foote, 1988).

Sob o ponto de vista da estrutura, uma das definições mais citadas é a de que um framework é um conjunto de classes abstratas e concretas que formam o projeto abstrato para uma família de problemas relacionados (Johnson \& Foote, 1988). As classes abstratas formam a base do framework sobre a qual classes concretas ou outras classes abstratas podem ser desenvolvidas. $\mathrm{O}$ projeto abstrato representa o projeto (design) de um sistema de software genérico, envolvendo os componentes do sistema, a forma de interação entre esses componentes e um programa principal, que pode ser reusado para o desenvolvimento de aplicações diferentes dentro de um domínio específico.

Uma característica importante dos frameworks é a inversão de controle (Johnson, 1997). No desenvolvimento de um sistema tradicional baseado em componentes, o desenvolvedor toma um conjunto de componentes de uma biblioteca de reuso e escreve um programa principal que

\footnotetext{
${ }^{10}$ O termo "framework" é utilizado nessa tese com o mesmo significado do termo "framework de aplicação" ou "framework de software orientado a objetos".
} 
invoca esses componentes quando necessário. Nesse caso, o desenvolvedor é o responsável pela estrutura e fluxo de controle do sistema, devendo decidir quando cada componente é invocado. No desenvolvimento de um sistema baseado em framework, o programa principal é reusado, cabendo ao desenvolvedor apenas decidir quais componentes serão conectados a ele. $\mathrm{O}$ código do desenvolvedor é então invocado pelo framework que determina a estrutura e o fluxo de controle do sistema.

A especialização de um framework dá-se pela customização e extensão da estrutura oferecida por ele. Os aspectos customizáveis de um framework são chamados de "pontos variáveis" (Hotspots) (Pree, 1995, 1999). Diferentes aplicações dentro de um mesmo domínio são distinguidas por um ou mais pontos variáveis, que representam as partes do framework específicas das aplicações. Os "pontos fixos" (Frozen-spots) formam a arquitetura geral reusável do framework incluindo componentes básicos e o relacionamento entre eles. Os pontos fixos são usados sem modificação em todas as instanciações de um framework de aplicação.

De acordo com a literatura, o potencial de reuso de um framework varia de acordo com o número de seus pontos fixos e variáveis, sendo que o potencial de reuso é menor se o número de pontos variáveis for grande em relação ao número de pontos fixos (Pree, 1999). Isso significa que o framework oferece pouco a ser reusado.

Os pontos variáveis de um framework são geralmente implementados por uma combinação de métodos e/ou classes "gancho" (Hooks) (Froehlich et al., 1997) e "gabarito" (Templates) (WirfsBrock \& Johnson, 1990). Os métodos de gabarito definem um comportamento abstrato ou um

fluxo de controle genérico por meio da união entre código padrão (necessário para o funcionamento do framework) e chamadas a métodos gancho. Os métodos gancho representam os pontos variáveis do framework propriamente ditos, sendo oferecidos como métodos abstratos sem implementação. A especialização de um ponto variável, que é geralmente feito por herança, fornece ao método gancho um comportamento específico para uma aplicação do framework.

\subsubsection{Classificação de frameworks}

Os frameworks de aplicação podem ser classificados em função da sua forma de reuso, podendo ser do tipo: caixa-branca, caixa-preta e caixa-cinza (Fayad et al., 1999). 
Nos frameworks caixa-branca (whitebox) a instanciação ocorre por meio de herança: o desenvolvedor da aplicação estende as classes abstratas do framework (criando classes concretas) e implementa o comportamento dos métodos "gancho". Já nos frameworks caixa-preta (blackbox) a instanciação é feita por meio de composição: o desenvolvedor combina classes concretas existentes (derivadas de classes abstratas e interfaces do framework) para obter a aplicação desejada.

Os frameworks caixa-preta são considerados menos flexíveis e mais fáceis de utilizar porque o desenvolvedor apenas reusa classes já implementadas. Entretanto, o desenvolvimento desse tipo de framework é considerado mais complicado, pois um amplo conjunto de casos de uso do domínio deve ser previsto e implementado. Os frameworks caixa-branca são mais fáceis de desenvolver porque não há a necessidade de prever todos os casos de uso inicialmente. Porém, seu uso é mais complexo porque o desenvolvedor de aplicações tem que interagir diretamente com o código do framework, o que requer conhecimento mais detalhado sobre sua estrutura interna.

Para superar as barreiras impostas pelos frameworks caixa-branca e caixa-preta, foi criado o conceito de framework caixa-cinza (graybox) (Fayad et al., 1999). Esse tipo de framework permite a extensão tanto em termos de herança quanto em termos de composição, dependendo da necessidade da aplicação. Dessa forma, os frameworks caixa-cinza possuem flexibilidade e facilidade de extensão sem ter que prever muitos casos de uso e sem expor informações desnecessárias ao desenvolvedor.

Como inicialmente é difícil conhecer todo o domínio da aplicação e prever todos os casos de uso para desenvolver um framework caixa-preta, a primeira versão de um framework é geralmente caixa-branca. À medida que vai sendo utilizado, o framework é melhorado sistematicamente até ser transformado em um framework caixa-cinza (tendência atual) e, posteriormente, caixa-preta (Fayad et al., 1999; Yassin \& Fayad, 1999).

\subsubsection{Desenvolvimento de sistemas baseados em frameworks}

A presença de frameworks reusáveis influencia o processo de desenvolvimento de sistemas. De acordo com Bosch et al. (1999), as seguintes fases são identificadas durante o desenvolvimento de um sistema baseado em frameworks: 
- Desenvolvimento do framework: essa fase, que geralmente consome maior parte do tempo de desenvolvimento do software, tem por objetivo produzir um projeto reusável dentro de um domínio que suporte a implementação do sistema desejado.

- Uso do framework: essa fase, que também pode ser identificada por fase de instanciação ou fase de desenvolvimento de aplicações, corresponde à instanciação do framework para um ou mais sistemas específicos.

- Evolução e manutenção do framework: nessa fase o framework evolui para incorporar novas funcionalidades do domínio ou é modificado para corrigir problemas que surjam a partir do seu uso real.

O desenvolvimento de um framework difere bastante do desenvolvimento de um sistema de software tradicional, pois um framework deve envolver todos os conceitos relevantes num dado domínio para que possa ser reusado, enquanto um sistema tradicional envolve apenas os conceitos mencionados nos seus requisitos. Em função disso, os processos tradicionais de desenvolvimento de software não suportam adequadamente o desenvolvimento de frameworks, fazendo com que vários processos mais específicos sejam propostos (Bosch et al., 1999).

Pree (1999) propõe um processo iterativo para construção de frameworks baseado na identificação de pontos variáveis (hotspots). O processo inicia-se com a definição do modelo de objetos de um sistema de software específico que é, então, refinado por um ciclo cujas iterações se repetem até que todos os pontos variáveis estejam sendo tratados pelo framework. A primeira atividade do ciclo é a identificação dos pontos variáveis (Pree, 1999). Esses pontos são então projetados e implementados na atividade de projeto do framework. Para garantir que satisfaça aos requisitos do domínio, o framework é avaliado durante a atividade de uso. Se novos pontos variáveis forem encontrados nessa atividade, o ciclo se repete incluindo nova análise do modelo de objetos, senão, o framework é liberado para uso.

Schmid (1999) também propõe um processo para desenvolvimento de frameworks, baseado em generalizações sistemáticas, que parte de um modelo de classes de um sistema de software específico. Inicialmente faz-se uma análise de alto nível do domínio para determinar os aspectos que precisam ter flexibilidade (pontos variáveis). A seguir, cada ponto variável é analisado e especificado em detalhes. Essas especificações passam pelo projeto de alto nível resultando em vários subsistemas de pontos variáveis. Depois disso, o modelo de classes do sistema específico 
é transformado por meio da substituição de grupos de classes do modelo original pelos subsistemas de pontos variáveis correspondentes identificados na atividade anterior. O resultado final dessa transformação é o modelo de classes a ser implementado para o framework.

Bosch et al. (1999) divide a fase de desenvolvimento de um framework em seis atividades. A análise de domínio corresponde à primeira atividade, cujo objetivo é descrever o domínio da aplicação por meio da análise de aplicações semelhantes e padrões do domínio e entrevistas com usuários. O resultado dessa atividade é o modelo do domínio com seus requisitos, conceitos e relacionamento entre conceitos. De posse do modelo do domínio, passa-se à atividade de projeto arquitetural na qual deve ser feito um projeto arquitetural de alto nível do framework. Esse projeto de alto nível é então refinado na atividade de projeto do framework, cujo resultado é codificado na atividade de implementação utilizando uma linguagem de programação específica. A atividade de teste é realizada com o resultado da atividade de implementação para avaliar tanto sua funcionalidade quanto sua usabilidade. Após os testes, o framework passa pela atividade de documentação. Um manual de usuário, a documentação do projeto do framework e a descrição de como o framework funciona são esperados como resultados dessa última atividade.

Além desses processos, existem ainda várias outras abordagens para a construção de frameworks, por exemplo: Roberts e Johnson(1998) e Braga (2002) descrevem processos para a construção de frameworks utilizando linguagem de padrões, Yang et al. (1998) apresentam um processo de desenvolvimento de frameworks baseado no uso da linguagem UML, Koskimies e Mössenböck (1995) também apresentam um processo baseado em generalização.

Conforme se observa, os processos de desenvolvimento de frameworks de aplicação são bastante divergentes. As abordagens de Schmid (1999) e Pree (1999) partem de modelos de sistemas específicos e incluem a flexibilidade desejada para o framework posteriormente, focando mais no desenvolvimento de sistemas baseados em frameworks. Na abordagem de Bosch et al. (1999), cujo foco principal é o desenvolvimento do framework que pode ser reusado em vários sistemas, o processo se inicia com a análise do domínio, o que torna os pontos variáveis do framework mais previsíveis inicialmente. Como o processo de desenvolvimento de frameworks é naturalmente iterativo e mais lento que o de uma aplicação tradicional (Jacobson \& Nowack, 1999), a vantagem da abordagem de Bosch et al. (1999) é que, quanto mais pontos variáveis forem identificados inicialmente, menos iterações o processo de desenvolvimento deve ter. Isso implica na redução do tempo de desenvolvimento do framework. 


\subsection{Padrões de projeto - Design Patterns}

O conceito de padrões de software foi criado com base nas idéias do arquiteto Christopher Alexander (Alexander, 1979 apud (Pree, 1995)) ${ }^{11}$ que, no final da década de 70, identificou e documentou a existência de vários padrões de construção que se repetiam inúmeras vezes em projetos diferentes.

Padrões de software, de forma análoga aos padrões definidos por Alexander, descrevem soluções para problemas que ocorrem com freqüência no desenvolvimento de software. Essas soluções, definidas com base na experiência adquirida pelos desenvolvedores durante anos de prática profissional, descrevem como resolver determinados problemas de desenvolvimento de forma conceitual. Diferente do reuso de componentes e frameworks, um padrão de software pode ser visto como uma forma de reuso de experiências, pois apresenta uma solução comprovada (reusada com eficiência em projetos diferentes) para ser utilizada por desenvolvedores com menos experiência no problema.

Os padrões são descritos com base nas seguintes informações principais (Gamma et al., 1994): nome do padrão, problema a ser resolvido, contexto (situações nas quais o problema costuma ocorrer e para as quais a solução é desejável), motivação para uso do padrão e solução para o problema (instruções que descrevem como o problema pode ser resolvido). A solução é descrita em termos gerais sem se prender a uma linguagem de programação em particular. Exemplos de uma ou mais aplicações do padrão e uma lista dos padrões relacionados também são importantes na sua descrição.

De acordo com Buschmann et al. (1996), os padrões de software podem ser subdivididos em padrões arquiteturais, de projeto e de programação, embora muitos padrões se encaixem em mais de um tipo. Os padrões de projeto (mais comumente utilizados), em particular, definem soluções para problemas de projeto de software. Alguns exemplos desse tipo de padrão são (Gamma et al., 1994): Abstract Factory, Command, Facade, Singleton, Template Method, entre outros.

O uso de um padrão de projeto acontece a partir da identificação de um problema pelo desenvolvedor do software; a análise dos padrões existentes, para encontrar um (ou mais) padrão que ofereça solução para o problema identificado; e a aplicação do padrão. Essa última etapa é

\footnotetext{
${ }^{11}$ C. Alexander. The Timeless Way of Building. New York, Oxford University Press.
} 
feita replicando no software, que está em desenvolvimento em alguma linguagem de programação, a solução conceitual definida pelo padrão.

Além de fornecer exemplos a serem seguidos e artifícios a serem replicados e posteriormente refinados ou estendidos para necessidades diferentes, os padrões de projeto garantem uniformidade na estrutura do software, o que aumenta a produtividade no seu desenvolvimento e manutenção. Por esse motivo, padrões de projeto podem ser utilizados com eficiência na construção de frameworks. Um framework pode ser desenvolvido utilizando-se no seu projeto vários padrões (Johnson, 1997) que ajudam a organizar a estrutura reusável do framework e melhorar o seu entendimento por parte dos desenvolvedores. A organização na estrutura do framework é um ponto favorável para a instanciação de sistemas mais adaptáveis e extensíveis.

Embora um padrão de projeto não esteja relacionado diretamente com uma linguagem de programação, é possível especializá-lo para que as soluções propostas sejam feitas com base em recursos de uma linguagem em particular. Isso é o que acontece com a linguagem Java, mais especificamente com os recursos da plataforma J2EE. O livro "Core J2EE Patterns - Best Practices and Design Strategies" (Alur et al., 2003) traz uma lista de padrões, baseada nos padrões de Gof (Gang of Four) (Gamma et al., 1994) e em outros mais específicos, com soluções de sucesso para vários problemas (de projeto e arquiteturais) utilizando os componentes da plataforma J2EE. A vantagem desse tipo de especialização é que o desenvolvedor já obtém a solução com exemplos mais próximos da sua realidade, ou seja, já na linguagem em que está utilizando.

\subsection{Sistemas modulares}

Uma das primeiras iniciativas para o desenvolvimento de sistemas mais flexíveis, antes mesmo do uso de componentes e objetos, foi o desenvolvimento de sistemas modulares.

De acordo com Myers (1975), um sistema modular é estruturado em termos de partes que independem umas das outras: os módulos. Em termos gerais, um módulo é visto como um artefato de programação que pode ser desenvolvido e compilado de forma independente de outros artefatos que compõem um determinado sistema (Staa, 2000). O propósito de um módulo é receber uma entrada, executar uma operação e retornar algum resultado como saída. 
Em geral, um módulo, como concebido por Myers (1975) é organizado em função de três atributos básicos: função, lógica e interfaces. A função de um módulo é a responsabilidade delegada a ele, ou seja, o que acontece quando um módulo é acionado. A forma como o módulo executa sua responsabilidade corresponde ao fluxo de programa (lógica) que está dentro dele. As interfaces do módulo são os meios pelos quais os módulos são invocados e conectados uns aos outros para formar o sistema modular. Módulos podem ser formados por um ou mais segmentos, que são agrupamentos de instruções dentro de um módulo.

Um modelo ideal de modularização prioriza a maximização da coesão e a minimização do acoplamento dos módulos.

Em termos da coesão, que mede quão relacionadas estão as responsabilidades do módulo internamente, Myers (1975) classifica os módulos em: funcionais, informacionais, comunicacionais, procedurais, clássicos, lógicos e coincidentais. Um módulo funcional é aquele em que todos os seus elementos estão relacionados com a execução de uma única função, enquanto um módulo informacional executa múltiplas funções com vários pontos de entrada e saída e todas essas funções lidam com apenas uma estrutura de dados.

Em relação ao acoplamento, que é medido em termos da dependência de um módulo em relação ao outro, os seguintes tipos de acoplamento são possíveis Myers (1975): acoplamento de dados, de marca, de conteúdo, comum, externo e de controle. Em especial, o acoplamento de dados, considerado o melhor tipo, acontece pela troca de dados simples (como parâmetros) entre os módulos. O acoplamento de marca, que também apresenta nível razoável de acoplamento, acontece pela troca de estruturas de dados mais complexas (como parâmetros).

Segundo Myers (1975), os módulos funcionais e informacionais e os acoplamentos de dado e de marca são considerados os mais indicados para a construção de sistemas modulares, pois possuem alto nível de independência de outros módulos, são menos susceptíveis a erros e possuem alta reusabilidade e extensibilidade.

De acordo com Staa (2000), a programação modular constitui a base para o desenvolvimento de sistemas de forma organizada. Por meio do particionamento criterioso de um sistema em módulos torna-se possível: 
- vencer barreiras de complexidade, pois um sistema complexo pode ser dividido em vários módulos mais simples de serem desenvolvidos que posteriormente são integrados para formar o sistema original;

- trabalhar em equipe, pois cada módulo pode ser desenvolvido por uma equipe diferente em paralelo, o que reduz o tempo de desenvolvimento do sistema;

- reutilizar módulos já desenvolvidos, já que alguns módulos agrupam funcionalidades exigidas por vários sistemas;

- gerenciar melhor o processo de desenvolvimento, já que é possível criar uma baseline de módulos que permite controlar o que já foi e o que ainda falta ser desenvolvido, dando mais visibilidade ao processo como um todo; entre outras vantagens.

O desenvolvimento baseado em módulos, que surgiu antes mesmo do paradigma de orientação a objetos, tem sido bastante utilizado desde sua concepção nos anos 70. Entretanto, diferente de componentes e frameworks, não há, na literatura, processos de software bem definidos para esse tipo de desenvolvimento (Staa, 2000). Basicamente, o que a maioria dos engenheiros de software utiliza no desenvolvimento dos seus sistemas modulares é o conceito de módulo como apresentado por Myers.

Uma das áreas que se destaca pelo uso dessa forma de desenvolvimento de software é a gerência de conteúdo na $W e b$, nos chamados sistemas de gerenciamento de conteúdo ou CMS (Browning \& Lowndes, 2001).Em geral os CMSs, que tem por objetivo a disponibilização e controle de conteúdo na Web (Browning \& Lowndes, 2001), são especializados para algum tipo de atividade como o gerenciamento de documentos específicos, a publicação de revistas e notícias eletrônicas, o comércio eletrônico, portais em geral, entre outros. Porém, uma característica presente em muitos CMSs disponíveis atualmente é a organização das suas funcionalidades na forma de módulos.

Um CMS não é visto como um pacote de software, mas sim como uma caixa de ferramentas (toolbox) com a qual cada organização constrói e customiza seu próprio ambiente de gerência de conteúdo na $\mathrm{Web}$ (Robertson, 2003). Essa customização se dá pela seleção e configuração dos módulos que compõem o ambiente. Os módulos geralmente agrupam um conjunto de funções relacionadas com um tipo de funcionalidade, por exemplo, autenticação de usuário, busca, 
download/upload de documentos, divulgações, etc. Esses módulos são gerenciados pelo núcleo do CMS.

Exemplos clássicos de CMSs baseados em módulos são o PostNuke (PostNuke, 2005) e PHPNuke (PHP-Nuke, 2006), bastante utilizados na construção de ambientes de gerenciamento de conteúdo de diversos domínios.

Embora o conceito de módulo como tratado por Myers (1975) remeta para o desenvolvimento de software sem considerar a dinâmica de processamento atual, provida por linguagens orientadas a objetos, esse conceito foi importante para auxiliar na concepção do framework proposto nesta tese, como poderá ser observado nos próximos capítulos.

\subsection{Considerações finais}

Conforme pode ser observado ao longo deste capítulo, a maioria das técnicas de projeto de software apresentadas dão ênfase para o aspecto de reusabilidade. Componentes e módulos enfatizam o reuso de partes do código que podem ser substituídos por outros, ou modificados para atenderem algum objetivo em especial. Frameworks sugerem o reuso não só de código, mas, também, da arquitetura genérica proposta por eles na implementação de vários sistemas diferentes. Padrões de projeto, por sua vez, destacam o reuso não de código, mas de aspectos conceituais de uma solução comprovada que pode ser utilizada, inúmeras vezes, em vários tipos de sistemas. Vários estudos da literatura apresentam os frameworks, componentes e padrões de projeto como técnicas (alguns autores chamam também de tecnologias) que cooperam entre si e se relacionam sinergicamente de diferentes maneiras (Johnson, 1997; Meijler \& Nierstrasz, 1997; Larsen, 1999; Larsson \& Sandberg, 2000).

Apesar do foco na reusabilidade é possível identificar nessas técnicas formas de se padronizar a estrutura interna de um software, tal que ele seja extensível e mais facilmente adaptável para atender objetivos não previstos quando da sua construção inicial. Combinando as características de cada uma dessas técnicas é possível construir um tipo de sistema que pode ser idealmente adaptado às necessidades de seus usuários. O uso de padrões de projeto na construção de frameworks pode melhorar a sua organização interna e oferecer maior facilidade de extensão e adaptação às aplicações instanciadas sobre ele. Adicionalmente, a criação de um framework modular e/ou baseado em componentes oferece a facilidade de se adicionar ou remover 
módulos/componentes nas aplicações de forma mais simplificada, já que as interfaces desses elementos são bem definidas.

A proposta de solução para o problema de flexibilidade dos sistemas educacionais mencionado nos Capítulos 1 e 2 foi baseada nessas possibilidades de agrupamentos dos conceitos framework, componentes, padrões e sistemas modulares. O resultado desse agrupamento foi a definição de um framework modular baseado em componentes que é apresentado no próximo capítulo. 


\subsection{Considerações iniciais}

Com base na análise dos sistemas educacionais e nos estudos sobre as técnicas de projeto de software que podem ser utilizadas para adicionar flexibilidade aos sistemas, foi proposto, no contexto desta tese, um framework de aplicação cujo objetivo é oferecer meios pelos quais as aplicações baseadas na $\mathrm{Web}$ possam ser criadas, adaptadas e estendidas para atender os objetivos específicos de seus usuários.

Apesar dessa proposta ter sido inicialmente investigada para resolver o problema de adaptação dos sistemas educacionais, uma análise sobre os requisitos e características estabelecidas para o framework revelou a possibilidade de generalizá-lo para o desenvolvimento de aplicações Web em geral ${ }^{12}$, já que tais requisitos e características não estavam diretamente relacionados com sistemas do domínio educacional. Após essa generalização, o nome do framework, que era Web MOdular Development for Education, foi alterado para Web MOdular DEvelopement (WebMODE).

A escolha pela abordagem baseada em framework se deu em função da capacidade de reuso e extensão inerentes nesse tipo de software. Como visto no capítulo anterior, um framework corresponde a uma aplicação semi-completa e reutilizável que, quando especializada, produz aplicações personalizadas (Johnson \& Foote, 1988). Para ser especializado, um framework deve possuir uma estrutura interna bem organizada e ser bem documentado, tal que um desenvolvedor seja capaz de produzir aplicações a partir dele, o que coincide com uma das características de flexibilidade identificadas no Capítulo 2.

\footnotetext{
12 Nesta tese, o termo "aplicação Web" é interpretado como um sistema $W e b$ que permite, ao usuário, executar lógica de negócio por meio do navegador, sendo que as entradas de dados e a navegação do usuário nesse sistema afetam seu conteúdo (Conallen, 2002).
} 
Apesar da afirmação “...uma aplicação semi-completa...” que define um framework como uma implementação de um conjunto de classes, o framework WebMODE é apresentado neste capítulo como uma abstração conceitual. Tal abstração permitiu identificar todos os aspectos relevantes do framework sem prendê-lo a uma tecnologia em especial. Para validar essa abstração, o WebMODE foi implementado utilizando a plataforma J2EE (Sun, 2006). Essa implementação, que representa o framework de aplicação propriamente dito, recebeu o nome de WebMODEJ2EE para denotar sua dependência com a abordagem tecnológica utilizada no seu desenvolvimento.

Assim, neste capítulo, apresenta-se uma visão geral da proposta do WebMODE, uma descrição de alto nível sobre o processo de desenvolvimento utilizado na sua concepção e, por fim, uma descrição da implementação do framework utilizando as tecnologias da plataforma J2EE.

\subsection{Visão geral do framework WebMODE}

O WebMODE foi proposto no intuito de flexibilizar o processo de criação e uso de aplicações baseadas na $W e b$. Como o próprio nome sugere, o WebMODE adota uma perspectiva modular de desenvolvimento de aplicações que permite a configuração das aplicações a partir da seleção e configuração de funcionalidades disponibilizadas na forma de módulos (Silva et al., 2004).

Os módulos do WebMODE foram inspirados na visão modular dos CMSs (citados no Capítulo 3), porque representam um conjunto de funcionalidades específicas que são apresentadas na interface da aplicação na forma de blocos de menu. No WebMODE, essas funcionalidades são organizadas nos módulos por meio de opções do módulo. Por exemplo, um módulo de usuário pode apresentar uma opção "gerenciar usuários", que inclui funcionalidades (ou ações) como "adicionar usuário", "remover usuário" e “editar usuário", e uma opção "atualizar informações pessoais", que inclui a funcionalidade "atualizar as informações do usuário". Essas opções correspondem aos itens de menu da aplicação instanciada sobre o framework.

Em termos de coesão, os módulos do WebMODE podem ser ditos informacionais (como descrito no Capítulo 3) sob o ponto de vista que todas as suas funções internas estão relacionadas com um único conceito (informação) da aplicação, como no caso do módulo de usuário. Em termos do acoplamento, os módulos do WebMODE são desacoplados uns dos 
outros porque um módulo não aciona outro diretamente, mas eles possuem acoplamento de marca com o núcleo do framework, que é responsável por gerenciá-los.

Quando um módulo é selecionado para compor uma aplicação WebMODE, ele deve ser configurado (Silva \& Moreira, 2004). Tal configuração estabelece, para cada opção do módulo, quais papéis ${ }^{13}$ possuem o direito de acesso sobre ela. Por exemplo, no caso do módulo de usuário, uma possível configuração seria: deixar que todos os usuários autenticados acessem a opção para alterar suas informações pessoais e limitar o acesso à opção de gerenciar usuários apenas aos administradores da aplicação, ou a um professor.

$\mathrm{Na}$ Figura 4.1 são apresentados os elementos que fazem parte da estrutura geral de uma aplicação instanciada utilizando uma implementação do framework WebMODE. Conforme se observa, a estrutura da aplicação está organizada em camadas de interface gráfica, controle e componentes, seguindo o padrão arquitetural MVC (Model View Controller) (Krasner \& Pope, 1988).

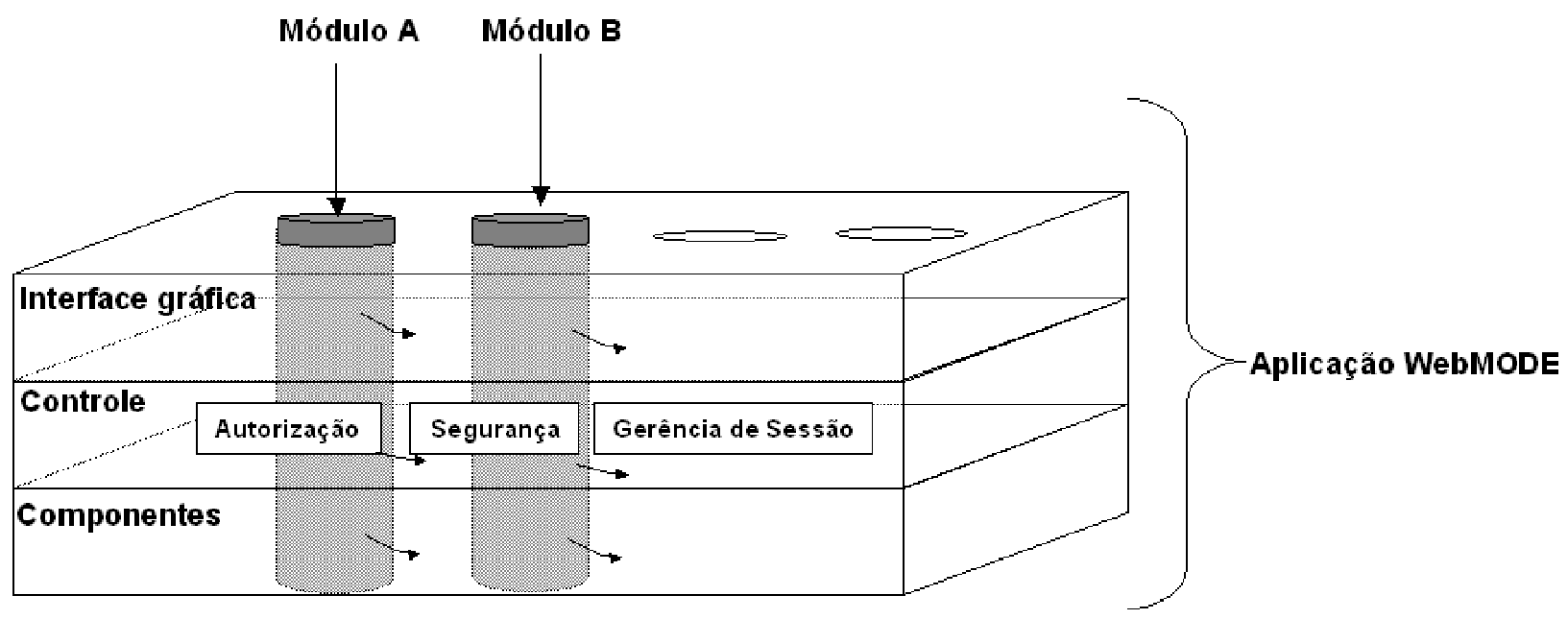

Figura 4.1 - Estrutura de uma aplicação WebMODE

A infra-estrutura das camadas é fornecida pelo framework para garantir a uniformidade dos módulos e seu correto funcionamento. Na camada de controle, os serviços de autorização, segurança e gerência de sessão são fornecidos pelo framework e não precisam ser desenvolvidos para cada nova aplicação. Os módulos são formados por elementos de interface gráfica, que são utilizados pelo usuário para interagir com a aplicação, por elementos de controle, que fazem a

\footnotetext{
${ }^{13}$ A afirmação "papéis possuem direito de acesso sobre opções do módulo" quer dizer que "usuários da aplicação que assumem esses papéis têm direito de acesso sobre as opções do módulo".
} 
conexão entre a interface gráfica e a lógica do módulo, e por componentes, que executam a lógica das funcionalidades oferecidas pelo módulo. Os módulos são "encaixados" na infraestrutura do framework para formar uma aplicação. Quando isso acontece, os elementos do módulo passam a fazer parte das camadas da aplicação, podendo ser compartilhados com outros módulos. Por exemplo, um componente de negócio de um módulo A pode ser utilizado como parte da lógica de negócio de outro módulo B por meio de uma chamada direta a esse componente.

Uma implementação do WebMODE pode ser classificada como um framework caixa-branca (whitebox), pois o desenvolvedor da aplicação pode criar novos módulos para sua aplicação, ou modificar os existentes, utilizando classes abstratas e documentações fornecidas pelo framework. Para facilitar a definição de aplicações, as implementações do WebMODE devem fornecer um mecanismo adequado para a composição e configuração de módulos, por exemplo, uma aplicação gráfica.A utilização de uma implementação dessa proposta de framework permite ao desenvolvedor instanciar suas aplicações de acordo com suas necessidades, podendo adicionar ou remover funcionalidades ou alterar o comportamento das funcionalidades da aplicação quando desejar.

\subsection{Processo de especificação e desenvolvimento do framework}

A preocupação principal da pesquisa reportada nesta tese foi, desde a sua concepção, a busca por uma abordagem de desenvolvimento de aplicações baseadas na Web que, além de oferecer liberdade ao desenvolvedor para criar suas aplicações a partir da seleção de um conjunto de funcionalidades (para evitar que a aplicação tenha muitas funcionalidades não utilizadas), pudesse facilitar a tarefa de adaptação e extensão dessas funcionalidades de forma organizada (para garantir que a aplicação atenda objetivos específicos dos seus usuários).

Com essa preocupação em mente, foi feito um levantamento na literatura de engenharia de software para identificar as técnicas de projeto mais adequadas para suportar as características de flexibilidade identificadas no Capítulo 2. Além da busca na literatura, também foram analisados frameworks de desenvolvimento para Web (Spielman, 2003; WebWork, 2006) e alguns sistemas de gerenciamento de conteúdo (CMS) (PostNuke, 2005; PHP-Nuke, 2006) utilizados no desenvolvimento de websites comerciais. Esses sistemas foram investigados por apresentar características como a flexibilidade para inserir/retirar funcionalidades dos websites. 
Por ser uma alternativa baseada no reuso de uma estrutura interna e na padronização e documentação das interfaces de comunicação, a proposta de uso de frameworks orientados a objeto mostrou-se adequada para permitir que diferentes aplicações de um dado domínio pudessem ser instanciadas de maneira organizada.

Identificada uma abordagem a ser adotada para o problema, passou-se então às atividades de projeto e especificação do framework. Essas atividades, que foram divididas em análise do domínio, projeto arquitetural e projeto do framework, implementação e teste, foram baseadas no processo simplificado proposto por Bosch et al. (1999), descrito no Capítulo 3.

$\mathrm{Na}$ atividade de análise, procurou-se identificar as características do domínio no qual o framework a ser desenvolvido estava inserido. Como a princípio o framework estava sendo proposto no domínio educacional, essa atividade foi realizada com base na exploração dos sistemas educacionais existentes e na experiência da pesquisadora desta tese com o desenvolvimento de aplicações para Web no domínio da informática na educação (Silva et al., 2002; Silva \& Moreira, 2003b, 2003a; Moreira \& Silva, 2005). Além de analisar os sistemas educacionais, os frameworks para desenvolvimento de aplicações Web em geral também foram analisados para extrair características que pudessem ser reusadas no projeto desse framework. Dentre os resultados dessa atividade estão os requisitos e os casos de uso do framework.

Nas atividades de projeto, os casos de uso e os requisitos foram analisados, juntamente com as técnicas de projeto de software apresentadas no Capítulo 3, na busca por uma arquitetura de software que atendesse os objetivos propostos para o framework. O projeto arquitetural de mais alto nível foi feito com base nos resultados da atividade de análise, sem considerar a abordagem tecnológica a ser utilizada. O resultado desse projeto revelou um aspecto não esperado na concepção do framework: ao contrário de um framework específico para aplicações educacionais, que era o objetivo inicial, o framework projetado apresentava características que permitiam seu uso no desenvolvimento de aplicações $W e b$ em geral, considerando a definição de aplicações Web adotada nesta tese. Dada essa constatação, o projeto do framework continuou por essa linha de interesse.

O refinamento desse projeto de alto nível e a inclusão dos aspectos de tecnologia deu origem ao projeto de mais baixo nível, que foi implementado e testado para validar os conceitos do 
framework proposto. Os testes da implementação foram feitos a partir da instanciação de uma aplicação de gerenciamento de atividades didáticas, apresentada no Capítulo 6.

\subsubsection{Levantamento e análise de requisitos}

O levantamento dos requisitos de um software tem por objetivo identificar o domínio do problema a partir da visão do usuário, tentando identificar qual é o objetivo do sistema que se pretende desenvolver.

$\mathrm{Na}$ literatura de engenharia de software são encontradas diversas técnicas para se realizar o levantamento de requisitos (Pfleeger, 2001; Ghezi et al., 2002) sendo que as mais tradicionais buscam investigar as necessidades do usuário e transformá-las numa lista de requisitos funcionais e não funcionais que devem ser atendidos pelo software a ser desenvolvido. Essa lista de requisitos é então analisada e uma arquitetura é identificada para o desenvolvimento do software.

Nesta tese, a análise de requisitos foi realizada com base nas limitações dos sistemas educacionais baseados na $W e b$, nas características de flexibilidade propostas para esses sistemas e na experiência dos pesquisadores envolvidos com este trabalho. Pelo fato de o objetivo da pesquisa ser a proposta de um framework para desenvolvimento de aplicações Web mais flexíveis em termos de adaptação e extensão ( e não a proposta de um sistema em particular), os requisitos listados abaixo se referem à proposta do framework WebMODE, sendo que vários deles estão relacionados com aspectos de projeto do framework para alcançar os objetivos desejados:

1. A estrutura interna do framework, bem como os pontos variáveis para sua extensão, deve ser organizada de forma modular. Um módulo deve ser interpretado como um conjunto de funcionalidades específicas organizadas na forma de opções do módulo, com base na forma de modularização dos CMSs.

2. A lógica de acesso aos dados manipulados por um módulo deve ser organizada em componentes, que podem ser reusados por outros módulos para evitar replicação.

3. Os módulos devem ser automaticamente reconhecidos pelo framework, e disponibilizados para uso nas aplicações, a partir do momento em que forem disponibilizados no servidor que executa o framework. 
4. O framework deve suportar a organização de aplicações pelo agrupamento de módulos de funcionalidades que podem ser ativados/desativados sem "parar" as aplicações.

5.Para gerenciar a sessão de usuário autenticado, o framework deve oferecer um mecanismo de autenticação configurável que possibilite a autenticação do usuário tanto em bases de dados específicas da aplicação quanto em bases de dados disponibilizadas por sistemas legados.

6. O núcleo do framework deve garantir, durante uma requisição, que o usuário tem direito de acessar o módulo e opção acionados na interface da aplicação. Isso é feito com base no papel assumido pelo usuário (no momento da requisição) e na opção do módulo que ele está acionando na aplicação.

7. O mecanismo de autorização do framework deve estar preparado para trabalhar com papéis de usuário e permissões personalizadas para cada aplicação. Uma forma de controlar as permissões é permitir ou não que o usuário que assume o papel " $x$ ” acesse a opção " $y$ ” do módulo "w".

8. O framework deve suportar a instanciação de mais de uma aplicação no mesmo servidor. Essas aplicações podem utilizar módulos e fontes de dados diferentes, mas a lógica central é a mesma. Isso quer dizer que o núcleo do framework não precisa ser replicado a cada nova aplicação instanciada, pois basta que ele saiba direcionar as requisições para a aplicação/módulo corretos.

9. A interface das aplicações instanciadas sobre o framework deve ser construída de forma dinâmica a partir dos módulos utilizados e do papel do usuário que acessa a aplicação. Somente as funcionalidades disponíveis para o usuário devem ser apresentadas.

10. O framework deve ser independente de plataforma.

11. O framework deve utilizar um mecanismo de persistência que deixe as aplicações independentes de um SGBD específico.

12. O framework e os módulos devem considerar a separação de interesses em termos de lógica de apresentação, lógica de negócio e dados. 
13. O framework deve ser desenvolvido utilizando-se tecnologias que sejam padronizadas oficialmente e que apresentem recursos para o desenvolvimento de aplicações enterprise (inclui recursos para tolerância a falhas, replicação, alta disponibilidade, entre outras).

Conforme se observa, esses requisitos visam permitir que as aplicações instanciadas sobre implementações do framework WebMODE possam receber as características de extensibilidade, adaptabilidade e reusabilidade necessárias para a construção de aplicações mais flexíveis, que são os principais requisitos não-funcionais dessa proposta.

Para permitir que a instanciação de aplicações sobre o WebMODE e a adaptação dessas aplicações possa ocorrer de forma mais natural, foram estabelecidos dois requisitos funcionais para uma aplicação gráfica que suporte a instanciação do framework:

14. O framework deve fornecer um mecanismo para a instanciação, edição e remoção de aplicações de forma visual. A edição de uma aplicação deve permitir a seleção de módulos para compor a aplicação e a configuração das permissões dos usuários sobre as opções de cada módulo.

15. O framework deve fornecer um módulo de login que pode ser ou não ativado nas aplicações instanciadas sobre ele. O módulo de login deve suportar o requisito de autenticação (requisito 5).

Esses requisitos mostram que uma implementação do framework WebMODE deve oferecer mais do que um conjunto de classes abstratas e uma especificação, ou seja, ela deve ser, de fato, uma aplicação semi-completa que pode ser utilizada para construir aplicações personalizadas..

O fato de o conjunto de requisitos estabelecidos para o framework WebMODE não estarem diretamente relacionados com o domínio educacional foi o que permitiu sua generalização para aplicações $W e b$ em geral. Além disso, como os requisitos do framework não estão diretamente ligados com as peculiaridades do ambiente $W e b$, é possível que essaa proposta possa ser expandida, ainda mais, para o desenvolvimento de aplicações não $W e b$, por exemplo, aplicações desktop. 


\subsubsection{Especificação de casos de uso}

A partir da análise dos requisitos foi feito o levantamento dos casos de uso para o framework WebMODE. Como muitos dos requisitos estabelecidos estão relacionados com o projeto do framework, os casos de uso especificados ficaram restritos à aplicação de suporte à instanciação de aplicações WebMODE, conforme ilustrado na XXX.

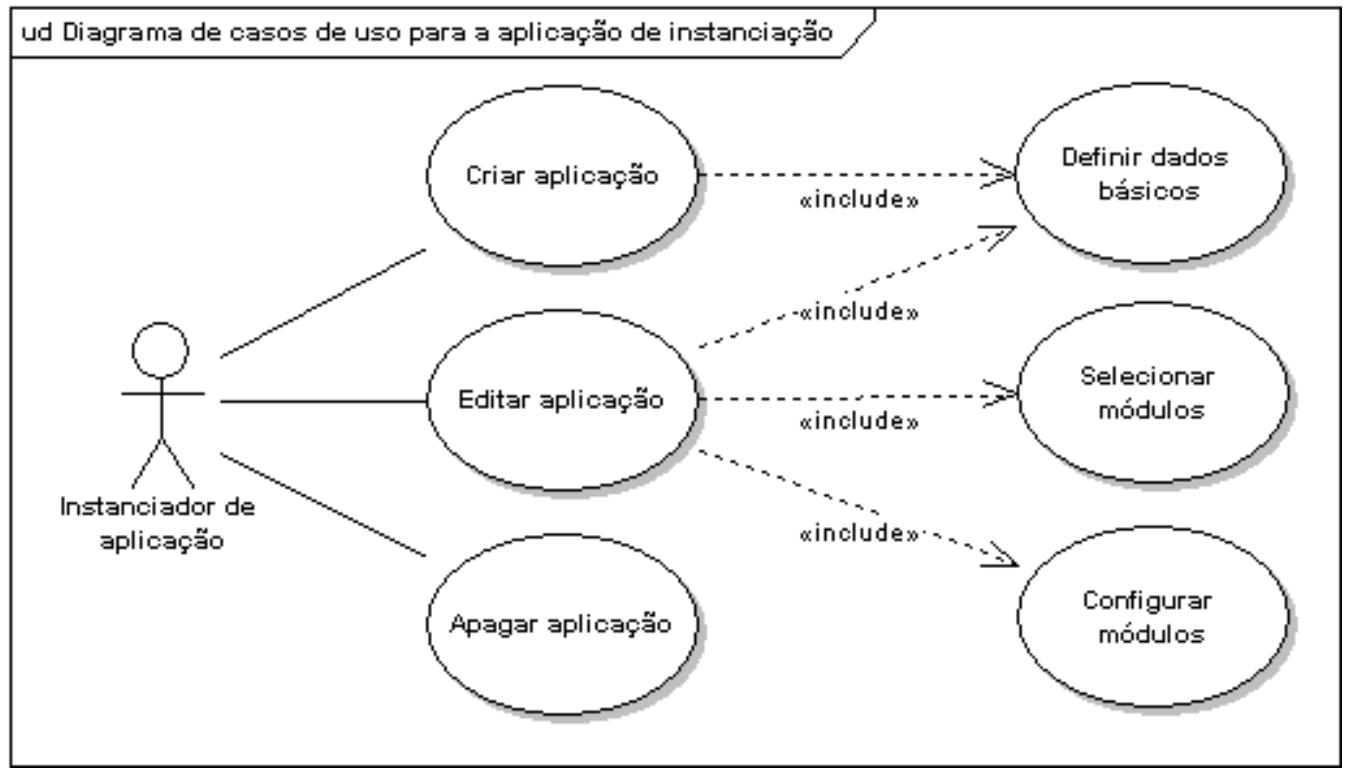

Figura 4.2 - Casos de uso de uma aplicação para instanciação do WebMODE

$\mathrm{Na}$ Figura 4.2, o usuário "Instanciador de aplicação" (ou desenvolvedor de uma aplicação WebMODE) pode criar, editar ou apagar aplicações. A criação de aplicações corresponde à inserção dos dados da aplicação, como nome, identificação, fonte de dados, fonte de autenticação, entre outros. A edição de uma aplicação permite mudar seus dados básicos, selecionar os módulos que irão fazer parte dessa aplicação e configurar os módulos selecionados.

\subsubsection{Projeto arquitetural do framework WebMODE}

Após a identificação dos casos de uso, foi realizada a atividade de projeto do framework WebMODE, no qual foi definido o fluxo geral de seu funcionamento.

Atendendo ao requisito 1 , que estabelece a definição de uma estrutura interna modular, o framework foi organizado em função de um núcleo reusável e de módulos de funcionalidades que possuem responsabilidades diferentes dentro da arquitetura estabelecida. 
O núcleo do framework tem como responsabilidades: a criação de uma aplicação que permite instanciar o framework (quando essa aplicação ainda não estiver disponível) e o processamento das requisições das aplicações instanciadas. O processamento de uma requisição pelo núcleo envolve, respectivamente:

- a identificação da aplicação sobre a qual a requisição está sendo realizada (já que podem existir várias aplicações sendo executadas sobre o framework - requisito 8);

- a identificação do módulo e da opção acessada pelo usuário;

- a autorização do usuário sobre a opção do módulo;

- a ativação do módulo, que inclui a adição de parâmetros de controle necessários para sua execução; e

- a apresentação do resultado da requisição, para a qual o núcleo deve organizar a informação a ser apresentada para incluir tanto os dados retornados pelo módulo quanto os dados para geração da interface do usuário.

Os módulos têm como responsabilidade a atualização de sua disponibilidade no framework (para atender ao requisito 3 , que requer o reconhecimento automático dos módulos) e o processamento das requisições invocadas pelo núcleo. Os próprios módulos devem gravar suas informações na base de dados do framework para que sejam automaticamente reconhecidos. Isso acontece quando um módulo é disponibilizado para uso ou quando ele é desacoplado do framework, ou seja, fica indisponível para qualquer aplicação. Para atender uma requisição, o módulo deve:

- preparar os parâmetros, que envolve a identificação dos parâmetros de controle enviados pelo núcleo e a organização os demais parâmetros da requisição num formato utilizável;

- validar os parâmetros, para verificar se os parâmetros recebidos no módulo são válidos, por exemplo, se não são nulos ou carregam valores inválidos; e

- executar a lógica do módulo que corresponde à opção acionada na aplicação.

A preparação dos parâmetros e a atualização da sua disponibilidade são realizadas nas classes abstratas que dão origem aos módulos. Após estender essas classes abstratas, os módulos devem executar a validação dos parâmetros e a execução da lógica da requisição (lógica específica da funcionalidade oferecida pelo módulo). 
Para atender aos requisitos pré-estabelecidos, o WebMODE foi projetado com base nas técnicas de projeto de software, apresentadas no Capítulo 3, que viabilizam a implementação de sistemas flexíveis, ou seja, extensíveis, adaptáveis e reusáveis.

A arquitetura geral do WebMODE está baseada no padrão arquitetural MVC (Krasner \& Pope, 1988), introduzido pelos desenvolvedores da linguagem Smalltalk na década de 80. Esse padrão sugere que a aplicação seja dividida em três camadas: modelo (model), que representa os dados e a lógica específica da aplicação para manipular esses dados; visão (view), que renderiza o conteúdo de um modelo acessando seus estados e especificando como eles são apresentados; e controlador (controller), que define o comportamento da aplicação enviando requisições para o modelo e selecionando as visões a serem apresentadas. A vantagem de utilizar esse padrão é que a divisão em camadas permite organizar melhor o código da aplicação e facilita sua manutenção, uma vez que cada camada pode ser modificada individualmente.

Além do MVC, o padrão FrontController, pertencente ao grupo de padrões definidos na tecnologia J2EE (Alur et al., 2003), também foi considerado para inspirar a organização interna do framework. Ao sugerir que as requisições sejam atendidas em um ponto central do sistema, esse padrão faz com que a lógica de controle do núcleo, que se repete em várias requisições, não tenha que ser replicada em outras partes do código. Isso evita a repetição de código que pode causar inconsistência na aplicação. Apesar de ser um padrão originalmente definido para a plataforma J2EE, o FrontController também pode ser aplicado na solução de problemas que não usam essa tecnologia.

Na camada de apresentação, o framework considera o uso do padrão J2EE Composite View (Alur et al., 2003), que sugere a criação de uma visão principal a partir de visões mais específicas. Isso é equivalente a dividir a interface da aplicação em vários "frames" que apresentam informações distintas. Cada um desses "frames" componentes da visão principal pode apresentar conteúdo que se repete em todas as visões da aplicação ou conteúdo dinâmico, que é apresentado de acordo com a interação do usuário. O padrão Composite View facilita a alteração do layout da aplicação como um todo, por meio da reorganização da visão principal, ou a mudança parcial do layout das suas áreas individuais. Como o FrontController, esse padrão também pode ser utilizado com outras tecnologias. 
A visão principal, que é fornecida pelo framework, pode ser composta por quantas visões forem necessárias, mas há pelo menos duas visões padrão: a visão que contém as opções do menu da aplicação (provenientes da configuração dos módulos) e a visão que apresenta o resultado retornado pelo módulo após sua execução. Na Figura 4.1 (pág. 53) é possível notar que o módulo possui uma parte visível na interface da aplicação. Essa parte visível é incluída na visão principal fornecida pelo framework após o acionamento de alguma opção do módulo.

O núcleo do WebMODE é composto por um "Controlador central" (inspirado no Front Controller), uma "Página principal” (visão) e "Componentes de negócio" responsáveis por suportar a execução da lógica de responsabilidade do núcleo do framework

Além da arquitetura geral, os módulos do WebMODE também estão baseados no MVC. Um módulo é formado por uma ou mais visões, um "Controlador de módulo", um arquivo de configuração, que descreve as funcionalidades (opções) oferecidas por esse módulo e, opcionalmente, um ou mais “Componentes de negócio". Esses componentes, que representam o modelo no MVC, fornecem ao módulo a lógica necessária para executar uma requisição. Eles são opcionais porque o módulo pode usar componentes agregados a outros módulos, assim como outros módulos podem usar os seus componentes (requisito 2).

Na Figura 4.3 é apresentado um diagrama que mostra os elementos principais do framework WebMODE envolvidos com o processamento de uma requisição.

Esse diagrama representa o projeto de mais alto nível do WebMODE. De acordo com essa figura, o "Controlador central" é o elemento que representa o padrão FrontController, sendo que todas as requisições, vindas da interface de usuário, passam por ele. O "Controlador de módulo" recebe a requisição do "Controlador central" e a processa fazendo chamadas a um ou mais "Componentes de negócio". De posse da resposta para a requisição, o "Controlador de módulo" utiliza um "Objeto de transferência de dados" para indicar a visão a ser apresentada como resposta da requisição e os dados que devem ser utilizados por essa visão. Esse objeto é enviado como resposta do módulo para o "Controlador central" que o modifica, inserindo dados com informações sobre a interface de usuário, e o envia, posteriormente, para a "Página principal". Essa página é renderizada com base nos dados do "Objeto de transferência de dados”, incluindo a visão indicada pelo módulo. 


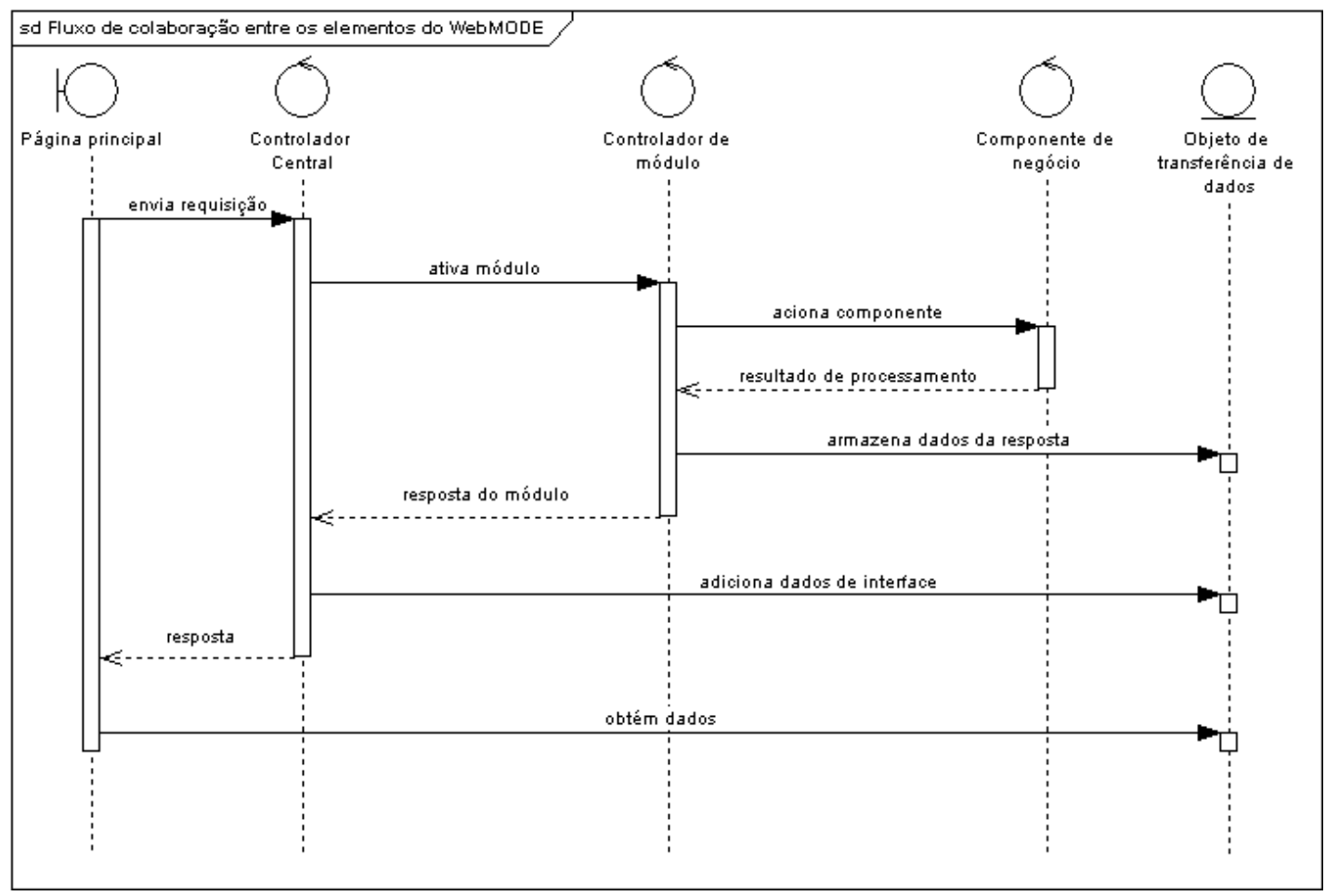

Figura 4.3 - Colaboração entre os elementos principais do WebMODE

O contrato entre o "Controlador central" e o "Controlador de módulo" está baseado no padrão TemplateMethod (Gamma et al., 1994).

O funcionamento geral do WebMODE, incluindo o processamento de requisições e o reconhecimento automático de módulos no framework, requer o uso de uma base de dados preparada para armazenar as informações a serem manipuladas. O diagrama de classes apresentado na Figura 4.4 representa o modelo conceitual proposto para organizar essas informações. As classes representadas em branco são utilizadas para armazenar informações sobre os módulos que estão disponíveis para serem usados nas aplicações. Quando o módulo é carregado no servidor em que o framework estiver executando, ele deve inserir essas informações com base no seu arquivo de configuração. Quando é retirado do servidor, o módulo remove essas informações e sinaliza às aplicações que o utilizam sobre sua indisponibilidade (atributo serverAvailable na classe ApplicationModule). Se voltar a ser disponibilizado no mesmo servidor, o módulo sinaliza às aplicações que está disponível e insere suas informações novamente na base de dados do framework. 


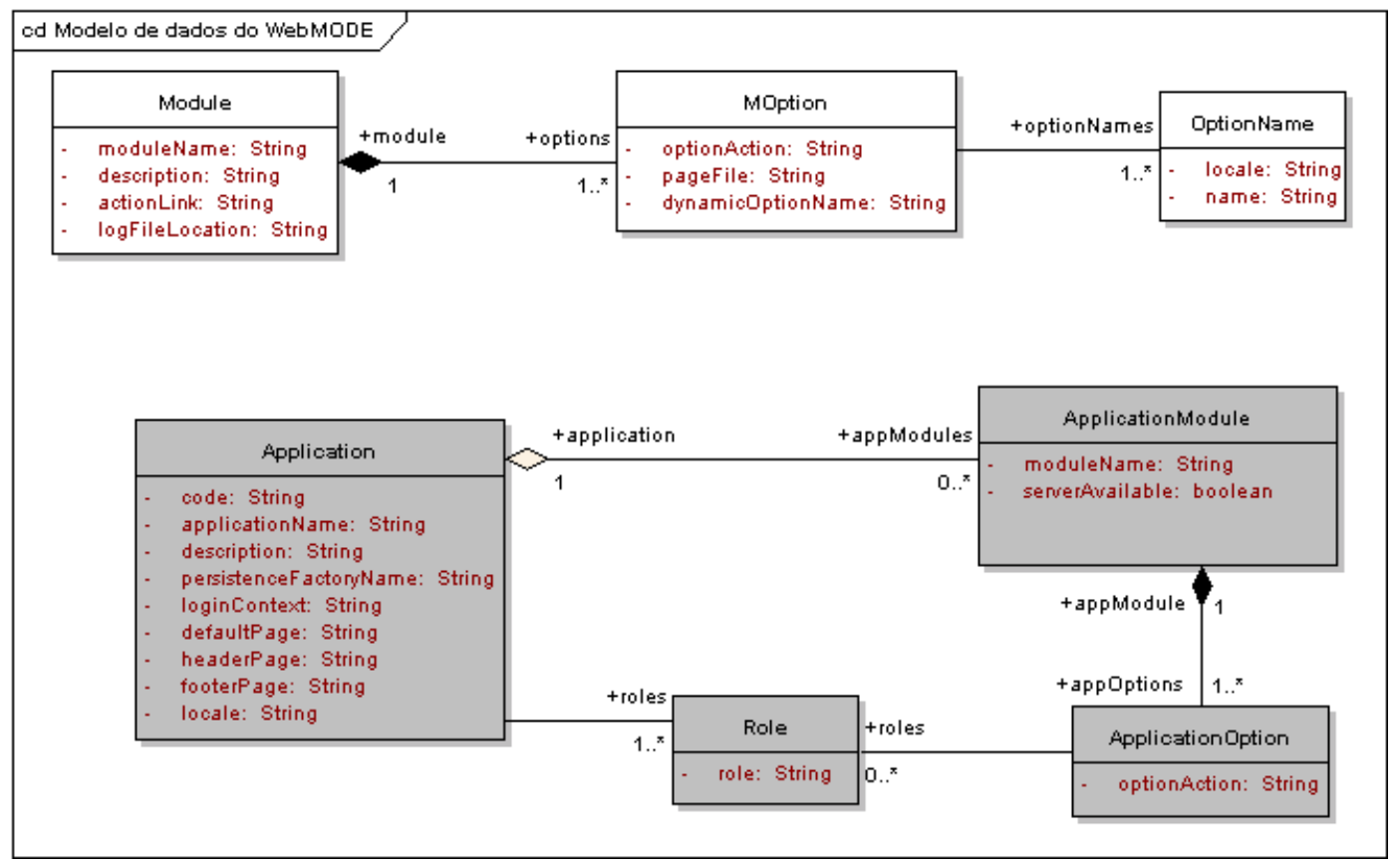

Figura 4.4 - Modelo de dados utilizado base do framework WebMODE

Ainda na Figura 4.4, as classes em cinza são utilizadas para gerenciar as aplicações instanciadas sobre o framework. O núcleo do framework consulta as informações dessas classes tanto para construir a interface gráfica da aplicação, a partir dos módulos e opções disponíveis e dos papéis que têm acesso a cada opção, quanto para autorizar o usuário a acessar uma opção da aplicação. A classe Role é a que garante a definição de papéis para cada aplicação.

As informações desse modelo de dados são gerenciadas por componentes de negócio que fazem parte do núcleo do framework: um componente de núcleo (Core) e um de aplicação (Application).

O componente de núcleo oferece serviços para:

- adicionar/remover módulos, que é utilizado pelo próprio módulo para atualizar sua disponibilidade;

- obter o caminho de acesso ao módulo, quando o "Controlador central" está atendendo uma requisição;

- obter opções de acesso disponíveis na aplicação (para construir a interface do usuário);

- autorizar usuário (com base no papel assumido e na opção que ele está acionando); 
- obter dados de uma aplicação (usados na lógica do "Controlador central");

- listar todas as aplicações do servidor; e

- instanciar a aplicação de instanciação do framework.

O componente de aplicação oferece serviços para manipular as aplicações, tais como adicionar/remover/atualizar aplicações, listar aplicações, obter e atualizar a lista de módulos da aplicação, obter e atualizar a lista de opções de um módulo (para configurar quais papéis estão relacionados a quais opções do módulo), entre outras. Esse componente dá suporte ao funcionamento da aplicação de instanciação do framework.

A sessão do usuário é utilizada para armazenar informações como o nome (username) e papel assumido pelo usuário, o identificador da aplicação acessada, o idioma da aplicação e a informação codificada da autenticação do usuário. Essas informações são utilizadas pelo “Controlador central” para identificar a aplicação, o usuário, o módulo e a opção da requisição.

O diagrama apresentado na Figura 4.5 mostra a colaboração entre os elementos do WebMODE num nível mais baixo de projeto Entretanto, a implementação desse projeto ainda requer o refinamento dessa arquitetura até chegar ao projeto de implementação que inclui os recursos de tecnologia a serem utilizados.

O funcionamento correto exigido do framework ainda requer, como parte do núcleo, a presença de dois módulos: um módulo de autenticação que deve ser tratado de forma especial pelo "Controlador de módulo" para gerenciar a sessão do usuário autenticado, e um módulo para gerenciar aplicações, que é utilizado para compor a aplicação de instanciação do framework. Esse último módulo utiliza o componente de aplicação (Application) do núcleo do framework.

Na sessão seguinte, o projeto do WebMODE é especializado para uma abordagem tecnológica específica com o objetivo de criar e testar uma versão funcional desse framework. No entanto, é importante salientar que o projeto arquitetural e conceitual do WebMODE, como descrito até este ponto, pode ser implementado utilizando outras abordagens tecnológicas. 


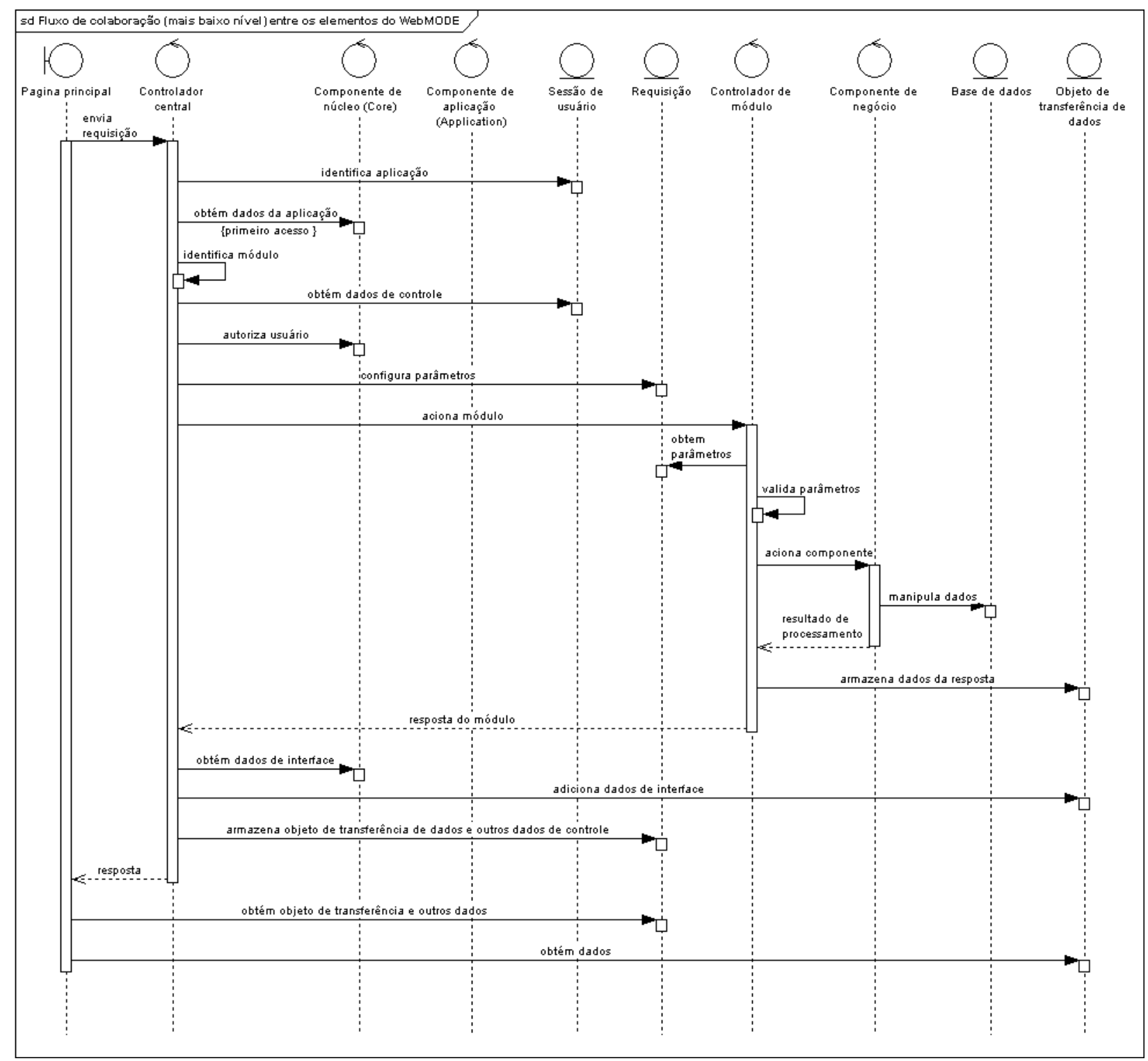

Figura 4.5 - Colaboração de mais baixo nível entre os elementos do WebMODE

\subsection{Exemplo de abordagem tecnológica para uma implementação do WebMODE}

A análise dos requisitos, dos casos de uso e da proposta arquitetural e de projeto do WebMODE, permitiu identificar aspectos importantes para a escolha de uma abordagem tecnológica a ser adotada no desenvolvimento de uma versão funcional desse framework. Para diferenciar da proposta conceitual apresentada até agora, essa implementação será chamada de framework WebMODE-J2EE. Na Tabela 4.1 apresenta-se uma relação entre os requisitos estabelecidos para o framework (Seção 4.3.1) e as tecnologias escolhidas para suportá-los. 
Tabela 4.1 - Relação entre os requisitos do framework e a tecnologia adotada.

\begin{tabular}{|c|l|}
\hline \hline Requisito & \multicolumn{1}{|c|}{ Tecnologia adotada para suportar o requisito } \\
\hline \hline 2 & $\begin{array}{l}\text { Enterprise Javabeans de Sessão (SessionBeans) localizados via JNDI (Java Naming and } \\
\text { Directory Interface) }\end{array}$ \\
\hline 3 & XML para descrever o módulo e Java Servlets para carregar o módulo no servidor \\
\hline 4 & Java Servlets \\
\hline 5 & JAAS (Java Authentication and Authorization Service) \\
\hline 8 & Java Servlets (multithreaded) \\
\hline 9 & $\begin{array}{l}\text { XHTML (Extensible HyperText Markyp Language), JSPs (Java Server Page), JSTL (Java } \\
\text { Standard Tag Library) e Javabeans }\end{array}$ \\
\hline 10 & Plataforma Java \\
\hline 11 & Persistência de objetos com Hibernate e padrão de projeto DAO (Data Access Object) \\
\hline 12 & $\begin{array}{l}\text { Agrupamento das tecnologias JSPs, XHTML, JSTL, Java Servlets, Enterprise Javabeans } \\
\text { e objetos Hibernate. }\end{array}$ \\
\hline 13 & Arquitetura e plataforma J2EE \\
\hline \hline
\end{tabular}

Para manter a organização interna padronizada e alcançar um bom nível de separação de interesses, o WebMODE-J2EE foi desenvolvido sobre uma arquitetura em camadas utilizando a padronização de componentes da plataforma J2EE (Sun, 2006).

A plataforma J2EE oferece uma arquitetura de componentes bem definida para o projeto, desenvolvimento e distribuição de aplicações enterprise (requisito 13) (Armstrong et al., 2005). Uma aplicação J2EE pode ser mais simples de desenvolver/manter porque sua lógica é organizada em componentes reusáveis sustentados por um modelo de aplicação distribuído e multicamadas. Os componentes J2EE compreendem aplicações clientes e Applets, que atuam na camada de cliente, Java Servlets e Java Server Pages (JSP) (Hall \& Brown, 2003), que atuam na camada de Web, e Enterprise JavaBeans (EJB) (Roman et al., 2002), que atuam na camada de negócios.

Os componentes J2EE seguem a especificação J2EE para serem implantados e gerenciados por um container (parte do servidor J2EE). Esse container é responsável por gerenciar os componentes e garantir sua robustez utilizando serviços internos que incluem suporte para redundância, monitores para alta disponibilidade, serviços de aplicações distribuídas de alto desempenho e suporte para acesso à base de dados e controle de transação. Usando essa tecnologia, programadores podem se beneficiar dos serviços oferecidos pelo container e se concentrar na lógica de negócio, sem ter que implementar funcionalidades de gerenciamento de 
baixo nível para garantir robustez dos componentes e da aplicação, além de manter o código naturalmente padronizado.

Uma vantagem especial da tecnologia J2EE para o WebMODE-J2EE é o hot deployment (Armstrong et al., 2005): os módulos do framework podem ser adicionados (ou removidos) a uma aplicação sem a necessidade de "parar" a execução do servidor no qual ele executa. Uma vez que o módulo é disponibilizado, ele é automaticamente reconhecido e pode ser utilizado em qualquer aplicação instanciada sobre o framework.

Para criar independência do SGBD (requisito 11), foi utilizada uma técnica de mapeamento objeto-relacional (ORM - Object Relational Mapping) (Bauer \& King, 2004). Essa técnica permite o mapeamento de classes de um modelo orientado a objetos para um modelo de dados relacional, utilizando um esquema baseado em SQL (Structured Query Language). A solução de ORM utilizada no WebMODE foi o Hibernate (Hibernate, 2005). Ele oferece uma API para realizar as operações de persistência com as classes Java, uma linguagem e uma API para a realização de consultas, um mecanismo para criação dos metadados que fazem a relação entre as classes persistentes e as tabelas da base de dados, e a implementação do ORM, que é responsável por interagir com os objetos transacionais e efetuar as operações de transformação dos dados entre os modelos.

Detalhes sobre a implementação do framework WebMODE-J2EE e sobre a aplicação para instanciação desse framework são descritos nas subseções seguintes.

\subsubsection{Implementação}

A implementação do MVC no WebMODE-J2EE foi baseada no padrão J2EE MVC-2 (Alur et al., 2003):

- os elementos que fazem papel de controlador ("Controlador central" e "Controlador de módulo") são implementados utilizando Java Servlet;

- os elementos que representam a visão ("Página principal” e visões específicas dos módulos) são implementados utilizando JSP, em conjunto com a biblioteca de marcação padrão do Java (JSTL) (Geary, 2002) para a formatação dos dados a serem apresentados;

- os elementos de modelo (componentes de negócio da aplicação) são implementados utilizando EJB. 
A transferência de dados da camada de controlador para a camada de visão foi feita utilizando componentes JavaBean padrão ("Objeto de transferência de dados”).

Na camada de modelo, os componentes EJB manipulam objetos Hibernate para persistência de dados. Esses objetos são implementados sob o padrão J2EE DAO (Alur et al., 2003) que sugere o encapsulamento do código de acesso a uma fonte de dados ${ }^{14}$ para garantir sua independência com o código da aplicação de tal forma que, se a fonte de dados for substituída, por exemplo, de um SGBD relacional para um orientado a objetos, a aplicação não precisa sofrer alterações. $\mathrm{O}$ uso desse padrão em conjunto com o Hibernate facilita a troca desse mecanismo de persistência por outro porque o DAO esconde as rotinas de acesso às APIs do Hibernate. O modelo conceitual apresentado no diagrama de classes da Figura 4.4 (pág. 64) foi expandido para um modelo de dados e implementado utilizando objetos Hibernate que são disponibilizados na forma de serviço no servidor de aplicação ${ }^{15}$.

O núcleo do framework WebMODE-J2EE é empacotado como um aplicação enterprise (.ear) porque envolve controladores, visões e componentes de negócio. Os módulos podem ser empacotados e disponibilizados como aplicações enterprise (.ear) ou como aplicações Web (.war), quando não possuírem componentes EJB próprios. O pacote de um módulo deve incluir nas suas bibliotecas, uma API utilitária (core-lib.jar) distribuída juntamente com o WebMODE-J2EE. Essa API dá suporte à extensão dos pontos variáveis do framework.

\subsubsection{Interface gráfica}

No WebMODE-J2EE, a "Página principal" (que faz parte do núcleo do framework) foi desenvolvida utilizando um documento JSP (template.jsp) escrito em XHTML (W3C, 2000). Esse documento é processado por uma folha de estilos XSLT (W3C, 1999b) para gerar a interface da aplicação. O documento XSLT é quem dá o formato da apresentação das aplicações, podendo ser modificado de acordo com os interesses de quem está desenvolvendo a aplicação WebMODE.

A "Página principal" é formada por quatro áreas (visões componentes da visão principal) preenchidas com o resultado do processamento de outros documentos JSPs (Silva \& Moreira, 2005a). Na Figura 4.6 apresenta-se o conteúdo do documento (template.jsp) que implementa a

\footnotetext{
${ }_{15}^{14}$ Fonte de dados é uma tradução de "datasource" no inglês.

${ }^{15} \mathrm{O}$ servidor de aplicação utilizado para testar a implementação do WebMODE foi o JBoss 3.x. (JBossPortal, 2005)
} 
"Página principal". Esse documento é processado pela folha de estilos (template.xsl) e o resultado desse processamento é incluído no corpo de um documento HTML, que é visualizado no navegador do usuário.

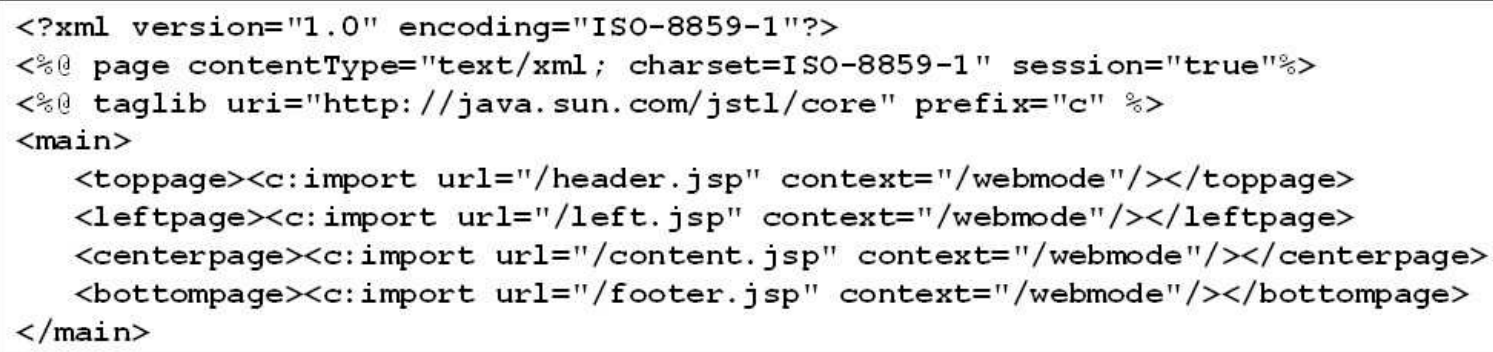

Figura 4.6 - Documento template.jsp que representa a visão principal do WebMODE-J2EE

As áreas de cabeçalho (toppage) e rodapé (bottompage) funcionam como containeres para inclusão de documentos Web específicos de cada aplicação. Se a aplicação não define nenhum documento para essas áreas, o próprio WebMODE-J2EE apresenta cabeçalho e rodapé padrão.

A área da lateral esquerda (letfpage) renderiza os itens de navegação armazenados no "Objeto de transferência de dados" pelo "Controlador central". Esses itens são obtidos com base na informação dos módulos utilizados na aplicação e no papel que o usuário assume no momento da requisição, sendo que somente as opções que o usuário pode acessar são disponibilizadas. Os itens de navegação são apresentados em blocos que organizam as funcionalidades da aplicação. A localização de uma opção nos blocos depende da forma como ela foi configurada no módulo: uma opção pode definir um novo bloco ou ser colocada no bloco principal, no de tarefas administrativas ou num bloco específico. A configuração dessas opções é feita no arquivo de configuração de módulos, que no WebMODE-J2EE é implementado por um documento XML (um exemplo desse documento é apresentado no capítulo seguinte).

A área central (centerpage) funciona como um container para o conteúdo dinâmico gerado a partir das interações com os módulos. O documento JSP a ser incluído nessa área é armazenado no "Objeto de transferência de dados" pelo "Controlador de módulo". Esse documento representa uma visão do módulo.

As quatro áreas que formam a "Página principal" são destacadas na Figura 4.7: (a) e (b) são o cabeçalho e o rodapé, respectivamente; (c) é a área lateral esquerda e (d) é a área central. A 
mudança na folha de estilos ou em cada um dos documentos JSPs incluídos nessas quatro áreas permite a mudança do layout da aplicação (por exemplo, criando skins diferenciados).

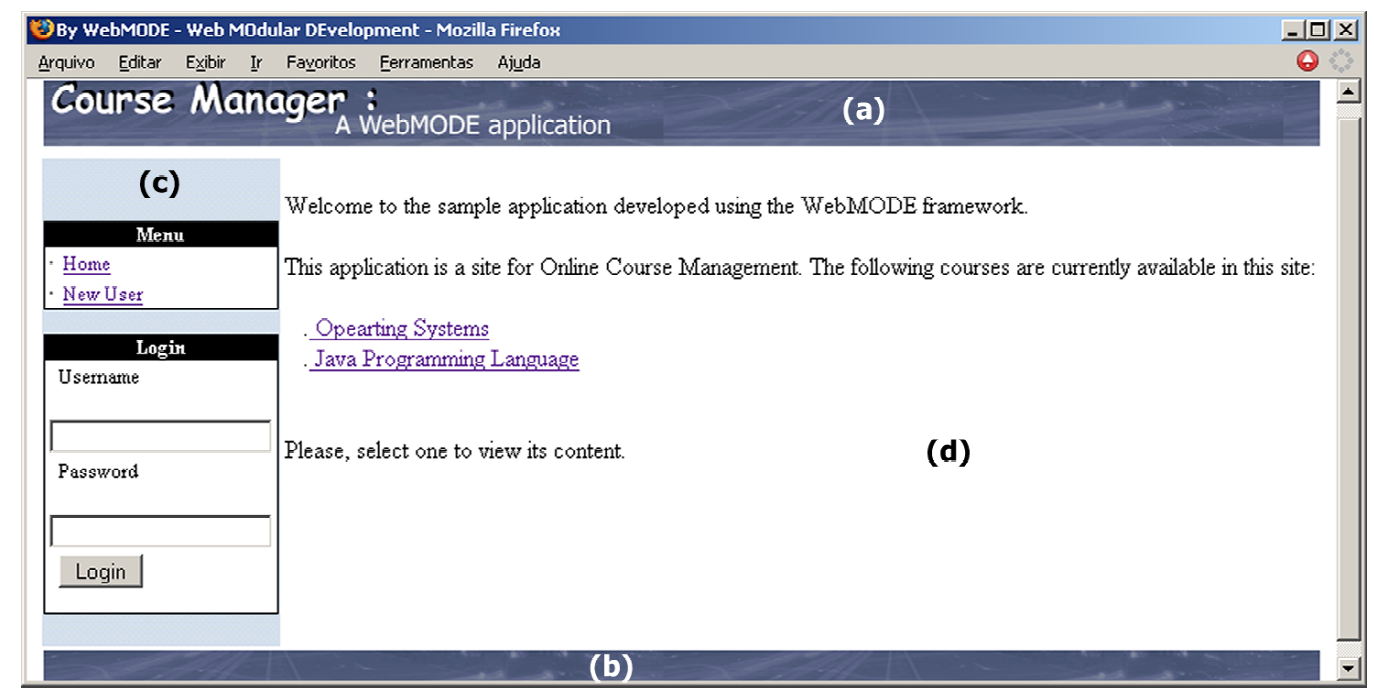

Figura 4.7 - Página principal de uma aplicação instanciada sobre o WebMODE-J2EE

\subsubsection{Autenticação e autorização}

O WebMODE-J2EE oferece uma implementação do módulo de autenticação (LoginModule) para ser utilizada em suas aplicações. Esse módulo foi implementado utilizando o serviço de autenticação e autorização oferecido pelo JAAS (Mahmoud, 2003).

O JAAS oferece um conjunto de APIs para autenticação e controle de acesso de usuários sobre componentes da plataforma Java. Sua API de autenticação, construída sobre o framework PAM (Pluggable Authentication Module) (Mahmoud, 2003), permite o uso de diferentes tecnologias de autenticação, por exemplo, baseada em sistemas operacionais, bases de dados específicas, LDAP $^{16}$, que podem ser alteradas sem mudar o código da aplicação. Isso é possível porque a tecnologia de autenticação é configurada externamente ao código da aplicação e relacionada com ele por meio da API JAAS.

As políticas de autenticação do JAAS são definidas em arquivos de configuração desse serviço (essa configuração é dependente do servidor de aplicação utilizado ${ }^{17}$ ) e podem ser referenciadas nas aplicações por meio de seus nomes no JNDI. Detalhes da implementação e uso do JAAS não

\footnotetext{
${ }^{16}$ Lightweight Directory Access Protocol - http://www.ldap.org.br/

17 No JBoss (versão 3.x), o arquivo utilizado é o login-config.xml localizado no diretório JBOSSHOME/server/default/conf (no lugar de default também pode serall ou minimal).
} 
são tratados nesta tese, mas podem ser encontrados nos documentos do portal da Sun (Sun, 2006;Mahmoud, 2003).

Apesar desse módulo de autenticação ser parte do núcleo do WebMODE-J2EE, sua ativação nas aplicações é opcional, já que existem aplicações que não exigem nenhuma forma de autenticação (todas as funcionalidades podem ser acessadas por usuários anônimos).

A autorização dos usuários no WebMODE-J2EE também foi implementada com base nos conceitos de autorização do JAAS: o papel assumido por um usuário autenticado é utilizado para verificar se a opção acionada por este usuário (na interface da aplicação) pode ou não ser acessada por ele. Essa verificação é feita a partir da configuração dos módulos da aplicação que estabelece a relação entre as opções dos módulos e os papéis de usuário que tem permissão de acesso sobre elas. A configuração dos módulos é apresentada na Seção 4.4.2.

Os papéis de usuário são configurados para cada aplicação (essa configuração também pode ser vista na Seção 4.4.2). Porém, no WebMODE-J2EE são definidos três (3) papéis comuns a todas as aplicações: papel de administrador (admin), papel de usuário autenticado (user) e papel de usuário anônimo (nobody).

Os usuários de uma aplicação instanciada sobre o WebMODE-J2EE podem assumir mais de um papel, mas somente um deles pode estar sendo utilizado num determinado momento. Por essa razão, o módulo de autenticação executa o processo de login em dois passos: no primeiro passo, o usuário fornece seu login (username) e sua senha pessoal, enquanto no segundo, ele seleciona o papel com o qual pretende utilizar a aplicação. Uma vez autenticado, o usuário pode ter a opção de alterar seu papel sem fazer login novamente, utilizando a opção "Change Login" do módulo de autenticação (LoginModule). A escolha do papel é importante porque a interface da aplicação é construída com base nesse papel e na configuração das opções dos módulos. Na Figura 4.8 são apresentadas duas interfaces de uma aplicação instanciada sobre o WebMODEJ2EE: a primeira (a) é acessada por um usuário que possui o papel de administrador (admin), e a segunda (b), pelo mesmo usuário com o papel de usuário autenticado (user). Essa figura mostra como os itens de navegação da aplicação mudam de acordo com o papel assumido pelo usuário. 


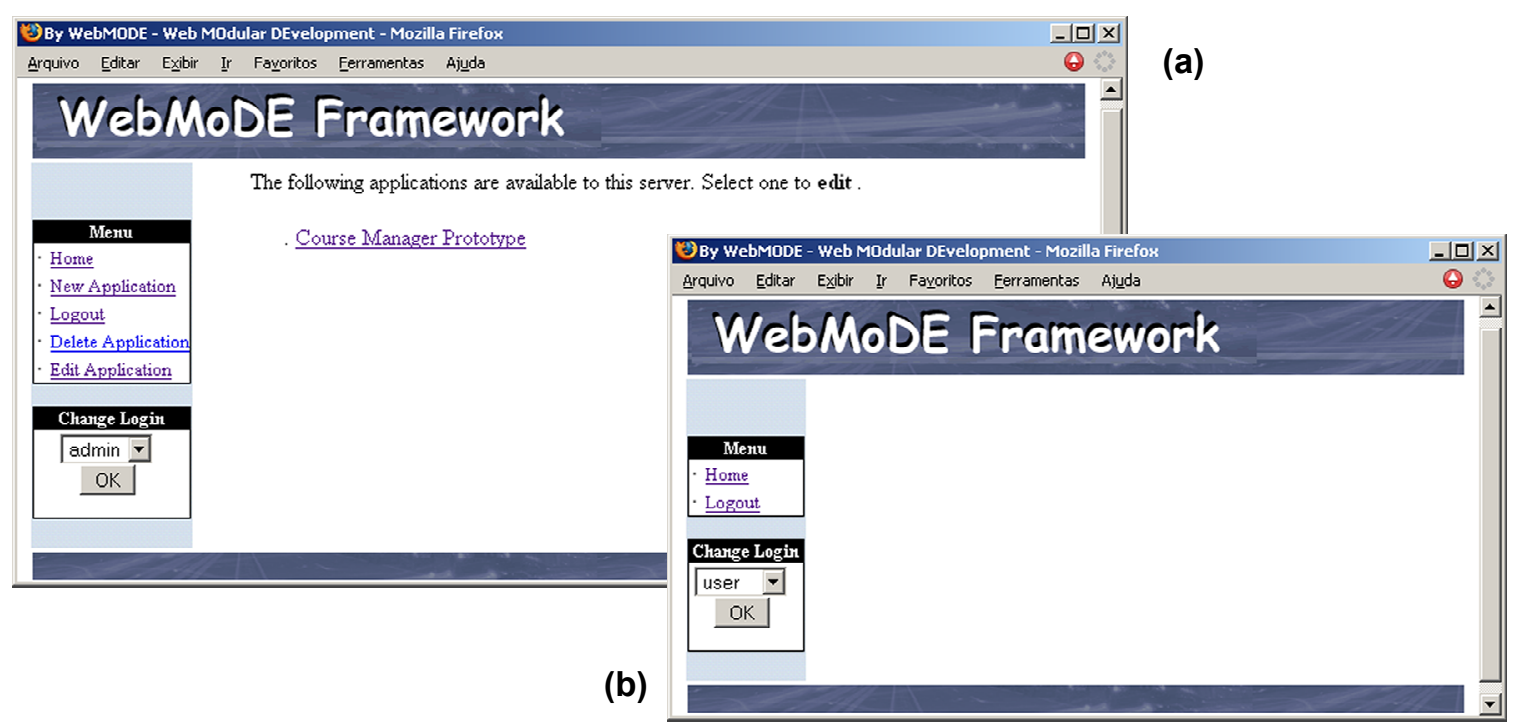

Figura 4.8 - Interfaces de aplicação WebMODE acessadas por usuário admin (a) e user (b).

\subsubsection{Extensão do framework WebMODE-J2EE}

A extensão do WebMODE-J2EE para a criação de aplicações personalizadas dá-se pela implementação de módulos específicos para essas aplicações. No entanto, a criação desses módulos precisa seguir algumas regras para que a comunicação com o "Controlador central" (que gerencia as requisições) seja efetiva.

O "Controlador de módulo" deve ser implementado a partir de uma classe abstrata (ServletModuleController) oferecida pela API utilitária do framework (core-1ib.jar). Essa classe possui um método template, baseado no padrão Template Method (Gamma et al., 1994), que recebe a requisição do controlador central, organiza os parâmetros da requisição HTTP, e invoca a execução dos métodos para validar os parâmetros e executar a lógica do módulo. Esses dois métodos são definidos como abstratos na classe abstrata e, portanto, precisam ser implementados nas suas subclasses.

Os componentes que executam a lógica do módulo também precisam seguir regras para serem desenvolvidos. Na API utilitária do WebMODE-J2EE há uma classe abstrata (BeanSupport) que é utilizada como superclasse da classe dos componentes de negócio. Ela define métodos úteis para configurar o gerenciador de persistência, abrir e fechar conexões e descarregar dados da memória para o gerenciador de persistência e criar referências para outros componentes. 
Em relação aos documentos JSPs, a única regra a ser seguida está relacionada com o formato desses documentos. Eles devem ser escritos em XHTML e devem incluir marcação (tags) somente para o corpo do documento (ou seja, somente conteúdo que é colocado dentro da tags $<$ body $></$ body $>$ ).

\subsubsection{Aplicação para instanciação do WebMODE-J2EE}

O WebMODE-J2EE oferece, como parte do seu núcleo, um módulo com funcionalidades para a instanciar aplicações a partir dessa implementação do framework WebMODE. Esse módulo (ApplicationCreatorModule) é utilizado juntamente com o módulo de autenticação (LoginModule) para definir uma aplicação - Application Manager - que permite o uso de interfaces gráficas para instanciar aplicações sobre esse framework (Silva \& Moreira, 2005c) .

A aplicação "Application Manager" é instanciada automaticamente pelo "Controlador central" do WebMODE-J2EE quando ele identifica que ela ainda não está disponível no servidor. Uma interface dessa aplicação pode ser vista na Figura 4.8a. Por meio dessa aplicação padrão do framework, um administrador pode criar, editar ou remover aplicações.

Como ilustrado na Figura 4.9, as seguintes informações são necessárias para se criar uma nova aplicação utilizando a aplicação Application Manager:

- identificador, nome e descrição da aplicação;

- arquivos JSP com conteúdo a ser apresentado no cabeçalho e rodapé (opcional) e com conteúdo a ser apresentado na região central da página de entrada;

- papéis da aplicação, que na figura incluem os papéis default do WebMODE-J2EE e os papéis específicos da aplicação que está sendo instanciada (teacher and student);

- nome do gerenciador de persistência Hibernate configurado para os objetos desta aplicação no JNDI (Persistence Manager Factory); e

- nome da política de autenticação (Login Context) a ser utilizada.

Tanto a política de autenticação como o gerenciador de persistência devem ser configurados antes da instanciação da aplicação. O nome da política de autenticação é aquele utilizado no arquivo de configuração do JAAS (que é dependente de cada servidor de aplicação). O nome do 
gerenciador de persistência é o utilizado na configuração do Hibernate ${ }^{18}$ (que também depende do servidor de aplicação utilizado)

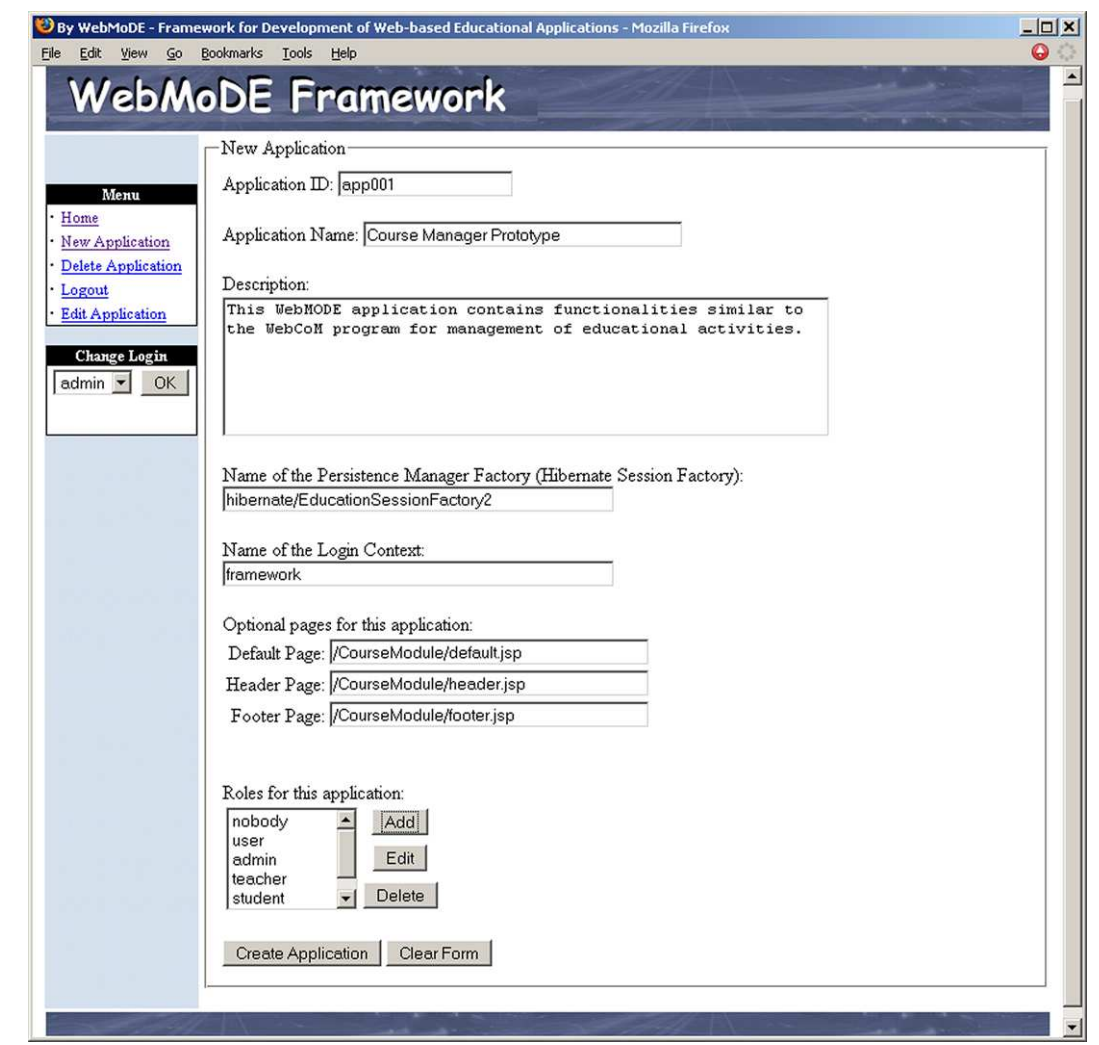

Figura 4.9 - Interface para a criação de uma aplicação WebMODE-J2EE

Cada aplicação deve utilizar um gerenciador de persistência diferente, pois esse gerenciador corresponde a uma base de dados específica para a aplicação (definida pela fonte de dados utilizada na sua configuração). Porém, o mesmo conjunto de objetos Hibernate pode ser reusado para configurar mais de um gerenciador de persistência, o que equivale a criar mais de uma base de dados com as mesmas tabelas. Essa estratégia permite criar aplicações independentes dentro do mesmo domínio ${ }^{19}$.

Após a criação da aplicação, ela deve ser editada para incluir as funcionalidades desejadas. A edição de uma aplicação permite a seleção e a configuração dos módulos. Na fase de seleção, cuja interface é apresentada na Figura 4.11, os módulos desejados são escolhidos a partir de uma lista com todos os módulos disponíveis no framework. Posteriormente, cada módulo selecionado

${ }^{18}$ No servidor JBoss, o Hibernate é configurado no arquivo jboss-service.xml que acompanha os objetos persistentes.

${ }^{19} \mathrm{O}$ WebMODE-J2EE fornece cinco (5) gerenciadores de persistência já configurados para o modelo de objetos para o domínio de gerenciamento de atividades. Esses gerenciadores são nomeados da seguinte forma EducationalSessionFactory1, EducationalSessionFactory2, etc. 
pode ser configurado, como apresentado na Figura 4.10. Essa configuração envolve a ligação entre as opções do módulo e os papéis de usuário que podem acessar essas opções.

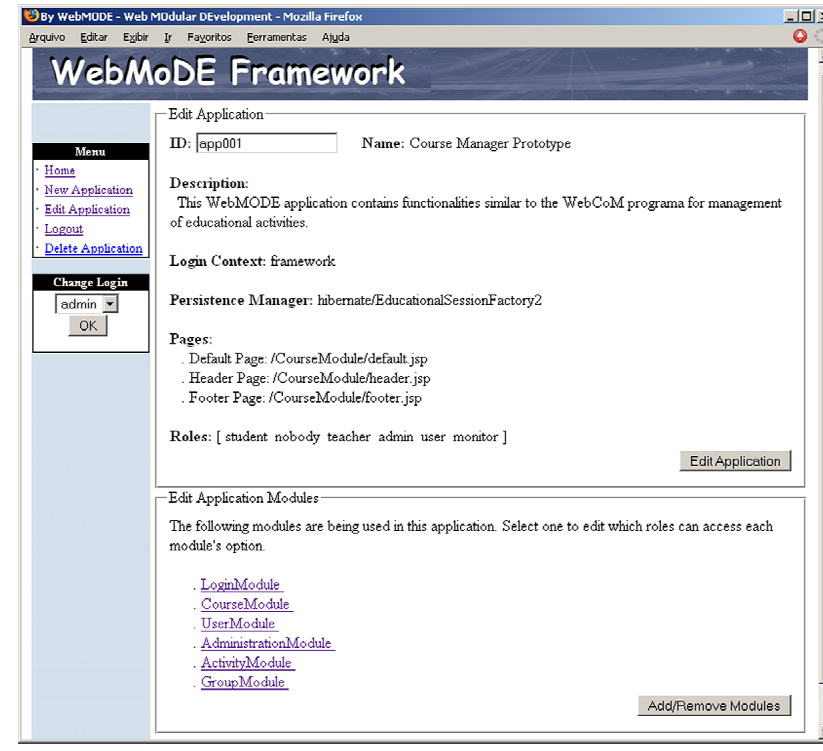

(a)

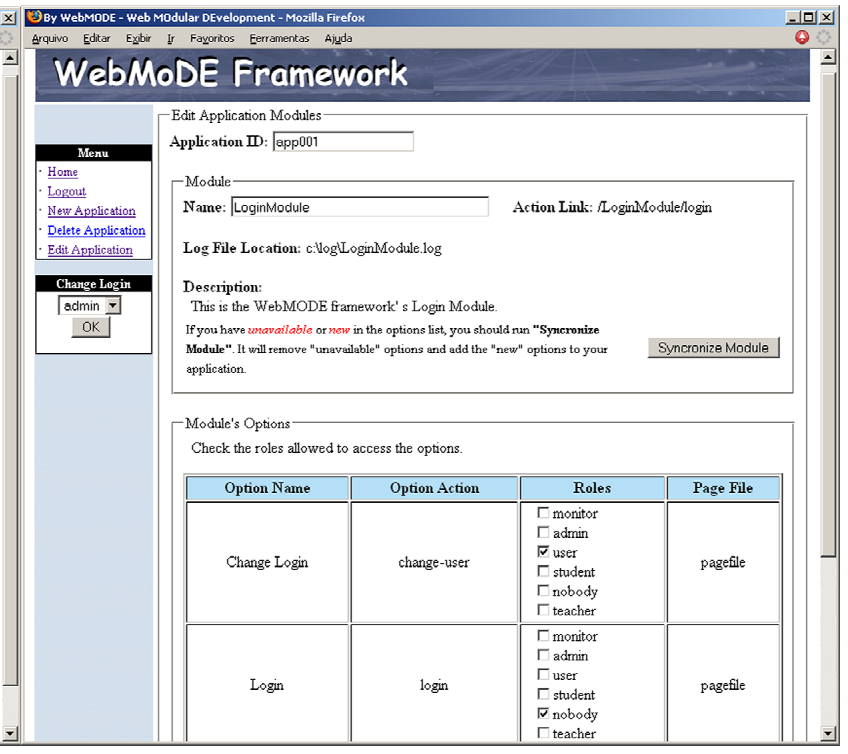

(b)

Figura 4.10 - Interface para edição de aplicação (a) e para configuração de módulo (b)

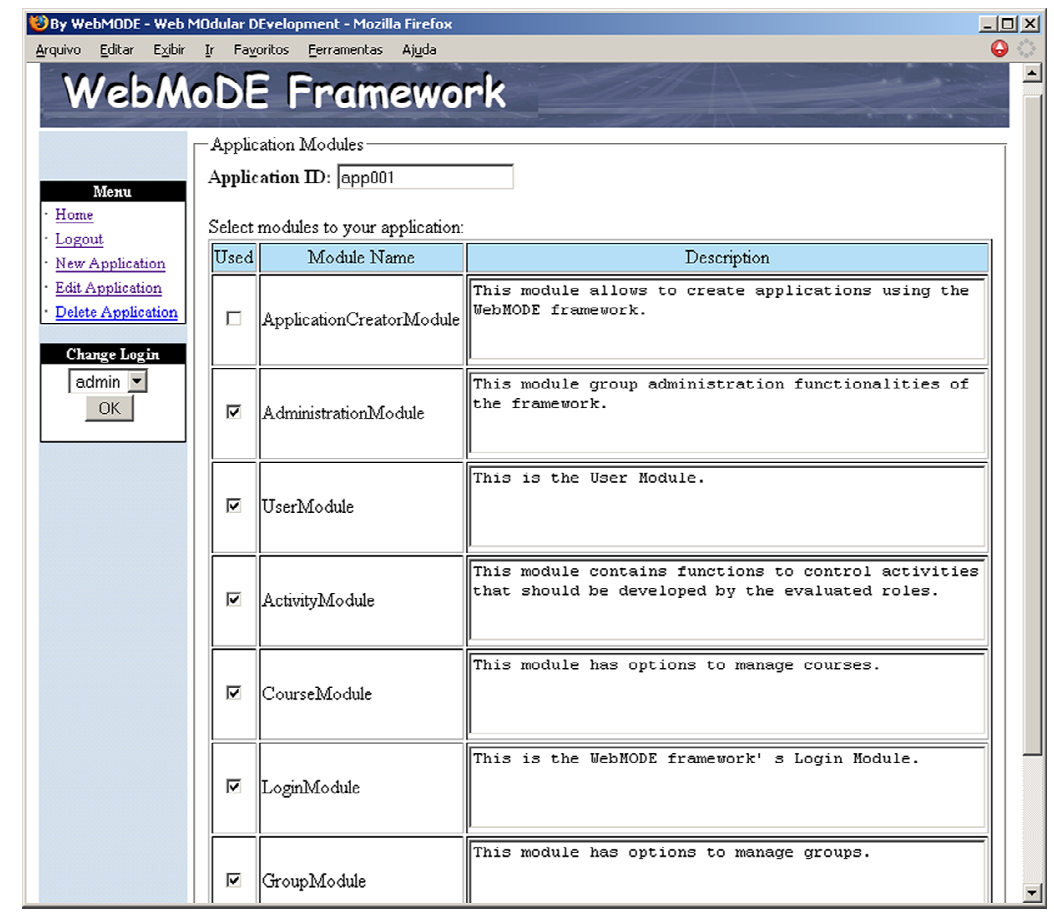

Figura 4.11 - Interface para seleção de módulos 
As informações provenientes da configuração dos módulos são usadas para estabelecer as regras de autorização e para construir a interface do usuário, tal que o mesmo só possa visualizar as opções que ele pode acessar na aplicação (de acordo com o seu papel).

As aplicações instanciadas sobre o WebMODE-J2EE podem ser acessadas por meio de uma página dedicada, como apresentado na Figura 4.12. A url dessa página, que é distribuída com o framework, é http: // nome do host:8080/webmode/.

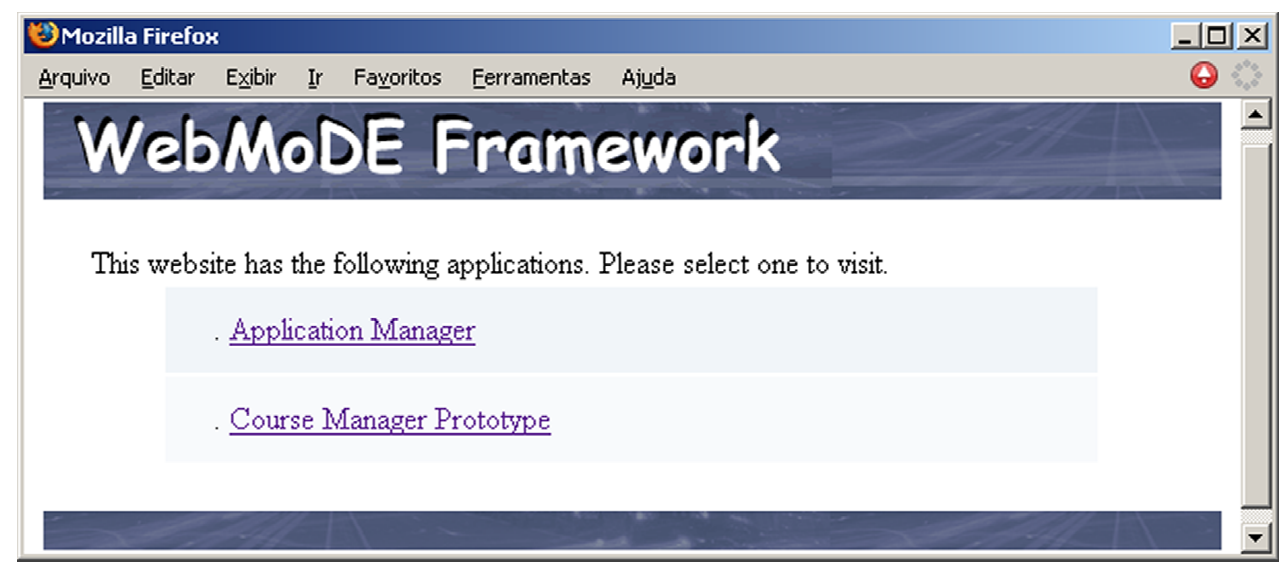

Figura 4.12 - Interface do WebMODE-J2EE com a lista de aplicações disponíveis

\subsection{Considerações finais}

O framework WebMODE, apresentado neste capítulo, foi proposto com o objetivo de aumentar a flexibilidade das aplicações baseadas na $W e b$ principalmente em relação às possibilidades de extensão e adaptação de suas funcionalidades. Por ter sido inicialmente pensado para a construção de sistemas educacionais, os requisitos desse framework foram estabelecidos com base nas características de flexibilidade identificadas a partir dos sistemas educacionais analisados no Capítulo 2. Somente após a análise dos seus requisitos é que a proposta do framework foi abstraída para o desenvolvimento de aplicações Web em geral.

A vantagem dessa proposta de framework é que as aplicações são construídas de acordo com os interesses dos seus usuários, já que os módulos de funcionalidades podem ser selecionados e configurados para formar as aplicações. Se os módulos já implementados não oferecem a funcionalidade desejada, o framework dá ao usuário a possibilidade de criar módulos específicos ou modificar os implementados para atender seus objetivos. 
Para facilitar a instanciação do WebMODE no nível caixa-branca, que considera o desenvolvimento de módulos para as aplicações, foi definido um processo de instanciação que é apresentado no Capítulo 5. Assim como neste capítulo, que apresentou a proposta conceitual do framework independente da sua implementação, o processo de instanciação do WebMODE também separa a especificação de módulos da sua implementação. 


\section{.}

\subsection{Considerações iniciais}

Um dos principais problemas do desenvolvimento de aplicações baseadas em framework é a dificuldade de instanciação desse tipo de software. Diferente do desenvolvimento de aplicações convencionais, que contam com processos de software bem estabelecidos, tanto o desenvolvimento baseado em framework quanto o de aplicações baseadas na Web ainda encontram dificuldades pela falta de processos que auxiliem o desenvolvedor, principalmente nas atividades de especificação das aplicações (Bosch et al., 1999; Conallen, 2002).

Para evitar esse tipo de problema com o framework WebMODE, neste capítulo é descrito um processo de instanciação que foi proposto, com base nos processos de engenharia de software convencionais e de aplicações Web, para auxiliar o desenvolvedor a instanciar aplicações utilizando esse framework. Esse processo está focado, principalmente, na especificação e desenvolvimento dos módulos da aplicação, sendo que a especificação dos módulos permite sua codificação independente da tecnologia de desenvolvimento utilizada na implementação do framework WebMODE.

As atividades desse processo são ilustradas neste capítulo por artefatos da aplicação de gerenciamento de atividades didáticas, cujo funcionamento geral é apresentado no capítulo seguinte.

\subsection{Domínio: Gerenciamento de atividades didáticas via Web}

Durante a realização de um curso, várias atividades didáticas são conduzidas com o envolvimento de diversos atores da comunidade do curso tais como professores, administradores, estudantes e monitores. Geralmente, as informações produzidas por essas atividades podem ser coletadas e disponibilizadas para uso de outros usuários interessados. Elas podem ser utilizadas 
para avaliação do trabalho, feedback para os estudantes, ponto de partida para novas atividades e outras funções. De modo geral, esse volume de informações tende a ser alto e sua manipulação, muitas vezes, pode levar a uma sobrecarga de trabalho do responsável por essa tarefa.

A função de um sistema de gerenciamento de atividades via Web é facilitar o controle dessas informações, de modo que os usuários possam se concentrar na parte conceitual das atividades, deixando tarefas de mais baixo nível, como organizar a apresentação dos trabalhos dos estudantes, para o computador (Silva et al., 2000). Além disso, esse tipo de sistema permite descentralizar o gerenciamento das atividades permitindo, por exemplo, que professores e estudantes tenham acesso às atividades a partir de qualquer local que tenha um computador conectado à Internet.

Como observado no Capítulo 2, a maioria dos sistemas educacionais baseados na $\mathrm{Web}$ inclui a parte de gerenciamento de atividades nas suas funcionalidades. Entretanto, o gerenciamento de atividades é um dos aspectos que mais varia dentro de um sistema educacional porque ele fornece a base para a aplicação de diferentes métodos educacionais. Como essa foi uma das motivações para o início do trabalho reportado nesta tese, a avaliação do framework proposto foi realizada utilizando-se uma aplicação simplificada para o gerenciamento de atividades didáticas. As funcionalidades dessa aplicação, que foram baseadas nos recursos da ferramenta WebCoM (Silva \& Moreira, 2000a) (discutida no Capítulo 2), incluem: a criação e o gerenciamento de cursos e turmas, a definição de atividades (individuais e em grupo), o gerenciamento de usuários e membros de turma, a entrega de trabalhos, a alocação de revisores e a visualização de trabalhos postados no website do curso.

A instanciação dessa aplicação sobre o framework WebMODE-J2EE permitiu estabelecer e avaliar as atividades do processo de instanciação descrito neste capítulo.

\subsection{O processo de instanciação: visão geral}

Com base nas definições da literatura (Pfleeger, 2001; Ghezi et al., 2002), um processo de software tem por objetivo organizar as atividades de desenvolvimento de um sistema. Um processo define os fluxos de trabalho (workflows), as atividades e os artefatos que devem ser produzidos, de maneira que o desenvolvimento do sistema aconteça de forma documentada, organizada e eficiente. 
Para organizar a instanciação de aplicações sobre o WebMODE, foi definido um processo de instanciação baseado nos processos de desenvolvimento de aplicações existentes na literatura de engenharia de software (Cheesman \& Daniels, 2001; Pfleeger, 2001; Ghezi et al., 2002). Esse processo $^{20}$, apresentado na Figura 5.1, está organizado em três fluxos de trabalho gerais, que são: análise e especificação da aplicação, desenvolvimento de módulos, e instanciação e teste da aplicação. Cada um desses fluxos define um conjunto de atividades a serem seguidas e os artefatos a serem produzidos durante o desenvolvimento da aplicação. Esses fluxos são detalhados nas seções seguintes.

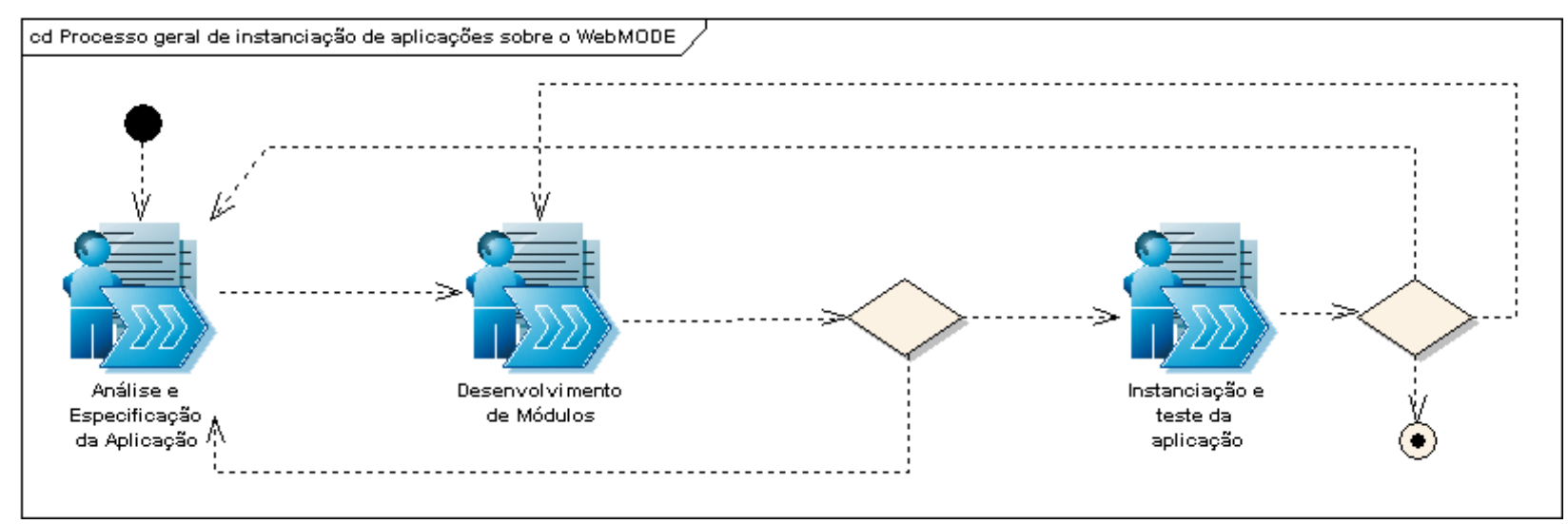

Figura 5.1 - Processo de instanciação de aplicações utilizando o WebMODE

De modo especial, o fluxo de especificação foi fortemente inspirado no processo $U M L$ Components (Cheesman \& Daniels, 2001), que se destina ao desenvolvimento de aplicações baseadas em componentes. Entretanto, as fases do processo UML Components (descritas no Capítulo 3) foram adaptadas, neste processo de instanciação, para permitir a especificação dos elementos necessários à instanciação de aplicações WebMODE. Esses elementos incluem os módulos e os componentes utilizados para executar a lógica de negócio da aplicação.

\subsection{Análise e especificação da aplicação}

O fluxo de análise e especificação, detalhado na Figura 5.2, é realizado pelo projetista da aplicação e envolve atividades que têm por objetivo analisar o domínio da aplicação que se pretende desenvolver e especificar os módulos que serão desenvolvidos. Os artefatos produzidos nessas atividades são utilizados como entrada do fluxo de desenvolvimento de módulos da aplicação. Cada atividade desse fluxo é descrita nas subseções seguintes.

\footnotetext{
${ }^{20}$ A notação utilizada nos gráficos do processo é baseada no metamodelo SPEM (Software Process Engineering Metamodel) (OMG, 2005).
} 


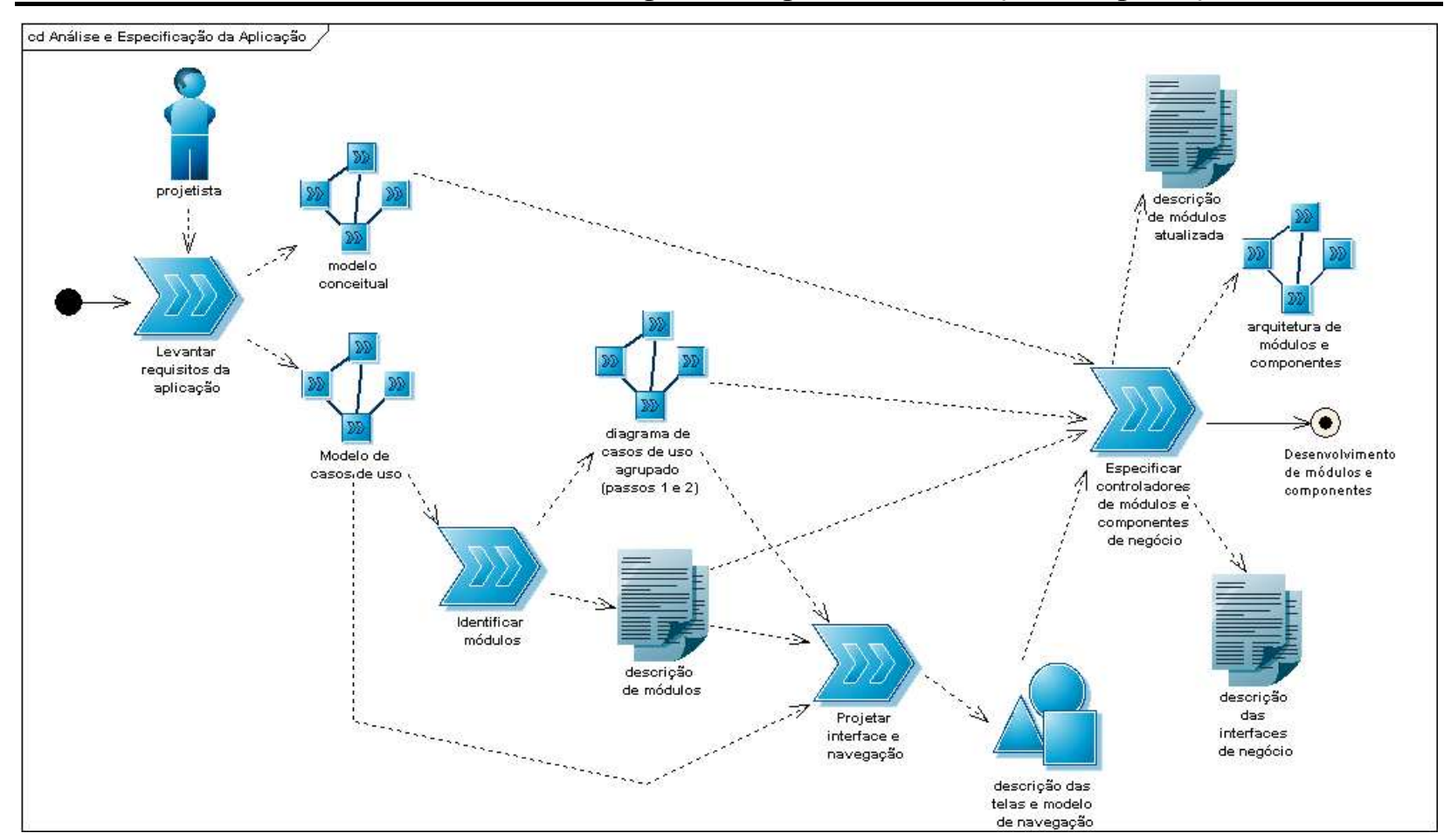

Figura 5.2 - Fluxo de análise e especificação da aplicação detalhado

\subsubsection{Levantar requisitos da aplicação}

Um requisito define uma propriedade ou um comportamento que um sistema de software deve possuir. Em geral, os requisitos de um sistema podem ser classificados em requisitos funcionais e não funcionais. Os requisitos funcionais expressam uma ação que o sistema deve executar (e os dados de entrada e saída dessa ação), enquanto os requisitos não funcionais expressam atributos e propriedades que devem ser contemplados no sistema (Ghezi et al., 2002).

$\mathrm{Na}$ literatura de engenharia de software é possível encontrar uma variedade de técnicas e métodos para elicitar, analisar e especificar requisitos de software com qualidade (Pfleeger, 2001; Ghezi et al., 2002). Também é possível encontrar diferentes formas de representar esses requisitos (Fowler \& Scott, 2000; Ghezi et al., 2002).

No processo para instanciação de aplicações sobre o framework WebMODE, a atividade de levantamento de requisitos pode ser feita com base na técnica ou método (da literatura) preferido pelo desenvolvedor da aplicação. No entanto, esse processo considera que os artefatos resultantes dessa atividade devem contemplar a especificação funcional do sistema. Com base num modelo de análise orientado a objetos, os artefatos mínimos necessários são: o modelo de casos de uso da aplicação (que inclui o diagrama e documento de descrição de casos de uso) e o modelo conceitual (que inclui o diagrama de classes e um glossário). 
Os casos de uso representam os requisitos funcionais de um sistema (Fowler \& Scott, 2000). Um caso de uso descreve uma funcionalidade do sistema por meio da modelagem (em passos detalhados) do diálogo entre o ator e o sistema. Esse tipo de representação é particularmente útil para facilitar a comunicação entre as pessoas envolvidas com o desenvolvimento do sistema e também com o usuário. Na Figura 5.3 é apresentado o diagrama de casos de uso (construído utilizando a linguagem UML (Unified Modeling Language) (Fowler \& Scott, 2000; UML, 2006)da aplicação para gerenciamento de atividades didáticas.

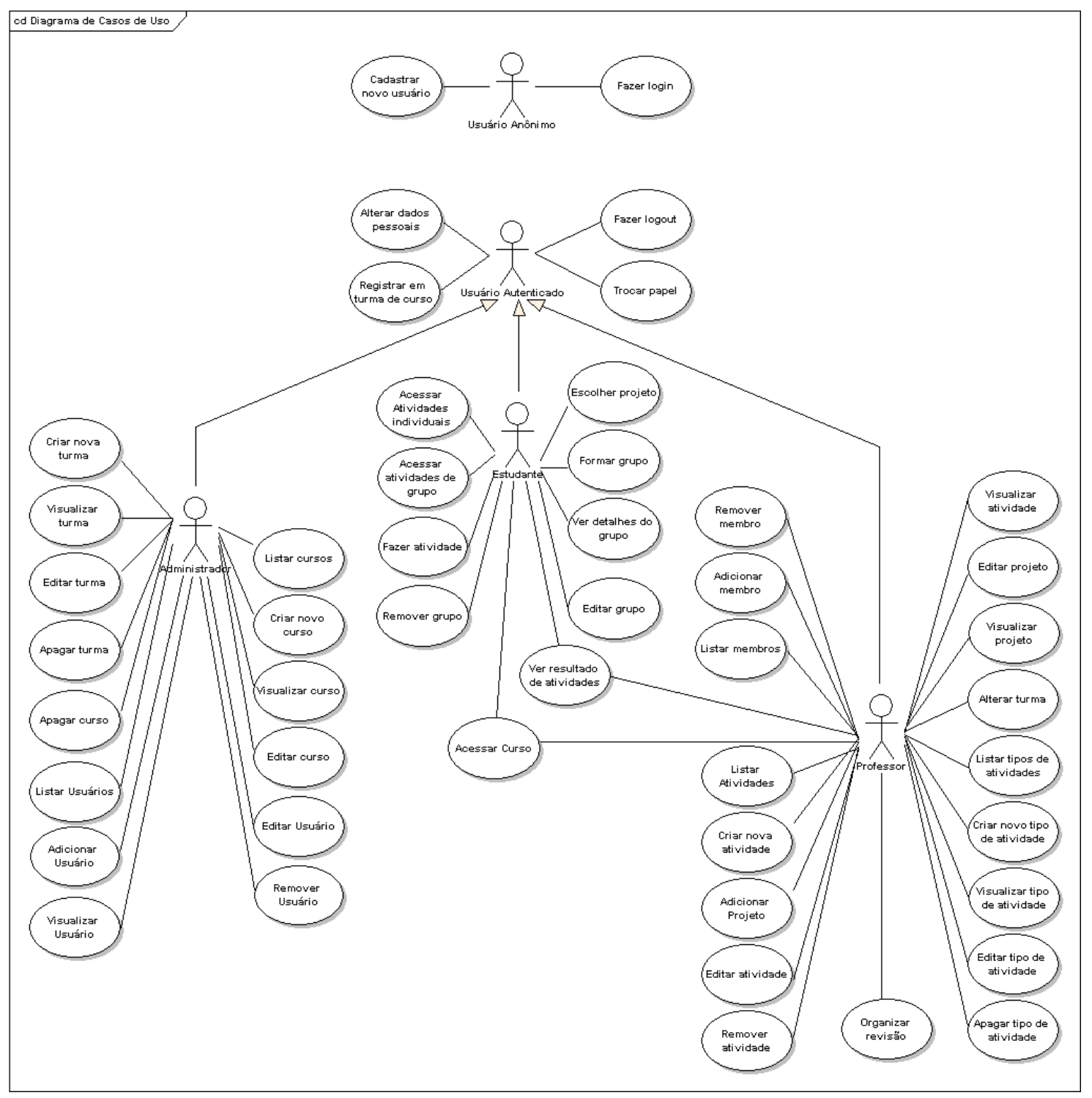

Figura 5.3 - Diagrama de casos de uso da aplicação de gerenciamento de atividades

De acordo com a Figura 5.3, essa aplicação considera a existência de cinco tipos de usuários: o usuário anônimo, que pode se cadastrar na aplicação; o usuário autenticado que é um usuário 
que efetuou login no sistema, e os usuários: administrador, professor e estudante, que são especializações do usuário autenticado.

O modelo conceitual, como o próprio nome sugere, expressa os conceitos envolvidos no domínio da aplicação e os relacionamentos entre esses conceitos, representando a informação que o sistema deve gerenciar. Embora tenha relação com os dados manipulados pelo sistema, o modelo conceitual não deve ser confundido com o modelo de dados, mas pode ser utilizado como base para sua definição. Na Figura 5.4 é apresentado o modelo conceitual estabelecido para a aplicação de gerenciamento de atividades didáticas. Nesse modelo conceitual, o conceito "papel” é utilizado para representar os tipos de usuários que a aplicação possui, e o conceito de “avaliado" é utilizado para representar o usuário que é um estudante na aplicação.

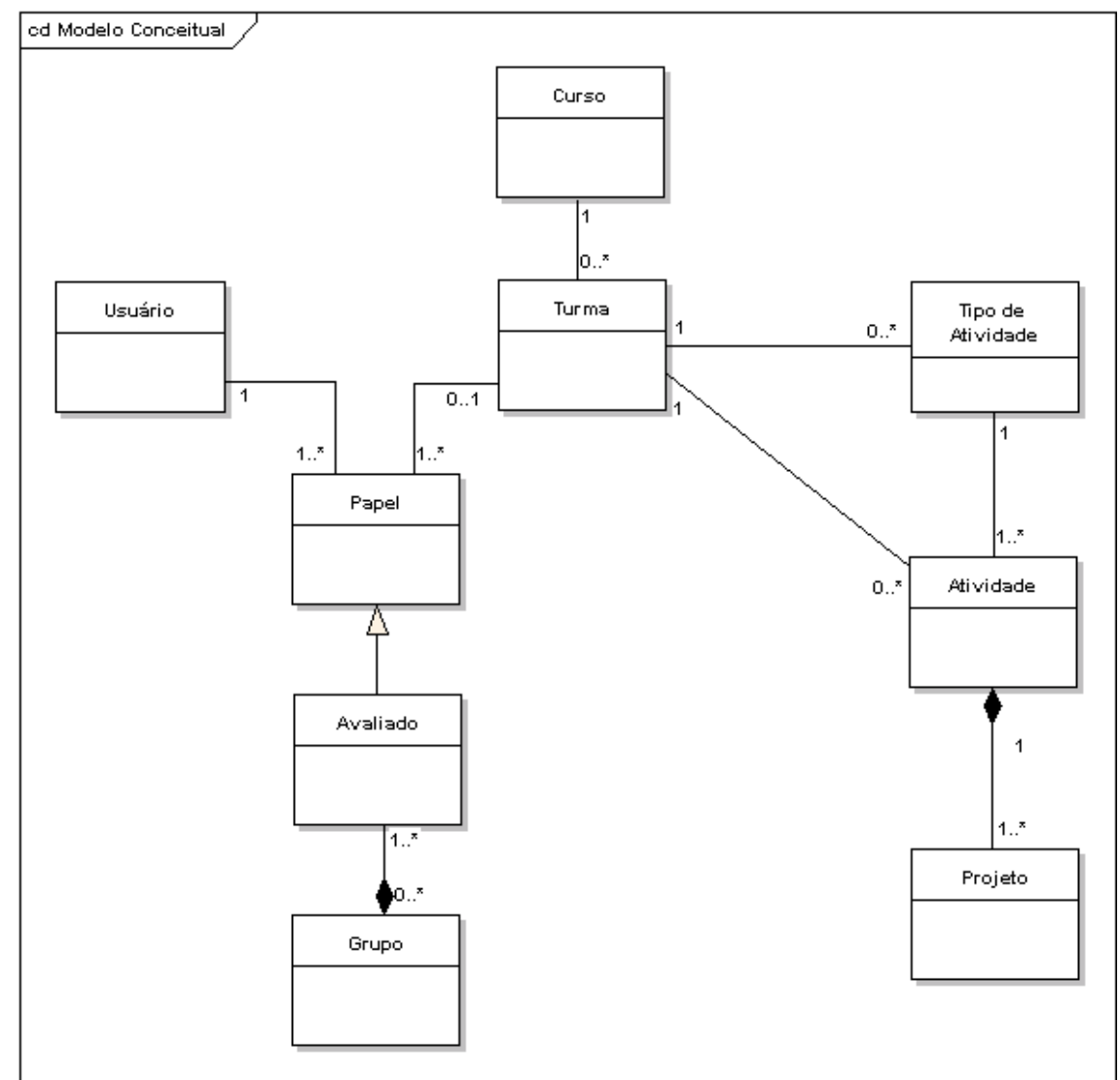

Figura 5.4 - Modelo conceitual da aplicação de gerenciamento de atividades

De posse do diagrama e descrição de casos de uso e do modelo conceitual, passa-se às atividades de especificação dos módulos da aplicação. 


\subsubsection{Identificar módulos}

Considerando a perspectiva modular do framework WebMODE, a próxima atividade do processo de instanciação envolve a identificação dos módulos que irão compor a aplicação (ver Figura 5.2 pág. 81) .

Como discutido no Capítulo 4, os módulos do framework WebMODE representam um conjunto de funcionalidades da aplicação. Essas funcionalidades podem ser identificadas a partir dos casos de uso definidos na atividade de levantamento de requisitos. O módulo é organizado em termos de opções e ações. A opção representa uma funcionalidade de mais alto nível (por exemplo: "gerenciar usuários"), acessível ao usuário a partir do menu principal da aplicação. A ação corresponde a cada funcionalidade específica que faz parte da opção do módulo (por exemplo: na opção "gerenciar usuários" as seguintes ações são possíveis: "listar usuários", "adicionar usuário", "remover usuário", "editar usuário"). Para que uma ação seja executada num módulo específico, tanto a opção quanto a ação desejada devem ser especificadas como atributos da requisição que é enviada ao módulo.

As atividades de identificação dos módulos da aplicação (atividades de modularização), propostas neste processo, têm por objetivo identificar os módulos a partir das suas opções e das ações que fazem parte dessas opções. Por se tratar de um modelo orientado a objetos, a modularização pode ser feita sobre os próprios casos de uso, levando-se em consideração os conceitos gerenciados por eles. A escolha desse tipo de diagrama se deve à facilidade de visualizar as funcionalidades da aplicação, o que torna a modularização uma atividade mais visual.

O primeiro passo da modularização (passo 1) é o agrupamento dos casos de uso em função do que se espera que seja apresentado ao usuário como itens do menu principal da aplicação (Figura 5.5). O projetista da aplicação deve analisar os casos de uso e tentar identificar quais deles podem ser agrupados num caso de uso mais geral. Essa atividade de agrupamento permite identificar as opções da aplicação e as ações que formam cada opção. 


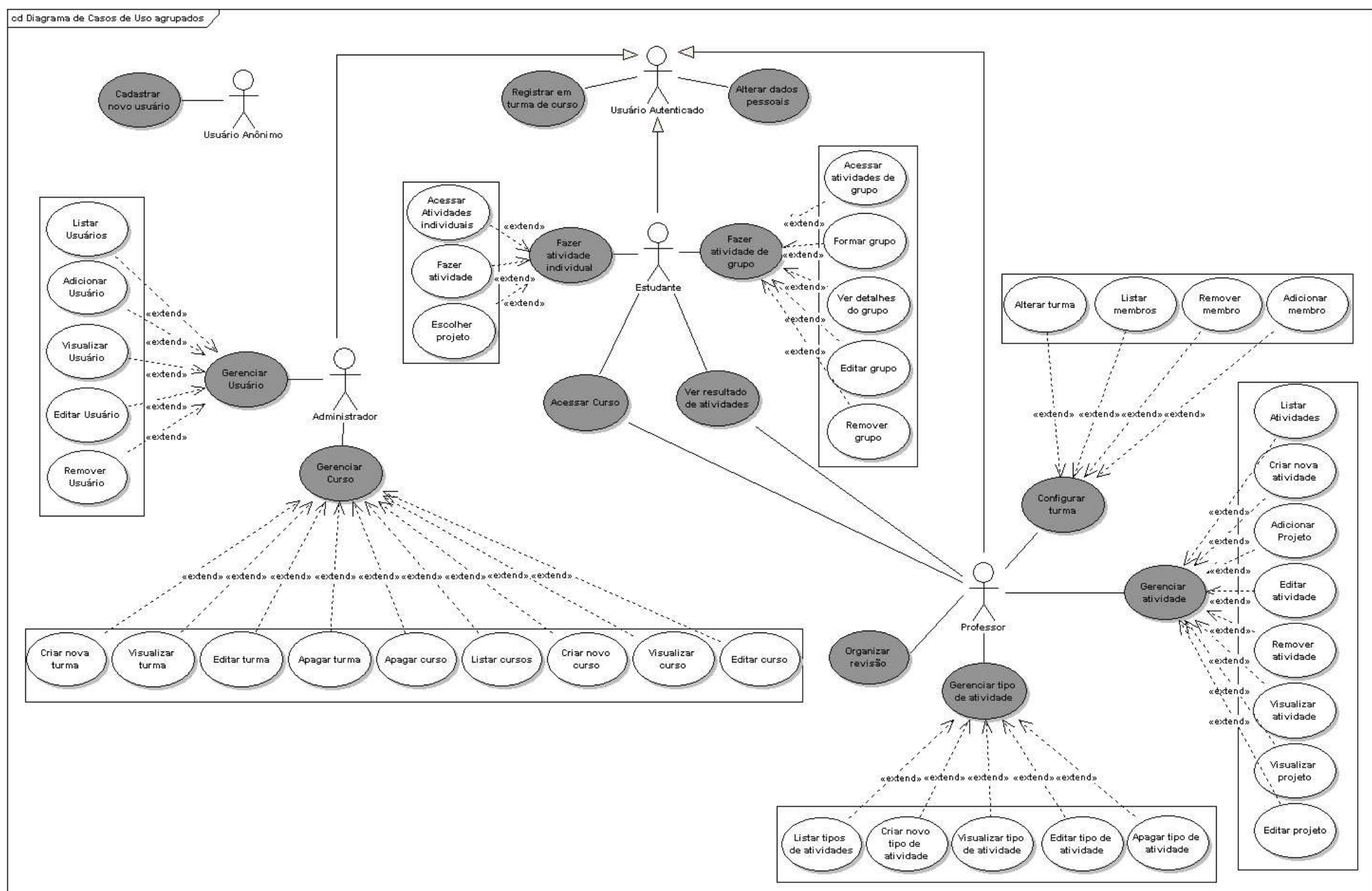

Figura 5.5 - Diagrama de casos de uso agrupados para modularização (passo 1) 
Em algumas situações, o próprio caso de uso é identificado como a opção a ser disponibilizada diretamente no menu principal. Nesse caso, o caso de uso é identificado como opção e possui uma única ação específica. O diagrama apresentado na Figura 5.5 mostra o agrupamento dos casos de uso da aplicação de gerenciamento de atividades didáticas ${ }^{21}$. Nessa figura, é possível notar que alguns dos casos de uso em tons de cinza não faziam parte dos casos de uso originais (da Figura 5.3 pág. 83). Eles foram criados para abstrair os casos de uso mais específicos.

O segundo passo para a modularização (passo 2) é o agrupamento das opções, identificadas no passo anterior para formar os módulos (Figura 5.6). Esse agrupamento pode ser feito com base no tipo de informação tratado por cada opção. Por exemplo: as opções que estão relacionadas com o conceito de usuário, como "gerenciar usuário" e "alterar cadastro pessoal" podem ser identificadas como opções do módulo de usuário (UserModule).

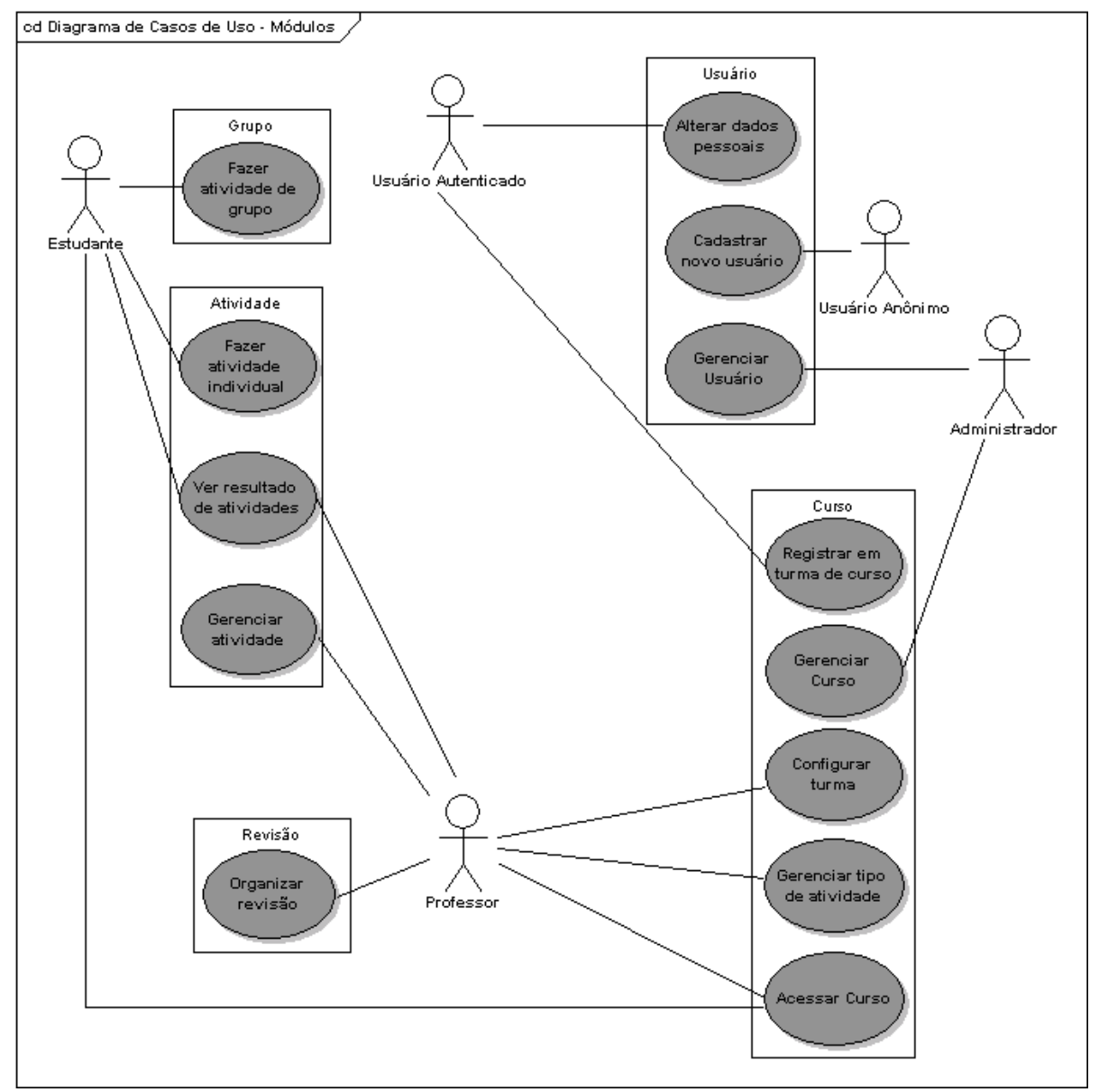

Figura 5.6 - Diagrama de casos de uso agrupados para modularização (passo 2)

\footnotetext{
21 Os casos de uso login e logout e trocar papel do usuário foram eliminados do diagrama porque essas funcionalidades devem ser fornecidas pela implementação do framework WebMODE.
} 
O diagrama apresentado na Figura 5.6 ilustra o agrupamento dos casos de uso mais gerais (as opções) para formar módulos da aplicação de gerenciamento de atividades didáticas. Nesse diagrama, somente os casos de uso identificados como opções no passo anterior são incluídos. Após os dois passos da modularização foram identificados cinco módulos para a aplicação de gerenciamento de atividades didáticas: usuário, curso, atividade, grupo e revisão.

Concluídas as atividades de agrupamento, o projetista da aplicação deve organizar as informações produzidas nesses dois passos em um documento que descreve cada módulo identificado, como no exemplo apresentado na Figura 5.7.

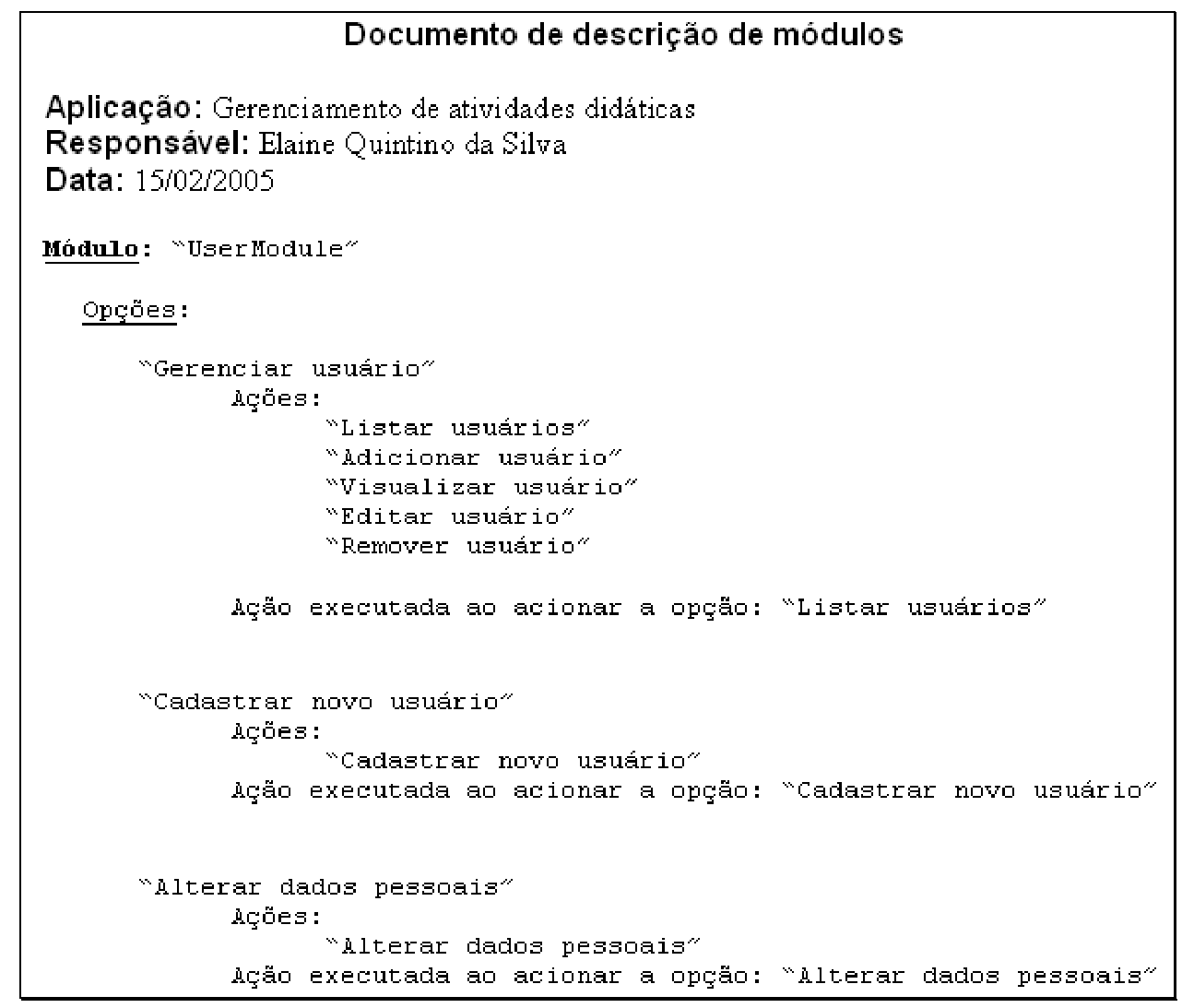

Figura 5.7 - Documento de descrição de módulos

O objetivo desse documento é facilitar a leitura do desenvolvedor durante a atividade de desenvolvimento dos módulos. Conforme pode ser visto na Figura 5.7, é importante que o projetista identifique a ação que será executada quando a opção for acionada, ou seja, uma ação padrão. Caso não haja uma ação padrão, o projetista deve definir um comportamento para quando o usuário acessar essa opção, por exemplo, mostrar uma tela com alguma informação. Nos casos em que a opção possui apenas uma (1) ação, ela deve ser considerada a ação padrão. 
De posse desse documento de descrição de módulos e dos artefatos produzidos na atividade de levantamento de requisitos, passa-se às atividades de projeto da interface e navegação da aplicação (ver Figura 5.2 pág. 81).

\subsubsection{Projetar interface e navegação}

O projeto de interfaces gráficas é uma atividade importante no desenvolvimento de sistemas computacionais, sendo que, na literatura, existem diversas técnicas e métodos de modelagem e avaliação de interface que tratam os diferentes aspectos dessa atividade, tais como a informação, a navegação, a representação visual e as regras de usabilidade (Schwabe \& Rossi, 1999; Ceri et al., 2000; Baresi et al., 2001; Conallen, 2002; Koch \& Kraus, 2003).

As interfaces das aplicações WebMODE podem ser projetadas utilizando-se uma dessas várias técnicas de modelagem existentes na literatura. No entanto, esse projeto deve ser feito levando-se em consideração cada uma das opções dos módulos a serem desenvolvidos. Cada opção do módulo apresenta um cenário de uso completo que envolve um conjunto de telas e um modelo de navegação. Por exemplo, a funcionalidade "Gerenciar usuários" (opção do módulo "Usuário") envolve um conjunto de telas e um modelo de navegação que viabiliza a realização das várias ações desta opção: adicionar usuário, remover usuário, ver dados de um usuário, editar ou remover um usuário.

Independente da técnica, método ou estratégia de projeto de interface utilizada, o resultado dessa atividade deve produzir alguns artefatos principais, que são: um modelo de navegação (considerando as opções e ações acionadas em cada transição entre as interfaces) e a descrição das telas da aplicação. Esses artefatos são importantes para a atividade de desenvolvimento dos módulos.

No caso da aplicação de gerenciamento de atividades didáticas, o projeto das interfaces foi feito de maneira simplificada utilizando storyboards e protótipos escritos em HTML (W3C, 1999a). $\mathrm{Na}$ Figura 5.8 é apresentado um modelo simplificado de navegação que mostra as interfaces relacionadas com a opção "Gerenciar usuários". Nesta figura, as opções e ações são representadas nos indicadores de transição de uma interface para outra, e o texto acima de cada interface representa seu nome. Quando o fluxo de transição termina em um nome de interface é porque, depois de executar a ação indicada pelo fluxo, a próxima interface a ser visualizada é a indicada (pelo nome). 
Tanto o modelo de navegação quanto a descrição das telas são artefatos importantes na especificação das interfaces dos componentes, que são responsáveis por manipular os dados apresentados nessas telas.

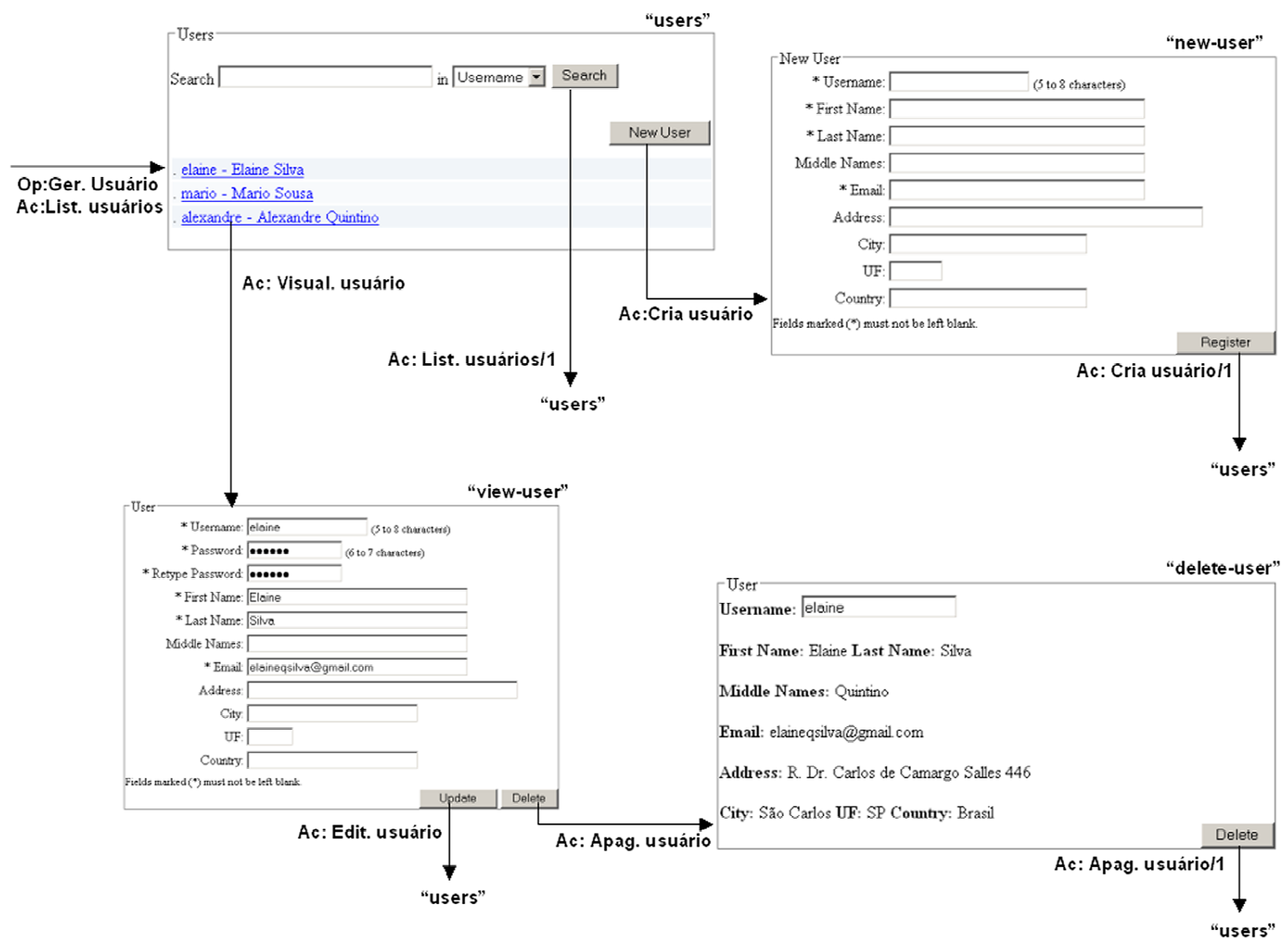

Figura 5.8 - Modelo de navegação da opção "Gerenciar usuários"

\subsubsection{Especificar controladores de módulo e componentes de negócio}

No framework WebMODE, os controladores de módulo são os elementos responsáveis pela ligação entre a interface de usuário e os componentes de negócio que formam o módulo. Os componentes de negócio são utilizados pelos controladores de módulo para processar uma requisição, pois são eles que possuem a lógica de negócio propriamente dita.

As atividades de especificação dos controladores de módulo e dos componentes foram estabelecidas com base nas atividades de especificação e interação de componentes de sistema e negócio descritas no processo de UML Components ${ }^{22}$ (Cheesman \& Daniels, 2001). Porém, a

${ }^{22}$ Os componentes de sistema e negócio do processo UML Components são definidos no Capítulo 3, na Seção 3.2.1. 
especificação dos componentes de sistema tem por único objetivo guiar o projetista na especificação dos controladores de módulo, já que o conceito de componente de sistema não faz parte dos conceitos envolvidos no framework WebMODE.

Em função da perspectiva modular atribuída ao WebMODE, as atividades do processo $U M L$ Components devem ser aplicadas levando-se em consideração os módulos identificados nas atividades anteriores. Sendo assim, os seguintes artefatos são necessários para dar continuidade às atividades de especificação: modelo conceitual, modelo de casos de uso, documento de descrição dos módulos e artefatos da atividade de projeto de interface e navegação (Figura $\mathbf{5 . 2}$ pág.82).

A atividade de especificação dos controladores de módulo e dos componentes de negócio é subdivida em cinco fases, descritas a seguir.

\section{Fase 1: Especificar interfaces e operações de sistema}

A especificação das interfaces e operações de sistema deve ser feita como sugere o processo UML Components (Cheesman \& Daniels, 2001): cada caso de uso dá origem a uma interface de sistema e cada responsabilidade do sistema, descrita no caso de uso, dá origem a uma operação dessa interface.

Por uma questão de organização, essa atividade deve ser aplicada sobre o diagrama de casos de uso agrupados no primeiro passo (passo 1) da atividade de identificação dos módulos (Figura 5.5 pág. 86). Os casos de uso gerados pela atividade de agrupamento não devem ser considerados para a definição de interfaces. Por exemplo, os casos de uso "Gerenciar usuários", "Gerenciar cursos", "Configurar turma", "Gerenciar tipos de atividade", "Gerenciar atividade", "Organizar revisão", "Fazer atividade individual" e "Fazer atividade em grupo", do diagrama apresentado na Figura 5.5, não devem ser analisados nessa atividade porque, além de não existirem no diagrama de casos de uso original, não são considerados casos de uso atômicos.

O resultado esperado desta fase é o conjunto de interfaces de sistema para os casos de uso da aplicação, como descrito no processo UML Components. 


\section{Fase 2: Especificar interfaces de negócio}

De acordo com o processo UML Components, a identificação das interfaces dos componentes de negócio é feita com base no modelo de tipos do negócio ${ }^{23}$ (BTM) construído a partir do modelo conceitual (Cheesman \& Daniels, 2001). Após a identificação dos tipos core e type, deve-se definir as interfaces de negócio para os tipos core e adicioná-las no BTM. Depois disso é necessário especificar as responsabilidades dessas interfaces sobre os tipos de negócio, também no BTM.

Apesar de estar baseado no processo UML Components, a identificação dos tipos core e type, nesse processo de instanciação, deve ser feita em função dos módulos. O projetista da aplicação deve identificar os tipos core considerando apenas os conceitos diretamente manipulados por cada módulo. Assim, um número maior de tipos core é identificado sendo que cada interface, criada a partir desses tipos, dá origem a um componente que é distribuído como parte do módulo. Com um número maior de componentes, menor é necessidade de usar componentes de outros módulos e, conseqüentemente, menor é a dependência entre os módulos.

O BTM da aplicação de gerenciamento de atividades didáticas é apresentado na Figura 5.9. As linhas pontilhadas delimitam os tipos envolvidos com cada módulo, com exceção do módulo "Revisão" que não possui nenhum tipo no BTM. A identificação dos tipos core é feita somente sobre os tipos envolvidos em cada limite, sendo que para os quatro módulos da aplicação, foram identificados cinco (5) tipos core. Se esse BTM tivesse sido analisado considerando apenas o domínio da aplicação, somente "Usuário" e "Curso" teriam sido identificados como core. Nesse caso, a modularidade da aplicação seria diminuída em função da dependência maior entre os módulos.

O resultado dessa fase é o BTM com as interfaces de negócios da aplicação e as responsabilidades delegadas a cada interface.

\section{Fase 3: Especificar operações das interfaces de negócio}

As operações das interfaces de negócio são identificadas com base na atividade de interação de componentes do UML Components (Cheesman \& Daniels, 2001): para cada operação das

\footnotetext{
${ }^{23}$ O BTM é um modelo de especificação que mostra os tipos do negócio classificados em core ou type, e as interfaces de negócio que gerenciam esses tipos. Os tipos core são independentes de outros tipos, enquanto os type precisam de outros tipos para existir.
} 
interfaces de sistema, cria-se um (ou mais) diagrama de interação mostrando o fluxo de execução resultante da sua invocação. Essa interação deve revelar as operações das interfaces dos componentes de negócio e, possivelmente, os parâmetros e os retornos das operações.

Em especial, os artefatos do projeto de interface e navegação podem auxiliar nessa fase para permitir a definição de interfaces mais completas em relação aos tipos de retorno e parâmetros.

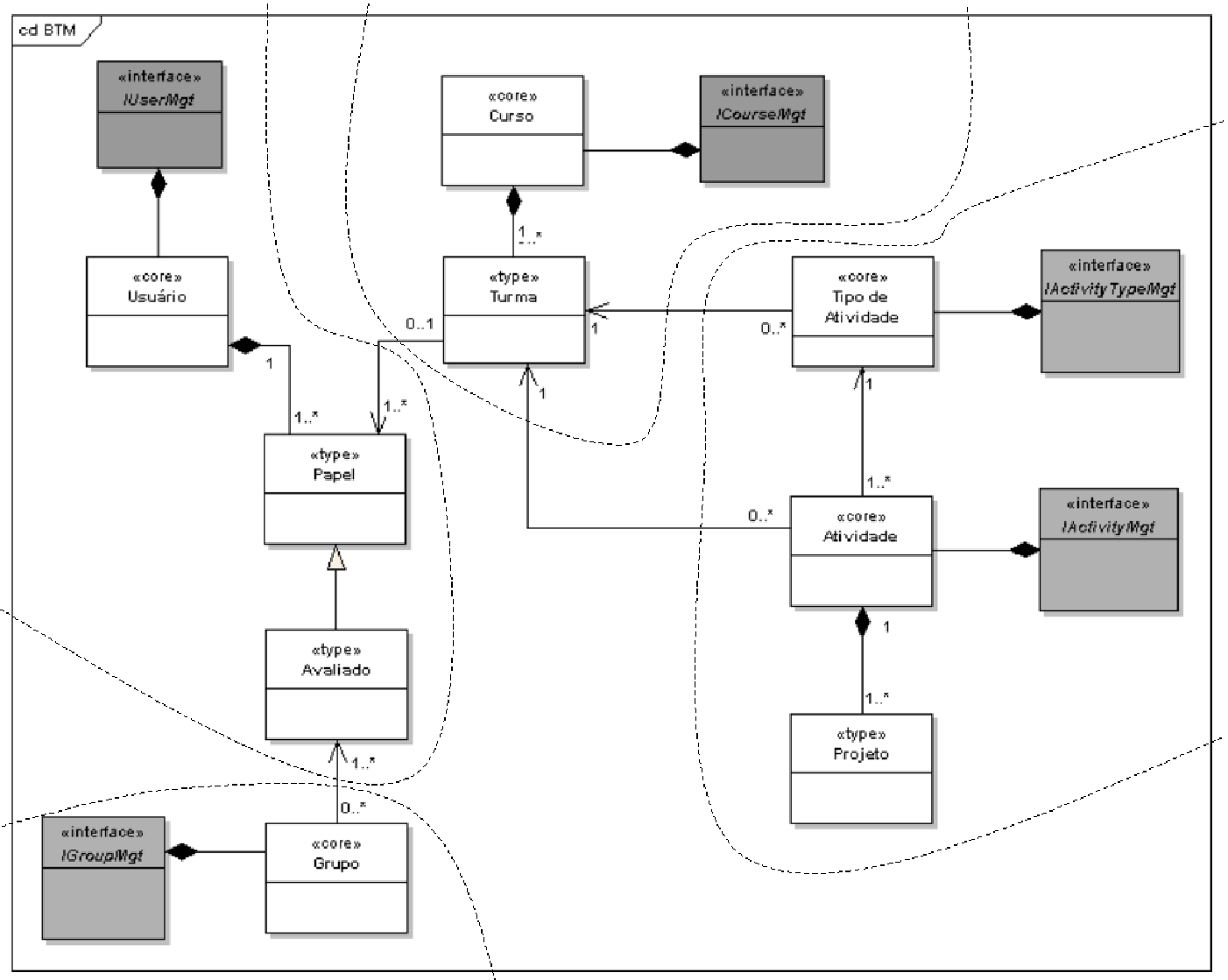

Figura 5.9 - BTM da aplicação de gerenciamento de atividades

\section{Fase 4: Atualizar documento de descrição de módulos}

Após identificar as interfaces de sistema e de negócio definidas no processo UML Components, é necessário atualizar o documento de descrição de módulos, pois esse documento será de grande importância para as atividades de desenvolvimento dos módulos.

Considerando que os casos de uso originais (Figura 5.5 pág.86) identificam as ações dos módulos e que cada caso de uso dá origem a uma interface de sistema pelo processo $U M L$ Components, pode-se dizer que: cada operação identificada nas interfaces de sistema corresponde a um (1) comportamento executado pela ação relacionada ao caso de uso que deu 
origem àquela interface. Por exemplo, na ação "Remover usuário" pode haver dois comportamentos: apresentar os dados de um usuário para confirmação e confirmar a exclusão do usuário. Esses comportamentos são identificados na interface de sistema gerada a partir do caso de uso "Remover usuário".

Os comportamentos identificados nas interfaces de sistema devem ser adicionados no documento de descrição de módulos juntamente com as interfaces e métodos de negócio que precisam ser invocados para executar a lógica da ação.

Algumas ações, tais como "Adicionar novo usuário", requerem que o sistema apresente, inicialmente, um formulário para a entrada dos dados. Esse também é um comportamento que deve ser adicionado no documento de descrição de módulos. No entanto, nenhum método de componente de negócio deve ser executado nesse caso. Na Figura 5.10 é apresentado um exemplo do documento de descrição de módulos atualizado da aplicação de gerenciamento de atividades didáticas.

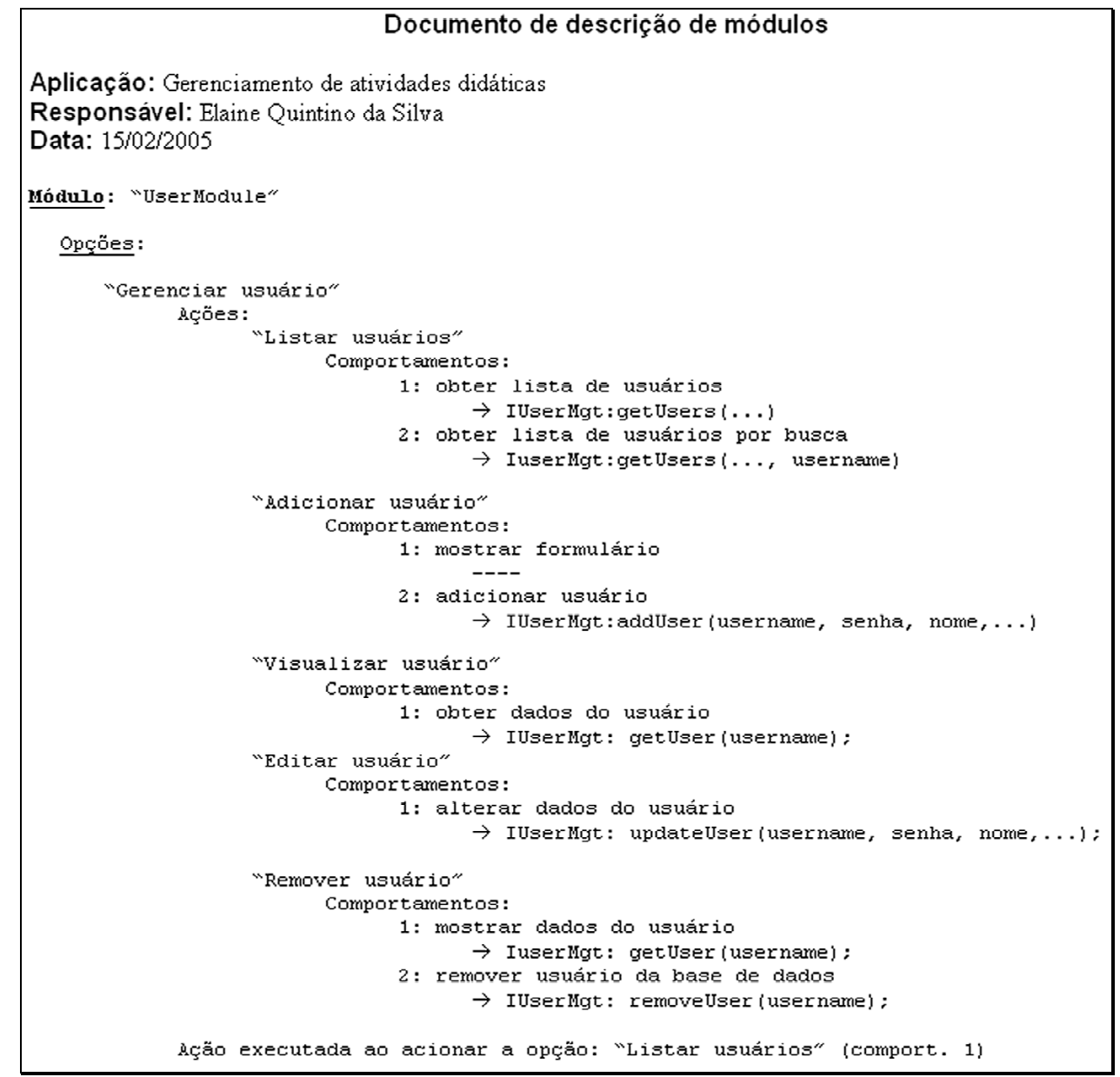

Figura 5.10 - Documento de descrição de módulos completo 


\section{Passo 5: Mapear relacionamento entre controladores de módulos e componentes}

Uma vez que os componentes de negócio e os módulos foram especificados, ainda é necessário construir uma representação gráfica que relacione os controladores de módulos de cada módulo e os componentes de negócio utilizados por eles. Com essa representação, feita utilizando diagramas de componentes UML, a dependência entre os módulos da aplicação fica mais explícita, o que pode auxiliar nas atividades de manutenção.

A criação do diagrama de componentes pode ser realizada com base no documento de descrição dos módulos: para cada interface de componente de negócio utilizada pelo módulo, cria-se um relacionamento entre o controlador do módulo e o componente de negócio a ser solicitado (ambos são representados por componentes do diagrama UML).

Na Figura 5.11 é apresentado o diagrama de relacionamento entre os controladores de módulo e os componentes de negócio que formam os módulos da aplicação de gerenciamento de atividades didáticas. Nesse diagrama deve-se procurar organizar os componentes de tal forma que a dependência entre eles fique clara. As linhas pontilhadas nesse diagrama representam o limite de cada módulo. Conforme se observa, a dependência entre os módulos ocorre apenas em um sentido, por exemplo, o módulo de "Revisão" depende do módulo de "Grupo" que depende do módulo de "Atividade" e assim por diante. No sentido contrário, os módulos não são dependentes, por exemplo, o módulo de "Usuário" não depende de outros módulos. Essa forma de dependência tende a facilitar a troca de módulos dessa aplicação, se necessário.

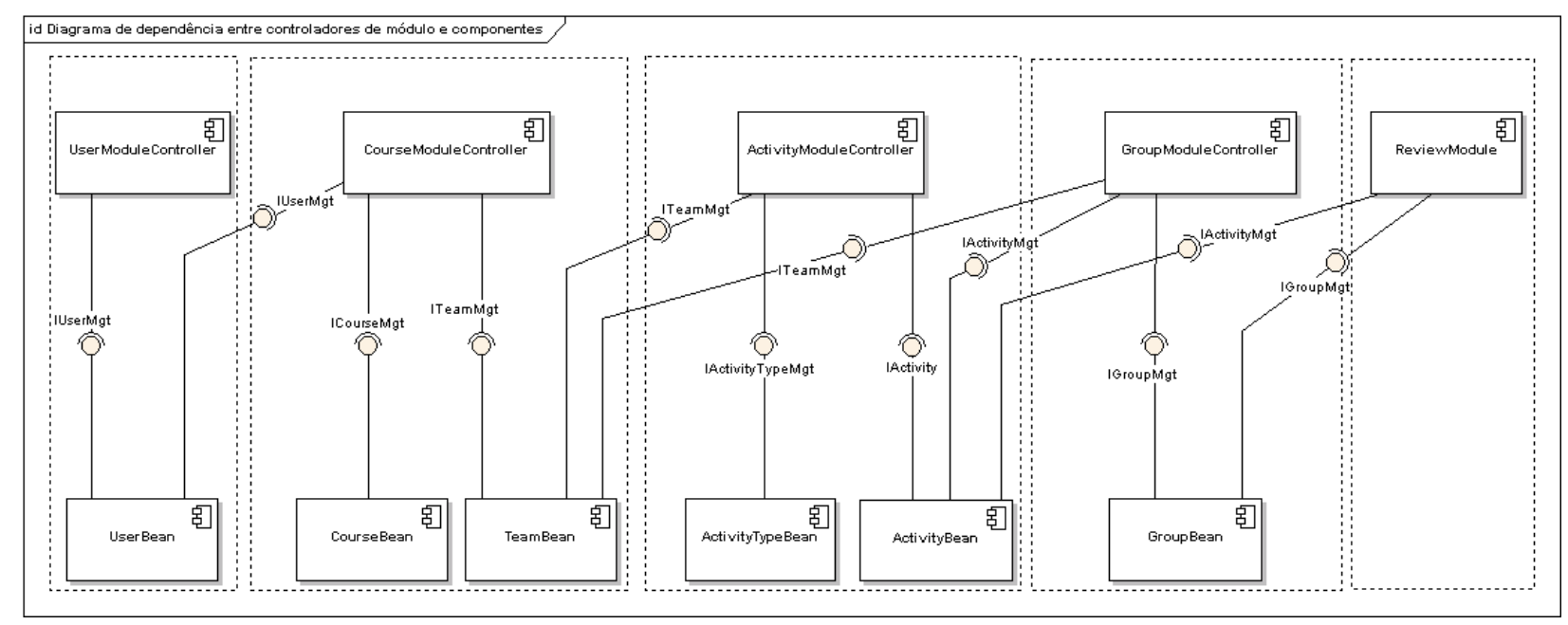

Figura 5.11 - Relacionamentos entre controladores de módulos e componentes 


\subsection{Desenvolvimento de módulos}

O fluxo de análise e especificação se preocupa, basicamente, com a especificação dos elementos (componentes de negócio, controlares de módulo e interfaces) dos módulos que irão fazer parte da aplicação que está sendo instanciada sobre o framework WebMODE. Porém, essa especificação não está ligada a nenhuma implementação desse framework em particular. Já o fluxo de desenvolvimento de módulos está mais diretamente ligado a uma implementação específica do WebMODE, que nesse caso é o WebMODE-J2EE descrito no Capítulo 4.

O fluxo de desenvolvimento de módulos ocorre com base nos artefatos produzidos nas atividades do fluxo de análise e especificação da aplicação, como pode ser visto no diagrama detalhado da Figura 5.12.

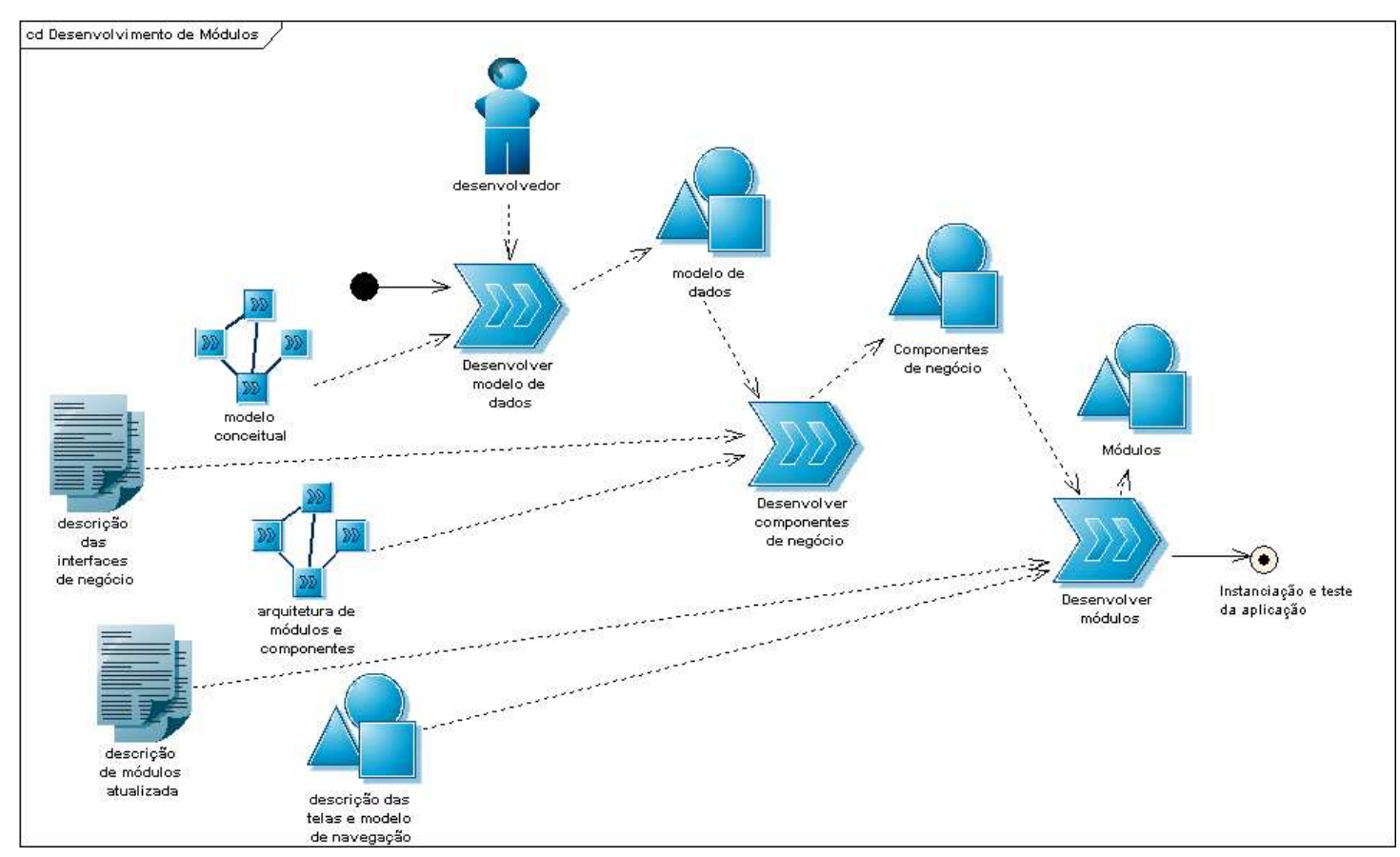

Figura 5.12 - Fluxo de desenvolvimento de módulos detalhado

Apesar dos componentes de negócio fazerem parte dos módulos, neste processo eles são desenvolvidos em atividades separadas. Inicialmente são desenvolvidos os componentes de negócio e o modelo de dados gerenciado por eles (atividades "Desenvolver modelo de dados" e "Desenvolver componentes de negócio"). Posteriormente são desenvolvidos os demais elementos que formam o módulo, incluindo as interfaces de usuário, os controladores de módulo e o arquivo de configuração (atividade "Desenvolver módulo"). Essas atividades foram divididas dessa forma porque há módulos que não precisam incluir componentes de negócio, podendo utilizar componentes já desenvolvidos e disponibilizados por outros módulos. 


\subsubsection{Desenvolver modelo de dados}

Os módulos do WebMODE usam os componentes de negócio para realizar a lógica de negócio da aplicação. Esses componentes gerenciam dados que precisam ser armazenados numa fonte de dados. Como o framework é orientado a objetos, a maneira mais interessante de manter esses dados é utilizando objetos de dados.

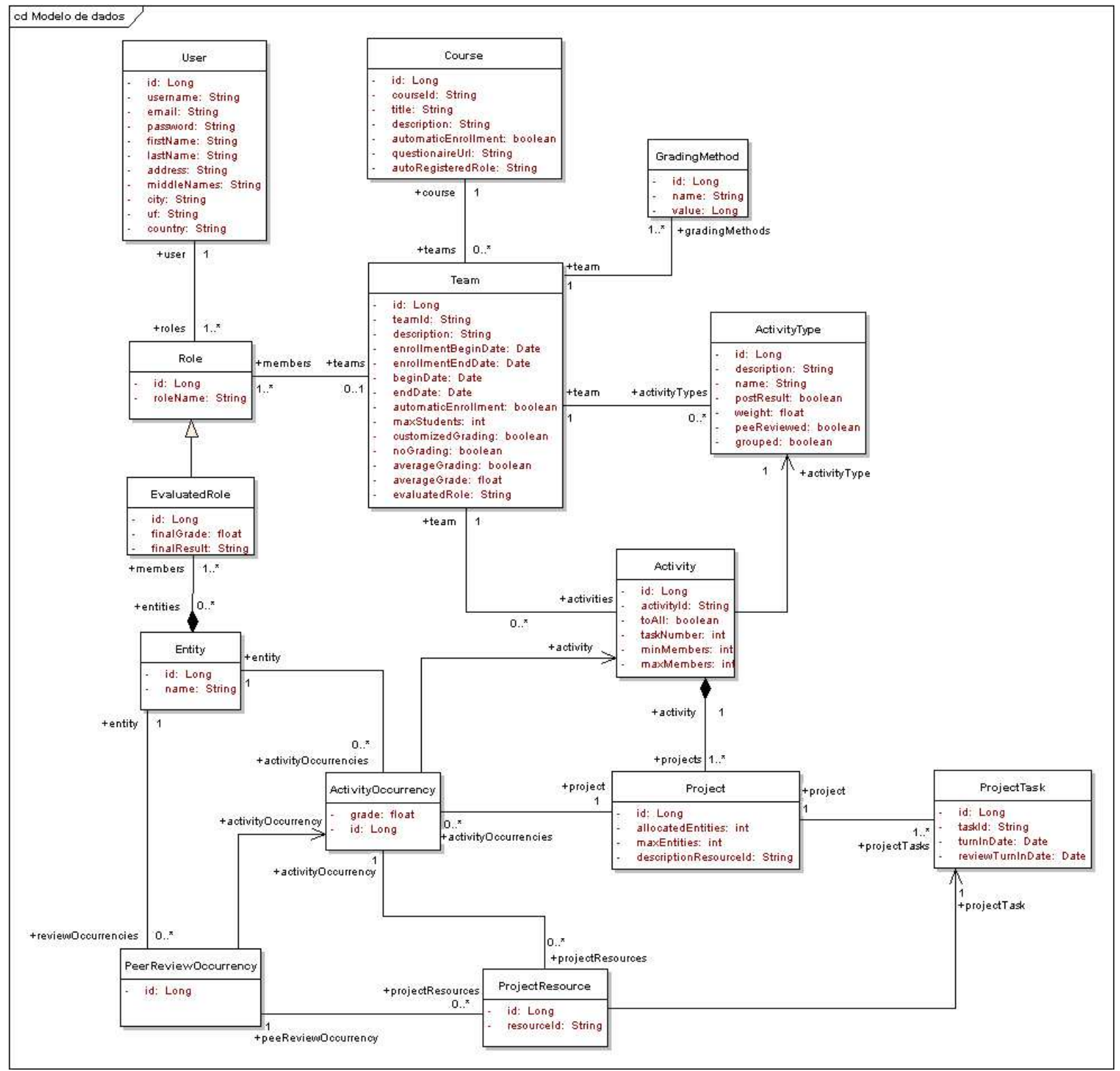

Figura 5.13 - Modelo de dados da aplicação de gerenciamento de atividades

No Caso do WebMODE-J2EE, a fonte de dados é desenvolvida utilizando o Hibernate que faz o mapeamento objeto-relacional (Hibernate, 2005). O modelo de classes utilizado para representar os dados gerenciados pelos componentes (também chamado modelo de dados) pode ser criado a partir de um refinamento do modelo conceitual, envolvendo a criação de novas classes e 
relacionamentos e a atribuição de navegabilidades aos relacionamentos. O diagrama de classes da Figura 5.13 representa o modelo de dados para a aplicação de gerenciamento de atividades didáticas.

A implementação do modelo de dados no WebMODE-J2EE deve seguir as regras estabelecidas para o desenvolvimento utilizando a tecnologia Hibernate (Bauer \& King, 2004). A distribuição dessa implementação deve ser feita como um serviço (disponível no JNDI) que executa de forma independente da aplicação no servidor JBoss (JBossPortal, 2005) (no qual o framework WebMODE-J2EE foi testado). A título de ilustração, na Figura 5.14 é apresentada a estrutura de um arquivo (SAR - Service Archive) utilizado para disponibilizar objetos Hibernate como um serviço no servidor JBoss (versão 3.x), e o arquivo de configuração desse serviço, no qual podese observar seu nome no JNDI e o tipo de base de dados relacional utilizada. O nome da fonte de dados configurada para o Hibernate deve ser informada à aplicação quando da sua instanciação.

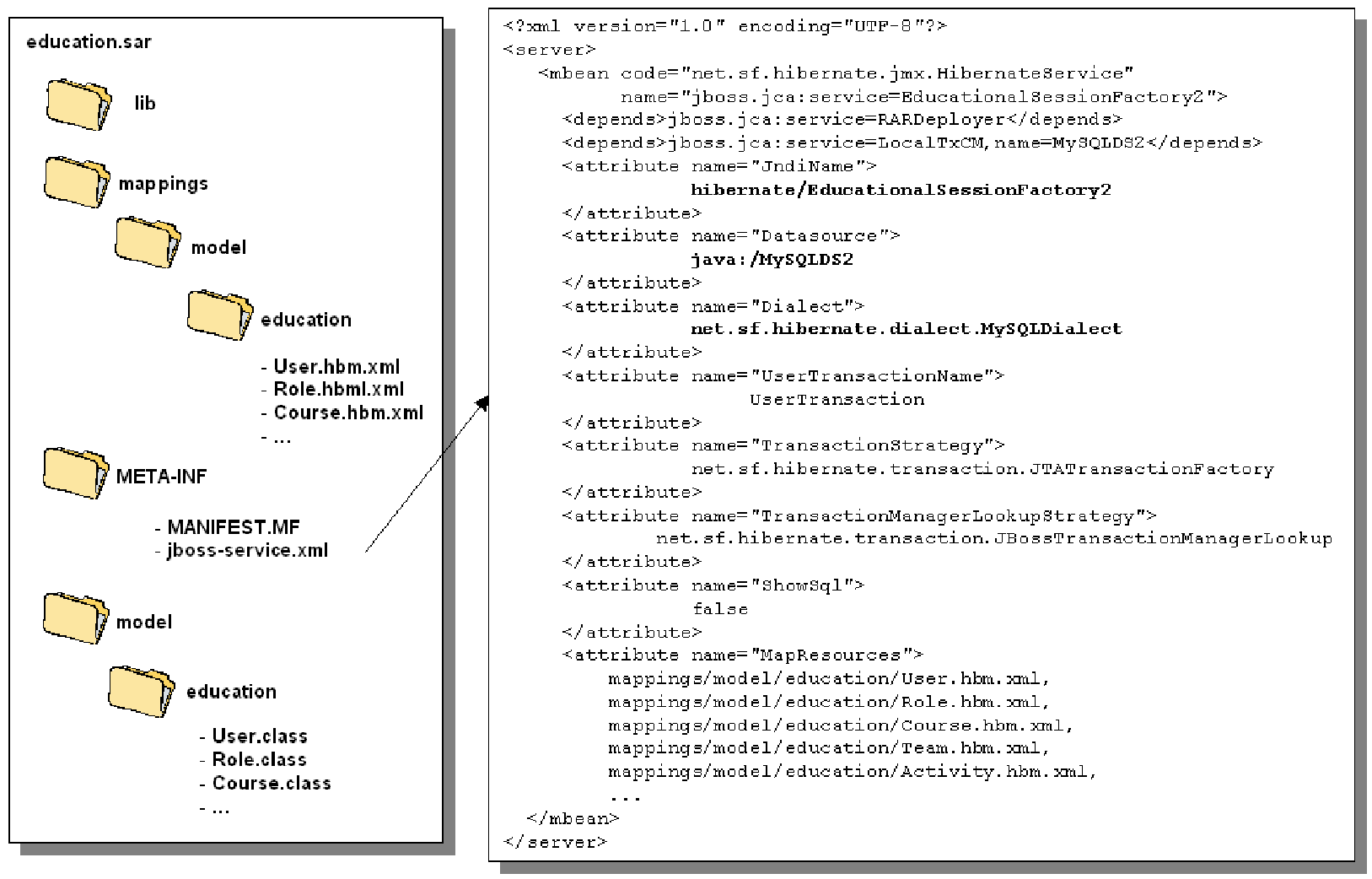

Figura 5.14 - Formato de distribuição dos objetos Hibernate para o WebMODE-J2EE 
As classes dos objetos Hibernate devem ser encapsuladas dentro de objetos $\mathrm{DAO}^{24}$, como no exemplo da Figura 5.15. O parâmetro do tipo Object, passado nos métodos da classe DAO, encapsulam a conexão com a fonte de dados, que no caso do Hibernate é uma fábrica de sessões (SessionFactory).

A implementação do modelo de dados deve oferecer uma biblioteca (por exemplo: education.jar) com as classes Hibernate que serão utilizadas nos componentes de negócio.

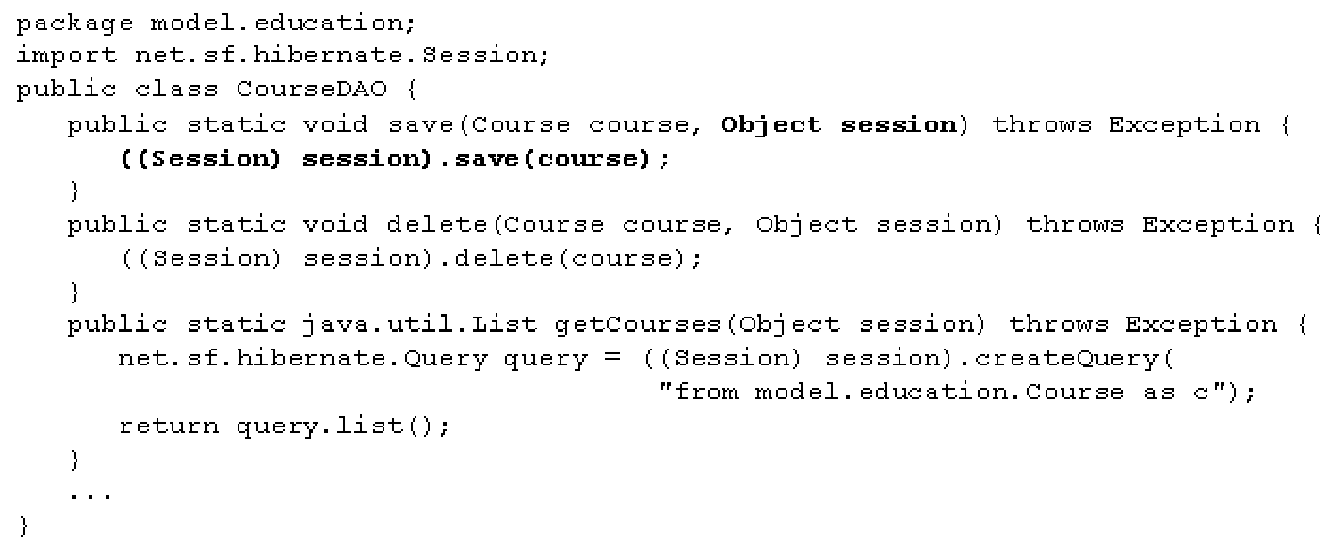

Figura 5.15 - Exemplo de um objeto DAO no WebMODE-J2EE

\subsubsection{Desenvolver componentes de negócio}

Após a criação da fonte de dados é necessário criar os componentes de negócio que gerenciam os dados. Como apresentado no Capítulo 4, no WebMODE-J2EE esses componentes são desenvolvidos utilizando os Enterprise Javabeans da plataforma J2EE.

Os componentes de negócio são implementados como EJBs padrão. Porém, a classe de implementação do componente deve estender a classe abstrata - BeanSupport. class - que faz parte da biblioteca core-lib.jar, oferecida pelo WebMODE-J2EE para regular a interface entre o controlador de módulo e os componentes.

Essa classe abstrata exige que o componente implemente um método por meio do qual a conexão com a fonte de dados será informada. Além disso, essa classe também oferece métodos para que o componente manipule a conexão com a fonte de dados e estabeleça comunicação com outros

\footnotetext{
${ }^{24}$ O modelo de DAO utilizado no WebMODE-J2EE não inclui o conceito de fábrica de DAOs (DAOFactory), pois esses objetos são utilizados apenas como forma de encapsular o código de acesso à fonte de dados. Quando um objeto precisar ser salvo, atualizado, removido ou localizado, o DAO recebe o ponteiro da conexão.
} 
componentes de forma simplificada (quando necessário). Um exemplo da classe de implementação de um componente de negócio do WebMODE-J2EE é apresentado na Figura 5.16, na qual pode se observar os métodos herdados da classe BeanSupport.

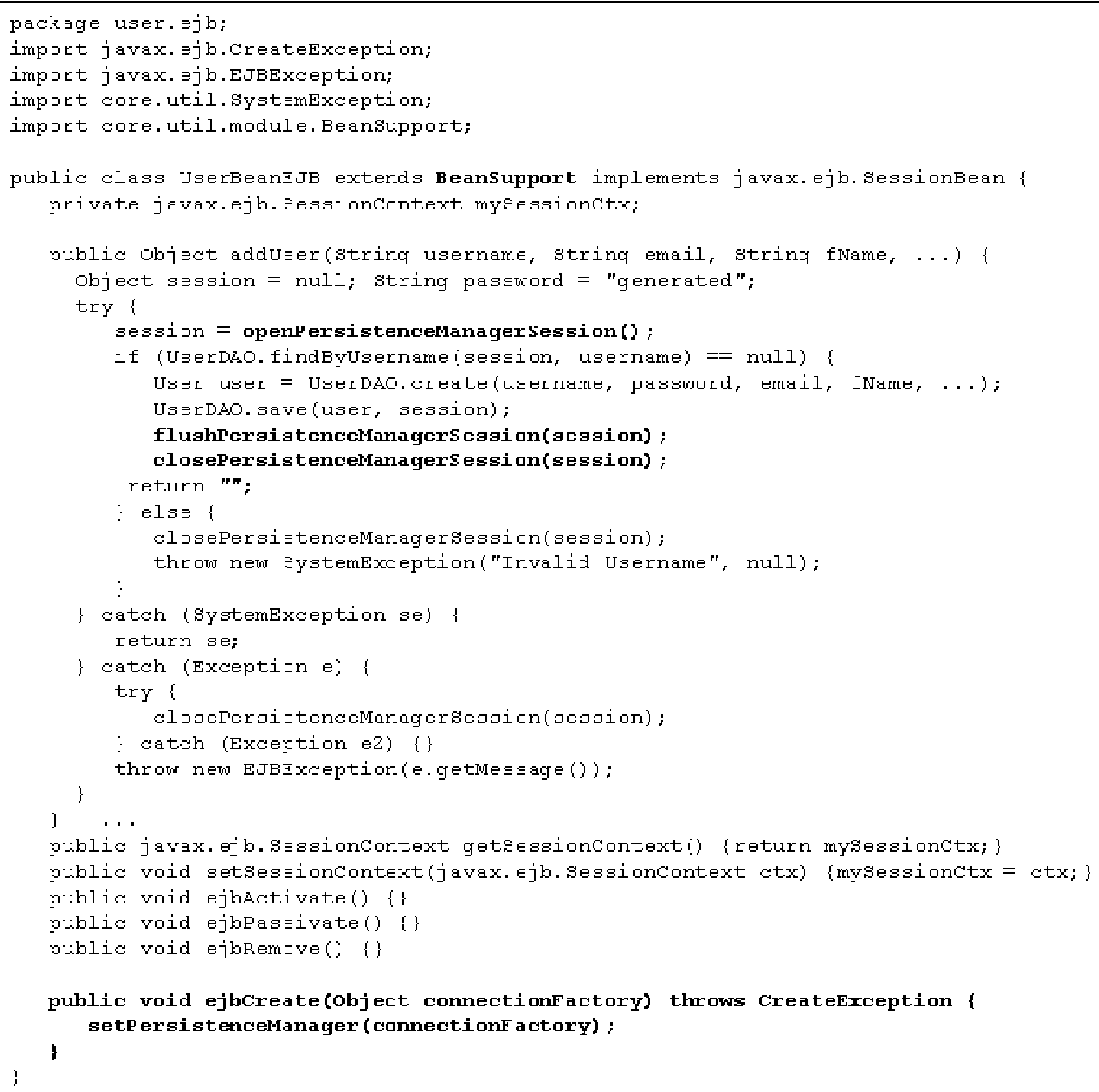

Figura 5.16 - Exemplo do código de um componente de negócio no WebMODE-J2EE

Como os componentes de negócio fazem parte dos módulos, eles não devem ser distribuídos separadamente. Eles são distribuídos na forma de pacotes de componentes EJB como parte dos pacotes dos módulos, que é descrito na próxima subseção. As interfaces desses componentes devem ser disponibilizadas na forma de bibliotecas para que possam ser utilizadas por outros módulos dos quais os componentes não fazem parte. O formato de empacotamento desses componentes de negócio é descrito na próxima subseção.

\subsubsection{Desenvolver módulos}

Com os componentes de negócio desenvolvidos, passa-se à atividade de desenvolvimento dos módulos propriamente ditos. Essa atividade envolve a implementação das interfaces de usuário, 
do controlador de módulo e do arquivo de configuração, e o relacionamento dessas interfaces com os componentes de negócio (desenvolvidos na atividade anterior) por meio do controlador de módulo.

Como mencionado no início da Seção 5.5, apesar dos componentes fazerem parte do módulo, o seu desenvolvimento foi separado em outra atividade pelo fato de alguns módulos usarem componentes já desenvolvidos.

No WebMODE-J2EE, os módulos podem ser disponibilizados como aplicações Web ou aplicações enterprise no padrão Java (Armstrong et al., 2005). Uma aplicação enterprise (. ear) possui pacotes de aplicação Web (.war) e de componentes EJB (.jar). Como os componentes de negócio são disponibilizados em pacotes de componentes EJB, a aplicação Web pode ser utilizada para disponibilizar os demais elementos do módulo (as interfaces de usuário, controlador de módulo e arquivo de configuração). Um módulo é uma aplicação enterprise somente quando ele possui seus próprios componentes de negócio. Caso contrário, o módulo é apenas uma aplicação Web que acessa componentes de negócio, disponibilizados por outros módulos, por meio de suas bibliotecas de interface.

\section{Arquivo de configuração do módulo}

O arquivo de configuração tem por objetivo descrever o módulo de tal forma que, quando ele for adicionado ao framework, suas informações possam ser utilizadas para garantir o correto funcionamento do módulo.

No WebMODE-J2EE, o arquivo de configuração do módulo - module.xml - é escrito no formato XML e colocado no classpath da aplicação Web (por exemplo: WEB$\mathrm{INF} / \mathrm{module} . \mathrm{xml}$ ) para que seja encontrado quando o módulo for carregado no servidor. Esse arquivo contém informações sobre a identificação do módulo (nome, descrição, url de acesso), os idiomas nos quais o módulo é disponibilizado (locale) e as opções oferecidas pelo módulo. Um exemplo desse arquivo é apresentado na Figura 5.17.

As opções do módulo, que são retiradas do documento de descrição de módulos criado no fluxo especificação, são configuradas de acordo com a forma em que devem aparecer na interface da aplicação. Uma opção pode definir um bloco de menu ou ser colocada no bloco principal, no de tarefas administrativas ou em um bloco específico usando as seguintes configurações: 
- <common-option>opcao1</common-option>: a opção é apresentada no bloco do menu principal;

- <admin-option icon="x.gif">opcao2</admin-option>: a opção é apresentada dentro do bloco de administração e o ícone é utilizado para identificá-la;

- <block-option page-file="x.jsp">opcao3</block-option>: a opção é transformada em um bloco do menu e a página identificada é usada dentro do bloco;

- <specific-option related-to="opcao3">opcao4</specifica-option>: a opção é apresentada dentro de um bloco específico identificado pela opção de bloco relacionada (neste caso, dentro do bloco criado pela opção3).

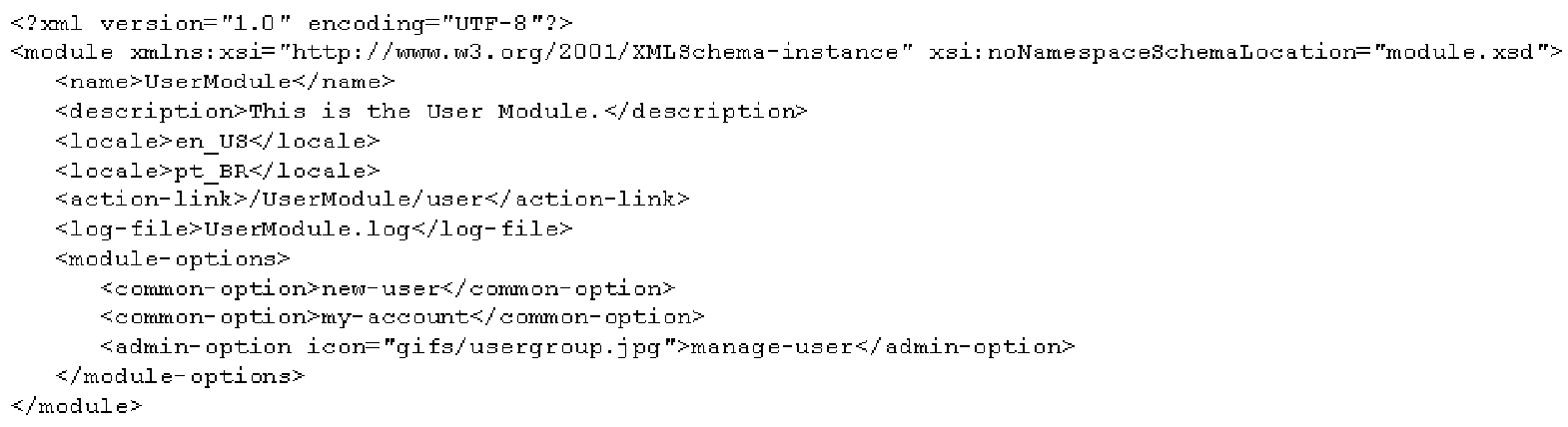

Figura 5.17 - Exemplo de arquivo de configuração de módulo (module . xml)

Para cada idioma definido no arquivo de configuração do módulo, deve-se criar um arquivo de propriedades para suportar a internacionalização. Esses arquivos de propriedade devem ser nomeados adicionando-se o locale identificado no arquivo de configuração do módulo ao nome do módulo, por exemplo, UserModule_en_US.properties e UserModule_pt_BR.properties. Para cada opção indicada no arquivo de configuração do módulo, deve haver uma entrada no arquivo de propriedades para que o módulo seja carregado corretamente. Um exemplo desse arquivo pode ser visto na Figura 5.18. O texto em negrito nesta figura indica as entradas das opções identificadas na Figura 5.17.

\section{Classe de Constantes para as opções e ações do módulo}

Uma vez definido o arquivo de configuração do módulo, pode-se criar uma classe Java que armazena constantes para as opções e ações desse módulo. Essa classe não é obrigatória, mas facilita a identificação de opções e ações dentro do controlador de módulo e das interfaces de usuário, e evita erros de digitação de strings. 


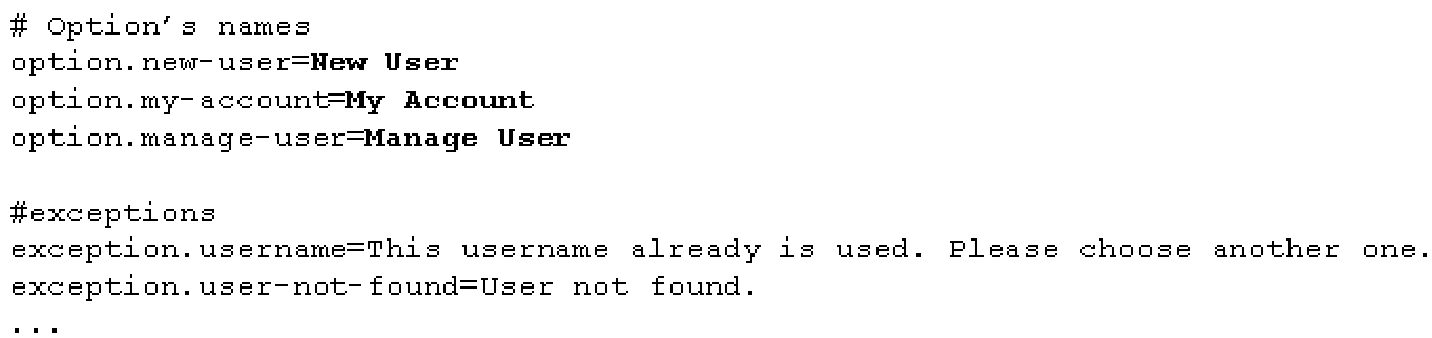

Figura 5.18 - Arquivo de propriedades UserModule_en_US.properties

As opções e ações descritas no documento de descrição de módulos são transformadas em constantes dessa classe. Somente as ações padrão de cada opção não precisam ser transformadas, pois quando a opção do módulo é acionada no menu da aplicação, nenhuma ação é identificada, ou seja, a ação é nula (null). Na Figura 5.19 é apresentado um exemplo dessa classe de constantes. Nessa figura, a ação "Listar usuários" (list-users) que é identificada como a ação padrão da opção “Gerenciar usuários” (manage-user) não deveria ser representada por uma constante, porém, essa ação tem dois comportamentos: o primeiro comportamento corresponde ao ato de listar os usuários quando a opção "Gerenciar usuários" é acionada (a ação indicada foi nula); o segundo comportamento corresponde ao ato de listar os usuários a partir de uma busca (por nome do usuário, por exemplo) depois de ter acionado a opção “Gerenciar usuários”. Nesse caso, a ação a ser acionada é a "Listar usuários".

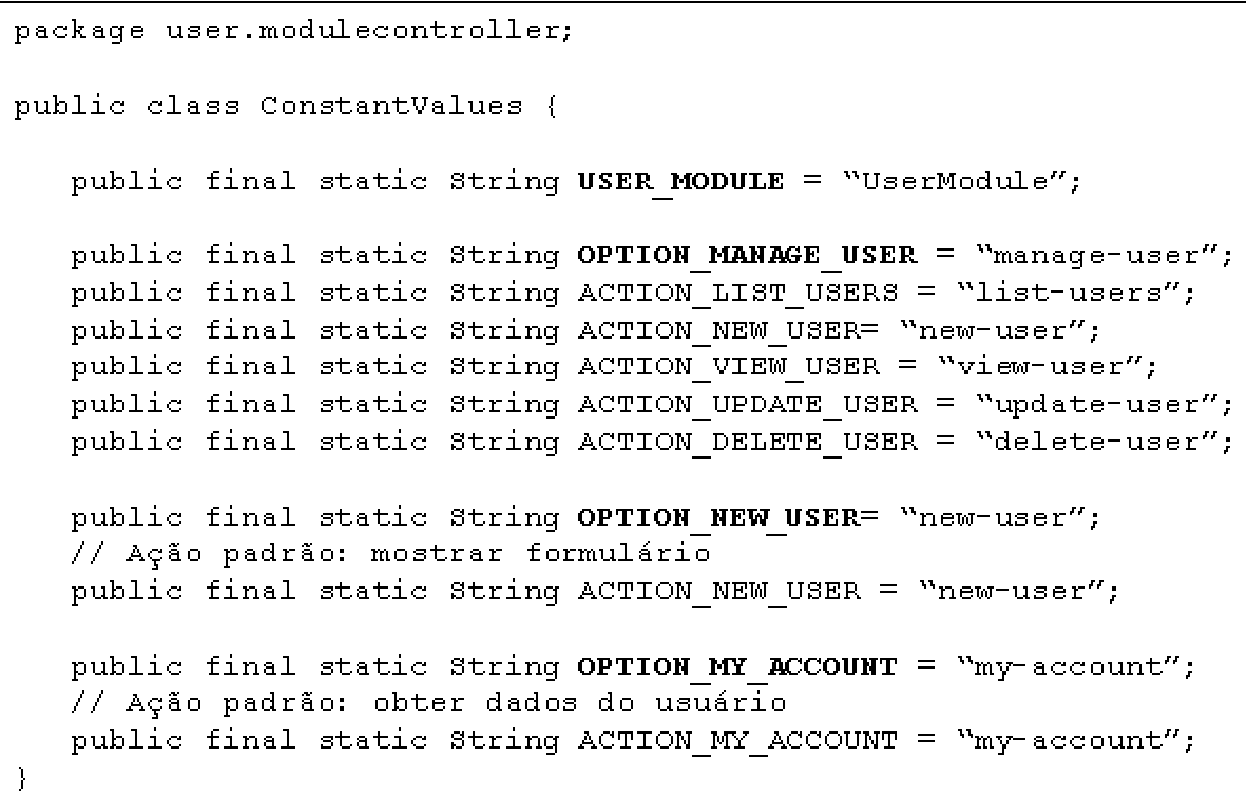

Figura 5.19 - Classe de constantes do módulo (ConstantValues . Java) 


\section{Controlador de módulo e interfaces de usuário (visões do modelo MVC)}

Com base na descrição das telas e do modelo de navegação criados no fluxo de análise e especificação, são construídas as interfaces de usuário e a lógica do controlador de módulo que implementa o modelo de navegação.

No WebMODE-J2EE, as interfaces da aplicação são implementadas por documentos JSP (ou páginas JSP) que ativam opções no controlador do módulo por meio de requisições HTTP. Para isso, essa requisição (post ou get) deve informar o módulo, a opção e a ação a ser acionada, como no exemplo da Figura 5.20. Essa requisição deve ser direcionada para o controlador principal do núcleo do WebMODE-J2EE (por exemplo, usando o nome "main" no campo action do formulário HTML - Figura 5.20) que a repassa ao controlador do módulo acionado. As informações sobre o módulo, a opção e ação são obtidas nos artefatos produzidos na atividade de projeto de interface e navegação e do documento de descrição de módulos.

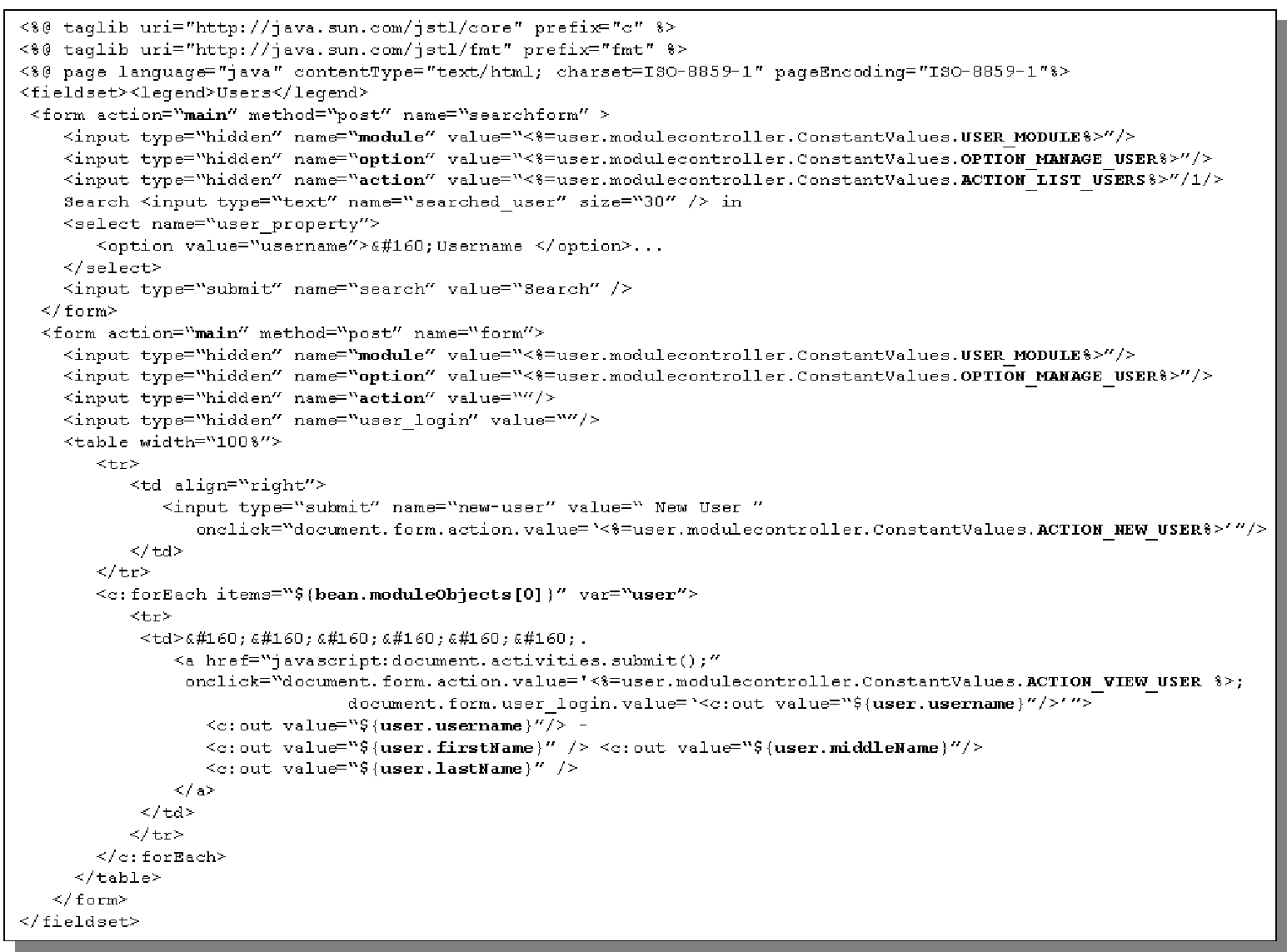

Figura 5.20 - Página JSP users.jsp $p^{25}$

\footnotetext{
${ }^{25}$ Essa página é o resultado do acionamento da opção "Gerenciar usuário" e da ação padrão "Listar usuários".
} 


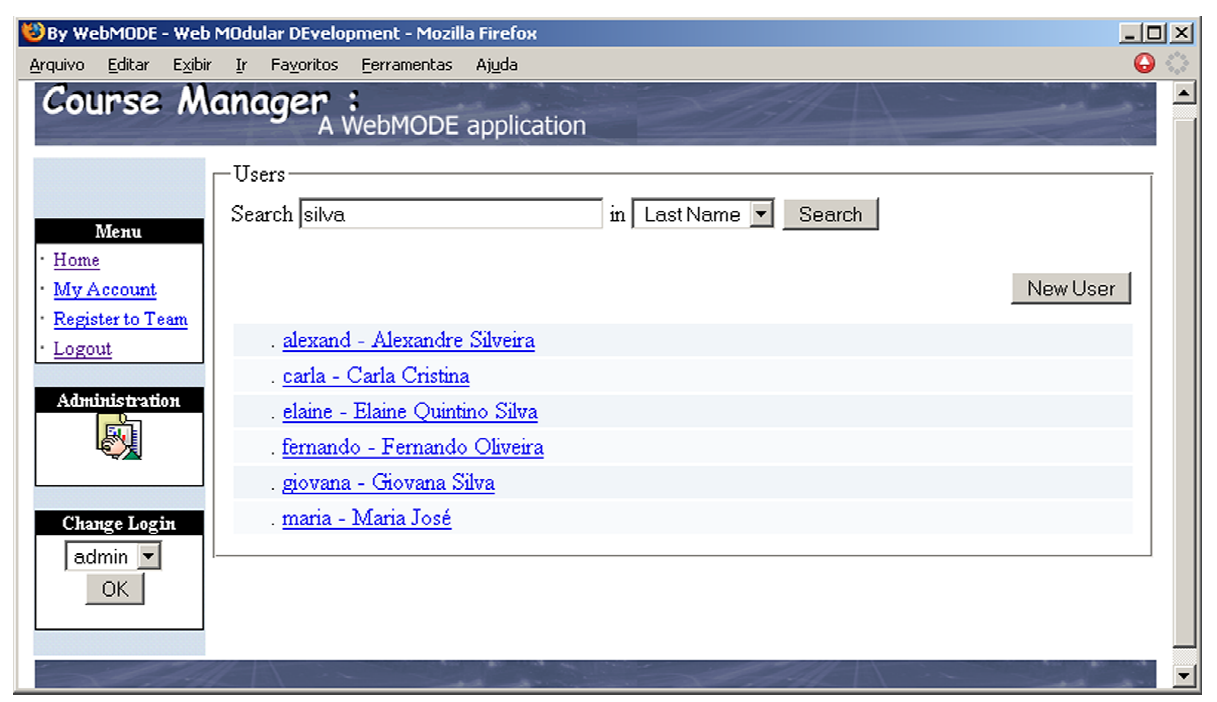

Figura 5.21 - Interface da aplicação mostrando o conteúdo visualizado na página users.jsp

Para implementar o controlador de módulo, que é um Java Servlet, deve-se estender a classe abstrata ServletModulecontroller da biblioteca core-lib.jar, oferecida pelo WebMODE-J2EE. Na Figura 5.22 é apresentado o trecho de uma classe que implementa o controlador de módulo do módulo "Usuário" (UserModule). Essa classe abstrata disciplina o funcionamento do controlador do módulo requerendo a implementação de dois métodos "gancho" do padrão TemplateMethod (Gamma et al., 1994): um para validar os parâmetros recebidos e outro para responder à requisição. Para que o módulo seja automaticamente reconhecido ao ser carregado no servidor, essa classe deve ainda ser configurada para executar no startup ${ }^{26}$.

Para facilitar o desenvolvimento, sugere-se que, antes de fazer as chamadas aos componentes de negócio, que o desenvolvedor estabeleça o relacionamento entre as páginas JSP e o controlador de módulo, criando, assim, todo o esquema de navegação entre as páginas. Esse esquema pode ser testado antes de concluir a implementação do módulo usando-se dados fíctícios nas páginas. Para isso, o desenvolvedor pode empacotar o módulo semi-pronto (Figura 5.23), implantá-lo no servidor J2EE e incluí-lo numa aplicação de teste.

\footnotetext{
${ }^{26}$ A instrução $<$ load-on-startup $>1</$ load-on-startup $>$ deve ser colocada na configuração do servlet no arquivo web. xml.
} 


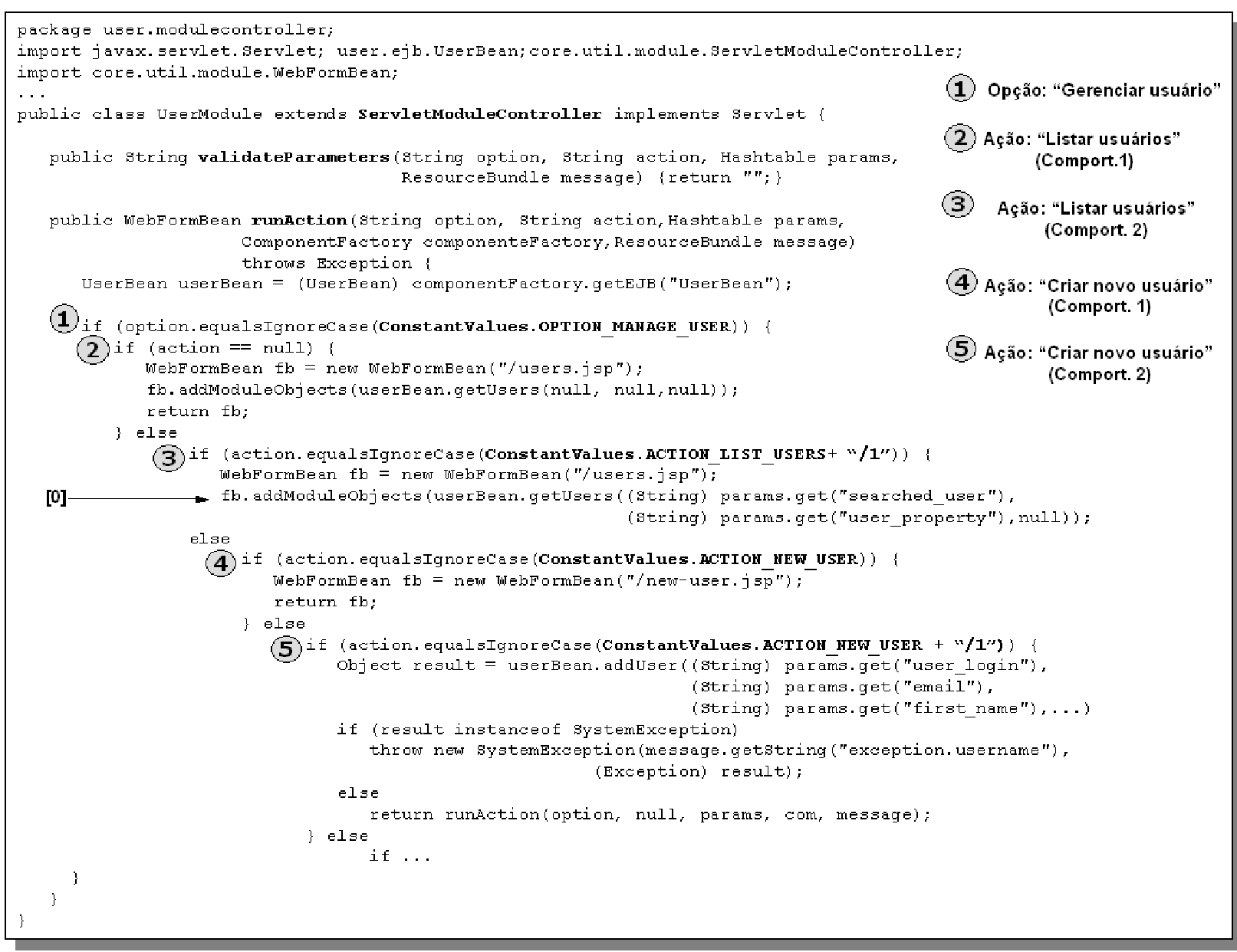

Figura 5.22 - Controlador de módulo do módulo de usuário (UserModule)

\section{Ligação com os componentes de negócio}

Concluído (e verificado) o esquema de navegação entre as páginas, passa-se à ligação do controlador de módulo com os componentes de negócio. No controlador de módulo, deve-se identificar a ação que dá origem a cada página, seguindo o modelo de navegação, e acionar os componentes identificados no documento de descrição dos módulos. O resultado dos componentes deve ser adicionado em um objeto Javabean (WebFormBean), juntamente com o nome da página a ser apresentada como resposta da requisição. A ordem de inserção desses dados (em uma lista) deve ser documentada para que eles possam ser corretamente recuperados pela lógica de apresentação da página JSP.

\section{Distribuição dos módulos}

Conforme citado no início desta subseção, o módulo pode ser distribuído tanto como aplicação Web quanto como aplicação enterprise. 
No caso do módulo incluir componentes de negócio, o pacote da aplicação enteprise (User.ear - Figura 5.23c) inclui, além do pacote da aplicação Web (UserModule.war - Figura 5.23a), o pacote dos componentes EJBs (User.jar - Figura 5.23b).

A distribuição do módulo é feita com inserção desses arquivos num servidor de aplicações J2EE. Se o servidor estiver executando, o módulo é automaticamente carregado, senão, ele é carregado quando o servidor for executado.

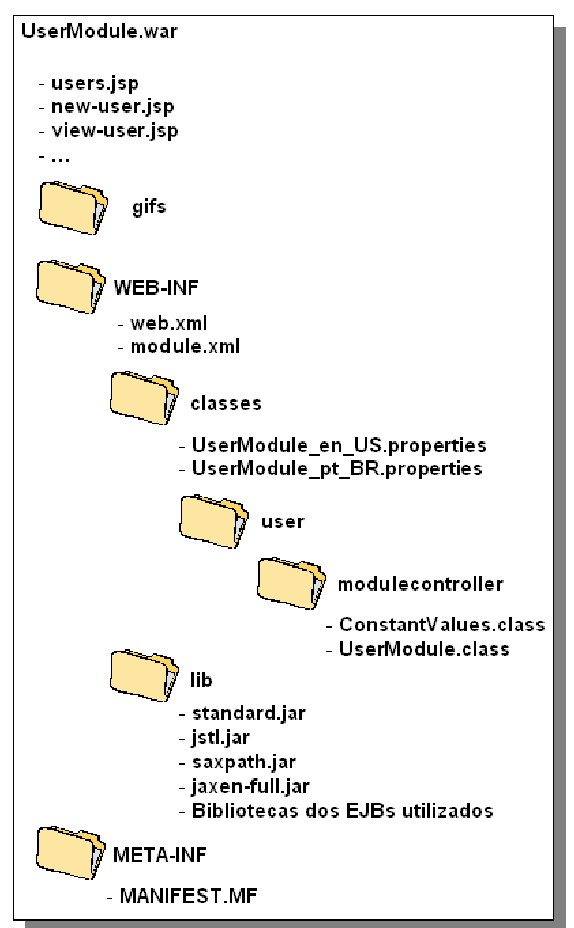

(a)

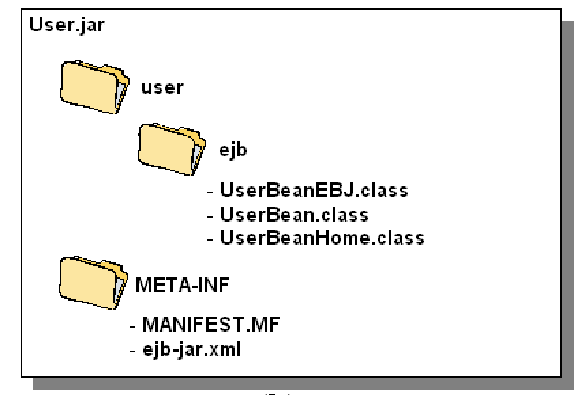

(b)

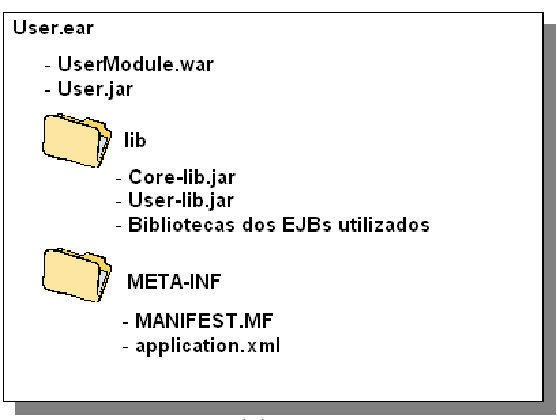

(c)

Figura 5.23 - Estrutura dos pacotes para distribuição dos módulos do WebMODE-J2EE

\subsection{Instanciação e teste da aplicação}

O fluxo de instanciação e teste da aplicação é detalhado na Figura 5.24. Uma vez que os módulos necessários estão disponíveis no servidor, a instanciação da aplicação deve ser feita utilizando a interface gráfica da aplicação de instanciação, descrita no Capítulo 4 na Seção 4.5 . Os casos de uso definidos nas primeiras atividades do processo podem auxiliar nessa atividade. Esse fluxo não precisa ser necessariamente realizado pelo próprio projetista da aplicação (o desenvolvedor dos módulos), já que não exige conhecimento sobre linguagem e lógica de programação. Ele pode ser realizado por um desenvolvedor (ou usuário) que conheça as funcionalidades dos módulos e os objetivos da aplicação. 
A atividade de teste da aplicação, que está mais relacionada com a avaliação sobre a execução correta da aplicação e não com os conceitos de testes de software, pode ser feita seguindo estratégias de teste que o desenvolvedor achar mais adequadas para seu domínio.

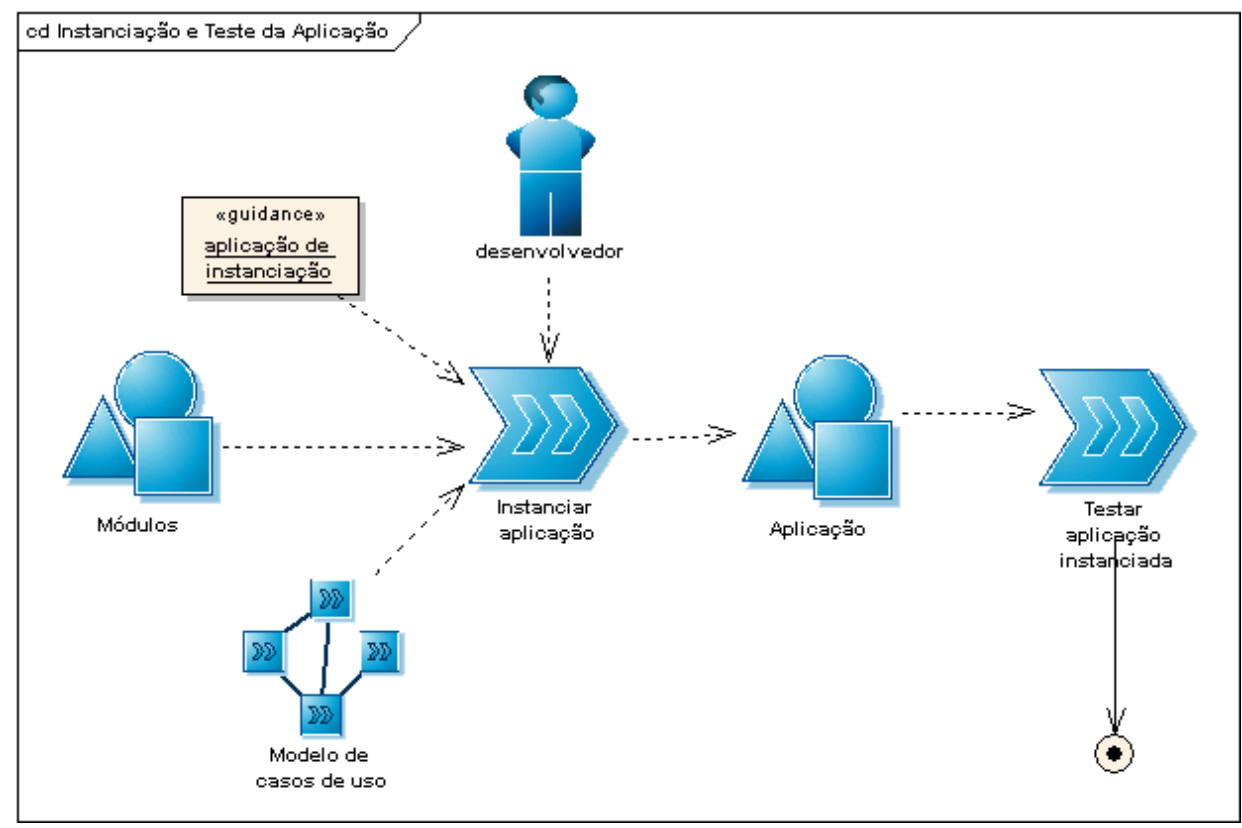

Figura 5.24 - Fluxo de instanciação e teste da aplicação

\subsection{Considerações finais}

Um processo de software tem por objetivo auxiliar no desenvolvimento de sistemas de software de forma disciplinada. O processo descrito neste capítulo, definido com base nos processos de engenharia de software existentes na literatura, tem por objetivo auxiliar no desenvolvimento de aplicações sobre o framework WebMODE. Este processo separou o fluxo de especificação do fluxo de desenvolvimento para garantir a independência da tecnologia utilizada para implementar a proposta do framework WebMODE.

As atividades de projeto dos módulos podem ser realizadas por projetistas que não desenvolvem código, enquanto as atividades de desenvolvimento requerem conhecimento detalhado sobre as tecnologias utilizadas na implementação do framework. Uma vez desenvolvidos os módulos, qualquer usuário que conheça o domínio da aplicação e o funcionamento da aplicação de instanciação, pode instanciar uma aplicação WebMODE por meio da agregação de módulos.

O capítulo seguinte mostra o funcionamento geral da aplicação de gerenciamento de atividades didáticas, cujos artefatos foram utilizados neste capítulo para exemplificar a aplicação do processo descrito. 


\section{Um exemplo de aplicação WebMODE-J2EE}

\subsection{Considerações iniciais}

A aplicação de gerenciamento de atividades didáticas (Silva \& Moreira, 2005b), cujo domínio foi descrito no capítulo anterior, foi instanciada com o propósito de experimentar a implementação do framework WebMODE-J2EE e de auxiliar na validação dos conceitos de modularização propostos pelo framework WebMODE. Além disso, a instanciação dessa aplicação também auxiliou na definição e verificação da aplicabilidade das atividades do processo de instanciação apresentado no capítulo anterior.

Neste capítulo, essa aplicação de gerenciamento de atividades didáticas é apresentada sob uma visão geral para exemplificar tanto o uso do framework WebMODE-J2EE na construção de aplicações educacionais baseadas na $W e b$ quanto a flexibilidade dessas aplicações. Para exemplificar essa flexibilidade é apresentada uma proposta de adaptação para atender uma necessidade específica não contemplada, inicialmente, no projeto dos módulos.

Tanto o framework WebMODE-J2EE quanto essa aplicação de gerenciamento de atividades didáticas foram testados em um cluster WebFarm (6 nós - 12 CPUs) rodando o servidor de aplicação JBoss versão 3.x, que é um servidor J2EE de uso livre.

\subsection{A aplicação de gerenciamento de atividades}

A aplicação de gerenciamento de atividades didáticas foi instanciada sobre o framework WebMODE-J2EE utilizando os módulos (Silva \& Moreira, 2005b; Silva \& Moreira, 2006):

- LoginModule: módulo de autenticação oferecido pelo WebMODE-J2EE;

- AdministrationModule: módulo oferecido pelo WebMODE-J2EE para agrupamento de funcionalidades de administração; 
- UserModule: módulo de funcionalidades relacionadas com usuários da aplicação;

- CourseModule : módulo de gerenciamento de cursos e turmas;

- ActivityModule : módulo de gerenciamento e realização de atividades de um curso;

- GroupModule : módulo de funcionalidades para realização de trabalhos em grupo; e

- ReviewModule : módulo de funcionalidades para controle de revisores de atividades.

Além dos papéis default fornecidos pelo framework (admin, user e nobody), foram definidos dois novos papéis de usuário: professor (teacher) e estudante (student).

Como visto no diagrama de casos de uso, apresentado no capítulo anterior, um usuário anônimo (papel nobody) pode se cadastrar no ambiente da aplicação e se tornar um usuário autenticado (papel user), utilizando a interface para cadastro de usuário apresentada na Figura 6.1.

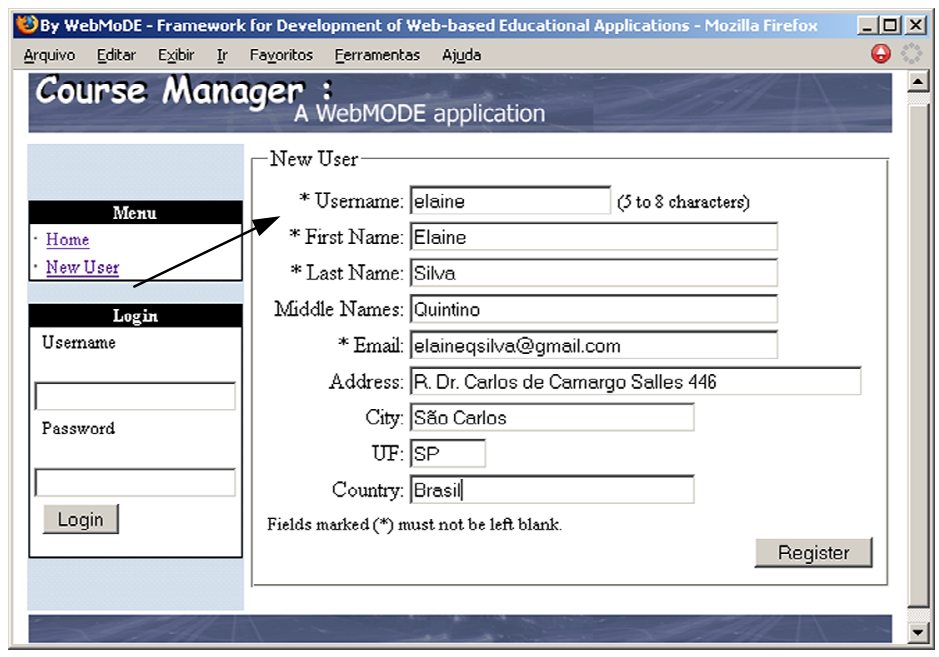

Figura 6.1 - Interface para cadastro de usuário

Um usuário autenticado pode pedir sua inscrição em um curso que tenha turmas disponíveis, ver seus dados de cadastro, trocar de $\operatorname{papel}^{27}$ (se já tiver algum outro) ou sair da aplicação. Ao se inscrever em uma turma de um curso, o usuário recebe o papel de estudante (student) automaticamente e passa a ter permissão para acessar os cursos das turmas que participa.

O usuário administrador ( $a d m i n$ ) é o responsável por criar os cursos na aplicação e definir turmas para esses cursos. Ao definir uma turma, o administrador informa o username do professor

\footnotetext{
${ }^{27}$ O usuário pode assumir somente um papel por vez no uso da aplicação, mas ele pode trocar de papel quando precisar (se essa opção tiver sido disponibilizada para a aplicação).
} 
responsável por ela, sendo que esse professor já deve ser um usuário da aplicação. Como os papéis da aplicação são variáveis, ao criar a turma, o administrador também define qual é o papel que será usado para representar o usuário avaliado (o estudante). Esses papéis são listados para o administrador com base nos papéis criados para a aplicação.

Professores e estudantes podem acessar as turmas dos cursos nos quais estão associados acessando a opção "Courses" no bloco Menu ilustrado na Figura 6.2. Ao acessar uma turma, professores e estudantes têm acesso ao bloco de menu relativo à área do curso (bloco Course Area na Figura 6.2). Nesse bloco ficam as opções de menu relacionadas com o curso acessado.

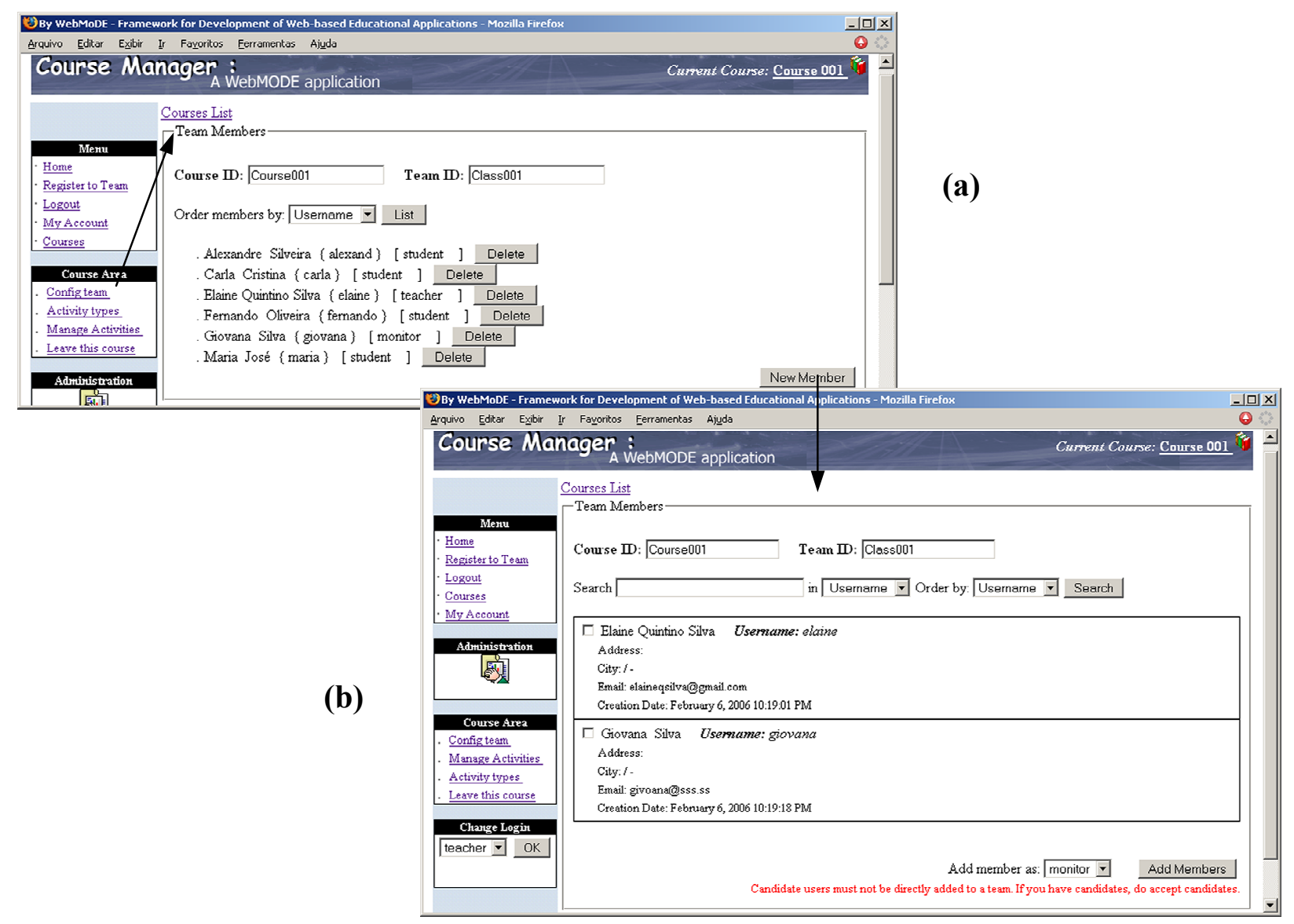

Figura 6.2 - Interfaces para gerenciamento (a) e inclusão (b) dos membros da turma

O professor tem a opção de configurar a turma mudando seus dados ou estabelecendo os seus membros, que incluem estudantes, outros professores e, se existir, outros tipos de usuários (por exemplo: monitores, visitantes, palestrantes, candidatos a cursos). Na Figura 6.2a é ilustrada uma interface da aplicação para o gerenciamento dos membros de uma turma e na Figura 6.2b, uma interface para adicionar membros na turma a partir de uma lista dos usuários da aplicação. 
O professor também pode definir os tipos de atividades (Figura 6.3a) que deseja utilizar na turma e criar atividades relacionadas com esses tipos (Figura 6.3b).

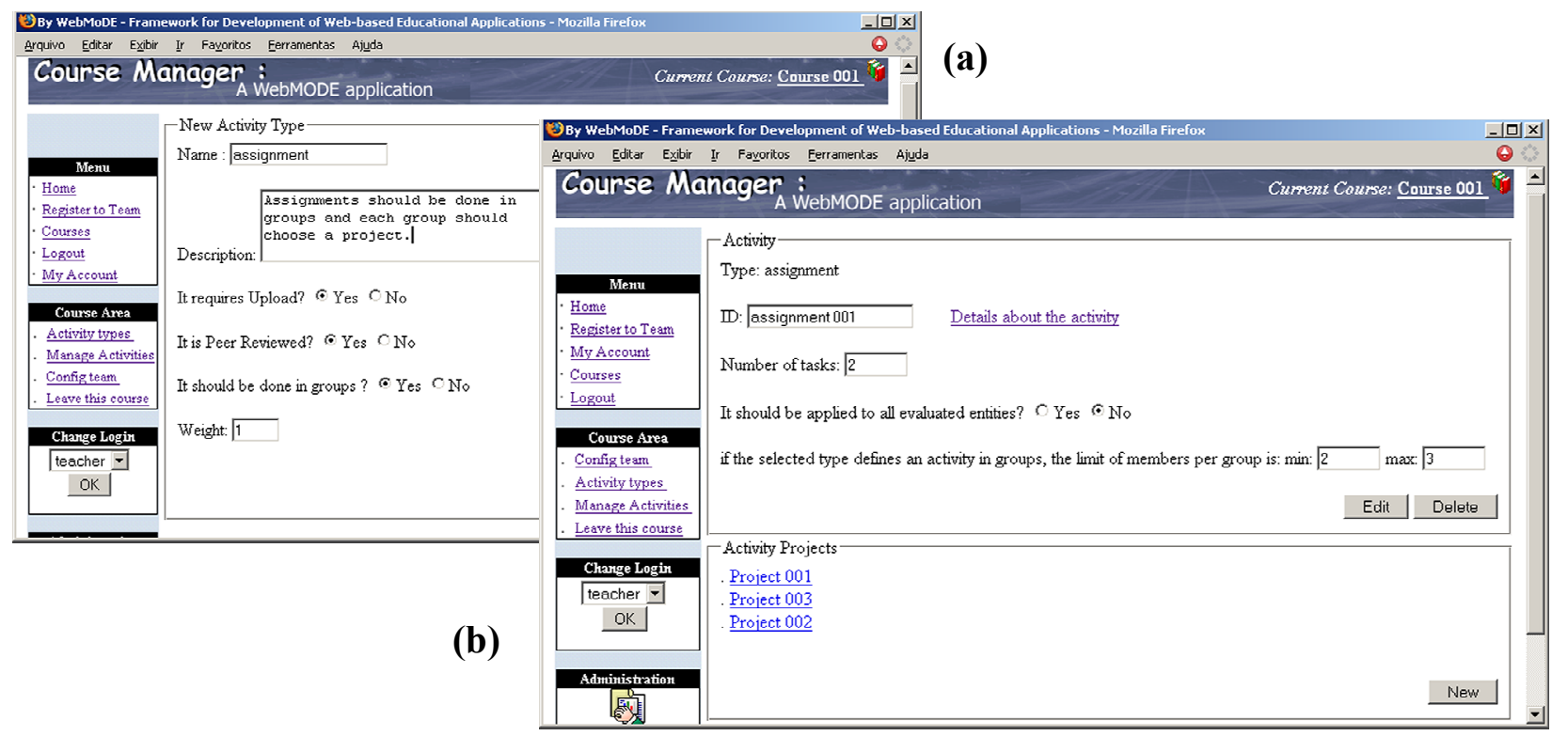

Figura 6.3 - (a) Interface para criação de um tipo de atividade e (b) para edição de atividade

Da forma como foi desenvolvido, o módulo de atividades permite a definição de quatro classes de atividades (que requerem ou não o upload de arquivos para o servidor): atividade individual, atividade individual com peer review, atividade em grupo e atividade em grupo com peer review. Se o professor define um tipo de atividade que envolve o peer review, o módulo de peer review deve ser utilizado na aplicação. O mesmo é válido para as atividades em grupo.

Independente do tipo, uma atividade deve possuir pelo menos um projeto, e cada projeto tem pelo menos uma tarefa. Cada tarefa representa uma parte do projeto que deve ser completada até a data estipulada pelo professor. Isso é útil para dividir o desenvolvimento de um projeto em várias fases. A interface apresentada na Figura 6.3b permite alterar os dados da atividade, apagar a atividade ou gerenciar seus projetos. A interface apresentada na Figura 6.4 permite alterar os dados de um projeto da atividade.

Quando a atividade é individual, o professor tem a opção de definir que todos os estudantes devem fazer todos os projetos daquela atividade ou deixar que cada estudante escolha o projeto que mais lhe interessar. Nesse último caso, o estudante deve se associar a um dos projetos da atividade, sendo que o número de entidades (que são os estudantes ou grupos de estudantes) 
associadas ao projeto pode ser limitado na definição da atividade. Essa possibilidade de limitar entidades por projeto permite fazer um controle para evitar que todos os estudantes escolham o mesmo projeto (o mais simples, por exemplo).

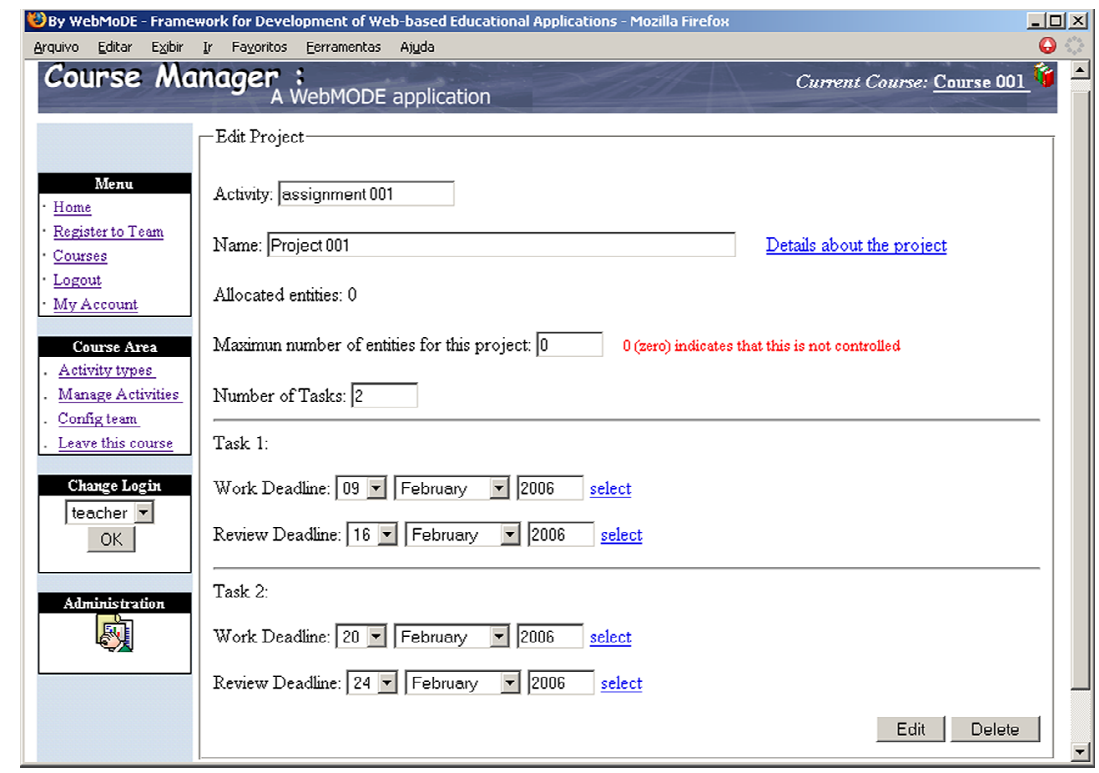

Figura 6.4 - Interface para a edição de um projeto que faz parte de uma atividade

Quando a atividade é em grupo, o próprio grupo é quem escolhe o projeto que deseja fazer. Se for necessário que todos os grupos façam o mesmo projeto, o professor deve definir várias atividades com um projeto cada e não limitar as entidades por projeto. Assim, os grupos devem fazer todas as atividades e só tem uma escolha de projeto em cada uma. A formação de cada grupo é feita pelos próprios estudantes e acontece juntamente com a escolha do projeto, como apresentado na Figura 6.5.

Uma vez estabelecido o grupo, seus membros podem ser alterados, mas o projeto não pode ser trocado. Se isso for necessário, o grupo deve ser apagado (botão "Remove group" na Figura 6.6b) e formado novamente.

$\mathrm{Na}$ bloco relativo à área do curso, o estudante pode acessar a lista de atividades individuais e em grupo (se esse módulo fizer parte da aplicação) que ele deve fazer e que ele deve se associar (Figura 6.6a). Ao acessar uma das atividades na qual já está associado, o estudante tem a opção de postar resultados para cada uma das tarefas do projeto (Figura 6.6b). Essa funcionalidade é semelhante tanto na atividade individual quanto em grupo (com ou sem peer review). 


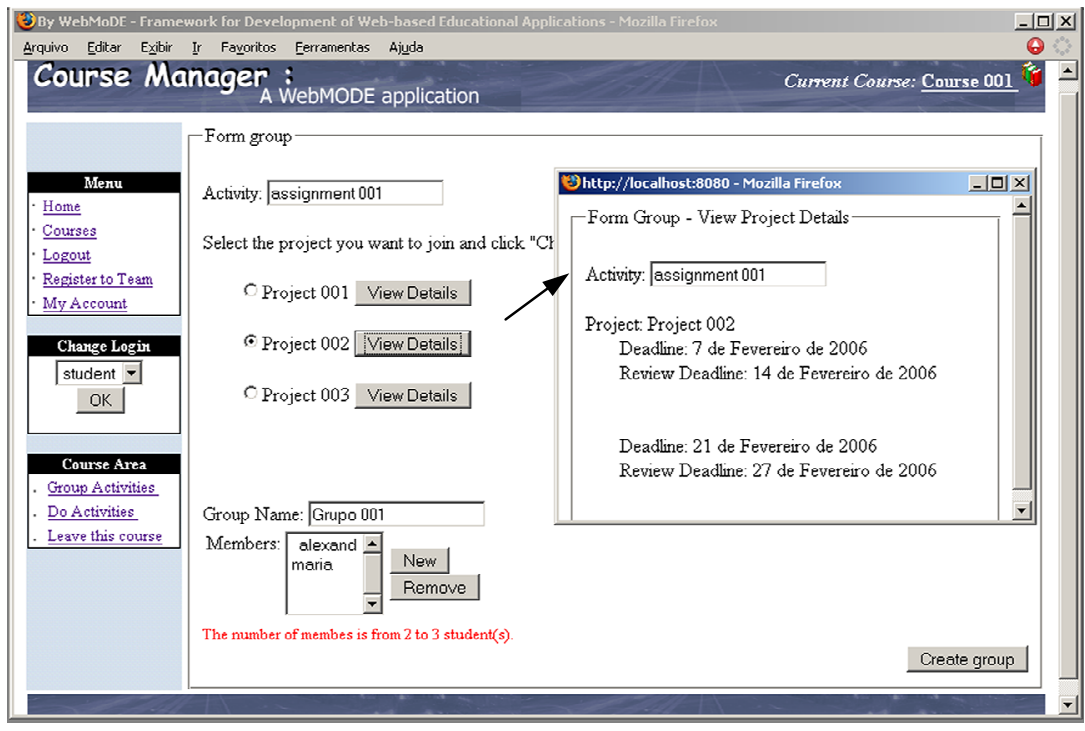

Figura 6.5 - Interface para formação de grupo e escolha de projeto

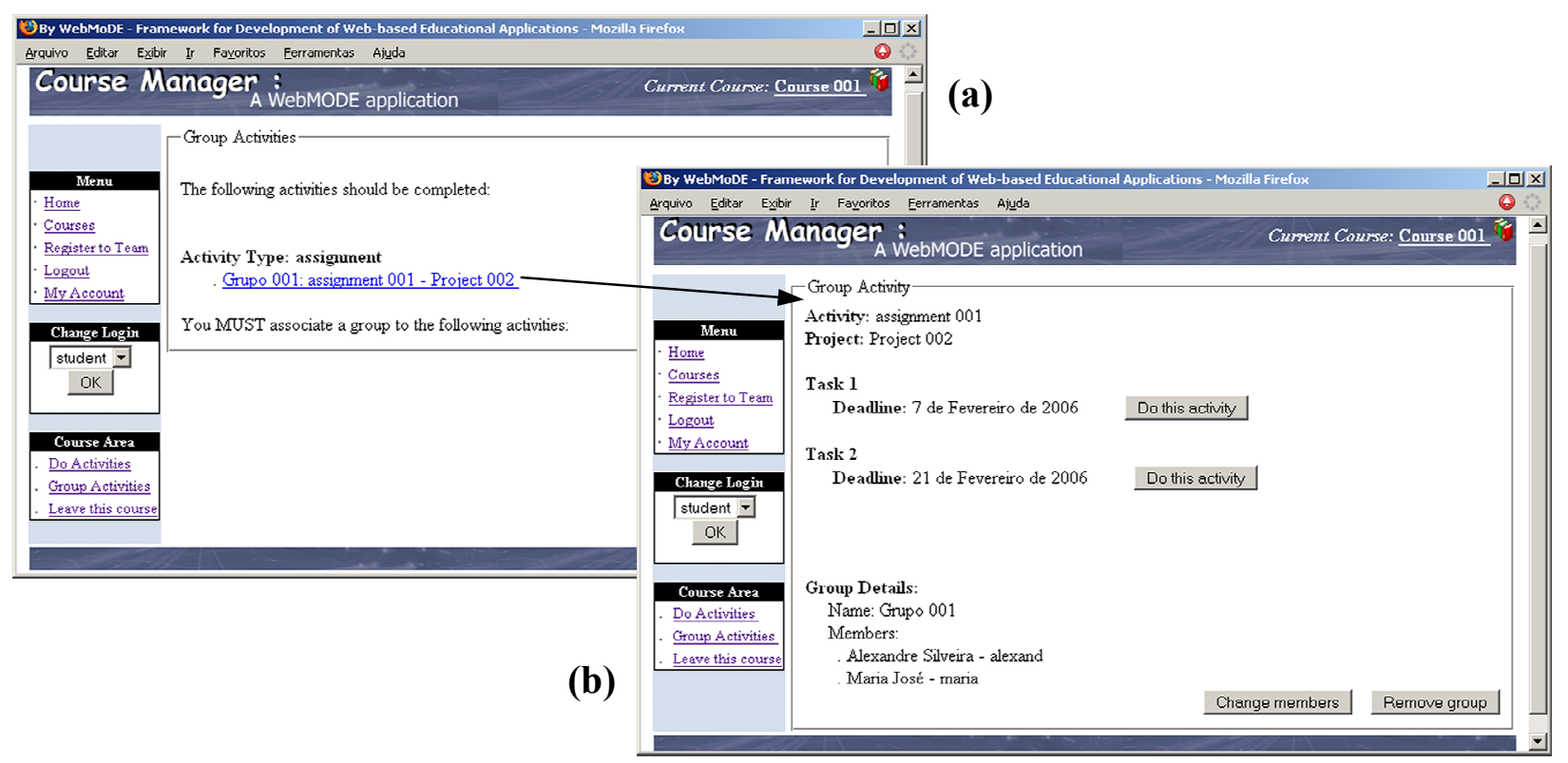

Figura 6.6 - Interface para acesso (a) e realização (b) de atividades em grupo

A postagem dos resultados da atividade pelos estudantes ou grupos de estudantes é feita por meio de um editor WYSWYG para criação de conteúdo HTML (Souza \& Moreira, 2005). Nesse editor, o estudante pode escrever o resultado da sua atividade no formato HTML ou, se preferir, pode fazer o upload de um arquivo e criar um link no conteúdo do editor. Esse editor HTML ${ }^{28}$, cuja interface é apresentada na Figura 6.7, não faz parte do framework, nem foi desenvolvido como um módulo da aplicação. Ele foi criado num projeto de iniciação científica (Souza \&

${ }^{28}$ Como o editor gráfico foi reutilizado, a sua interface ainda está em português. 
Moreira, 2005) com base no editor FCKEditor (FCK, 2006) e, por ser oferecido como um serviço, pôde ser facilmente integrado ao módulo de atividade.

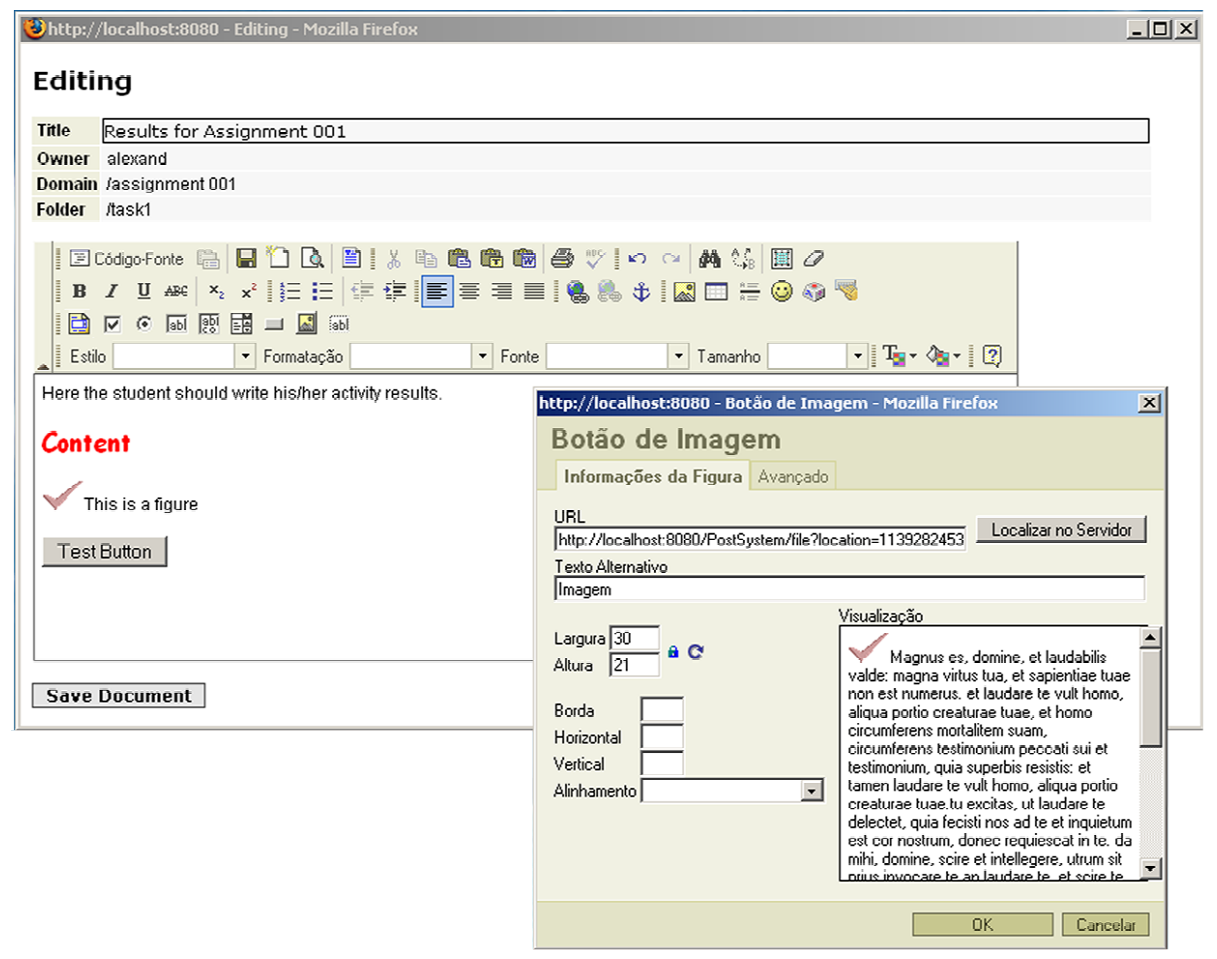

Figura 6.7 - Interface do editor de conteúdo

Para uma atividade com peer review, o professor pode estabelecer os revisores de cada projeto, o que pode ser feito por uma interface do módulo PeerReviewModule, ilustrada na Figura 6.8. Uma vez estabelecidos os revisores, as atividades de revisão são listadas juntamente com as demais atividades individuais ou em grupo.

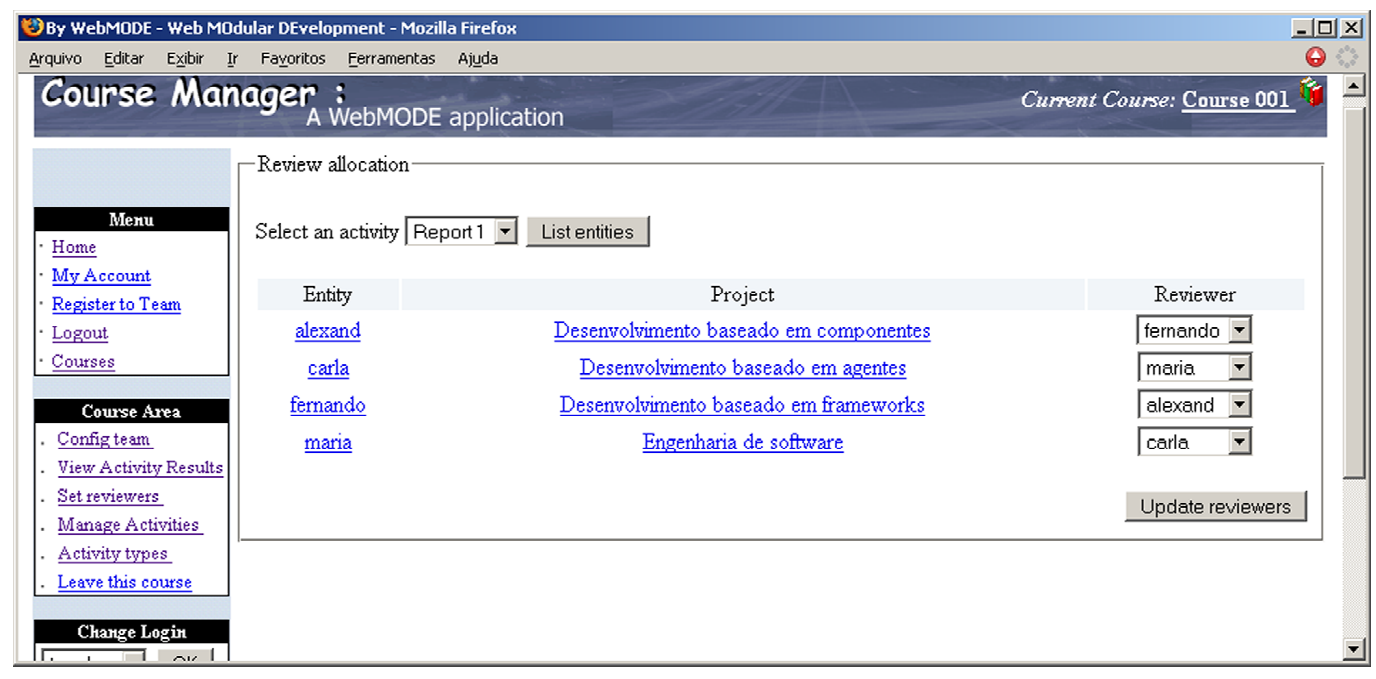

Figura 6.8 - Interface para alocação de revisores de uma atividade individual 
A entrega dos resultados de uma revisão é feita da mesma forma que a entrega de resultados de uma atividade, e o resultado das atividades realizadas pelos estudantes e grupos pode ser visto tanto por professores quanto por estudantes por meio de uma opção disponível no bloco de menu relativo à área do curso. Na Figura 6.9 é ilustrada a interface para visualização dos trabalhos (e das revisões) feitos pelos estudantes numa atividade individual.

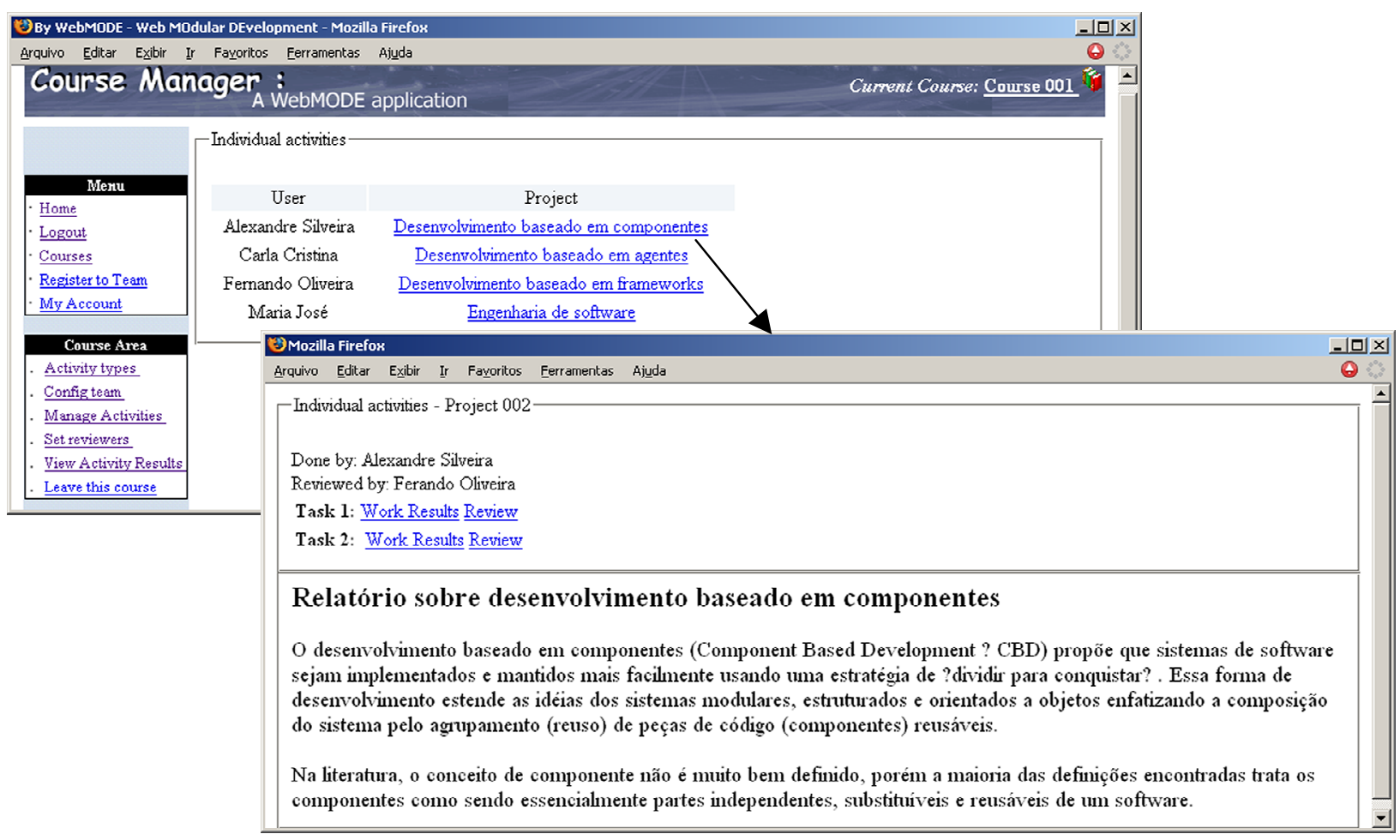

Figura 6.9 - Interface para visualização dos resultados das atividades individuais

Esse conjunto de funcionalidades corresponde aos casos de uso apresentados no Capítulo 5 para a aplicação de gerenciamento de atividades didáticas. A inclusão de novos casos de uso deve permitir o incremento desta aplicação por meio da inclusão de outros módulos mais específicos, como o módulo de notas, calendário, bate-papo (chat), notícias (news), entre outros, ou por meio da adaptação dos módulos já utilizados.

A configuração de uma aplicação WebMODE-J2EE, utilizando a interface da aplicação para instanciação do framework (apresentada no Capítulo 4), permite a adaptação dessa aplicação em termos de usuários e opções dos módulos. Algumas configurações, como incluir um usuário ou omitir uma funcionalidade do módulo, podem ser feitas na própria configuração da aplicação, porém, mudanças mais elaboradas, como a inclusão de uma nova opção, devem ser feitas na 
implementação do módulo. A seção seguinte mostra um exemplo de como essa aplicação de gerenciamento de atividades didáticas pode ser modificada, para incluir uma nova funcionalidade, de forma mais simplificada do que em um sistema que não segue a perspectiva modular proposta pelo framework WebMODE.

\subsection{Adaptando a aplicação de gerenciamento de atividades}

Numa situação em que um usuário com papel de monitor tem a responsabilidade de auxiliar o professor no gerenciamento de atividades, por exemplo, tendo o direito de alterar informações das atividades definidas pelo professor, a aplicação de gerenciamento descrita na seção anterior não seria adequada porque não considera o usuário monitor. No entanto, devido à sua perspectiva modular e às suas características de desenvolvimento, ela pode ser adaptada para atender a essa necessidade.

A forma mais simples de adaptação é definir um papel de monitor e configurar o módulo de atividade (ActivityModule) para que o usuário com esse papel tenha acesso à opção "Gerenciar atividades". Porém, em função da forma como o módulo de atividade foi especificado, essa forma de adaptação dá ao usuário com papel de monitor, mais direitos do que ele realmente precisa, já que a opção "Gerenciar atividades” inclui adicionar/remover/editar atividades. Neste caso, uma alternativa melhor de adaptação é a alteração do módulo de atividade (ActivityModule) que suporta a gerência de atividades.

Como no módulo de atividade a funcionalidade "Editar atividade" é tratada como uma ação da opção "Gerenciar atividades", ela não pode ser acessada diretamente pelo usuário com o papel de monitor porque somente as opções do módulo são acessíveis aos usuários a partir do menu da aplicação. Para resolver esse problema é necessário definir uma nova opção - "Editar atividades" - no módulo de atividade.

Essa adaptação envolve os seguintes passos na alteração do módulo de atividade:

- inclusão de uma nova opção no documento de descrição de módulos: essa opção deve aparecer no bloco da opção "course" relativa à área do curso (por exemplo: <specific-option related-to="course">edit-activity</specific-option>)

- inclusão da referência dessa nova opção nos arquivos de propriedades para a internacionalização (por exemplo: option.edit-activity=Edit activities); 
- inclusão de uma nova constante de opção na classe de constantes do projeto Web do módulo (por exemplo: public static string OPTION_EDIT_ACT = "edit-activity";);

- criação dos documentos JSP (ou alteração dos existentes) das páginas relacionadas com a edição da atividade: esses documentos não devem exibir funcionalidades que o monitor não pode acessar, por exemplo, "Criar nova atividade" e "Remover atividade", pois o framework irá negar esse acesso;

- tratamento da opção "Editar atividades" no controlador de módulo: como esse tratamento é praticamente o mesmo da opção "Gerenciar atividades" e o controle é interno ao módulo, a lógica das ações implementadas na opção "Gerenciar atividades" podem ser reusadas, trocando-se apenas a página que mostra o resultado da requisição;

- empacotamento e (re) disponibilização do módulo de atividade no servidor;

- configuração do módulo de atividades na aplicação para garantir os direitos de acesso do papel monitor sobre essa opção (como ilustrado na Figura 6.10), e configuração do módulo de curso (CourseModule) para permitir que monitor acesse a opção que corresponde ao bloco da área do curso e possa ver a opção "Editar atividades"; essas configurações são feitas utilizando a aplicação para instanciação do framework.

- Inserção dos usuários monitores nas turmas desejadas.

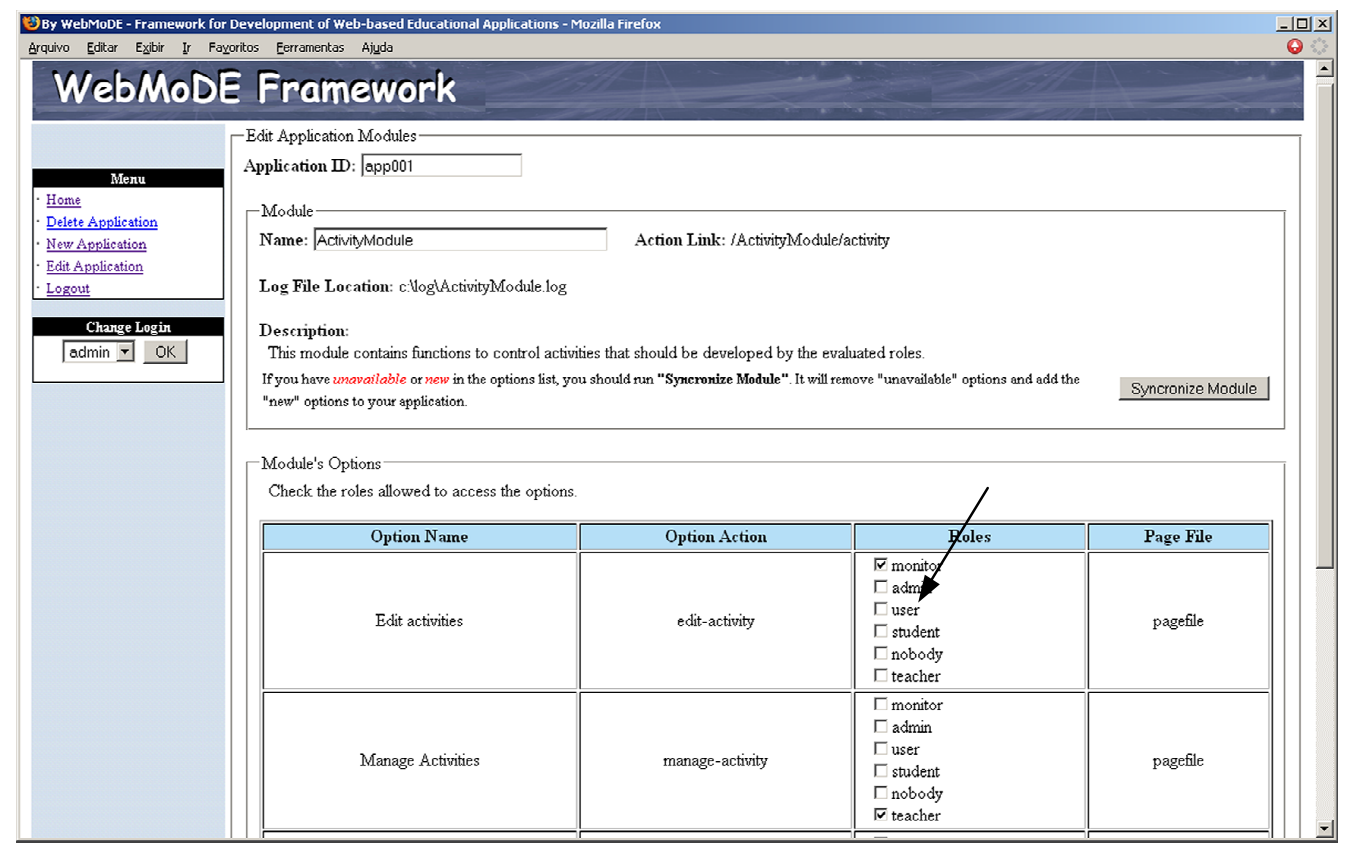

Figura 6.10 - Interface para configuração do módulo de atividade 
Com essas alterações, o usuário que tem o papel de monitor na turma acessada por ele passa a ter a possibilidade de acionar a opção "Editar atividades", como pode ser visto na Figura 6.11.

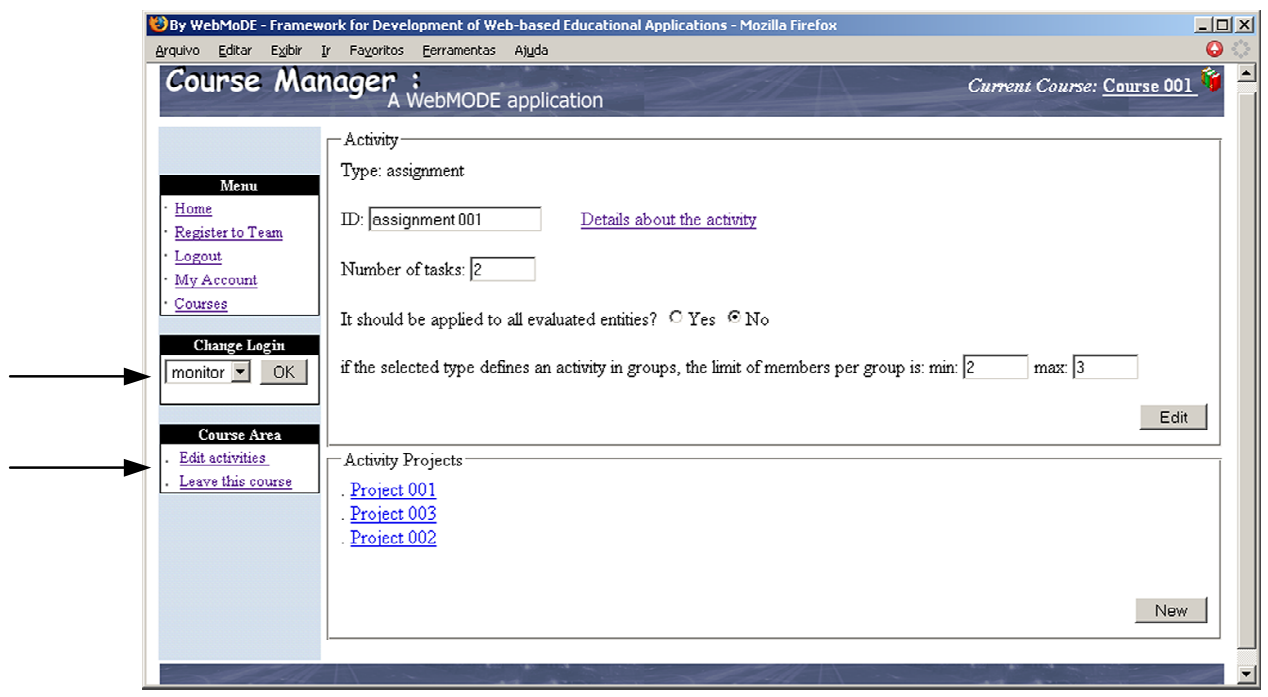

Figura 6.11 - Interface para edição de atividades pelo usuário monitor

Essa adaptação da aplicação de gerenciamento de atividades didáticas mostra que a proposta do framework WebMODE, implementada usando a tecnologia J2EE (WebMODE-J2EE), atinge seus objetivos no que tange ao aumento das possibilidades de adaptação e extensão das aplicações porque, diferente das aplicações desenvolvidas sobre arquiteturas mais integradas, permite a alteração das suas funcionalidades de maneira independente de outras partes da aplicação. Em outras palavras, a inclusão de uma nova funcionalidade na aplicação exigiu apenas o entendimento e a alteração do módulo relacionado com a funcionalidade inserida. Uma avaliação mais formal dessa proposta, não contemplada nesta tese, poderia considerar a extensão dessa aplicação por um usuário que não conhece o framework.

\subsection{Considerações finais}

Este capítulo teve por objetivo descrever a aplicação de gerenciamento de atividades didáticas, instanciada sobre o framework WEBMODE-J2EE (que é uma implementação do framework WebMODE), e demonstrar, por meio dessa aplicação, que os conceitos de modularização e componentização do WebMODE, como propostos nesta tese, podem auxiliar na adaptação e extensão das aplicações desenvolvidas utilizando implementações desse framework.

O exemplo de adaptação, apresentado na Seção 6.3, demonstra que, por estar baseada no agrupamento e configuração de módulos, a aplicação pode ser adaptada tanto em termos da 
configuração dos módulos utilizados quanto da alteração das funcionalidades dos mesmos. Quando existe a necessidade de adaptar a aplicação em termos de implementação, a organização da aplicação em módulos e a separação de interesses (separation of concerns) internamente aos módulos, tornam a aplicação mais estruturada, o que facilita essa adaptação.

No capítulo seguinte são apresentadas outras abordagens para o desenvolvimento Web que, de alguma forma, visam a criação de aplicações e websites a partir das necessidades de seus usuários e uma análise comparativa dessas abordagens com a proposta apresentada nesta tese. 


\section{Outras abordagens de desenvolvimento Web}

\subsection{Considerações iniciais}

Com a evolução e a disseminação da Internet, o desenvolvimento de sistemas baseados na $\mathrm{Web}$ tem se tornado uma prática cada vez mais comum. Além da popularidade, esses sistemas também têm evoluído consideravelmente em relação ao seu escopo e complexidade (Ginige \& Murugesan, 2001), o que permite observar a variedade de formas de uso dessas tecnologias nos diferentes domínios, tais como educação, jornalismo, publicidade, governo, entre outros.

Para acompanhar a evolução da Internet, dos sistemas Web e das tecnologias que suportam o desenvolvimento desses sistemas, várias abordagens de desenvolvimento têm sido propostas, usadas e melhoradas a cada dia.

Neste capítulo apresenta-se alguns exemplos dessas abordagens de desenvolvimento, considerando-se, inicialmente, suas descrições gerais, e, posteriormente, comparando essas abordagens com a proposta do framework WebMODE apresentada nesta tese. As abordagens de desenvolvimento tratadas neste capítulo são aquelas que, de alguma forma, tiveram influência na proposta do WebMODE ou que podem ser comparadas com essa proposta em função de suas características.

\subsection{Struts}

O framework Struts (Spielman, 2003) é um projeto open-source mantido pela Apache Software Foundation cujo objetivo é auxiliar no desenvolvimento de aplicações baseadas na Web utilizando tecnologias Java e o padrão arquitetural MVC. Tendo sido um dos pioneiros no desenvolvimento Web utilizando esse padrão, o projeto Struts começou a ser desenvolvido no ano de 2000 e sua primeira versão foi disponibilizada em Julho de 2001, quando passou a ser extensamente utilizado na construção de aplicações $W e b$. 
Em resumo, o framework Struts é uma implementação do padrão MVC-2. Esse padrão é uma especialização do padrão MVC original para uso dos componentes da plataforma J2EE.

Os elementos da arquitetura de uma aplicação Struts são:

- o controlador principal (ActionServlet) fornecido pelo framework, que coordena a execução de ações da aplicação com base nas informações do arquivo de configuração (struts-config.xml);

- classes de ação (Action) que contêm a lógica de negócio da aplicação (modelo do MVC);

- páginas JSPs que utilizam a biblioteca de tags oferecida pelo framework para apresentar o resultado das requisições da aplicação (visão do MVC);

- formulários de ação (ActionForm) que validam os dados de formulário e transportam dados entre a visão e o modelo (do MVC); e

- um arquivo de configuração (struts-config.xml) que define o relacionamento entre as ações, os formulários de ação e as páginas JSPs.

$\mathrm{O}$ arquivo de configuração é o que permite a execução do controlador principal. Ele possui, entre outras informações, uma lista dos formulários de ação (form-beans) apontando para a classe que implementa esse formulário (ActionForm), os mapeamentos (action-mappings) para as ações (Action) da aplicação e a fonte do arquivo de propriedades para internacionalização. Nos mapeamentos para as ações, cada ação é descrita em termos da URL que dá acesso à ação, a classe que implementa a ação, o formulário de ação relacionado e a indicação das páginas JSPs que devem ser apresentadas após a lógica da ação ser executada (no caso de sucesso e/ou erro).

O fluxo de execução de uma requisição no Struts ocorre da seguinte forma: ao receber a requisição, o controlador do framework identifica o mapeamento da ação, no qual ele encontra informações sobre o formulário de ação a ser utilizado para validar os dados e sobre a ação a ser executada. Então, o controlador preenche o formulário da ação com os dados da requisição, solicita a validação dos dados e, posteriormente, a execução da ação relacionada. A classe da ação recebe a requisição, efetua seu processamento e armazena os dados da resposta em componentes Javabeans, que são anexados na sessão HTTP. O retorno da ação é a indicação, por 
meio de um nome lógico, da página a ser apresentada. O controlador identifica a página retornada na resposta da ação (por meio do mapeamento da ação) e redireciona a requisição para essa página. A página é renderizada utilizando os dados dos Javabeans colocados pela ação na sessão HTTP.

Uma aplicação Web baseada no Struts é distribuída como uma Web application (war) Java. O Struts é distribuído como uma biblioteca de classes que deve ser colocada no classpath da Web application que estiver sendo desenvolvida. O controlador principal do framework é configurado no descritor da aplicação $W e b($ web. $\mathrm{xml}$ ) para receber todas as requisições.

Seguindo a proposta do Struts, vários outros frameworks, com abordagens semelhantes em relação ao uso do MVC-2 em aplicações $W e b$, foram propostos, sendo que a diferença entre eles está, principalmente, nas técnicas de desenvolvimento utilizadas. Como exemplo, pode-se citar WebWork $^{29}$, Turbine ${ }^{30}$, entre outros.

\subsection{JSF - Java Server Faces}

O JSF (Mahmoud, 2004) é uma especificação padronizada criada pela Sun Microsystems para construir interfaces de usuário para aplicações $W e b$. O projeto JSF teve início em 2001 e a primeira implementação oficial dessa especificação saiu em Março de 2004, sendo que seu objetivo inicial era permitir o desenvolvimento de interfaces de aplicações $W e b$ de forma visual (suportada por IDEs especializados), assim como acontece nas linguagens Delphi e Visual C.

O JSF é considerado um framework MVC que reúne características do framework Struts, em relação ao modelo de controlador, e do framework Swing ${ }^{31}$, em relação ao modelo de componentes e eventos (Armstrong et al., 2005). O JSF é composto por uma API e bibliotecas de tags. A API oferece recursos para representação de componentes gráficos e gerenciamento de seus estados, manipulação/controle de eventos, validação de entradas, conversão de dados, internacionalização e acessibilidade. As bibliotecas de tags permitem expressar os componentes JSF nas páginas JSPs e realizar a conexão desses componentes com objetos no lado servidor.

Uma aplicação construída utilizando JSF é formada por (Armstrong et al., 2005):

29 http://www.opensymphony.com/webwork/documentation.action

$30 \mathrm{http}: / /$ jakarta.apache.org/turbine/

${ }^{31} \mathrm{O}$ Swing é um framework para desenvolvimento de interfaces gráficas de aplicações Java standalone e applets. Mais informações sobre esse framework podem ser encontradas em http://java.sun.com/products/jfc. 
- um controlador principal fornecido pelo framework, que gerencia as requisições da aplicação (FacesServlet);

- páginas JSP construídas com componentes JSF (visão do MVC); esses componentes referenciam propriedades e métodos dos seus componentes de backend (as páginas JSP que contêm componentes JSF também são referenciadas simplesmente como páginas JSF);

- componentes Javabeans (modelo do MVC) que funcionam como backend das páginas JSF para executar a lógica de negócio;

- e um arquivo de configuração (faces-config.xml).

Todo o controle da execução de uma requisição no JSF está a cargo do controlador principal. Ele recebe todas as requisições da aplicação $W e b$ e executa uma série de passos ${ }^{32}$ para processar essas requisições e devolver uma resposta ao cliente. Como o JSF é orientado a eventos, o acionamento de um botão ou a alteração de um texto numa página JSF, por exemplo, faz com que um evento seja gerado e atendido pelo componente de backend da página, que deve executar a lógica relacionada com o evento. Após a execução do método que responde ao evento no backend, o controlador central direciona a requisição para a página referenciada no arquivo de configuração.

Os componentes JSF são considerados stateful porque seus estados são mantidos numa árvore de componentes no controlador central, podendo ser recuperados, por exemplo, no caso da mesma página ser reapresentada. Outro aspecto interessante é que o JSF disponibiliza os componentes de tal forma que eles possam ser renderizados dependendo do tipo de cliente que estiver sendo utilizado. Isso é possível porque a renderização do componente, que acontece no lado do servidor, é delegada para kits de renderização que são configurados no framework. Além dos kits de renderização, recursos para validar e converter valores também podem ser configurados para cada componente.

Apesar de ser uma tecnologia recente, o JSF vem ganhando a atenção dos desenvolvedores e se tornando um padrão no desenvolvimento de aplicações $W e b$. Em função do seu foco na interface, o JSF também tem sido utilizado para incrementar as funcionalidades oferecidas por outros frameworks, como é o caso do Struts. Por ser uma especificação, o JSF depende de

\footnotetext{
${ }^{32} \mathrm{O}$ ciclo de vida do processamento de requisições no JSF pode ser visto em (Armstrong et al., 2006).
} 
implementações desenvolvidas por terceiros. Atualmente, uma das implementações mais utilizadas é a MyFaces, mantida pela Apache MyFaces Project (MyFaces, 2006).

A implementação do JSF é distribuída da mesma forma que o Struts: como um conjunto de bibliotecas que deve ser adicionada no classpath da Web application (war) que estiver sendo desenvolvida. O controlador central também deve ser configurado no descritor da aplicação.

\subsection{Sistemas de Gerenciamento de Conteúdo (CMSs)}

\subsubsection{PHPNuke}

O PHPNuke (PHP-Nuke, 2006) é um sistema de gerenciamento de conteúdo (CMS) (Browning \& Lowndes, 2001) para a criação e gerenciamento de portais de informação na $W e b$. Escrito na linguagem PHP e extensamente utilizado desde 2000, o PHPNuke tem por objetivo facilitar o modo como os usuários organizam os seus portais, incluindo o gerenciamento de usuários, notícias, fóruns de discussão e várias outras funcionalidades organizadas e gerenciadas por meio de um sistema centralizado de administração.

As funcionalidades de um portal desenvolvido utilizando um CMS como o PHPNuke são organizadas na forma de blocos, módulos e temas (Karakas \& Erba, 2005). Os blocos representam os menus, geralmente na forma de caixas (boxes), disponíveis nas páginas da interface do portal, por exemplo, um bloco de menu principal, um bloco de notícias, entre outros. Os módulos são as diferentes funcionalidades do portal que os usuários podem ter acesso, por exemplo, um módulo de administração, um módulo de download, um módulo de notícias, entre outros. Os temas são os elementos que controlam a aparência do portal e como as informações são apresentadas. Informações como cores, layout e configurações de tabelas, são definidas nos temas que, em geral, podem ser trocados por outros (Karakas \& Erba, 2005).

Como o PHPNuke, existem vários outros CMSs, a maioria escrito na linguagem PHP, que podem ser usados no desenvolvimento de portais modulares na $\mathrm{Web}$, dentre os quais é possível citar PostNuke ${ }^{33}, \mathrm{Xoops}^{34}, \mathrm{Mambo}^{35}$, Drupal $^{36}$, e107 ${ }^{37}$, entre outros. Muitos desses CMS foram

\footnotetext{
${ }^{33} \mathrm{http}: / /$ www.postnuke.com

${ }^{34} \mathrm{http}: / /$ www.xoops.org/

${ }^{35} \mathrm{http}: / /$ www.mamboserver.com/

${ }^{36}$ http://drupal.org/

37 http://e107.org/
} 
desenvolvidos com base nos princípios do PHPNuke, que foi um dos pioneiros nessa abordagem de desenvolvimento $\mathrm{Web}$.

Como são projetos open-source, esses CMSs valorizam a política de compartilhamento desses elementos entre a comunidade de usuários Por isso, uma das vantagens no uso de CMSs para o desenvolvimento de portais na $W e b$ é a variedade de blocos, módulos e temas, criados por seus colaboradores, disponíveis para download.

Pela forma como são estruturados, os CMS podem ser vistos como formas de frameworks de aplicação modulares porque permitem o desenvolvimento de novos elementos, incluindo blocos, módulos e temas, a partir de especificações que garantem a sua ligação com o CMS. Esses elementos são organizados por um administrador do portal que tem a possibilidade de trocar o tema e organizar os blocos e módulos utilizados.

\subsubsection{Moodle}

O Moodle (Modular Object-Oriented Dynamic Learning Environment) é um CMS open-source, como o PHPNuke, voltado para a criação de portais educacionais na Web (Dougiamas \& Taylor, 2003). Também desenvolvido utilizando a linguagem PHP, o Moodle teve sua primeira versão oficial (1.0) lançada em agosto de 2002, e desde então, vem sendo bastante utilizado na construção de websites de universidades de diversos países.

Como no PHPNuke, as funcionalidades do Moodle são organizadas em função de módulos, blocos e temas que são organizados pelo projetista do site de acordo com as necessidades de seus usuários. Apesar de ser bastante semelhante a outros CMS baseados em PHP, o principal foco do Moodle está nos módulos de atividade, tais como projetos (Assignment Module), batepapo (Chat Module), fóruns (Fórum Module), conteúdo (Lesson Module), que podem ser utilizados na criação de ambientes educacionais.

\subsection{Sakai}

O projeto Sakai (Sakai, 2006) é uma colaboração entre universidades americanas para desenvolver um sistema open source de suporte à educação superior. Esse projeto teve início em 2003 com uma versão preliminar lançada em outubro de 2004 e uma outra versão lançada em junho de 2005. De acordo com a documentação encontrada no website do projeto, o sistema 
Sakai de apoio ao ensino colaborativo, como é classificado, está sendo construído sobre o Sakai Java Framework (Counterman et al., 2005).

O Sakai Java Framework, juntamente com o Sakai TSPP (Tool and Service Portability Profile), tem por objetivo garantir que ferramentas e serviços (que suportam essas ferramentas) sejam facilmente integrados para formar o ambiente Sakai (Counterman et al., 2005). De acordo com esse framework, uma ferramenta Sakai é formada por uma parte de apresentação, desenvolvida com componentes JSF fornecidos pelo próprio Sakai, e uma parte de lógica da ferramenta, desenvolvida num componente Javabean que é o backend da página JSF. A lógica da ferramenta pode ou não utilizar serviços Sakai. Esses serviços são desenvolvidos como componentes Javabeans padrão e utilizados via um mecanismo de injeção de dependência (Fowler, 2004; Johnson, 2005), por meio do qual a classe que usa o serviço recebe a sua implementação do mesmo através de um método de acesso (accessor method).

As ferramentas Sakai são renderizadas por um agregador, que na última versão desse sistema, é um framework para desenvolvimento de portais na $\mathrm{Web}$ - Uportal ${ }^{38}$.

O Sakai é distribuído na forma de Web applications Java (war) separadas que são instaladas num servidor de aplicação (não necessariamente enterprise). Na sua distribuição atual, há em torno de 40 pacotes de aplicações que representam cada parte do sistema, incluindo as ferramentas. $\mathrm{O}$ desenvolvimento de novas ferramentas para o Sakai inclui a criação de uma nova Web application e o uso das bibliotecas oferecidas pelo framework do Sakai.

\subsection{Tidia-Ae}

O Tidia-Ae (Tecnologia da Informação no Desenvolvimento da Internet Avançada Aprendizado Eletrônico) (Tidia-Ae, 2006) é um projeto, financiado pela FAPESP (Fundação de Amparo à Pesquisa do Estado de São Paulo), cujo objetivo é o desenvolvimento de um ambiente virtual open source de apoio à educação baseada na Web que explora as características de redes de alta velocidade (Internet 2). Esse projeto, que é desenvolvido em parceria com várias instituições educacionais do estado de São Paulo, teve início em agosto de 2004, sendo que suas primeiras versões ainda não foram disponibilizadas para uso público.

\footnotetext{
${ }^{38} \mathrm{http}: / /$ www.uportal.org
} 
O ambiente Tidia-Ae está organizado com base nos seguintes conceitos: usuários, contextos, papéis (e permissões), ferramentas e atividades de aprendizagem. Uma das ferramentas principais desse ambiente é o Gerenciador de Contextos que funciona como um agregador de ferramentas e usuários, ou seja, ela permite que usuários participantes de um contexto tenham acesso a todas as ferramentas disponíveis naquele contexto.

Tanto o Gerenciador de Contextos quanto as demais ferramentas do ambiente Tidia-Ae estão sendo desenvolvidos sobre uma arquitetura em camadas baseada em componentes J2EE especificados utilizando o processo UML Components (Cheesman \& Daniels, 2001; Kudo et al., 2005). Cada ferramenta do ambiente é disponibilizada como uma aplicação enterprise e acessada por meio do Gerenciador de Contextos.

Apesar de ainda não ser considerado um framework, os desenvolvedores do ambiente Tidia-Ae estão trabalhando na criação de uma arquitetura bem consolidada e em uma especificação adequada de ferramentas, que favoreçam o desenvolvimento e a agregação de novas ferramentas e a configuração personalizada desse ambiente. A expectativa é que o resultado desse projeto seja um tipo de ambiente educacional que permita a configuração das ferramentas do ambiente a partir das necessidades de cada instituição usuária.

\subsection{Análise comparativa}

Conforme se observa, o desenvolvimento de sistemas baseados na Web é uma área que vem sendo explorada já há algum tempo sob várias abordagens diferenciadas. Como a proposta apresentada nesta tese também se encaixa nesse domínio, com o objetivo de flexibilizar as aplicações construídas para o ambiente $W e b$, é importante fazer algumas comparações entre essa proposta e as demais abordagens citadas neste capítulo.

Em relação às abordagens de desenvolvimento $W e b$ apresentadas neste capítulo, o diferencial do framework WebMODE é que ele tem um processo de software associado que permite especificar, de forma completa, os módulos que compõem as aplicação instanciadas sobre esse framework. As outras abordagens citadas são centradas nos aspectos tecnológicos e, basicamente, no padrão arquitetural MVC. Além disso, o WebMODE é uma especificação de framework modular e baseado em componentes independente de tecnologias de implementação, ou seja, assim como existe o WebMODE-J2EE, podem existir outras implementações desse framework utilizando tecnologias diferentes, como um "WebMODE-.NET". 
As subseções seguintes apresentam alguns aspectos de comparação mais específicos da proposta desta tese em relação às demais abordagens de desenvolvimento Web citadas neste capítulo.

\subsubsection{Struts e JSF}

O framework WebMODE pode ser comparado ao Struts e ao JSF em relação à proposta de uso dos padrões de projeto MVC e Front Controller. O Struts e o JSF são apenas implementações do padrão MVC que podem ser utilizadas na construção dos mais variados tipos de aplicações Web. No entanto, além de propor o uso desses padrões, o WebMODE considera aspectos não enfatizados por esses frameworks. Dentre esses aspectos pode-se citar a proposta de desenvolvimento baseado em módulos de funcionalidades e o oferecimento de um módulo de autenticação, pronto para configuração e uso nas aplicações, e de uma aplicação para instanciar o framework de forma visual. Além disso, no WebMODE, a autorização baseada nos papéis definidos para cada aplicação já faz parte do framework. Tanto no Struts quanto no JSF, esses aspectos precisam ser implementados pelo desenvolvedor da aplicação, pois eles não fazem parte da especificação do framework.

Diferente do Struts e JSF, que fornecem APIs para o desenvolvedor utilizar dentro da sua aplicação, a proposta do WebMODE é que o framework seja a aplicação que o desenvolvedor customiza utilizando módulos com funcionalidades específicas da sua aplicação.

\subsubsection{CMSs}

Em relação aos CMSs, como o PHPNuke e Moodle, o framework WebMODE pode ser comparado a eles pelo fato de considerar a criação das aplicações de forma modular. Apesar de os módulos desses CMSs terem inspirado os módulos do WebMODE, há diferenças entre essass duas abordagens. No WebMODE, os módulos são bem definidos em termos de suas opções, ações, componentes de lógica e páginas de visão (do padrão MVC), enquanto no PHPNuke e Moodle (incluindo outros frameworks do mesmo tipo), não há especificação sobre como os módulos são formados, nem como devem ser especificados. Os blocos e módulos do PHPNuke e Moodle são desenvolvidos como partes separadas, enquanto no WebMODE, as próprias opções dos módulos podem ser transformadas em blocos, o que faz com que apenas os módulos precisem ser desenvolvidos. Além disso, no PHPNuke e Moodle, o controle de permissões de usuários é feito em cada módulo, diferente do WebMODE que atribui essa responsabilidade ao controlador principal. 
Uma outra diferença é que os CMSs como o PHPNuke e Moodle não carregam o conceito de instanciação, como proposto no framework WebMODE, sendo que a instalação do CMS já dá origem a uma aplicação que é configurada pelo administrador. Em geral, para criar uma nova aplicação é necessário fazer uma nova instalação do CMS. No WebMODE, a instalação do framework é única podendo dar origem a várias aplicações, o que pode facilitar a manutenção do servidor

\subsubsection{Sakai}

O projeto Sakai pode ser comparado com o framework WebMODE em termos da sua organização interna. A estrutura de ferramentas e serviços Sakai pode ser comparada à estrutura de módulos e componentes do WebMODE. Porém, no Sakai não há nenhum documento definindo o conteúdo de uma ferramenta ou de um serviço Sakai, ao contrário do WebMODE que, além de definir precisamente os módulos e componentes, propõe um processo para sua especificação (e desenvolvimento usando a implementação WebMODE-J2EE). A falta de documentação adequada sobre a arquitetura interna do Sakai torna mais complicado identificar até que ponto esse ambiente pode ser utilizado no desenvolvimento de outros ambientes fora do domínio da educação, por exemplo, não é possível saber se os papéis definidos no ambiente (professor, assistente e estudante) podem ser trocados por outros, como é possível no WebMODE, no qual os papéis são definidos em função das aplicações

\subsubsection{Tidia-Ae}

No caso do projeto Tidia-Ae, o WebMODE pode ser comparado em termos da arquitetura e especificação de componentes. Apesar da semelhança entre os componentes Tidia-Ae e WebMODE, pelo fato de ambos serem especificados com base no processo UML Components, no WebMODE os componentes de sistema são substituídos pelos controladores de módulo que agrupam funcionalidades de mais de um componente de sistema. Comparações mais detalhadas sobre as capacidades de extensão e adaptação do TIDIA-Ae não são possíveis pelo fato desse projeto estar ainda em fase inicial de desenvolvimento, com o qual a proposta desta tese deve contribuir.

\subsection{Considerações finais}

Considerando o fato de que os sistemas Web mudam e crescem muito rapidamente em termos de requisitos, conteúdo e funcionalidades, diferentemente dos sistemas tradicionais, a maioria das 
abordagens apresentadas neste capítulo tenta simplificar os passos para o desenvolvimento desses sistemas. Algumas dessas abordagens também se preocupam com aspectos de adaptação do sistema para que os interesses dos usuários possam ser atendidos. No entanto, todas essas abordagens estão fortemente amarradas às tecnologias utilizadas no seu desenvolvimento, o que permite dizer que o WebMODE tem uma contribuição original no contexto do desenvolvimento de aplicações baseadas na Web por carregar um processo de instanciação de aplicações associado. Esse processo permite especificar completamente os módulos de uma aplicação WebMODE. Além disso, a proposta do WebMODE é que toda a aplicação seja constituída de módulos, diferente de outras abordagens, como os CMSs que tratam alguns aspectos (por exemplo autenticação, administração, etc) como parte do núcleo e não como módulos.

No capítulo seguinte são apresentadas as conclusões deste trabalho bem como as propostas para sua continuação, que envolve, por exemplo, uma proposta de (re) implementação do framework WebMODE usando o JSF descrito neste capítulo. 


\section{Conclusões}

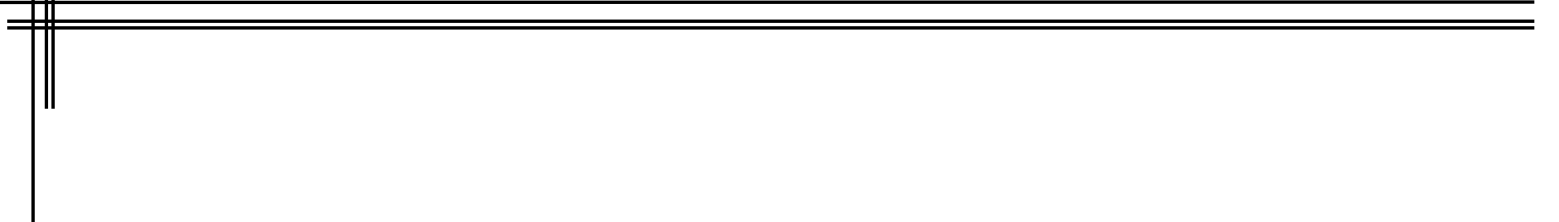

\subsection{Resumo do trabalho realizado}

A proposta deste trabalho teve início com a investigação sobre sistemas educacionais baseados na $W e b$ que ofereciam suporte para a aplicação do peer review como um método educacional. Após várias experimentações desse método em cursos do ICMC-USP utilizando a ferramenta WebCoM (Moreira \& Silva, 2002; Silva et al., 2002; Silva \& Moreira, 2003b, 2003a; Silva et al., 2004; Moreira \& Silva, 2005), desenvolvida especialmente para esse propósito, houve o interesse de investigar como os outros ambientes educacionais suportavam esse tipo de atividade. Nessa investigação, foi constatado que a maioria dos sistemas educacionais suportavam apenas métodos tradicionais nas atividades e que, além disso, apresentavam pouca preocupação com aspectos de adaptação das funcionalidades oferecidas.

Esse aspecto, em particular, criou o interesse de investigar quais características desses sistemas dificultavam sua adaptação às necessidades dos usuários. O resultado dessa investigação deu origem a um conjunto de características que pode dar, aos usuários (ou desenvolvedores) desses sistemas, maior capacidade de adaptá-lo às suas necessidades, ao invés de construir uma nova aplicação a cada novo problema.

$\mathrm{Na}$ busca por uma alternativa de desenvolvimento que contornasse a falta de flexibilidade das aplicações, optou-se pela proposta e desenvolvimento de um framework de aplicação que pudesse promover flexibilidade nas aplicações educacionais baseadas na $\mathrm{Web}$.

As características de flexibilidade levantadas na análise dos sistemas educacionais (Capítulo 2) foram então utilizadas como base para o estabelecimento dos requisitos desse framework. Pelo fato de os requisitos estabelecidos não estarem diretamente relacionados com o domínio educacional, a proposta do framework, que foi baseada numa perspectiva de desenvolvimento 
modular e no uso de componentes, pôde ser generalizada para permitir o desenvolvimento de aplicações $W e b$ flexíveis também fora desse domínio, embora esse aspecto não tenha sido avaliado

Apesar da proposta de solução do problema tratado nesta tese ser um framework de aplicação, que pela definição da literatura é uma aplicação semi-completa, ou seja, que possui código-fonte, a proposta do framework foi abstraída para que a sua implementação pudesse ser feita independente de tecnologia. A implementação desse framework na plataforma J2EE serviu para avaliar a sua proposta de modularização e componentização.

Com a especificação e a implementação do framework WebMODE, que foi um dos produtos gerados com esta tese, foi possível instanciar uma aplicação no domínio educacional para avaliar sua capacidade de adaptação. A instanciação dessa aplicação auxiliou no estabelecimento de um processo de software (e na verificação de sua aplicabilidade) para guiar a especificação e o desenvolvimento de módulos para as aplicações instanciadas sobre implementações desse framework.

\subsection{Contribuições}

A realização deste trabalho gerou contribuições importantes dentro da área de engenharia de aplicações baseadas na $W e b$. Essas contribuições são descritas nas subseções seguintes.

\subsubsection{Framework modular baseado em componentes}

A proposta do framework WebMODE tem por objetivo auxiliar no desenvolvimento de aplicações $W e b$ com melhores condições de adaptação e extensão para atender às diferentes necessidades de seus usuários. Por permitir a "montagem" da aplicação por meio do agrupamento e configuração de módulos de funcionalidades, o framework WebMODE dá mais liberdade ao desenvolvedor para colocar, na sua aplicação, a funcionalidade que deseja, contando, ainda, com a possibilidade de configurá-la para ser acessada pelo tipo de usuário que ele definir.

\subsubsection{Processo de instanciação de aplicações sobre o WebMODE}

Além da proposta do framework, uma das principais contribuições desta tese é o processo de especificação e desenvolvimento de seus módulos. Esse processo foi separado em três grandes 
fluxos de trabalho, sendo que o primeiro - a análise e especificação de módulos - pode ser utilizado na especificação desses elementos de forma independente da tecnologia utilizada na sua implementação. Como o desenvolvimento modular e baseado em componentes não é uma característica encontrada apenas no framework WebMODE, como visto no Capítulo 7, é possível que o primeiro fluxo desse processo também possa ser utilizado para especificar elementos de outras abordagens de desenvolvimento $\mathrm{Web}$, por exemplo ferramentas do projeto Sakai ou módulos do CMS PHPNuke.

\subsubsection{Requisitos para aplicações Web flexíveis}

O resultado da análise dos sistemas educacionais, juntamente com as técnicas de projeto da literatura de Engenharia de Software, permitiu identificar um conjunto de requisitos (apresentados no Capitulo 4) para o framework WebMODE. Esse conjunto de requisitos pode ser visto como uma contribuição para a área de engenharia de aplicações Web porque, se observados no desenvolvimento de novas aplicações (educacionais ou de uso geral), mesmo que não utilizando a proposta desse framework, pode aumentar a flexibilidade dessas aplicações em relação aos aspectos de adaptação e extensão de suas funcionalidades.

\subsubsection{Características para flexibilização de sistemas educacionais}

A avaliação dos sistemas educacionais permitiu identificar um conjunto de sete características que podem aumentar a flexibilidade dos sistemas de apoio à educação baseada na $W e b$, tal que elas possam ser adaptadas para atender às necessidades de seus usuários. Esse conjunto de características, discutido no Capítulo 2, também pode ser considerada uma contribuição desta tese.

\subsection{Oportunidades para desenvolvimento}

$\mathrm{Na}$ implementação J2EE do framework WebMODE (WebMODE-J2EE), apesar de ter sido criada uma interface para o controlador de módulo, somente a implementação baseada em Java Servlet foi desenvolvida. Isso gera uma limitação no sentido que o uso do módulo está fortemente acoplado com a requisição HTTP baseada na interação via navegador (essa limitação não acontece com os componentes). Uma das formas de se eliminar essa limitação é promover a generalização dos controladores de módulo para que, como os componentes de negócio, eles também possam ser utilizados por sistemas que não são baseados na requisição HTTP 
proveniente do navegador do usuário. Uma possível investigação seria a utilização de práticas de Web Services (W3C, 2004b). Essa alteração iria incrementar o poder de uso dos módulos.

Em termos da proposta do framework, existe uma limitação em relação às permissões dos usuários. No WebMODE, apesar de permitir a inserção de papéis de acordo com a demanda da aplicação, a única permissão possível é acessar ou não uma opção do módulo. Uma sugestão de melhoria seria adicionar permissões também sobre as ações, por exemplo, o usuário $x$ poderia ter acesso às ações "ver" e "adicionar" da opção $y$. Essa evolução daria uma flexibilidade ainda maior às aplicações WebMODE.

\subsection{Trabalhos futuros}

Além dos trabalhos sugeridos para vencer as limitações discutidas na seção anterior, esta tese ainda pode originar outros trabalhos de pesquisa, por exemplo:

- Incrementar a aplicação de gerenciamento de atividades com outros módulos que ficaram faltando para permitir seu uso (por exemplo, calendário, notas, notícias) e avaliar a capacidade de adaptação dessa aplicação, por exemplo, com o uso de diferentes abordagens do método de revisão pelos pares (peer review). Esse trabalho deve incluir uma atividade, não avaliada durante o desenvolvimento desta proposta, que é a extensão de módulos.

- Avaliar a proposta do framework do ponto de vista do desenvolvedor de módulos da aplicação com o objetivo de verificar o nível de dificuldade exigido para instanciar novas aplicações. Também seria válido avaliar a aceitação dos usuários em relação à proposta de instanciação de aplicações de forma visual.

- Implementar uma nova versão da proposta utilizando tecnologias mais recentes, como o JSF (Mahmoud, 2004), ou até mesmo a plataforma .Net da Microsoft (Microsoft, 2006b), para verificar sua adaptabilidade. Isso inclui investigar como seriam construídos os controladores, páginas compostas, objetos de dados e componentes, de forma que suportem os requisitos de projeto do framework WebMODE.

- Analisar o comportamento do processo de instanciação proposto a partir da criação de uma nova aplicação fora do domínio educacional. Se a instanciação for sobre a implementação J2EE do framework, então todo o processo deve ser seguido; caso contrário, apenas a análise e especificação de módulos e componentes pode ser validada. 
- Realizar a generalização dos controladores de módulo, sugerida na seção anterior, para implementar uma versão do framework que utilize outras formas de interação, por exemplo, baseada em agentes de software (Jennings \& Wooldridge, 1996) ou Web Services (W3C, 2004b).

- Avaliar o processo de especificação de módulos utilizando outra abordagem de desenvolvimento Web como o CMS PHPNuke ou o projeto Sakai para verificar sua generalidade.

- Investigar a possibilidade de uso de técnicas de MDA (Model Driven Architecture) na criação dos módulos a partir dos modelos gerados. 


\section{Referências bibliográficas}

Abowd, G., Pimentel, M. G. C., Kerimbaev, B., Ishiguro, Y. and Guzdial, M.: Anchoring Discussions in Lecture: An Approach to Collaboratively Extending Classroom Digital Media. Computer Support for Collaborative Learning, CSCL'99, Palo Alto, California, December, 1999. pp. $11-19$.

ABowd, G. D.: Classroom 2000: An Experiment with the Instrumentation of a Living Educational Environment. IBM Systems Journal - Special Issue on Pervasive Computing, v.38, n.4, pp. 508 - 530, 1999.

Abowd, G. D., Harvel, L. D. and Brotherson, J. A.: Building a Digital Library of Captured Educational Experiences. Kyoto International Conference on Digital Libraries, Kyoto, Japan, November, 2000. v.38, pp. 395-402.

Alur, D., CruPI, J. and Malks, D.: Core J2EE Patterns - Best Practices and Design Strategies. Palo Alto, California,, 2003.

Anido-Rifón, L., Llamas-Nistal, M. and FernándeZ-Iglesias, M. J.: A Component Model for Standardized Web-based Education. 1Oth International Conference on World Wide Web, Hong Kong, 2001. pp. 86-95.

Armstrong, E., Ball, J., Bodoff, S., Carson, D. B., Evans, I., Green, D., HaAse, K. and JENDROCK, $\quad$ E.: $\quad$ The J2EE 1.4 Tutorial. http://java.sun.com/j2ee/1.4/docs/tutorial/doc/index.html. Acesso em Fevereiro de 2006.

ArrudA-JR., C. R., Izeki, C. A. and Pimentel, M. G. C.: CoTeia: Uma Ferramenta Colaborativa de Edição Baseada na Web. VIII Simpósio Brasileiro de Sistemas Multimídia e Hipermídia, Fortaleza-CE, Brasil, 2002. pp. 371-374.

AUlANET: Projeto Aulanet. http://guiaaulanet.eduweb.com.br/. Acesso em Dezembro de 2005.

Baresi, L., Garzotto, F. and Paolini, P.: Extending UML for Modeling Web Applications. 34th Hawaii International Conference on System Sciences, HICSS, Maui, Hawaii, USA, IEEE Computer Society Press, January, 2001.

Bauer, C. and King, G.: Hibernate in Action. 1ed. Manning Publications, 2004.

BLACKBOARD: Blackboard Learning System. http://www.blackboard.com/. Acesso em Janeiro de 2006. 
Bosch, J., Molin, P., Mattsson, M., Bengtsson, P. and Fayad, M. E.: Framework Problem and Experiences. In: FAYAD, M. E., SCHIMIDT, D. C. and JOHNSON, R. E., Building Application Frameworks: Object-Oriented Foundations of Framework Design, John Wiley \& Sons, 1999. pp.55-86.

Braga, R. T. V.: Um Processo para Construção e Instanciação de Frameworks baseados em uma Linguagem de Padrões para um Domínio Específico. São Carlos, 2002. 171p. Instituto de Ciências Matemáticas e de Computação, Universidade de São Paulo.

Brown, A. W. and SHORT, K.: On components and Objects: the Foundations of Componentbased Development. 5th International Symposium on Assessment of Software Tools, SAST'97, Pittsburgh, PA, USA, IEEE Computer Society Press, 1997. pp. 112-121.

Browning, P. and Lowndes, M.: Content Management Systems. JISC TechWatch Report, 2001. http://www.jisc.ac.uk/uploaded_documents/tsw_01-02.pdf.

Brusilovsky, P.: KnowledgeTree: a Distributed Architecture for Adaptive e-Learning. Thirteenth International World Wide Web Conference, WWW 2004, New York, USA, 2004. pp. 104-113.

Buschmann, F., Meunier, R., Rohnert, H., Sommerlad, P. and Stal, M.: Pattern-Oriented Software Architecture - A System of Patterns. Wiley \& Sons, 1996.

Cattelan, R. G.: iClass: Um Sistema para Captura e Acesso de Sessões em Ambiente Educacional. Revista eletrônica de Iniciação Científica da Sociedade Brasileira de Computação, v.3, n.1, pp. 10-28, 2003.

Cattelan, R. G.: Construção de Aplicações de Captura e Acesso Baseada em Recorrência de Funcionalidades. São Carlos, 2004. 100p. Dissertação de Mestrado. Instituto de Ciências Matemáticas e de Computação, Universidade de São Paulo.

Ceri, S., Fraternali, P. and Bongio, A.: Web Modeling Language (WebML): a Modeling Language for Designing Web Sites. Computer Networks (Amsterdam, Netherlands: 1999), v.33, n.1-6, pp. 137-157, 2000.

Cheesman, J. and Daniels, J.: UML Components. Addison-Wesley, 2001.

CoAD, P. and Yourdon, E.: Object-Oriented Analysis. 2ed. Englewood Cliffs, NJ, Prentice Hall PTR, 1990.

COL: Cursos On-Line. http://col.colserver.usp.br/portal/. Acesso em Janeiro 2006.

Conallen, J.: Building Web Applications with UML. 2ed. Addison-Wesley Professional, 2002.

Counterman, C., Golden, G., Gollub, R., Norton, M., Severance, C. and Speelmon, L.: Technical Report Sakai Project. http://cvs.sakaiproject.org/release/1.5.1/docs/Sakai-JavaFramework-1.5.0.pdf. Acesso em Fevereiro de 2006. 
Crespo, R. M., Pardo, A. and Kloos, C. D.: An Adaptative Strategy for Peer Review. 34th Annual Frontiers in Education, FIE'04, Savannah, GA, IEEE Education/Computer Society, 2004. 2, pp. F3F7-13.

CyBerChAIR: CyberChair: A Web-based Paper Submission and Reviewing System. http://www.cyberchair.org. Acesso em Dezembro de 2005.

Dougiamas, M. and Taylor, P. C.: Moodle: Using Learning Communities to Create an Open Source Course Management System. ED-MEDIA - World Conference on Education Multimedia, Hypermedia \& Telecommunications, Hawaii, USA, AACE - Association for the Advancement of Computing in Education, 2003. http://dougiamas.com/writing/edmedia2003/.

EBERSPÄCHER, H. and JOAB, M.: A Role-based Approach to Group Support in a Collaborative Learning Environment. Fifth International Conference on Advanced Learning Technologies,ICALT'05, Kaohsiung, Taiwan, IEEE Computer Society, 2005. pp. 64-65.

Fayad, M. and Cline, M. P.: Aspects of Software Adaptability. Communications of the ACM, v.39, n.10, pp. 58-59, 1996.

FAYAD, M. E., Schimidt, D. C. and Jonhson, R. E.: Application Frameworks. In: FAYAD, M. E., SCHIMIDT, D. C. and JOHNSON, R. E., Building Application Frameworks: ObjectOriented Foundations of Framework Design., John Wiley \& Sons, 1999. pp.3-27.

FCK: FCKeditor - The Text Editor for Internet. http://www.fckeditor.net/. Acesso em Janeiro.

Ferreira, T. B., Otsuka, J. L. and Rocha, H. V.: Interface para Auxílio à Avaliação Formativa no Ambiente TelEduc. XIV Simpósio Brasileiro de Informática na Educação, SBIE, Rio de Janeiro-RJ, Brazil, Novembro, 2003. pp. Anais em mídia digital. http://teleduc.nied.unicamp.br/teleduc/publicacoes/tjh_sbie2003.pdf.

Filho, C. S. S. and MACHADO, E. D. C.: O computador como Agente Transformador da Educação e o Papel do Objeto de Aprendizagem, Portal Universia. http://www.universiabrasil.net/materia/materia.jsp?id=5939. Acesso em Janeiro de 2005.

Fowler, M.: Inversion of Control Containers and the Dependency Injection Pattern. http://martinfowler.com/articles/injection.html. Acesso em Fevereiro de 2006.

Fowler, M. and ScotT, K.: UML Distilled. Reading, MA, Addison -Wesley, 2000.

Froehlich, G., Hoover, H. J., Liu, L. and Sorenson, P.: Hooking into Object-Oriented Application Frameworks. International Conference on Software Engineering, Boston-USA, 1997. pp. 491-501.

Fuks, H., Gerosa, M. A., Pimentel, M. G., Raposo, A. B., Mitchell, L. H. R. G. and LuCENA, C. J. P. D.: Evoluindo para uma Arquitetura de Groupware Baseada em Componentes: o Estudo de Caso do Learningware AulaNet. III Workshop de Desenvolvimento Baseado em Componentes, WDBC, São Carlos-SP, Brazil, Setembro, 2003.Anais eletrônicos. http://ritv.les.inf.puc-rio.br/groupware/publicacoes/WDBC2003.pdf. 
Gamma, E., Helm, R., Johnson, R. and Vlissides, J.: Design Patterns: Elements of reusable object-oriented software. Massachusetts, 1994

GEARY, D. M.: Core JSTL: Mastering the JSP Standard Tag Library. Prentice Hall, 2002.

GeHringer, E. F.: Strategies and Mechanisms for Electronic Peer Review. 30rd Annual Conference on Frontiers in Education, FIE, Kansas City, MO, IEEE Education/Computer Society, 2000. v.1, pp. F1B/2-F1B/7.

Ghezi, C., JAzAYeri, M. and Mandrioli, D.: Fundamentals of Software Engineering. Upper Saddle River, NJ., Prentice Hall, Inc, 2002.

Ginige, A. and Murugesan, S.: Guest Editor's Introduction: Web Engineering - An Introduction. IEEE Multimedia, v.8, n.1, pp. 15-18, 2001.

GoldBerg, M. W.: World Wide Web Course Tool: An Environment for Building WWW-Based Courses. Computer Networks and ISDN Systems, v.28, n.7-11, pp. 1219-1231, 1996. http://www.ra.ethz.ch/CDstore/www5/www156/overview.htm.

GoldBerg, M. W.: Communication and Collaboration tools in World Wide Web Course Tools. http://www.enable.evitech.fi/enable97/. Acesso em Dezembro de 2005.

GRAF, S. and LIST, B.: An Evaluation of Open Source e-Learning Plataforms Stressing Adaptation Issues. Fifth International Conference on Advanced Learning Technologies, ICALT'05, Kaohsiung, Taiwan, 2005. pp. 163-165.

GUZDIAL, M.: Supporting learners as users. ACM SIGDOC Journal of Computer Documentation, v.23, n.2, pp. 3-13, 1999.

Hall, M. and Brown, L.: Core Servlets and JavaServer Pages, Volume 1: Core Technologies. Upper Saddle River, NJ, Prentice Hall PTR, 2003.

Helfers, C., Duerden, S., Garland, J. and Evans, D. L.: An Effective Peer Revision Method for Engineering Students in First-year English Courses. 30rd Annual Conference on Frontiers in Education, FIE, Kansas City,MO, IEEE Education/Computer Society, October, 2000. v.3, pp. 13A6/7-13A6/12.

HIBERNATE: Hibernate. www.hibernate.org. Acesso em Janeiro de 2005.

ICLASS: iClass software. http://iclass.icmc.usp.br. Acesso em Janeiro de 2006.

JACOBSON, E. E. and NowACK, P.: Frameworks and Patterns: Architectural Abstractions. In: FAYAD, M. E., SCHIMIDT, D. C. and JOHNSON, R. E., Building Application Frameworks: Object-Oriented Foundations of Framework Design., John Wiley \& Sons, 1999. pp.29-54.

JAFARI, A.: Conceptualizing Intelligent Agents For Teaching and Learning. EDUCAUSE Quarterly, v.25, n.3, 2002. http://www.educause.edu/pub/eq/eqm02/eqm023w.asp.

JBossPortal: JBoss Portal. http://www.jboss.org/products/jbossportal. Acesso em Dezembro de 2005. 
Jennings, N. R. and Wooldridge, M. J.: Software Agents. IEE Review, pp. 17-25, 1996.

JoHNSON, R.: Introduction to the Spring Framework. http://www.springframework.org/documentation. Acesso em Fevereiro de 2006.

Johnson, R. E.: Frameworks, Componentes, Patterns. ACM SIGSOFT Symposium on Software Reusability, Massachusetts, USA, ACM Press, 1997. pp. 10-17.

Johnson, R. E. and Foote, B.: Designing reusable classes. Journal of Object Oriented Programming, v.1, n.2, pp. 22-35, 1988.

KARAKAS, C. and ERBA, C.: PHP-Nuke: Management and Programming. http://phpnuke.org/modules.php?name=PHP-Nuke_HOWTO. Acesso em Fevereiro de 2006.

KeEGAN, D.: Foundations of distance education. 3ed. London, Routledge, 1996.

Kern, V. M., Saraiva, L. M. and Pacheco, R. C. S.: Peer Review in Education - Promoting Collaboration, Written Expression, Critical Thinking, and Professional Responsability. IFIP Journal of Education and Information Technologies, v.8, n.1, pp. 37-46, 2003.

Koch, N. and Kraus, A.: Towards a Common Metamodel for the Development of Web Applications. Third International Conference on Web Engineering-ICWE 2003, LNCS 2722 Springer Verlag, July, 2003. pp. 497-506.

Koskimies, K. and MössenbÖCK, H.: Designing a framework by stewise generalization. Fifth European Software Engineering Conference, LNCS 989, Springer-Verlag, 1995. pp. 479-497.

Krasner, G. and POPE, S. T.: A cookbook for using the model view controller user interface paradigm in Smalltalk 80. Journal of Object-Oriented Programming, v.1, n.3, pp. 26-49, 1988.

Kroll, P. and Kruchten, P.: The rational unified process made easy: a practitioner's guide to the RUP. Bonston, Addison-Wesley, 2003.

Kudo, T. N., Silva, E. Q., Jardim, C. H. O., Lara, S. M. A., Marteline-Jr., A., Freire, J., Pimentel, M. G. C. and Fortes, R. P. M.: Using UML Components for the specification of the Whiteboard tool. II Workshop Tidia FAPESP 2005, São Paulo, SP, Brazil, 2005. http://tidiaae.incubadora.fapesp.br/portal/documents/external_documents/IIWTF/fullpapers/15257.pdf.

LARsen, G.: Designing Component-based Frameworks Using Patterns in the UML. Communications of the ACM, v.42, n.10, pp. 38-45, 1999.

LARSSON, T. and SANDBERG, M.: Building flexible components based on design patterns. Mälardalen University, Västerås, Sweden. 2000. Technical report.

Latteier, A., Pelletier, M., McDonough, C. and Sabaini, P.: The Zope Book (2.6 Edition). http://www.zope.org/Documentation/Books/ZopeBook/2_6Edition/ZopeBook-2_6.pdf. Acesso em Fevereiro de 2006. 
LiU, E. Z., Lin, S. S. J., ChIU, C. and YuAn, S.: Web-based Peer Review: The Learner as Both Adapter and Reviewer. IEEE Transactions on Education, v.44, n.3, pp. 246-251, 2001.

Lucena, C. J. P., Fuks, H., Milidiú, R. and Laufer, C.: O AUlANET e as Novas Tecnologias de Informação Aplicadas à Educação Baseada na Web. $V$ Congresso internacional de educação à distância, Rio de Janeiro, RJ, Associação Brasileira de Educação à Distância ABED, 1999. pp. 3-14.

Lucena, C. J. P. D., Fuks, H., Milidiú, R., Laufer, C., Blois, M., Choren, R., Torres, V. and DAflon, L.: AulaNet: Helping Teachers to Do Their Homework. Multimedia Computer Techniques in Engineering Education Workshop, Graz, Austria, 1998. pp. 16-30. http://groupware.les.inf.puc-rio.br/groupware/publicacoes/aulanet.pdf.

Mahmoud, Q. H.: Java Authentication and Authorization Service (JAAS) in Java 2, Standard Edition (J2SE) 1.4. http://java.sun.com/developer/technicalArticles/Security/jaasv2/index.html. Acesso em Janeiro de 2005.

Mahmoud, Q. H.: Developing Web Applications with JavaServer Faces. http://java.sun.com/developer/technicalArticles/GUI/JavaServerFaces/. Acesso em Fevereiro de 2006.

MAYNARD, J.: Programação Modular. Rio de Janeiro, RJ, LTC, 1976.

MeiJler, T. D. and Nierstrasz, O.: Beyond Objects: Components. In: PAPAZOGLOU, M. P. and SCHLAGETER, G., Cooperative Information Systems: Current Trends and Directions., Academic Press, 1997. pp.49-78.

MicrosofT: COM: Component Object Model. http://www.microsoft.com/com. Acesso em Janeiro de 2006.

MicrosofT: Microsoft .NET. http://www.microsoft.com/net. Acesso em Janeiro de 2006.

MoreirA, D. A. and Silva, E. Q.: A Method to Increase Student Interaction using Student Groups and Peer Review over the Internet. IFIP WG3.2 Working Conference on Informatics Curricula, Teaching Methods and Best Practice, Florianópolis, SC, Brazil, July, 2002. pp. 183191. http://java.icmc.usp.br/dilvan/publications.html.

MoreIRA, D. A. and SiLVA, E. Q.: Improving Student Interaction with Internet \& Peer Review. In: PAGANI, M., Encyclopedia of multimedia technology and networking. Hershey USA,, Idea Group Reference, 2005. pp.375-381.

Moreira, D. A. and Walczowski, L. T.: Using Software Agents to Generate VLSI Layouts. IEEE Expert: Intelligent Systems and Their Applications, v.12, n.6, pp. 26-32, 1997.

Myers, G. J.: Reliable Software Through Composite Design. 1ed. New York, Petrocelli Chapter, 1975.

MYFACES: MyFaces Project. http://myfaces.apache.org/. Acesso em Fevereiro de 2006. 
NeLson, S.: Teaching Collaborative Writing and Peer Review Techniques to Engineering and Technology Undergraduates. 30rd Annual Conference on Frontiers in Education, Kansas City, MO, October, 2000. v.2, pp. S2B/1-S2B/5.

NiCOL, D. M.: Conference Program Management Using the Internet. IEEE Computer, v.29, n.3, pp. 112-113, 1996.

OMG: Common Object Request Broker Architecture (CORBA). Object Management Group. http://www.corba.org. Acesso em Janeiro de 2006.

Page-Jones, M.: Projeto Estruturado. São Paulo-SP, McGraw Hill, 1988.

PARrish, A., DiXon, B. and Cordes, D.: A Conceptual Foundation for Component-based Software Deployment. Journal of Systems and Software, v.57, n.3, pp. 193-200, 2001. http://www.informatik.uni-trier.de/ ley/db/journals/jss/.

Pfleeger, S. L.: Software Engineering Theory and Practice. 2nded. Upper Saddle River, NJ, Prentice Hall, Inc., 2001.

PHP-NuKE: PHP-Nuke Portal. http://phpnuke.org. Acesso em Fevereiro de 2006.

Pimentel, M., Gerosa, M. A., Filippo, D., Barreto, C. G., Raposo, A. B., Fuks, H. and LucenA, C. J. P. D.: AulaNet 3.0: Desenvolvendo Aplicações Colaborativas Baseadas em Componentes 3C. XVI Simpósio Brasileiro de Informática na Educação, SBIE, Juiz de ForaMG, Brazil, Novembro, 2005. Vol. II, pp. 761-770.

PostNuKe: PostNuke Content Management System. http://www.postnuke.com. Acesso em Dezembro de 2005.

PreE, W.: Design Patterns for Object-Oriented Software Development. New York, AddisonWesley/ACM Press, 1995.

PreE, W.: Component-based Software Development - A New Paradigm in Software Engineering. Software - Concepts and Tools, v.18, n.4, pp. 169-174, 1997.

PrEE, W.: Hot-Spot-Driven Development. In: FAYAD, M. E., SCHIMIDT, D. C. and JOHNSON, R. E., Building Application Frameworks: Object-Oriented Foundations of Framework Design., John Wiley \& Sons, 1999. pp.379-393.

Pressman, R. S.: Software Engineering - A Practitioner's Approach. 6ed. New York, NY, McGraw-Hill, 2005.

Roberts, D. and Johnson, R.: Evolving Frameworks: A Pattern Language for Developing Object-Oriented Frameworks. In: MARTIN, R. C., RIEHLE, D. and BUSCHMANN, F., Pattern Languages of Program Design 3., Addison-Wesley, 1998. pp.471-486.

Roberts, J. M.: The Story of Distance Education: a Practitioner's Perspective. Journal of the American Society for Information Science, v.47, n.11, pp. 811-816, 1996. 
Robertson, J.: A Content Management Project Presents Unique Challenges. Step Two Designs PTY LDTA. http://www.steptwo.com.au/papers/cmb_unique/index.html. Acesso em Dezembro de 2005.

Rocha, H. V.: O Ambiente TelEduc para Educação a Distância baseada na Web: Princípios, Funcionalidades e Perspectivas de Desenvolvimento. In: MORAES, M. C., Educacão a Distância: Fundamentos e Práticas. Campinas-SP, Brazil,, UNICAMP/NIED, 2002a. pp.197204. http://www.nied.unicamp.br/oea/pub/livro3/index.html.

Rocha, H. V.: Projeto TelEduc: Pesquisa e Desenvolvimento de Tecnologia para Educação à Distância. IX Congresso Internacional de Educação a Distância ABED, São Paulo-SP, Brazil, ABED - Associação Brasileira de Educação a Distância, $2002 b$. http://teleduc.nied.unicamp.br/teleduc/publicacoes/premio_abed2002.pdf.

Roman, E., Ambler, S. and Jewell, T.: Mastering Enterprise Javabeans. 2nd.ed. New York, John Wiley, 2002.

Romani, L. A. S.: InterMap: Ferramenta para Visualização da Interação em Ambientes de Educação a Distância na Web. Campinas-SP,Brasil, 2003. Dissertação. Instituto de Computação, Universidade de Campinas, Unicamp. http://teleduc.nied.unicamp.br/pagina/publicacoes/lromani_disser.pdf.

Rosa, V. F.: Educação Continuada à Distância: Um Estudo de Caso. São Carlos, 2001. 142p. Dissertação (Mestrado). Instituto de Ciências Matemáticas e de Computação, ICMC, Universidade de São Paulo.

Roschelle, J., Digiano, C., Koutlis, M., Repenning, A., Phillips, J., Jackiw, N. and SUTHERS, D.: Developing educational software components. IEEE Computer, v.32, n.9, pp. 50$58,1999$.

SAKAI: Sakai Project. http://www.sakaiproject.org. Acesso em Fevereiro de 2006.

SCHMID, H. A.: Framework Design by Systematic Generalization. In: FAYAD, M. E., SCHIMIDT, D. C. and JOHNSON, R. E., Building Application Frameworks: Object-Oriented Foundations of Framework Design., John Wiley \& Sons, 1999. pp.353-378.

SchwaBe, D. and Rossi, G.: Web Application Models are more than Conceptual Models. World Wild Web and Conceptual Modeling'99 Workshop, ER'99 Conference, Paris, France, LNCS 727 Springer Verlag, November, 1999. pp. 239-252.

SiEmens, G.: Learning Management Systems: the Wrong Place to Start Learning. http://www.elearnspace.org/Articles/lms.htm. Acesso em Janeiro de 2006.

Silva, E. Q., Brancalhone, P. and Moreira, D. A.: Peer Review e Aprendizagem Colaborativa: Experiências em Cursos de Computação. XXIV Congresso Nacional da Sociedade Brasileira de Computação, Workshop de Ensino de Informática, Salvador-BA, Brasil, Julho, 2004. pp. 141 (Anais em mídia digital pp. 1114-1125). 
Silva, E. Q. and MoreIRA, D. A.: Agente Gerenciador de Cursos a Distância via Internet. São Carlos - SP, 2000a. 94p. Dissertação (Mestrado). Instituto de Ciências Matemáticas e de Computação - ICMC, Universidade de São Paulo. http://java.icmc.usp.br/research.

Silva, E. Q. and MoreirA, D. A.: Gerenciamento de Cursos a Distância utilizando Agentes de Software. VI Workshop de Informática na Escola, WIE'2000, Curitiba-PR, Brasil, XX Congresso Nacional da Sociedade Brasileira de Computação, 2000b. pp. 82 (artigo completo CDROM).

Silva, E. Q. and MoreIRA, D. A.: Use of Software Agents for the Management of Distance Education Courses over the Internet. International Conference on Engineering and Computer Education, ICECE'2000, São Paulo-SP, Brasil, 2000c. pp. 10 (artigo completo em CD-ROM). http://java.icmc.usp.br/dilvan/publications.html.

Silva, E. Q. and MoReIRA, D. A.: Increasing Student Interaction using Student Groups and Peer Review over the Internet. IFIP Journal of Education and Information Technologies, v.8, n.1, pp. 47-54, 2003a.

Silva, E. Q. and MoreirA, D. A.: WebCoM: A tool to use peer review to improve student interaction. Journal on Education Resources in Computing, JERIC, ACM Press, v.3, n.1, pp. 1$14,2003 b$.

Silva, E. Q. and MoreirA, D. A.: Um Framework de Componentes para o Desenvolvimento de Aplicações Robustas de Apoio à Educação. XIII Simpósio Brasileiro de Informática na Educação, SBIE, Manaus-AM, Brasil, Novembro, 2004. pp. 158-167.

Silva, E. Q. and MoreirA, D. A.: A Component-based Framework for Customizable Webbased Education Application Development. International Conference on Engineering and Computer Education,ICECE, Madri, Spain, 2005a. pp. 48 (artigo completo em CDROM pp.1$6)$.

SiLva, E. Q. and MoreIRA, D. A.: Developing customizable web-based educational applications through a component based framework. International Conference on Next Generation Web Servicess Practices, NWeSP, Seoul, Korea, August, 2005b. pp. 394-399.

Silva, E. Q. and MoreirA, D. A.: A Framework for Development of Web-based Tools for Management of Educational Activities. 5th IEEE International Conference on Advanced Learning Technologies, ICALT, Kaohsiung, Taiwan, IEEE Computer Society Press, July, 2005c. pp. 922-924.

Silva, E. Q. and MoreirA, D. A.: WebMODE - Desenvolvimento modular de aplicações Web para gerenciamento de atividades. World Congress on Computer Sciense, Engineerin and Technology Education, WCCSETE, Santos, SP, Brazil, COPEC - Conselho de Pesquisas em Educacão e Ciências, 19-22 March, 2006. pp. 1562 - 1566.

Silva, E. Q., Moreira, D. A. and SAntos-JR, J. B.: Computadores no Ensino: Uma Abordagem voltada para o Suporte aos Professores no Desenvolvimento de Atividades Didáticas. XI Simpósio Brasileiro de Informática na Educação, SBIE, Maceió, AL, Brasil, Novembro, 2000. pp. 81-88. 
Silva, E. Q., RosA, V. F. and MoreirA, D. A.: Peer Review e Educação Continuada a Distância utilizando o WebCoM como Ferramenta de Suporte. XIII Simpósio Brasileiro de Informática na Educação, SBIE, São Leopoldo, RS, Brasil, Novembro, 2002. pp. 254-262.

SommerVILLE, I.: Software Engineering. Person Education, 2001.

SouzA, P. R. M. and MoreIRA, D. A.: PostSystem, Ferramenta J2EE para a Edição de Documentos Web Baseada em WYSIWYG. 13o SIICUSP - Simpósio Internacional de Iniciação Científica da Universidade de São Paulo, São Carlos,SP, Escola de Engenharia de São Carlos EESC -USP, 2005. pp. poster.

SpIELman, S.: The Struts Framework: Practical Guide for Java Programmers. Morgan Kaufmann Publishers, Elsevier Science, 2003.

StAA, A. V.: Programação Modular: Desenvolvendo Programas Complexos de Forma Organizada e Segura. Rio de Janeiro, Editora Campus Ltda, 2000.

Sun: Java 2 Platform, Enterprise Edition (J2EE) Releases and Technologies. http://java.sun.com/j2ee/releases/. Acesso em Janeiro.

TelEduc: Projeto TelEduc - Ambiente de Ensino Distância. http://teleduc.nied.unicamp.br/teleduc/. Acesso em Dezembro.

TIDIA-AE: Tidia-Aprendizado Eletrônico. http://tidia-ae.incubadora.fapesp.br/portal. Acesso em Fevereiro de 2006.

TOPClass: TopClass e-Learning Suite. http://www.wbtsystems.com. Acesso em Janeiro de 2006.

UML: The Unified Modeling Language. http://www.uml.org/. Acesso em Fevereiro de 2006.

VAlente, J. A.: Diferentes usos do Computador na Educação. In: VALENTE, J. A., Computadores e Conhecimento: Repensando a Educação. Campinas-SP, Brasil, 1995. http://www.nied.unicamp.br/publicacoes/pub.php?classe=separata.

W3C: HTML 4.01 Specification. http://www.w3.org/TR/html4/. Acesso em Janeiro de 2006.

W3C: W3C - XSL Transformations (XSLT) Version 1.0. http://www.w3.org/TR/xslt. Acesso em Janeiro de 2005.

W3C: W3C - XHTML 1.0 The Extensible HyperText Markup Language. http://www.w3.org/TR/xhtml1/. Acesso em Janeiro de 2005.

W3C: Extensible Markup Language (XML) 1.0 (Third Edition). http://www.w3.org/TR/REC$\mathrm{xml} /$. Acesso em Janeiro de 2006.

W3C: Web services activity. http://www.w3.org/2002/ws. Acesso em Fevereiro de 2005.

WEBCT: WebCT Learning without Limits. http://www.webct.com. Acesso em Janeiro de 2006. 
WeBWORK: WebWork Framework http://www.opensymphony.com/webwork/documentation.action. Acesso em Fevereiro de 2006.

WeISER, M.: The computer for the 21st century. Scientific American, v.265, n.3, pp. 94-104, 1991.

WiRfs-Brock, R. J. and Johnson, R. E.: Survying Current Reseach in Object-Oriented Design. Communications of the ACM, v.33, n.9, pp. 105-124, 1990.

Wong, W.-K., ChAn, B.-Y. and YIN, S.-K.: A Dynamic Geometry Environment for Learning Theorem Providing. Fifth International Conference on Advanced Learning Technologies, ICALT'05, Kaohsiung, Taiwan, IEEE Computer Society, 2005. pp. 15-17.

YAng, Y. J., KIM, S. Y., ChOI, G. J., ChO, E. S., KIM, C. J. and KIM, S. D.: A UML-based Object-Oriented Framework Development Methodology. Fifth Asia-Pacific Software Engineering Conference, IEEE Computer Society, Taipei, Taiwan, 1998. pp. 211-218.

YASsin, A. and FAYAD, M. E.: Application Frameworks: A Survey. In: FAYAD, M. E., SCHIMIDT, D. C. and JOHNSON, R. E., Domain-Specific Application Frameworks: Frameworks Experiences by Industry., John Wiley \& Sons, 1999. pp.615-632. 